NBSIR 82-2593

\title{
Investigation of Construction Failure of the Riley Road Interchange Ramp, East Chicago, Indiana
}

U.S. DEPARTMENT OF COMMERCE National Bureau of Standards National Engineering Laboratory Center for Building Technology Washington, DC 20234

and

U.S. Department of Transportation Federal Highway Administration Washington Bridge Division Washington, DC 20590

October 1982

Sponsored by

The Occupational Safety and Health

Administration

Tepartment of Labor

QC - ashington, DC 20001

100

.456

ช2-2593

1932

C.2 



\section{INVESTIGATION OF CONSTRUCTION}

FAILURE OF THE RILEY ROAD

INTERCHANGE RAMP, EAST CHICAGO, INDIANA
N. J. Carino
H. S. Lew
W. C. Stone
R. M. Chung

U.S. DEPARTMENT OF COMMERCE

National Bureau of Standards

National Engineering Laboratory

Center for Building Technology

Washington, DC 20234

and

J. R. Hoblitzell

U.S. Department of Transportation

Federal Highway Administration

Washington Bridge Division

Washington, DC 20590

October 1982

Sponsored by

The Occupational Safety and Health

Administration

Department of Labor

Washington, DC 20001

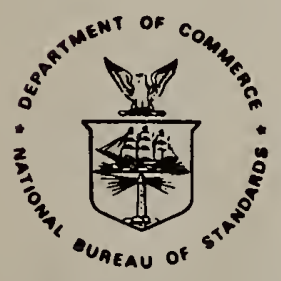

U.S. DEPARTMENT OF COMMERCE, Malcolm Baldrige, Secretary NATIONAL BUREAU OF STANDARDS, Ernest Ambler, Director 

The National Bureau of Standards (NBS), at the request of the Occupational Safety and Health Administration, conducted an investigation to determine the most likely cause of the collapse of a portion of a highway ramp in East Chicago, Indiana. The accident occurred on April 15, 1982, and resulted in the death of 13 workers. A team of engineers from NBS and the Federal Highway Administration carried out an extensive field investigation, in cooperation with personnel from the Indiana Occupational Safety and Health Administration, to ascertain the conditions prior to and after the accident. In addition, the NBS performed physical tests on key components of the temporary support system used to build the ramp. A structural analysis was also performed to compute the magnitude of the forces acting in various components of the support system. The calculated forces were compared with the expected strengths of these components. It is concluded that the most likely triggering mechanism of the collapse was the cracking of a concrete pad supporting a leg of the shoring towers. It is shown that this initial fallure caused additional components to fail which ultimately led to the collapse of the support system and major segments of the partially completed ramp. It is further concluded that the following deficiencies contributed directly to the collapse of a unit of the ramp construction: 1) specified wedges were omitted between stringers and crossbeams; 2) the concrete pads supporting the shoring towers had an inadequate margin of safety to resist the expected loads; 3 ) the tops of the shoring towers were not adequately stabilized against longitudinal movement; and 4) the weld quality in the U-heads supporting the crossbeams was poor. Had any of these deficiencies not existed, it is unlikely that the collapse would have occurred. Additional deficiencies contributed to the subsequent collapse of another ramp unit. They were as follows: 1) specified one-inch bolts were not provided for connecting crossbeams to stringers and overlap beams; 2) special overlap beams at the piers were not constructed as specified; and 3 ) the construction sequence deviated from the specified sequence.

Key Words: Bridge; collapse; concrete; construction; fallure investigation; falsework; field load tests; formwork; post-tensioning; structural analysis 
On April 15, 1982, a portion of Ramp C of the R1ley Road Interchange 1n East Chicago, Indiana collapsed during construction. The Occupational Safety and Health Administration requested the assistance of the National Bureau of Standards (NBS) to carry out an investigation of the technical reason for the accident, which resulted in the death of 13 workers.

On April 17, a team of structural engineers from the NBS arrived at the accldent site and 1nitiated 1ts study. The NBS team was later joined by a representative of the Federal Highway Administration, and they were assisted by personnel from the Indiana Occupational Safety and Health Administration (IOSHA), which had jurisdiction over the site, in obtaining the necessary documents for the investigation. In addition to an extensive fleld investigation, the NBS performed physical tests to characterize the behavior of various critical structural elements. In parallel with the testing, a detalled structural analysis was performed on the partially completed structure. The calculated forces in key components were compared with their expected strengths, from which the most likely cause of the fallure was determined.

The structure under construction was an approach ramp to an elevated highway over the East Chicago ship channel. The ramp was being built using the method known as cast-in-place, post-tensioned, prestressed concrete. The concrete formwork is supported by a temporary support system, known as "falsework". When the cast concrete has attalned a specifled strength, high-strength steel tendons passing longltudinally through the structure are tensioned, and this provides the needed reinforcement for the concrete structure to safely support the service loads. Before the steel is tensloned, the falsework provides the support for the construction loads and the partially completed structure.

The portion of Ramp $C$ under construction was to be bullt in five sections, or "units". At the time of the collapse, the tendons in three units had been post-tensioned, and two units were partially constructed. Concrete was beling placed to complete unit IV when, at about 10:40 a.m., the collapse occurred. Unit IV fell suddenly without apparent warning, and about five minutes later unit $V$ also collapsed. Early in the 1nvestigation, it was concluded that the collapse originated within the unit IV; this was the principal focus of the investigation.

Based on structural drawings and field measurements, the configuration of the falsework system, as 1 existed prior to accident, was determined. The falsework system was composed of "high-load capacity" shoring towers resting on Individual concrete pads placed on-grade. These towers were located adjacent to the bridge plers and at the third-points of the spans. The towers were bullt from prefabricated, welded frames and bolt-on tubular braces. Various standard-sized frames were stacked on top of each other to achleve the required tower helghts. The towers supported a steel framework, composed of longltudinal stringers and transverse crossbeams.

The structural drawings called for $1-1 \mathrm{n}(25-\mathrm{mm})$ steel bolts to connect certain stringers to the cross-beams. No evidence of these bolts was found during the 
field investigation. A frictional clip was used in place of the bolts, but no documentation was found authorizing this substitution. The drawings also specified wedges between crossbeams and stringers to compensate for the slope of the roadway. There was no evidence that wedges were used, and no documentation was found approving their omission. In addition, no calculations were found for the engineering design of the concrete pads, and the construction sequence deviated from that specified in the drawings.

Samples of key falsework components were delivered to the NBS for testing and inspection. The following items were tested: sand boxes that were used beneath the lower screw jacks of the shoring towers; U-heads which supported the crossbeams at the top of the towers; tube braces used to join together the prefabricated frames; and cores taken from various concrete pads. In addition, load tests were performed on an assembly simulating the falsework system, and metallographic examinations were made on portions of the upper screw jacks recovered from the collapse debris. Laboratory tests were supplemented with tests at the site to determine the load capacity of the concrete pads and the stiffnesses of the tower-leg foundations.

A linear-elastic structural analysis was performed on the critical portion of the structure. A computational model was developed, which included the actual construction sequence, the actual structural configuration, and the interaction between the tower legs and their foundations. The best estimate of the construction loads acting at the time of the failure was applied to the model in order to calculate the forces in the falsework system.

A comparison was made between the calculated forces and the expected strengths of various falsework components within unit IV. It was concluded that the most likely triggering mechanism of the collapse was a failure of a concrete pad. Subsequent analyses were performed to demonstrate how the initial failure led to the failure of additional components, causing an unstable condition whereby a crossbeam tipped over and resulted in the total collapse of the falsework system. It was further concluded that it is unlikely that the following failures initiated the collapse: failure of the wood sand boxes; failure of the U-heads; failure of the tubular braces; failure of the tower legs; and failure of the crossbeams.

While a detailed analysis of the cause of the collapse of unit $V$ was not performed, the following observations were noted. The falsework system lacked positive bracing in the longitudinal and transverse directions. Positive connections were lacking between the stringers and the crossbeams. Once unit IV collapsed, unit $\mathrm{V}$ was literally left "hanging in air" and eventually started to collapse. Falling stringers impaled shoring towers still standing and the collapse progressed in a domino-fashion throughout unit $\mathrm{V}$.

In summary, it is concluded that the following deficiencies contributed directly to the collapse of unit IV: 1) the omission of specified wedges between stringers and crossbeams; 2) the concrete pads had an inadequate margin of safety to resist the expected construction loads; 3 ) the tops of the shoring towers were not adequately stabilized against longitudinal movement; and 4 ) the weld quality in the U-heads was poor. Had any one of these deficiencies not existed, it is unlikely that the collapse would have occurred. Additional 
deficiencies contributed to the collapse of unit $V$. They were as follows: 1) specified one-inch bolts were not provided for connecting crossbeams to stringers and to overlap beams; 2 ) the special overlap beams at the plers were not constructed as specified; and 3 ) the construction sequence deviated from the specified sequence. 
ABSTRACT ............................................... 111

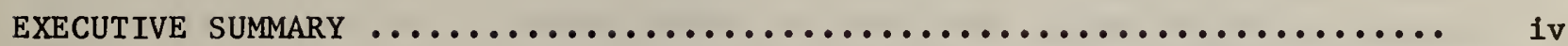

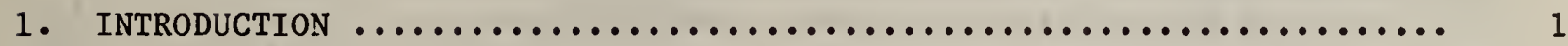

2. DESCRIPTION OF STRUCTURE AND COLLAPSE .......................

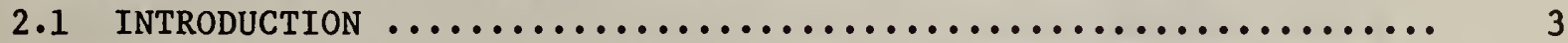

2.2 DESCRIPTION OF THE STRUCTURE ............................

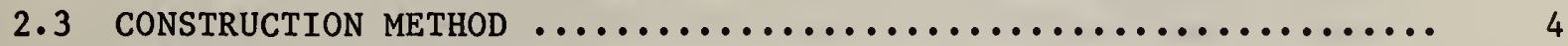

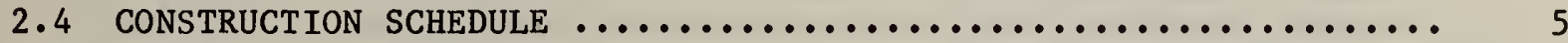

2.5 DESCRIPTION OF THE COLLAPSE ...........................

2.6 SUMMARY ..........................................

3. FIELD INVESTIGATION ................................... $\ldots \ldots$

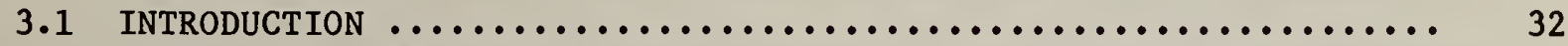

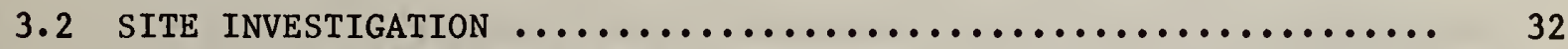

3.2 .1 Subsurface Investigation .......................... 32

3.2 .2 Supports for Shoring Towers ...................... 33

3.2 .3 Shoring Towers ................................ 34

3.2 .4 Steel Beams ................................... 35

3.2 .5 Formwork for Top slab ........................... 37

3.2.6 Location of Falsework Components After the Collapse .... 37

3.3 INTERVIEW STATEMENTS ...................................40

3.3.1 Previous Construction Problems ...................... 41

3.3 .2 Description of the Failure ....................... 42

3.4 SUMMARY ............................................. $\ldots 4$

4. EXPERIMENTAL INVESTIGATION ................................

4.1 INTRODUCTION ...................................... $\ldots \ldots$

4.2 SAND BOX TESTS .................................... $\ldots \ldots$

4.3 EXAMINATION AND TESTS OF UPPER SCREW JACKS ................ 80

4.4 FALSEWORK ASSEMBLY TESTS .............................. 81

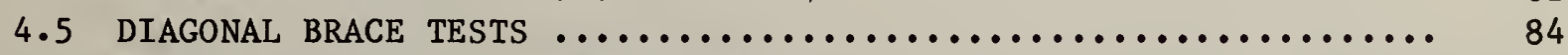

4.6 FIELD LOAD TESTS OF CONCRETE PADS .......................

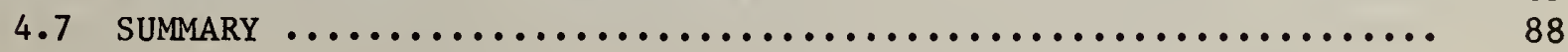

5. ANALYTICAL INVESTIGATION ... . . . . . . . . . . . . . . . . . . . . . . . . 144

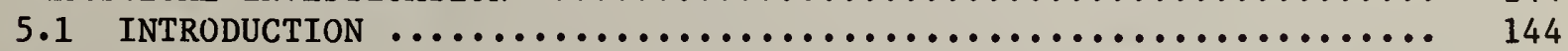

5.2 LOADS ................................................ $\ldots \ldots$

5.3 METHOD OF ANALYSIS ................................... 146

5.3 .1 Case I Mode1 ................................... 147

5.3 .2 Case II Mode1 ..................................... 148

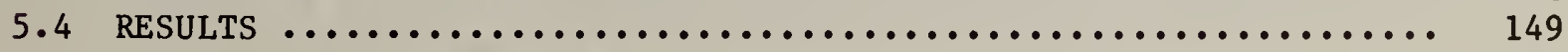

5.4 .1 Support Reactions ................................ 149

5.4 .2 Crossbeam and Stringer Reactions ................... 150

5.4 .3 Truss Brace Loads ............................... 150

5.5 SUMMARY .......................................... 151 
TABLE OF CONTENTS (Continued)

$\underline{\text { Page }}$

6. INTERPRETATION OF TESTS, ANALYSES AND OBSERVATIONS $\ldots \ldots \ldots \ldots \ldots \ldots \ldots$

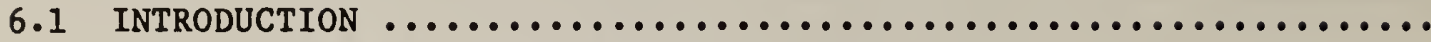

166

6.2 CAPACITY EVALUATION OF FALSEWORK COMPONENTS $\ldots \ldots \ldots \ldots \ldots \ldots \ldots$

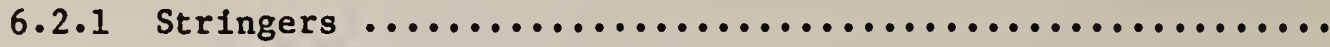

6.2 .2 Crossbeams $\ldots \ldots \ldots \ldots \ldots \ldots \ldots \ldots \ldots \ldots \ldots \ldots \ldots \ldots \ldots \ldots \ldots \ldots \ldots$

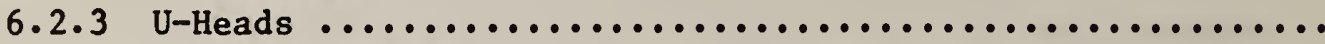

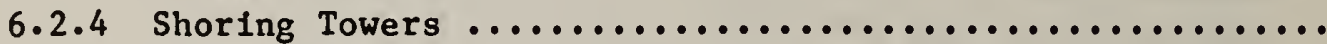

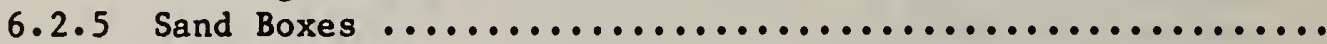

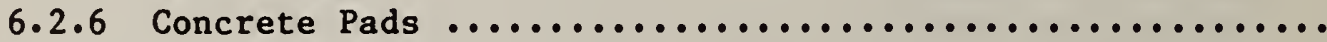

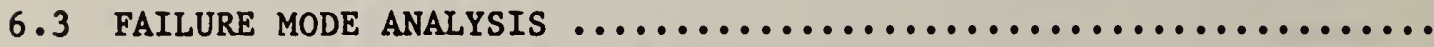

6.3 .1 Likely Fallure Mode of Unit IV $\ldots \ldots \ldots \ldots \ldots \ldots \ldots \ldots \ldots \ldots$

6.3 .2 Likely Fallure Mode of Unit $\mathrm{V} \ldots \ldots \ldots \ldots \ldots \ldots \ldots \ldots \ldots \ldots$

6.4 SUMMARY

166

166

166

167

167

168

169

169

171

171

173

174

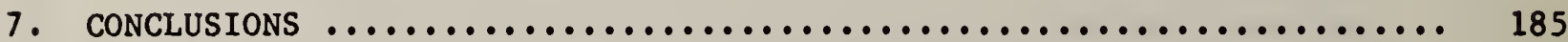

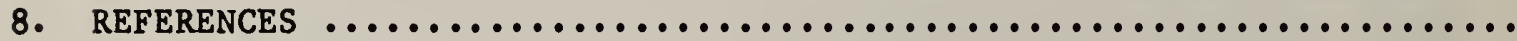

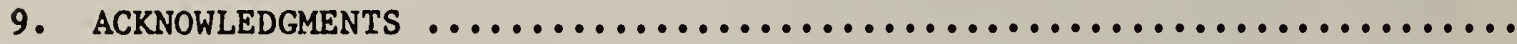

APPENDIX A. LOAD-DISPLACEMENT CURVES OF THE SCREW JACK BASES IN THE

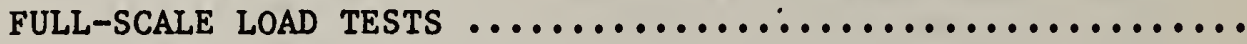

APPENDIX B. SHORING TOWER FINITE ELEMENT MODELS AND MEMBER

DESIGNATIONS $\ldots \ldots \ldots \ldots \ldots \ldots \ldots \ldots \ldots \ldots \ldots \ldots \ldots \ldots \ldots \ldots \ldots$

APPENDIX c. FINITE ELEMENT ANALYSIS OF CROSSBEAM CD7.2 $\ldots \ldots \ldots \ldots \ldots \ldots$ 


\section{INTRODUCTION}

On Thursday, April 15, 1982, a construction failure of a highway ramp structure occurred in East Chicago, Indiana. Thirteen workers were killed and 15 were injured, making it the worst construction accident in Indiana history. Immediately after the collapse, the Occupational Safety and Health Administration, Department of Labor, requested the technical assistance of the National Bureau of Standards (NBS) to investigate the cause of the failure. A team of NBS structural engineers arrived at the site on Saturday, Apri1 17, 1982, and were briefed by personnel of the Indiana Occupational Safety and Health Administration (IOSHA), which had jurisdiction over the collapse site.

Based on the initial field visits, the NBS team developed a comprehensive investigative plan which included securing construction documents and material samples, conducting interviews of workers on the project, performing physical tests on materials and components, and carrying out a structural analysis of the conditions existing at the time of the collapse. Personnel of the IOSHA provided invaluable assistance in many phases of the field investigation.

This report documents the results of the NBS investigation, and is divided into nine chapters and an appendix. Chapter 1 provides an overview of the report. Chapter 2 provides an overall description of the structure and the construction method being employed. The structure is an approach ramp to an elevated highway passing over the East Chicago ship canal. It was being built using the technique of cast-in-place, post-tensioned pretressed concrete, and the partially completed structure was being supported by a falsework system that included high-load capacity shoring towers. Chapter 2 reviews the construction history and explains the state of construction as it existed at the time of the accident. Also described is the appearance of the collapsed structure. Descriptions provided by eyewitnesses of the collapse revealed that the structure fell in two separate phases: the immediate collapse of that portion where fresh concrete was being placed (unit IV), and a more gradual collapse of the remaining unfinished structure (unit $V$ ). There was about a five-minute time interval between the two events. The focus of the NBS investigation was aimed at determining the cause of the initial failure.

Chapter 3 summarizes the field investigation conducted to establish the conditions of the structure as they existed prior to the collapse. Information was derived from site visits and from examinations of photographs and structural drawings. A representative of the Federal Highway Administration assisted in the field investigation. Also included in this chapter is a summary of the interview statements recorded by the IOSHA. A detailed description of the falsework system configuration is provided, and discrepancies between the structural drawings and what was observed in the field are noted. Finally, the locations within the collapse debris of major components of the falsework system are described, and this evidence is used to develop a possible collapse sequence.

Chapter 4 deals with the experimental investigation to establish the strength and deformation characteristics of key components of the falsework system. 
Laboratory tests were supplemented with full-scale load tests on concrete pads. The load tests were performed at the site and they provided data for analytical modelling as well as for the load capacities of the pads.

Chapter 5 presents the linear-elastic structural analysis performed on the critical portion of the ramp. The computational model and loading conditions are discussed. The model accounts for the two-stage casting sequence used in construction, and it incorporates foundation stiffness values derived from the full-scale load tests. The analytical results are summarized in terms of support reactions and member forces.

In chapter 6 a comparison is made between the strengths of falsework components and the calculated forces. It is shown that a concrete pad is the only component for which the applied load was as large as the expected strength, and it is concluded that the cracking of a pad is the most likely event which triggered the collapse. The computational model is used to demonstrate how the cracking of pads led to an instability condition which resulted in a collapse sequence that is consistent with the observed locations of falsework components in the collapse debris.

Chapter 7 is a summary of the findings, chapter 8 11sts the references cited in the report, chapter 9 acknowledges those individuals who contributed to the Investigation, and the appendix Includes supplementary data. 
2. DESCRIPTION OF STRUCTURE AND COLLAPSE

\subsection{INTRODUCTION}

This chapter provides background information on the configuration and construction method for Ramp $C$ of the Riley Road Interchange. In addition, there is a description of the appearance of the structure after the collapse. Much of the information was derived from documents and photographs obtained by IOSHA for the NBS investigation.

Section 2.2 describes the ramp structure in terms of its alignment, dimensions and specified construction materials. Most of these data were obtained from the structural drawings.

Section 2.3 discusses the construction method that was employed. This information also was developed mainly from the structural drawings.

Section 2.4 presents the construction sequence and the dates of major construction activities. The daily $\log$ of the project engineer is the main source of information. Photographs taken by various employees prior to the collapse helped to verify some details of the construction method.

Section 2.5 describes the appearance of the collapsed portions of the ramp. Photographs taken by a local newspaper provided valuable documentation of the appearance of the site shortly after the failure.

Section 2.6 summarizes the chapter.

\subsection{DESCRIPTION OF THE STRUCTURE}

The structure, known as Ramp $C$, is located at the interchange of Riley Road and Cline Avenue in East Chicago, Indiana. It is intended to move traffic from Riley Road onto the eastbound lane of Cline Avenue. Figure 2.1 is a view looking east taken shortly after the failure, and shows the portion of the ramp which remained standing. The ramp was to be built in two phases. In the first phase, the portion from pier 404 to an expansion joint beyond pier 409 was being built. In the second phase, the portion west of pier 404 and passing over Riley Road would be built. At the time of the collapse work was in progress east of pier 407 in the first portion.

Figures 2.2 and 2.3 are plan and elevation views, respectively, of Ramp C from the construction joint west of pier 404 to the expansion joint east of pier 409. Also indicated is the extent of the collapse zone. In plan (figure 2.2), this portion of Ramp $C$ is straight up to station $27+93.65$ at which point the roadway is on a horizontal curve of radius $716.2 \mathrm{ft}(218.3 \mathrm{~m})$. The superelevation is 1.56 percent up to station $27+10$ at which point it starts its transition to a superelevation of 7 percent at station $28+35$. The span lengths in figure 2.2 are along the center-line of the ramp. The roadway has a constant uphill grade of 3.569 percent. 
The structure was being built in sections, referred to as "units", as Indicated in figure 2.3. The construction method will be described in section 2.3. The cross section of the ramp was box-shaped as shown in figure 2.4. Each unft was cast in two sections. First the bottom slab and side walls were cast, and then at a later date the top slab was cast. The specifled 28-day compressive strength of the concrete is $5500 \mathrm{ps} 1$ ( $37.9 \mathrm{MPa})$.

The box girder was reinforced as indicated in figure 2.5. The top mat of bars in the top slab were epoxy-coated for corrosion resistance. In addition to the reinforcing bars, the box girder also contalned post-tensioning tendons in the side walls, as 1llustrated in figure 2.6 for unit IV. There were four tendons in each side wall, and each tendon was composed of $190.6-1 \mathrm{n}$ (15-mm), seven-wire strands with an ultimate strength of $270 \mathrm{ks} 1(1.86 \mathrm{GPa})$. The posttensioned tendons provide the main reinforcement in the longltudinal direction.

According to the structural drawings, the tendons were to be stressed when the compressive strength of the concrete in the top slab had reached at least 3500 ps1 (24.1 $\mathrm{MPa}$ ) and the concrete in the side walls had reached at least 4000 psi $(27.6 \mathrm{MPa})$. The tendons of a particular unit were attached to the tendons of the previous unit by means of special coupling hardware. As shown at the bottom of flgure 2.6, the jacking and coupler ends of each unit were enlarged to accommodate the anchorage stresses.

The concrete plers have a solid rectangular cross section with enlarged caps having the same transverse dimension as the bottom slab of the box girder. The pier shafts rest on $6-\mathrm{ft}(1.8-\mathrm{m})$ thick concrete pile caps. The pile caps are in turn supported by $14-1 \mathrm{n}$ (356- mm) high capacity steel piles, which were driven to bearing on rock and were then filled with concrete. The specified 28-day compressive strength of the pier concrete is $4000 \mathrm{ps} 1(27.6 \mathrm{MPa})$.

Figure 2.7 shows the dimensions and steel reinforcement for pler 408, as a typical example. Not shown in figure 2.7 are 111 dowel bars which extended from the pler cap into the box-girder dlaphragm. These dowel bars were used at all fixed bearings (refer to figure 2.3 for the type of bearing at the other plers).

\subsection{CONSTRUCTION METHOD}

The contract proposed by the Indiana State Highway Commission (ISHC) for the ramps of the Riley Road Interchange specifled that the concrete structural members be bullt of prestressed concrete using the technique known as segmental, pre-cast, post-tensioned construction. Basically this method involves the manufacture of pre-cast reinforced concrete segments, which are then 1 ifted into place and joined together by means of post-tensioning tendons which pass through the segments. However, the proposal had a provision which permitted a contractor to submit and bid on an alternate design provided the design criterla were met and that the contractor would retain a consultant to review the engineering design. The contractor who won the proposal submitted an alternate design based on construction by the cast-in-place, post-tensioned method. 
The method proposed by the contractor called for casting the ramp in sections or units as previously shown in figure 2.3. The units would be joined together with post-tensioning tendons to provide the required strength to resist loads. Prior to post-tensioning, the units were to be supported by falsework which included high-load capacity shoring towers. The proposed method was reviewed and approved by the review consultant and by ISHC.

Figure 2.8 shows an elevation view of the ramp with the locations of the high-load capacity shoring towers as specified in the structural drawings. It is seen that towers were provided at the piers and at the third points between piers. The formwork for the box girder was supported by steel beams (stringers) spanning between the towers. The stringers were supported by transverse beams (crossbeams) on top of the towers. Additional detalls of the falsework system will be presented in sub-sections 3.2 .2 to 3.2 .4 . The tower legs were supported by concrete pads which according to the structural drawings were to be $5 \times 5 \times 1 \mathrm{ft}(1.5 \times 1.5 \times 0.3 \mathrm{~m})$.

The box-girder units were cast in two stages, the bottom slab (flange) and side walls (webs) were cast first and then the top slab was placed. When the bottom portion of each unit was cast, a gap was provided over the piers which was filled-in during the top-slab placement. Figure 2.9 shows the planned dimensions of unit IV to illustrate the discontinuity at the pier for the bottoin portion of each unit. Note also that the right-hand* side wall (web) had blockouts for drain pipes. The blockouts were filled during the top-slab placement.

When the bottom portion was cast, the entire load was supported by the shoring towers, that is, none of the load was resisted by the concrete plers. When the top slab was placed, the plers supported only the fresh concrete placed in the diaphragm. Thus the towers supported all loads until the units were prestressed, at which time loads were transferred to the piers.

\subsection{CONSTRUCTION SCHEDULE}

According to sheet 342 of the structural drawings, the typical construction sequence for each unit was as follows:

"1. Erect scaffolding and forms.

2. Place rebar and post tensioning tendons in bottom slab and webs.

3 Pour bottom $s l a b$ and webs.

4. Place rebar in top slab.

5. When the concrete has reached a strength of 4,000 psi in the webs and 3,500 psi in the top slab, stress the post tensioning tendons. (See stressing sequence table.)

6. Remove forms and scaffolding."

* The term "right-hand" and left-hand" are based on the person looking up-station, that is from west to east. 
The above sequence implies that construction would have progressed one unit at a time from pier 404 to beyond pier 409, that is, the unit under construction would be pre-stressed before placing the bottom portion of the next unit. However, the actual construction sequence deviated from the above.

Table 2.1 gives the dates of major construction activities based on the daily reports of the project engineer for ISHC. It is seen that the bottom portion of unit II was cast before casting the top slab of unit I. This was followed by casting the bottom portions of units III and IV, after which there was about a two-month inactive period due to winter weather. Upon restart of construction in February 1982, the top slab of unit II and the bottom portion of unit $V$ were cast. In March the top of unit III was cast, and on Apr11 15, 1982 the top slab of unit IV was being placed when, at about 10:40 am, the collapse occurred. At the time of the collapse none of the supporting falsework (other than fornwork) had been removed from Ramp C.

Figures 2.10 and 2.11 are enlarged portions of photographs taken by an employee in December, 1981. The photos indicate that the bottom portion of unit IV had been cast and the forms are covered with blankets. Flgure 2.10 was taken from the southeast and 1 t shows the falsework as 1 existed from pler 407 to the end of construction. Figure 2.11 was taken from the northwest and it gives details of the falsework for a portion of unit IV. These photographs proved valuable in reconstructing the layout of the falsework.

The construction sequence that was used resulted in a modification of the casting of the units. Because the lower portion of the subsequent unit was cast before pre-stressing a unit, 1t was necessary to omit a portion of the bottom slab and side walls at the coupler end (f1gure 2.6) of the subsequent unit. This was required in order to be able to post-tension the tendons in the unit. This gap was filled before the top slab was placed. According to the project engineer's dally log, the gap at the coupler end of unit IV was filled two days before the collapse. Based on the information provided to NBS, there was no specification for the dimensions of the gap nor for the procedure to follow in its construction.

The precast concrete pads to support the shoring towers were placed on the ground using a levelling course of fine boller slag (known as "black beauty"). It appears that there was no specification for the subgrade preparation to be used before placing these pads into position. The excavated reglons around the piers were backfilled with the same boller slag. The concrete pads for the towers adjacent to the piers rested on the boller-slag fill. In subsection 3.3.1 the statements of workers involved in falsework erection are reviewed and they give further details of the construction methods that were used.

Figure 2.12 is a photograph taken by an employee on Apr11 11, 1982, just four days prior to the accident. The photo indicates the location of the scaffold stalr tower on the southside of unit IV. Also shown is the side-wall formwork that was in-place at the coupler end of unit $V$ (the construction joint).

At the time of the collapse, the top slab of unit IV and the diaphragm over pier 408 were being cast. According to the delivery tickets from the ready-mixed 
concrete plant, $140 \mathrm{yd}^{3}\left(107 \mathrm{~m}^{3}\right)$ of concrete had been delivered for the top slab. From field measurements it was found that the diaphragm had been filled to an elevation of about $5 \mathrm{ft}(1.5 \mathrm{~m})$, thus it was calculated that the top slab had been placed to a point about $20 \mathrm{ft}(6.1 \mathrm{~m})$ west of pier 408 , when the collapse initiated. This estimate was corroborated by worker statements and by measurements of the extent of the cement paste stain on the northern side wall of unit IV (see figure 2.17 ).

Figure 2.13 represents the state of construction as it probably existed just before the collapse. Post-tensioning tendons were in place in unit IV, but they were not yet tensioned. However, the tendons were wedged into place at the jacking end of unit IV and were coupled to the jacking end of unit III, which had already been pre-stressed. The gap at the coupler end of unit $V$ had formwork in place. Unit $V$ had two tendons in place in the left-hand side wall, but they were not coupled to unit IV. Thus, the only connection between unit IV and unit $V$ was provided by the formwork between the two units.

Based on interview statements, concrete was not being deposited on the deck at the time of collapse. Weather data from a nearby industrial plant shows that there was about a 15-mph $(24-\mathrm{km} / \mathrm{hr})$ wind blowing approximately from the south. The weather was described as "fair" by the field engineer and the temperature range for the day was $50^{\circ}$ to $70^{\circ} \mathrm{F}\left(10^{\circ}\right.$ to $\left.21^{\circ} \mathrm{C}\right)$.

\subsection{DESCRIPTION OF THE COLLAPSE}

This section discusses the appearance of the collapsed structure. Descriptions of the collapse as witnessed by various employees is presented in subsection 3.3 .2 .

Figures $2.14,2.15$, and 2.16 are aerlal photographs taken on the day of the failure. They show the location of the debris before a significant amount of it had been moved for rescue operations.

Figure 2.14 was taken from the southwest direction and shows the overall appearance of the site. The collapse extended from the construction joint east of pier 407 to the end of construction east of pier 409 . Figure 2.15 was taken from the east and gives another overall view of the site.

As will be discussed in subsection 3.3.2, the failure occurred in two stages: first, unit IV collapsed, and then unit $V$ collapsed. There was about a fiveminute time interval between the two stages. The collapse of unit IV was reported to be sudden, while unit $V$ came down in a more gradual "domino-fashion."

Unit $V$ came down in four main sections: two sections east of pier 409 and two sections west of it. The two sections east of pier 409 fell down in an approximately vertical direction. West of pier 409, there was evidence of translation. Specifically, the western most section translated toward the east and ended up beneath the other section.

At the east end of unit $V$, a "cherry picker" type crane was struck by the debris. This crane had been located at the north side of the unit IV for 
delivering concrete to the top slab. After unit IV fell, the crane was moved to the east end of unit $V$ in an attempt to rescue workers that had been trapped on top of that unit. There was only one stairway and it was located in unit IV (figure 2.12). While the operator was positioning the outriggers of the crane, unit $V$ fell. This confirms that there was a distinct time interval between the initial collapse of unit IV and the subsequent collapse of unit $V$.

Figure 2.16 shows unit IV as viewed from the northeast. The west end of unit IV (the coupler end) remained attached to unit III by means of the posttensioning tendons which were coupled to unit III. Unit IV hangs lower than unit III because of the slack originally in the tendons and additional slack produced during the collapse. It is also seen that the portion of unit IV which was orijinally located east of pier 408, flipped over pier 408 and landed upside down on the other portion of unit IV. A possible collapse mechanism resulting in the final configuration will be presented below. Also shown in figure 2.16 is the collapsed stairway which fell on top of the flipped-over section.

Figure 2.17, 2.18, and 2.19 are ground level views of unit IV. Figure 2.17 is a view from the northeast and shows the portions of unit IV that were adjacent to pier 408. Stains due to fresh cement paste can be seen on the northern side wall. The stained region ends at about $20 \mathrm{ft}(6 \mathrm{~m})$ from the end of the unit, and this is assuned to indicate how much of the top-slab concrete had been placed. In the foreground of figure 2.17 is seen a short, steel beam that was originally located next to the cap of pier 408 . The purpose of this beam is discussed in subsection 3.2 .4 .

Figure 2.18 is a partial view of unit IV as viewed from the southeast. The hanging portion has the wall forms in place that were required for filling the gap at the coupler end. This concrete was placed two days before the accident. In the foreground of figure 2.18 is one of the longitudinal beams (stringer) used to support the formwork. On top of the stringer there are $4 \times 6$ - timbers which supported the plywood decking.

Figure 2.19 is a view of the hanging portion of unit IV as seen from the southwest. The portion of the floor slab that is a lighter shade is the portion cast two days before the fallure. Also seen are the damaged shoring towers at pier 407. The two transverse beams on unit III were added after the collapse to help support the stringers which were originally supported by the towers at pier 407. Figure 2.19 also shows some of the falsework detalls to be discussed in section 3.2 .

Pigure 2.20 is a reconstruction of a possible mechanism of the collapse of unit IV. Field observations after the failure revealed a large gap in the northern wall of unit IV at approximately the same cross section containing the drain blockout on the south wall (see figure 2.9). Thus, it is suggested that unit IV developed initial cracking at the location of the cross-section with the blockout. As the unit fell it dragged with it the portion east of pier 408 $(\# 1)^{*}$, because the tendons were wedged in place at the jacking end of unit IV.

* These numbers refer to the sequencee numbers given in figure 2.20 . 
At some point the segment being dragged flipped over the pier and the segment was propelled westward (非 $2, \ldots 3)$. When the air-borne segment hit the portion of unit IV on the ground (非), two things occurred: the south wall between the drain blockout and the end of the segment was flattened and a second major break was created (非5). This sequence results in a final configuration consistent with field observations.

Prior to post-tensioning a unit, all construction loads were supposed to be resisted by the falsework system. Thus, cracking of unit IV was due to a failure of the falsework system, causing the unit to support construction loads that it was never intended to sustain.

\subsection{SUMMARY}

Ramp C of the Riley Road Interchange is constructed of prestressed concrete, and the roadway has a box-shaped cross section. The ramp was being built in segments, referred to as "units", which are prestressed by post-tensioning tendons in the side walls of the box girder. Prior to stressing, each unit is supported by a falsework system consisting of longitudinal stringers, cross beams and high-load capacity shoring towers. The unstressed units were not intended to support bending streses due to construction loads.

The construction sequence in the structural drawings indicated that each unit should have been pre-stressed before beginning the casting of the next unit. However, in the actual construction schedule, the bottom portions of subsequent units were cast prior to pre-stressing a unit. This resulted in greater portions of a partially completed structure during construction, than if the specified sequence had been followed. Had the specified sequence been followed the bottom portion of unit $V$ would not have existed when the top slab of unit IV was being cast.

On Thursday, April 15, 1982, units IV and V of the ramp collapsed. At the time of the collapse, the top slab of unit IV was being cast. According to witnesses, unit IV collapsed suddenly, without warning. Then there was approximately a five minute interval before unit $V$ collapsed in what has been described as a "domino" fashion. The fallure sequence indicates that the failure initiated within unit IV.

Since unit IV was supposed to be fully supported by the falsework system, it was concluded that the collapse was triggered by some type of failure in the falsework system of unit IV. Consequently, the NBS investigation was focused on determining the cause of the collapse of unit IV, and did not attempt to determine the exact collapse mechanism of unit $V$. 
Table 2.1 Dates of Major Construction Activities

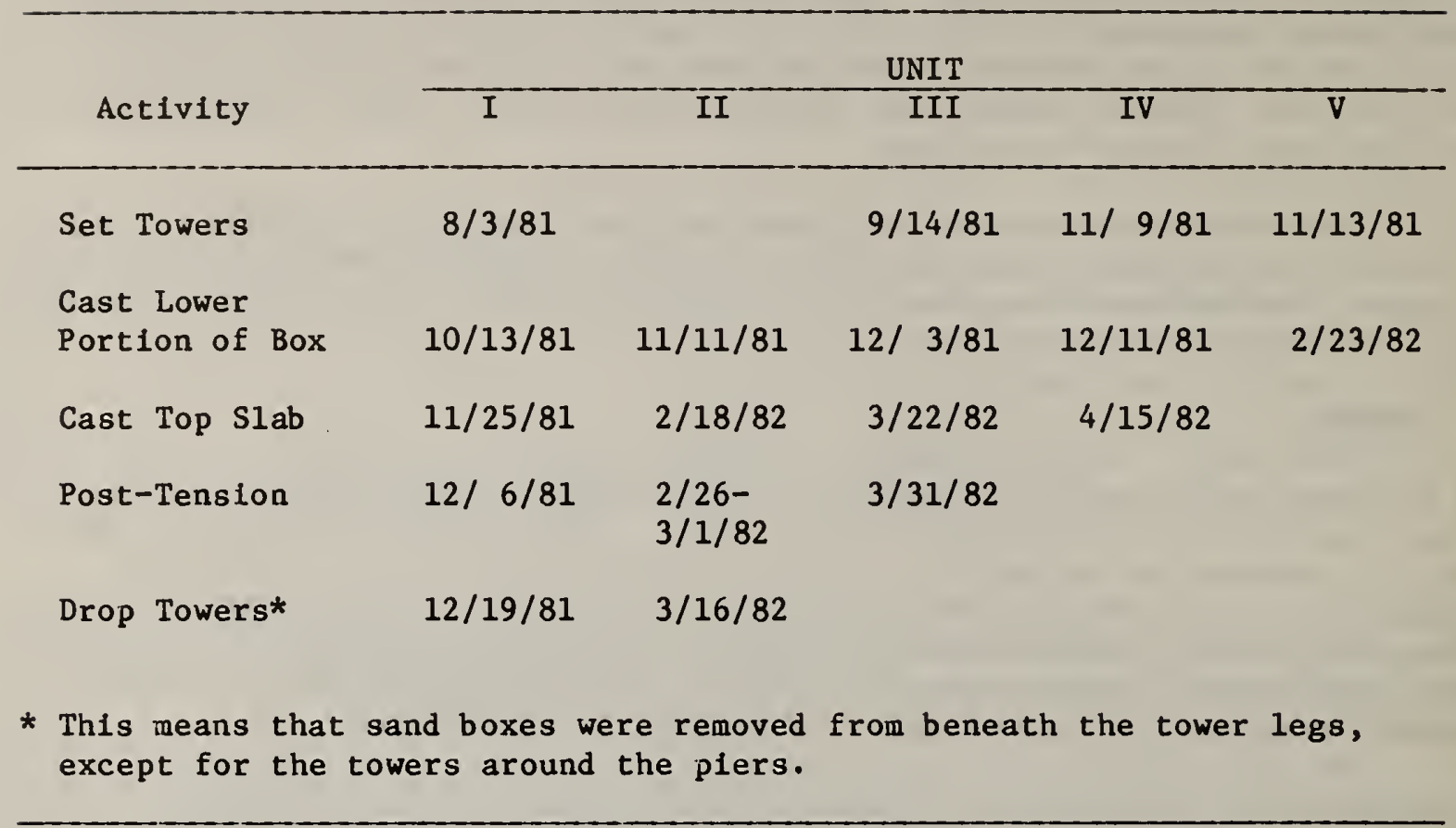




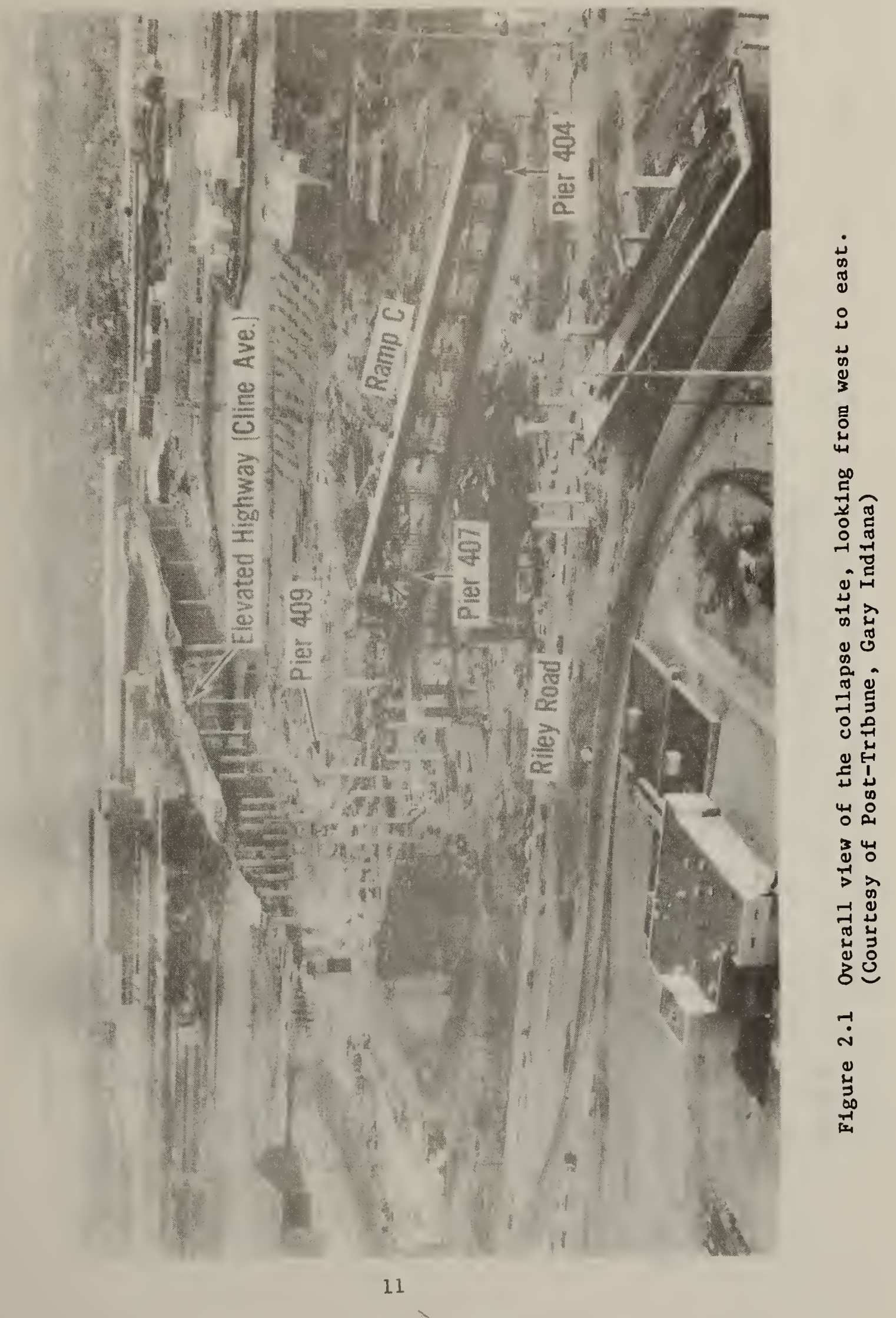



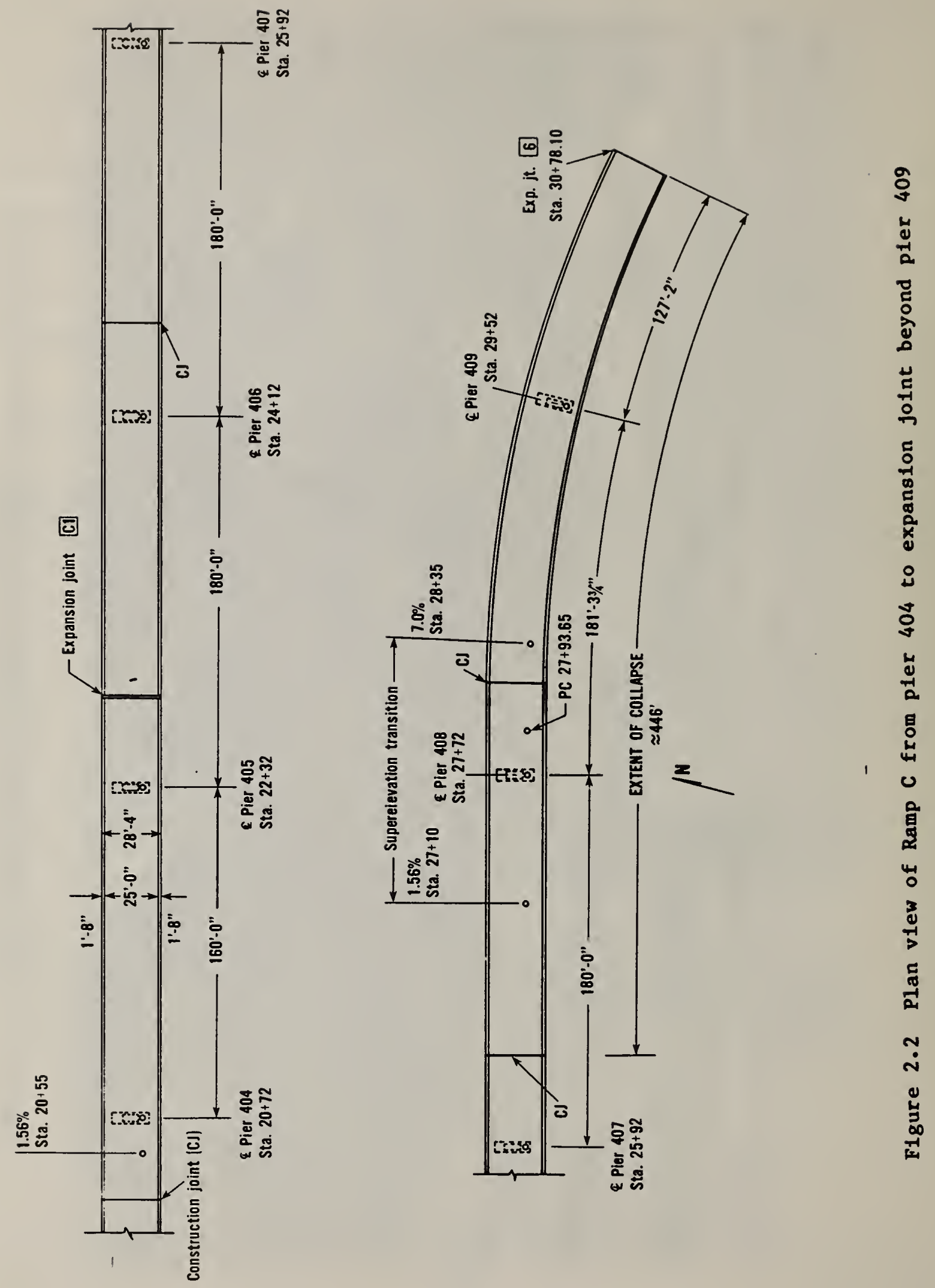

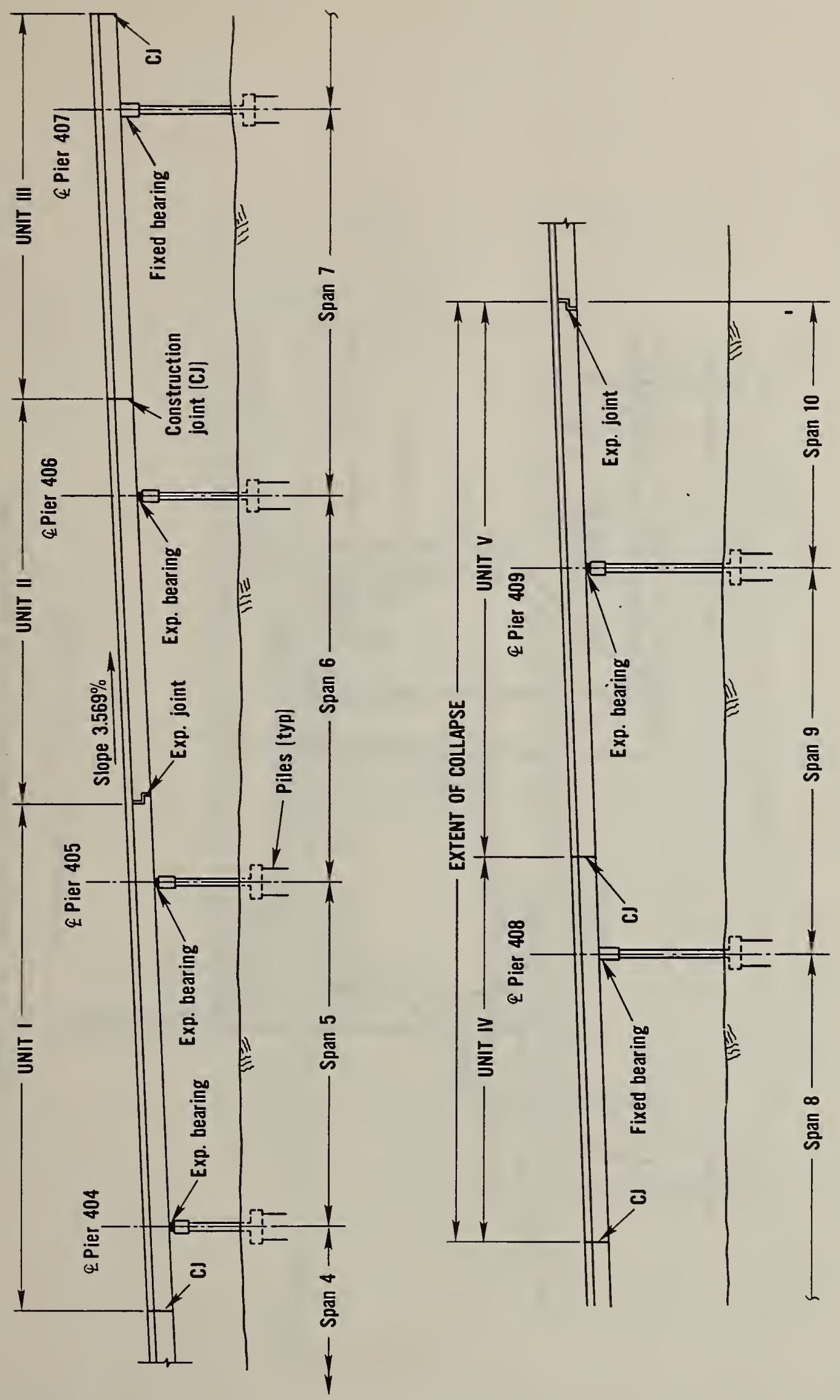

gे

㟧

है

吾

ㅇ

ఫ্

岂

0

量

씽

总

苟

iे

营 


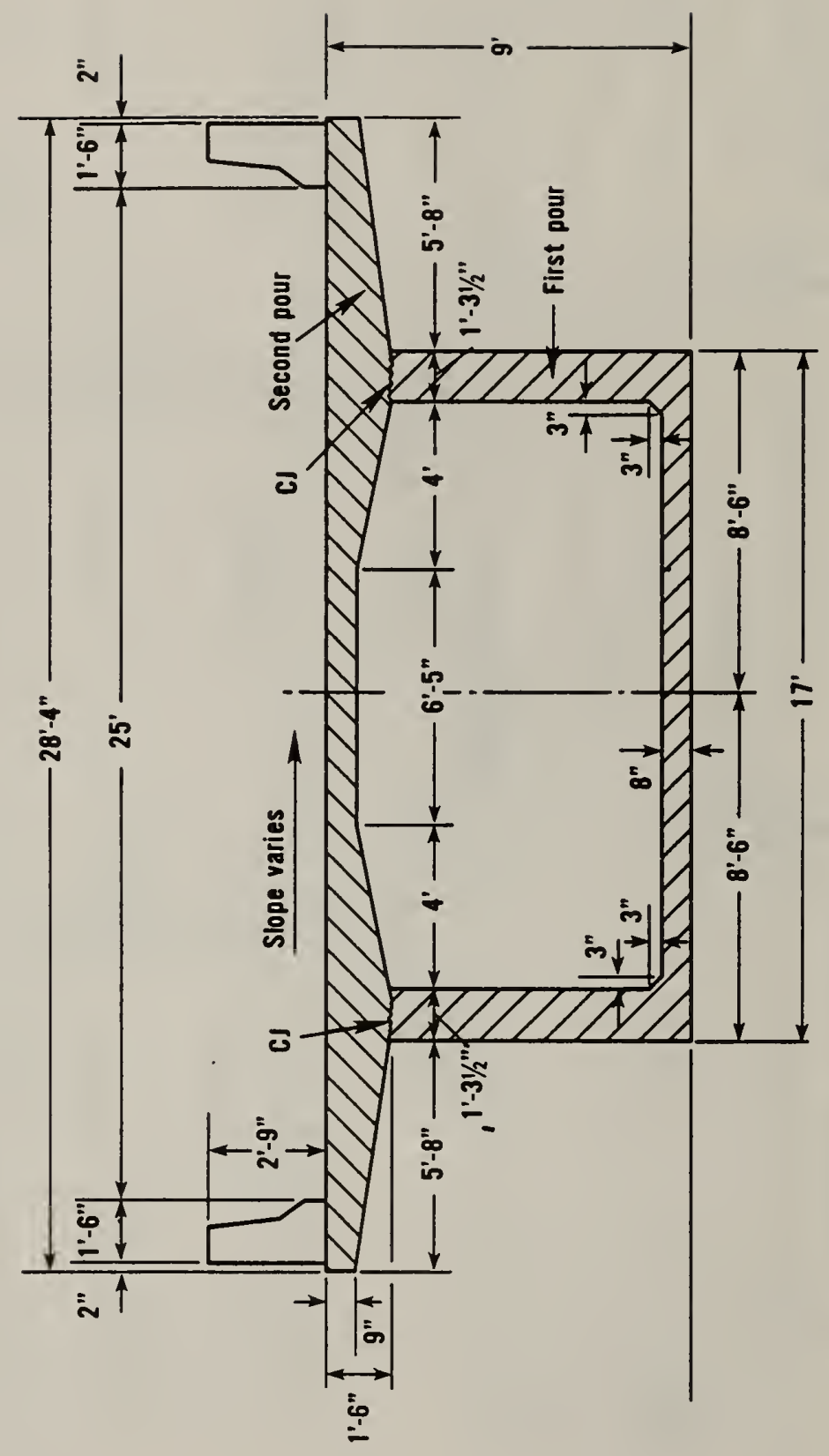

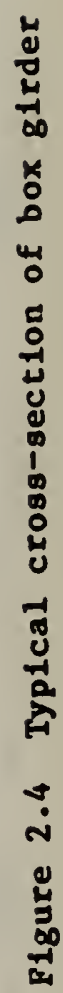




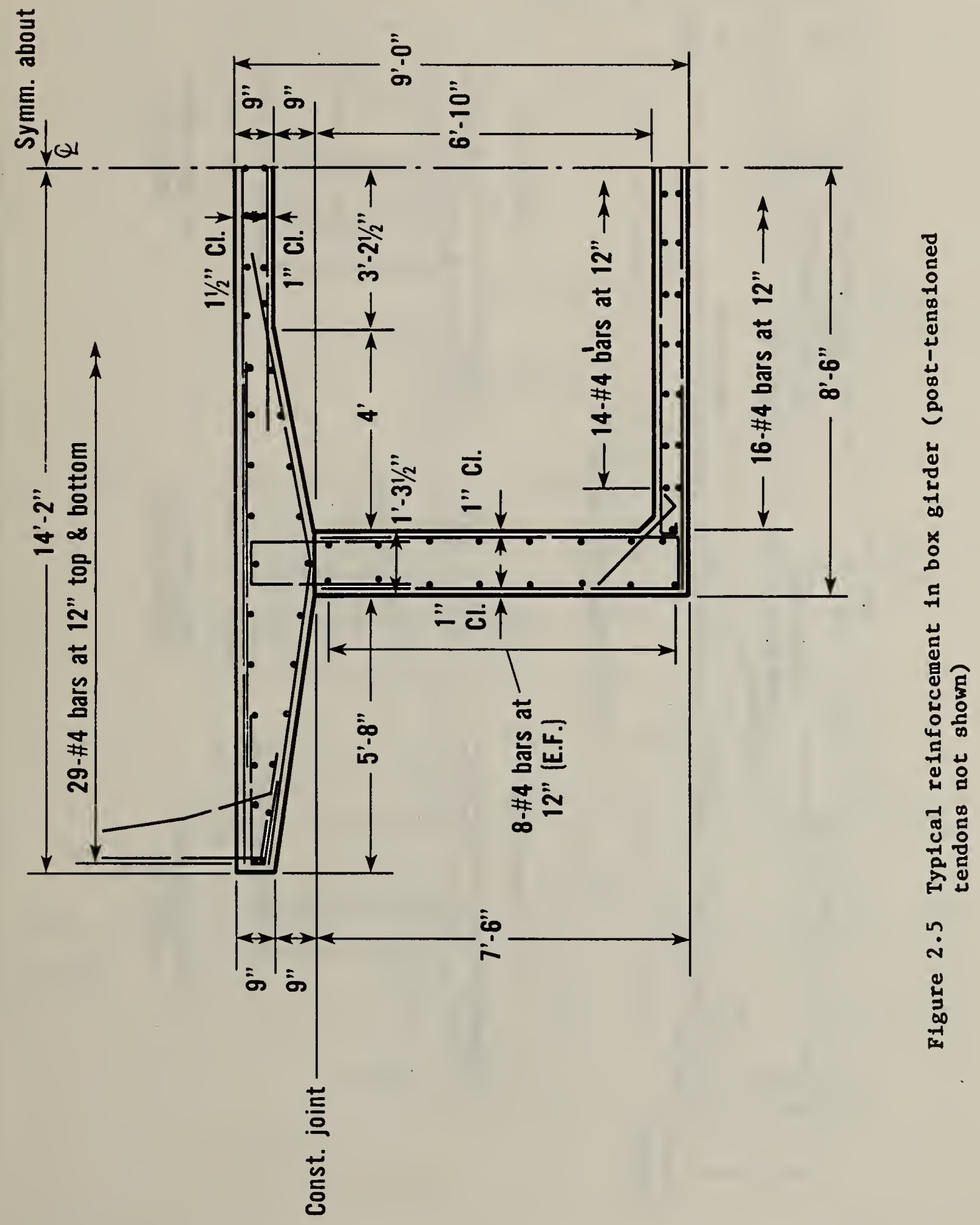




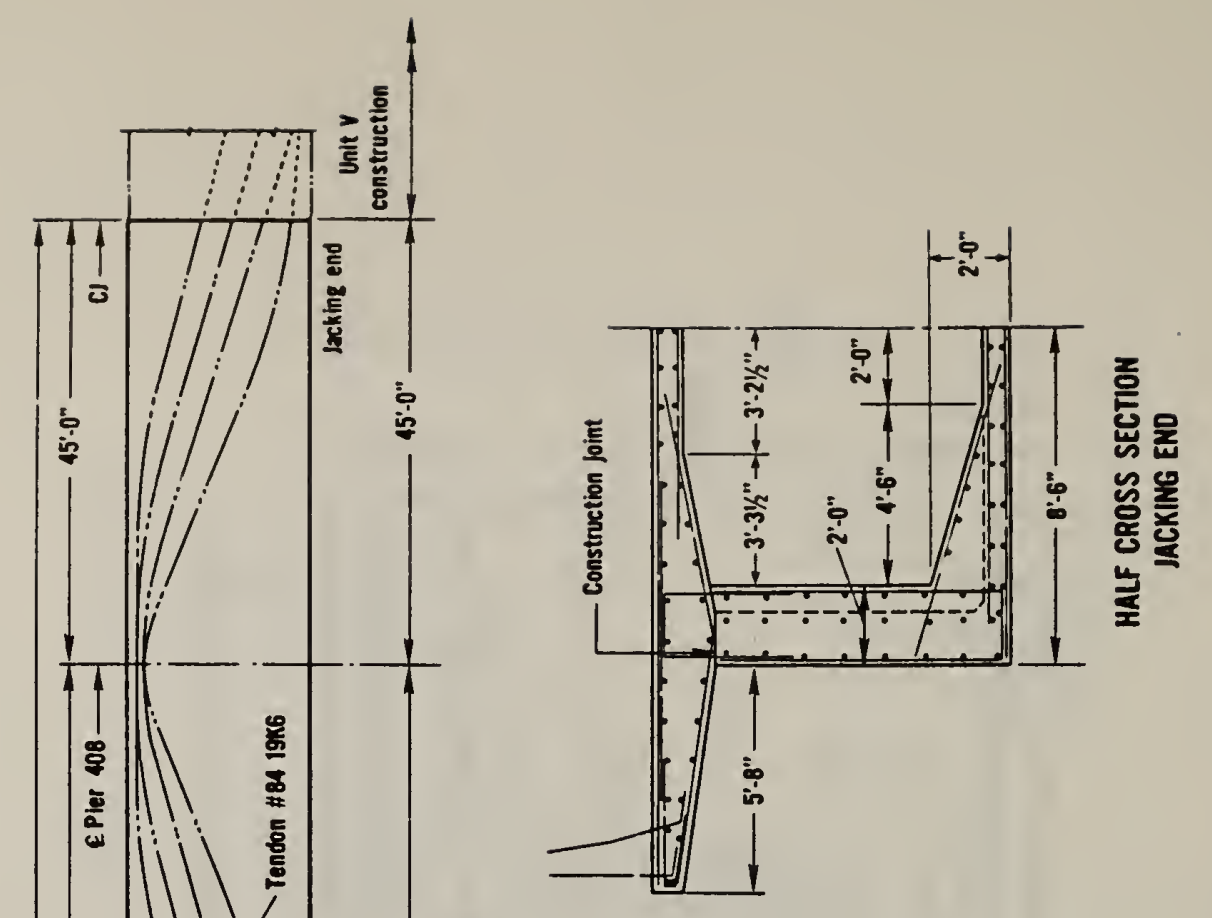

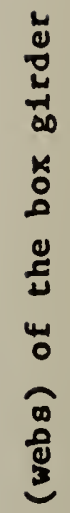
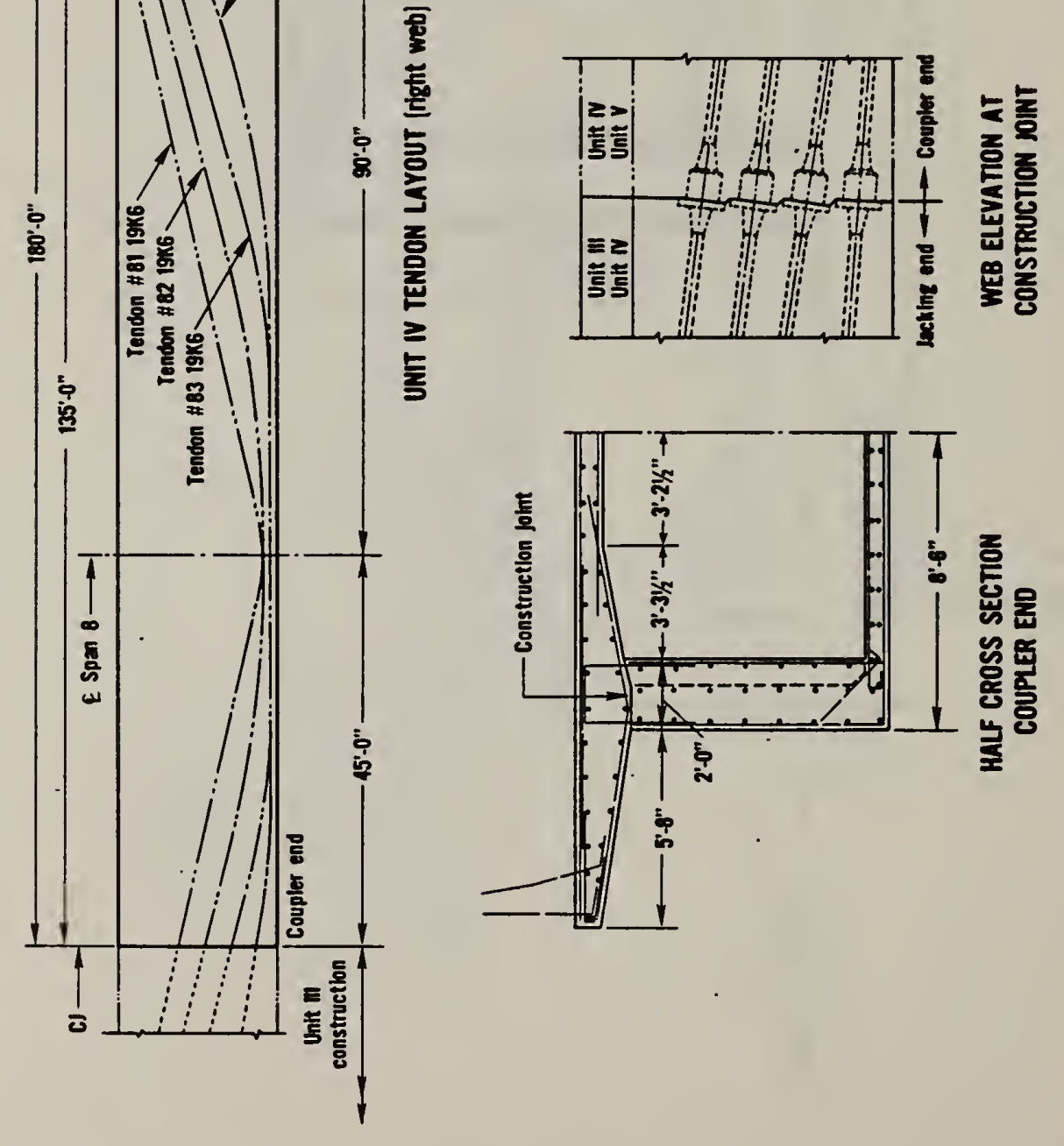


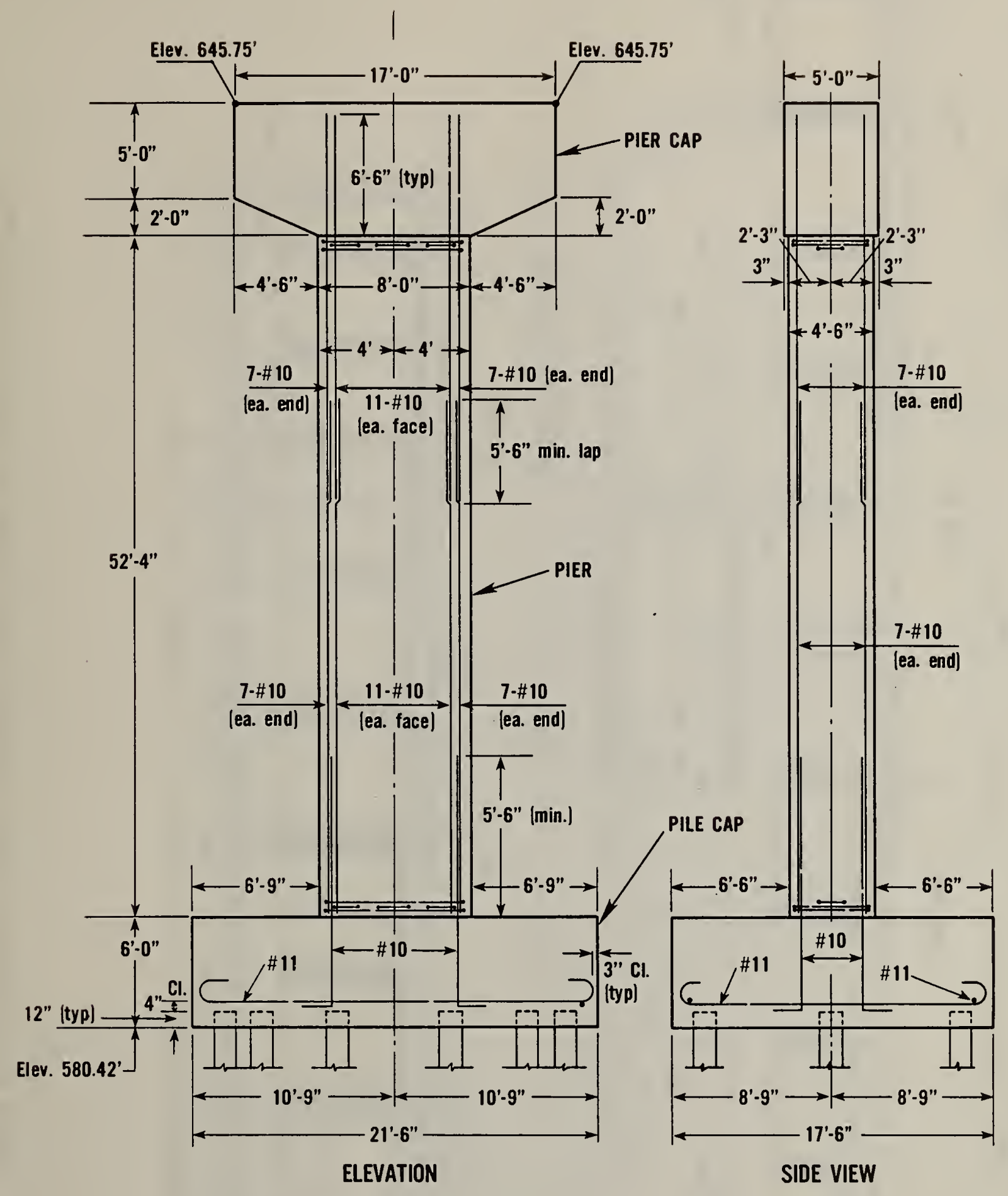

Figure 2.7 Dimensions and steel relnforcement layout for pier 408 

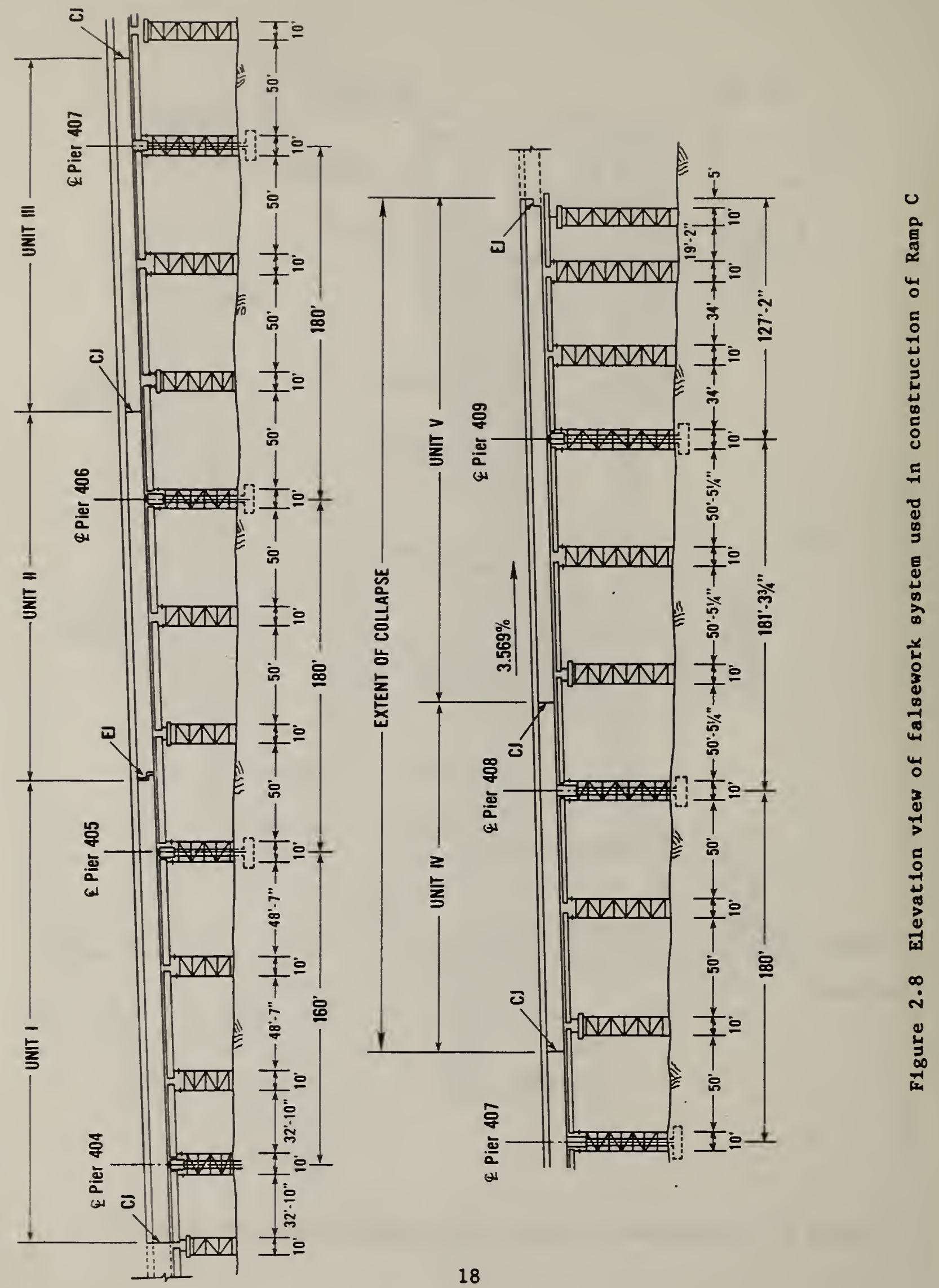


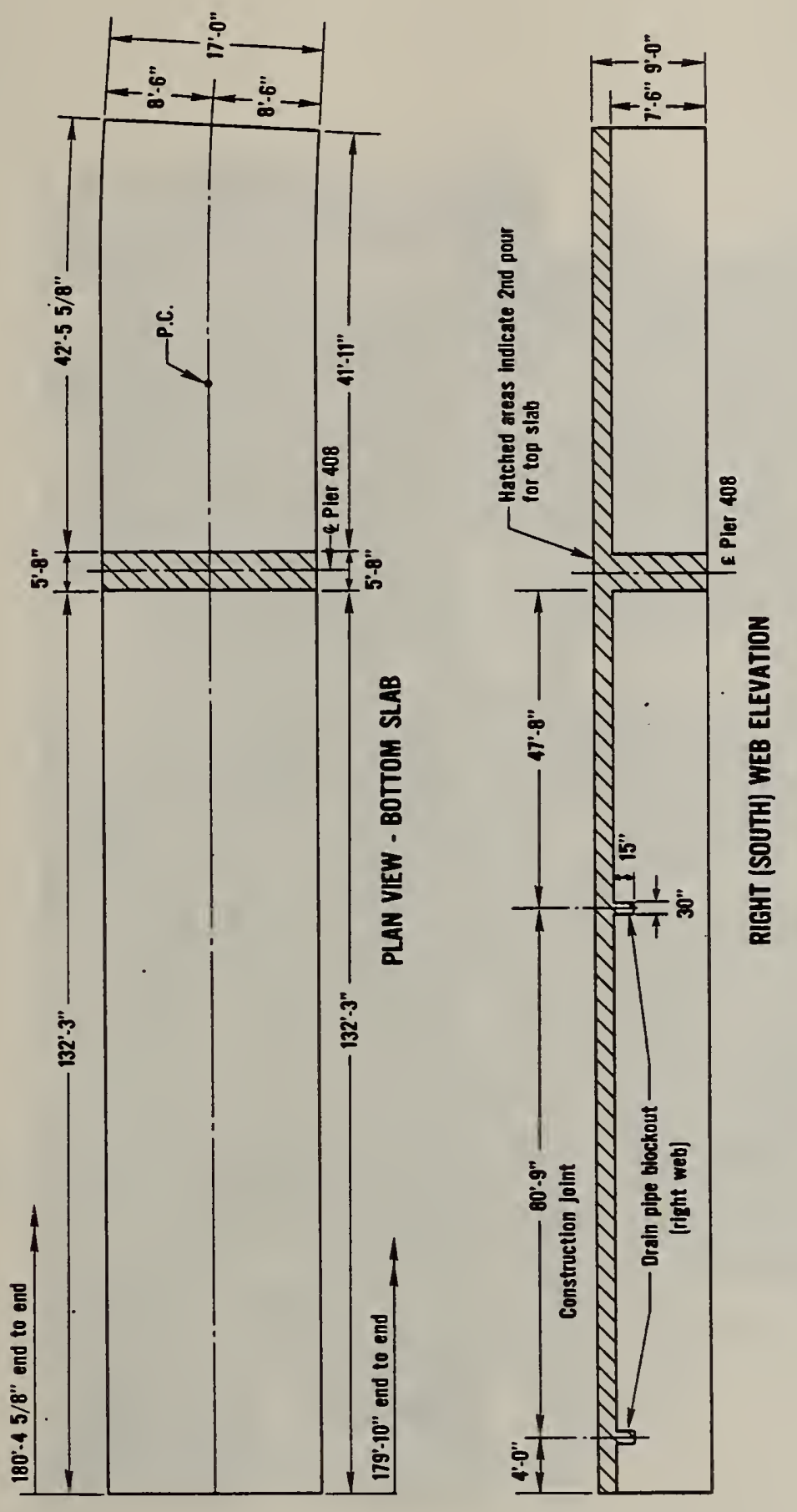

Z 


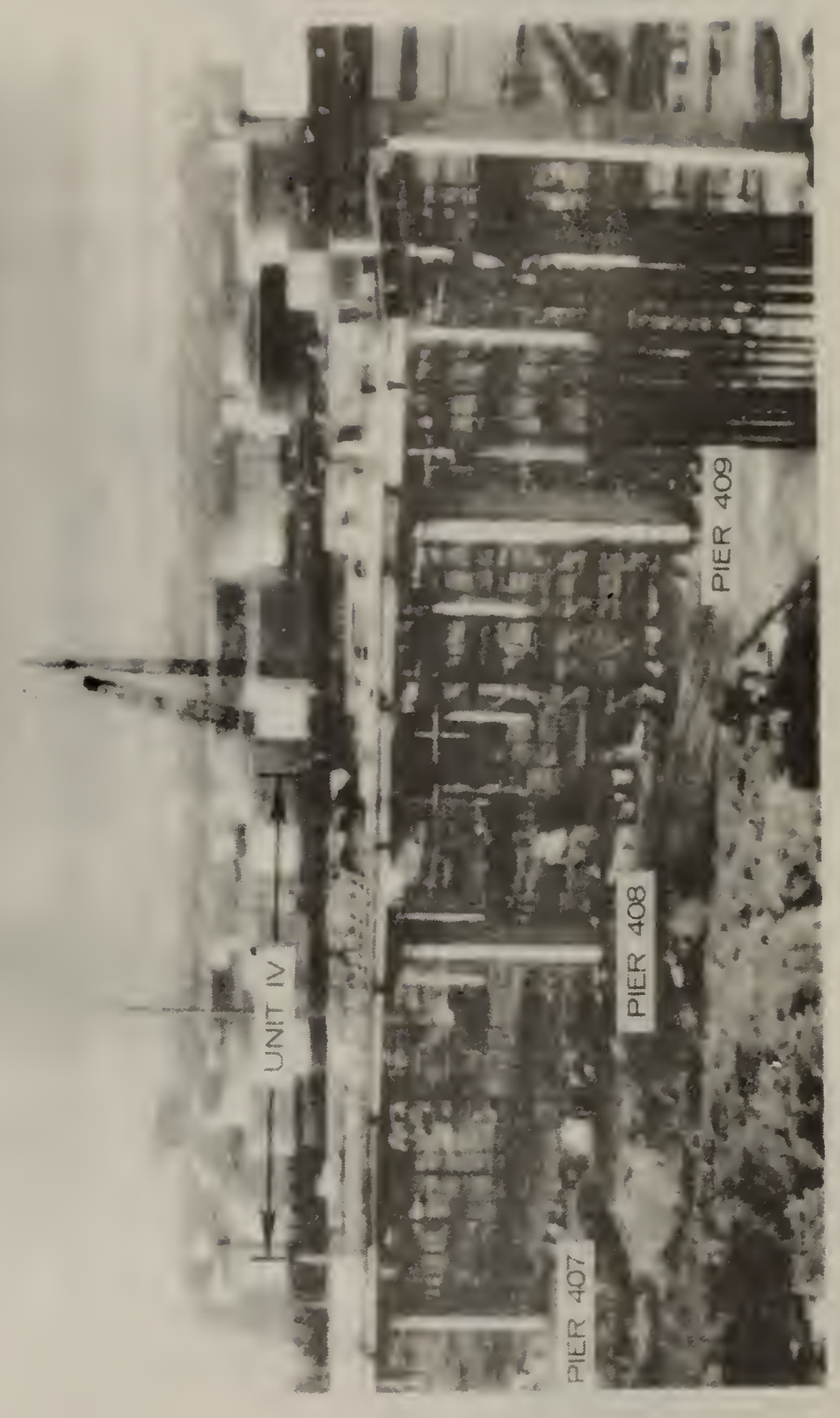

Uू 


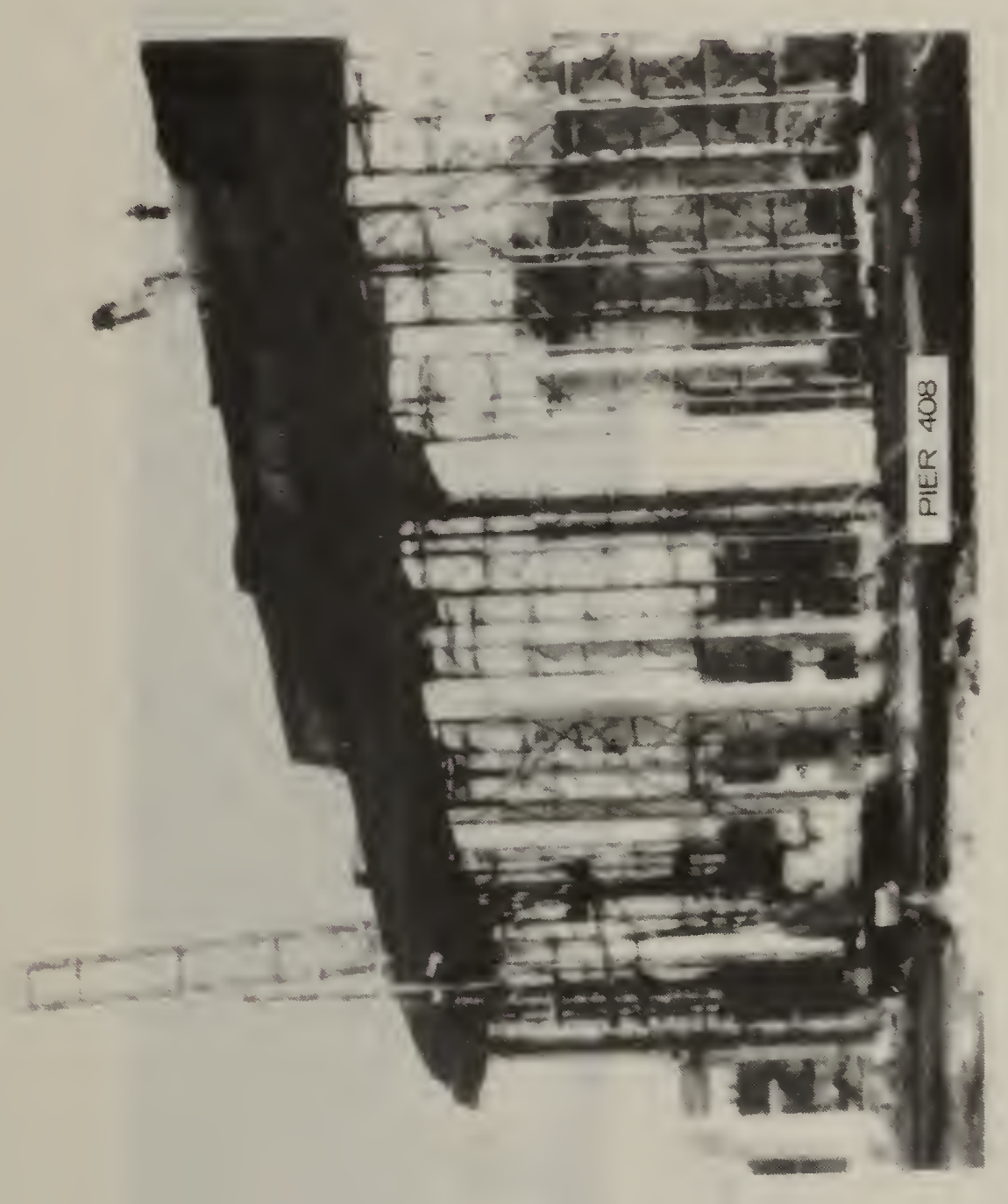

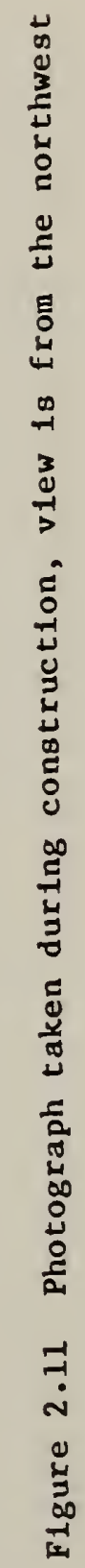



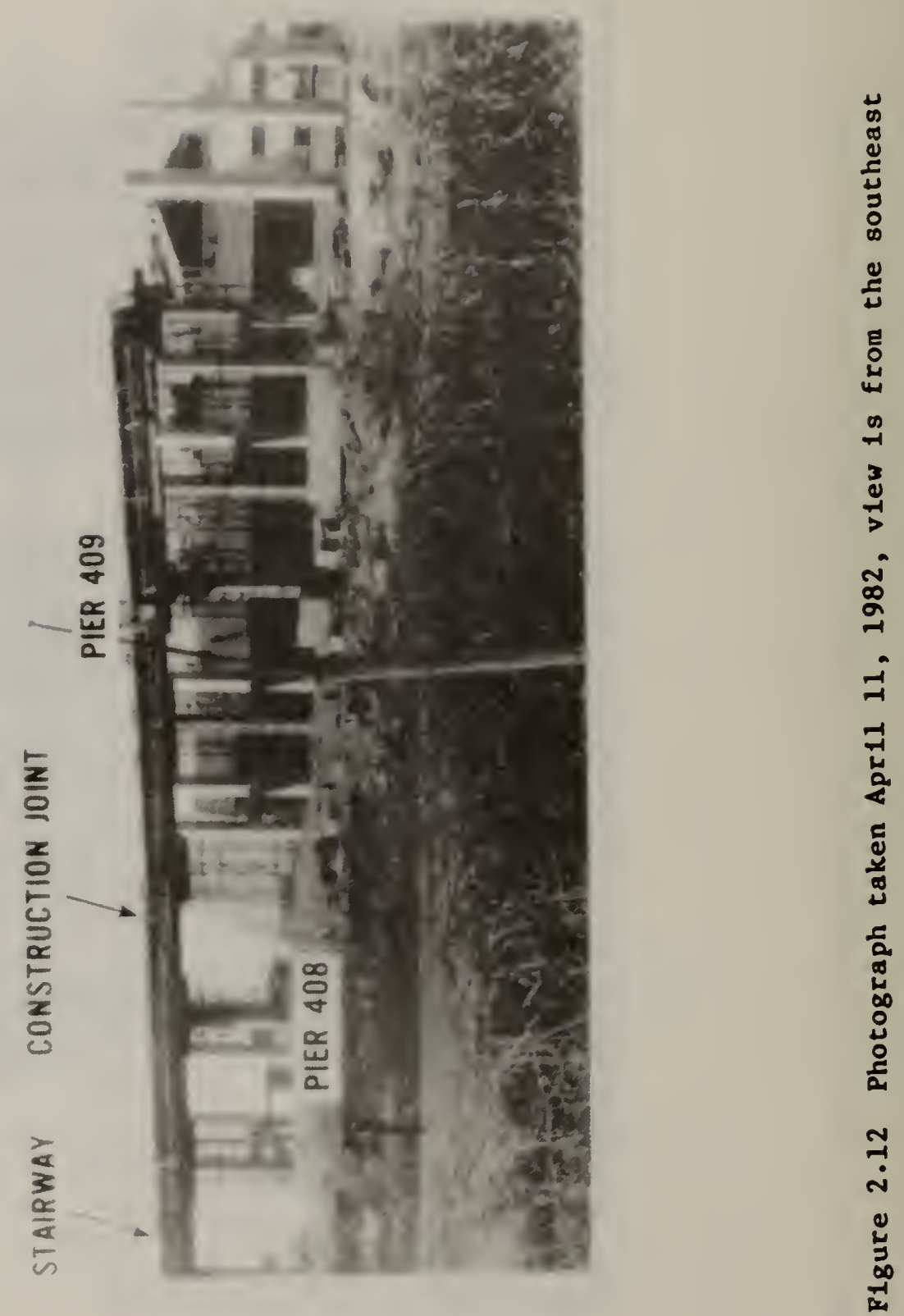

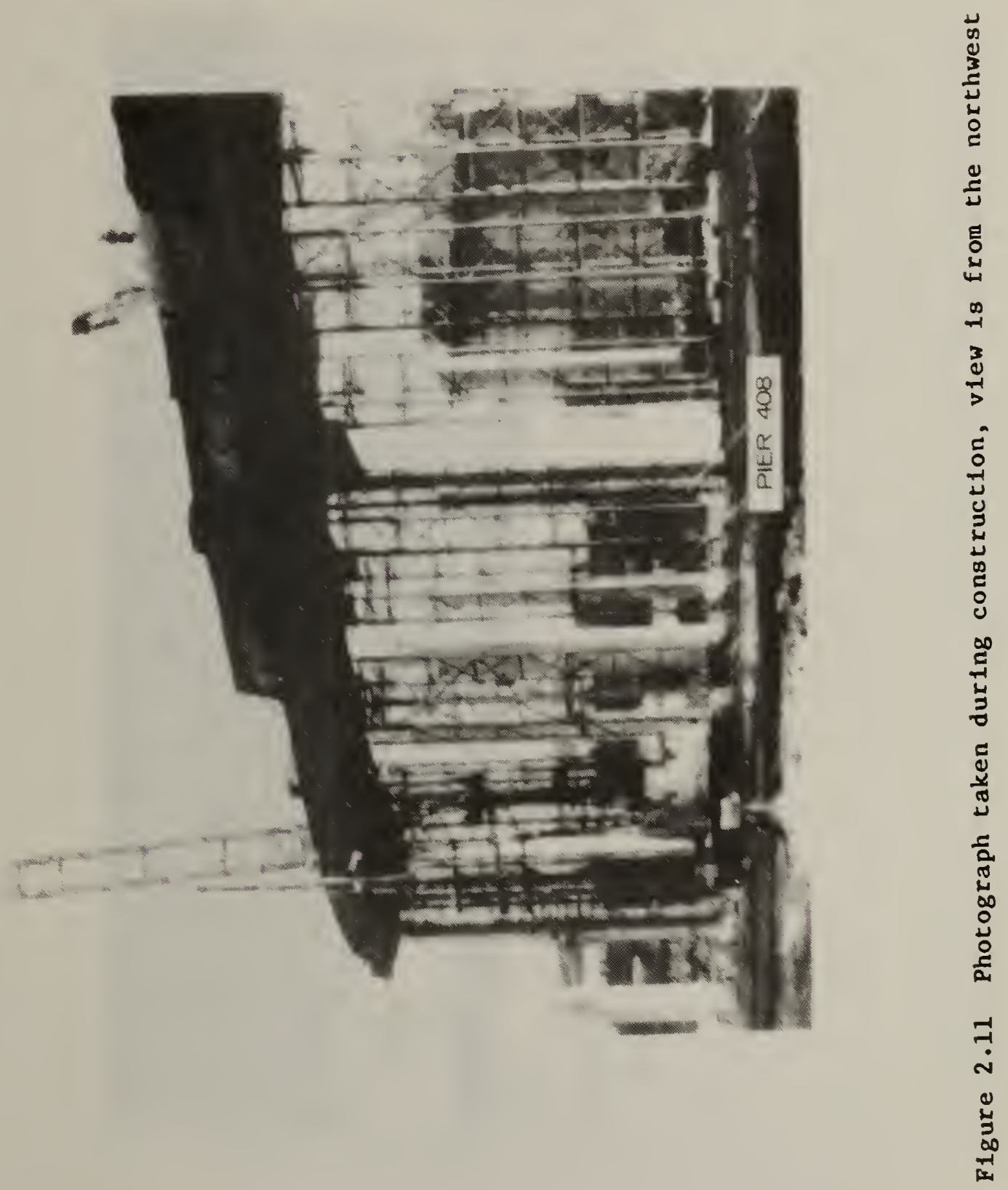

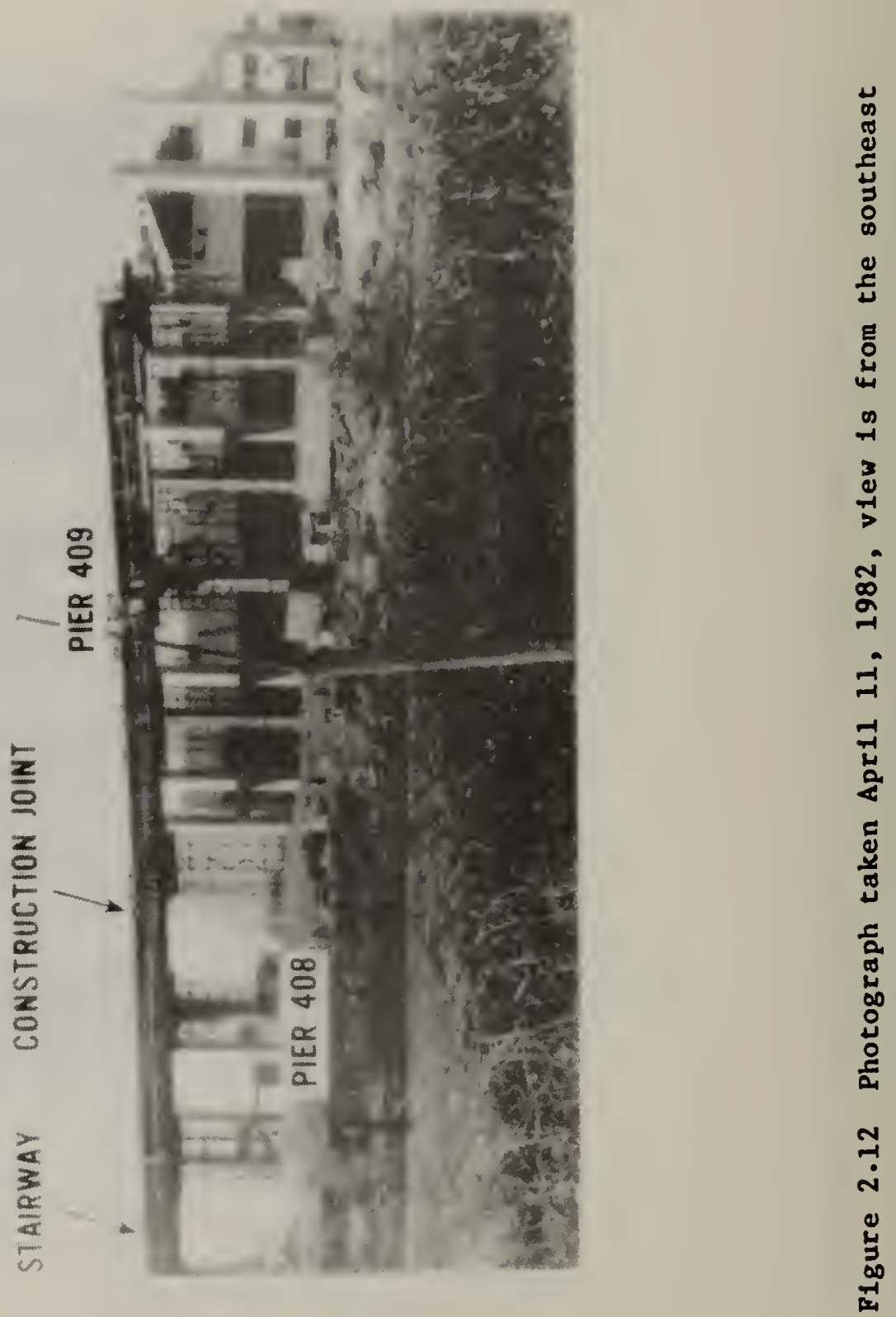


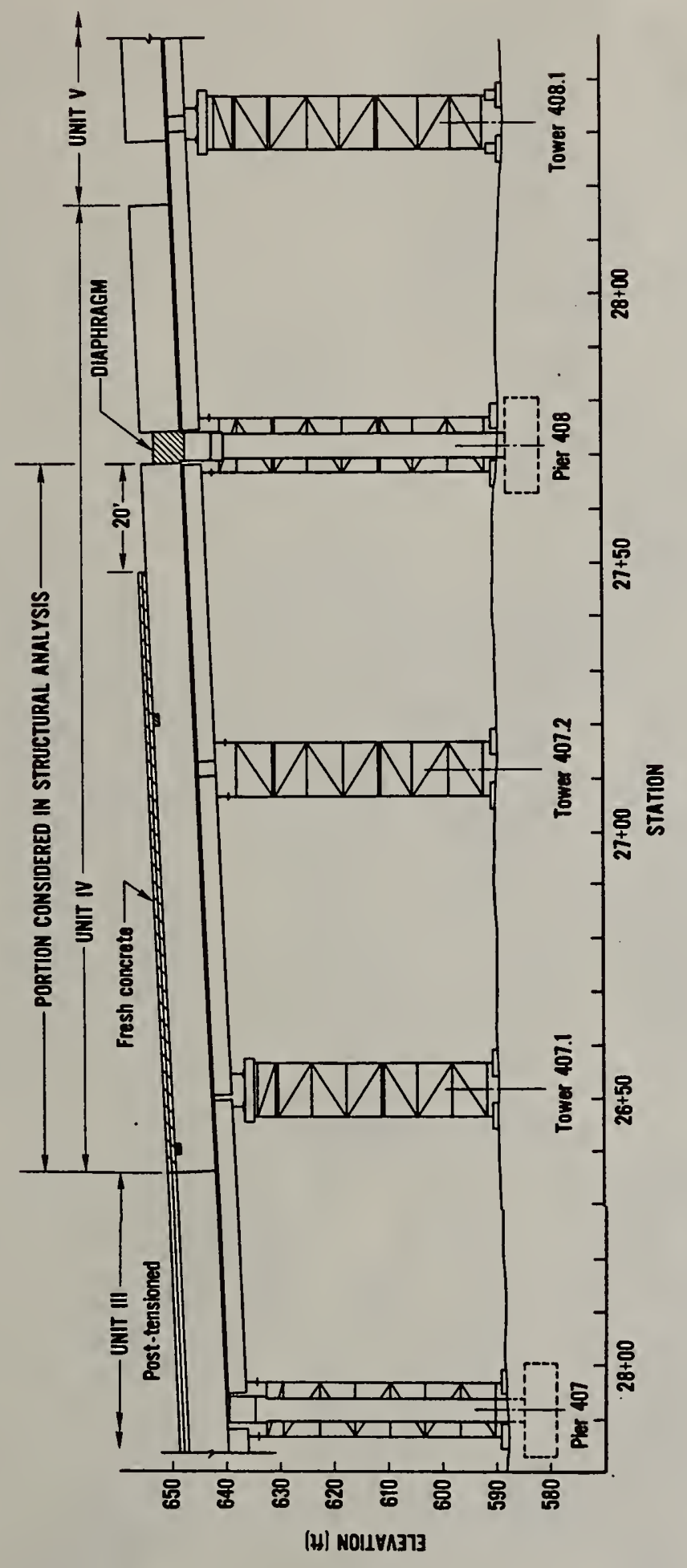

ป 
if 905 ? है 

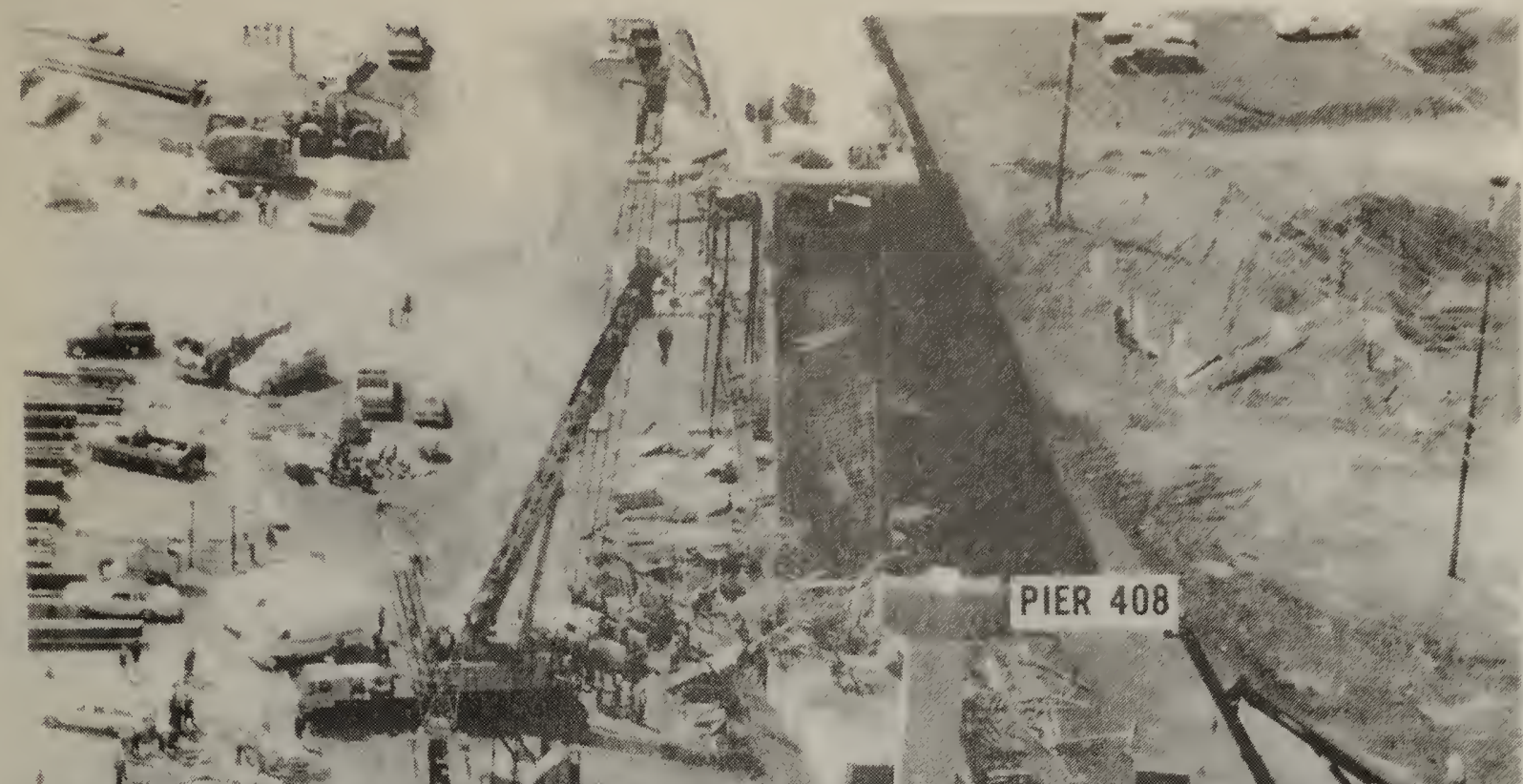

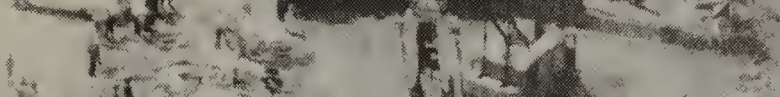
$45^{3}-y^{2}=1+4$ a $x^{2}-1$

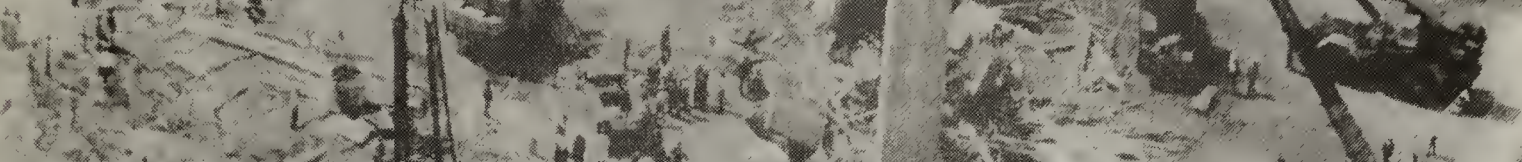

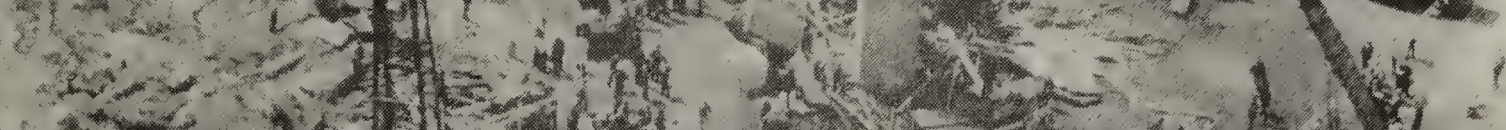

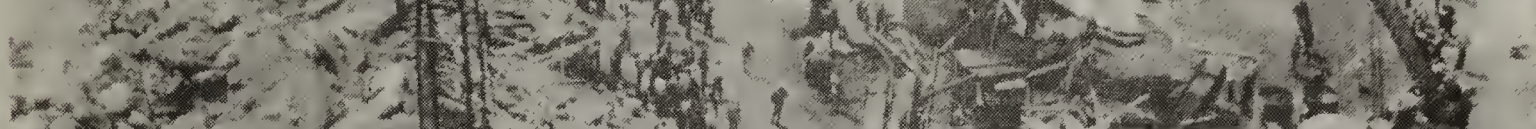

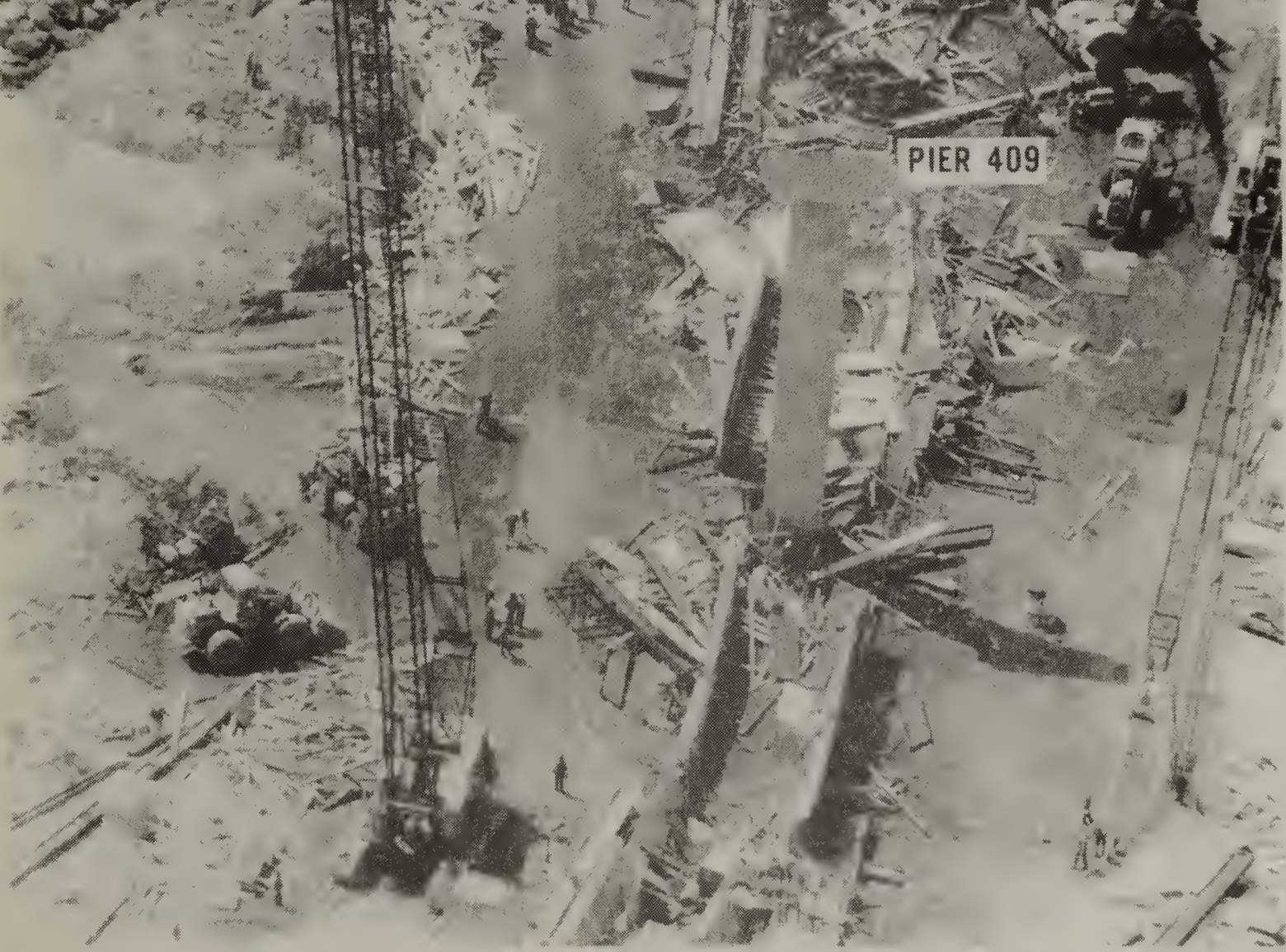

Figure 2.15 View of collapse as seen from the east. (Courtesy of PostTribune, Gary Indiana) 


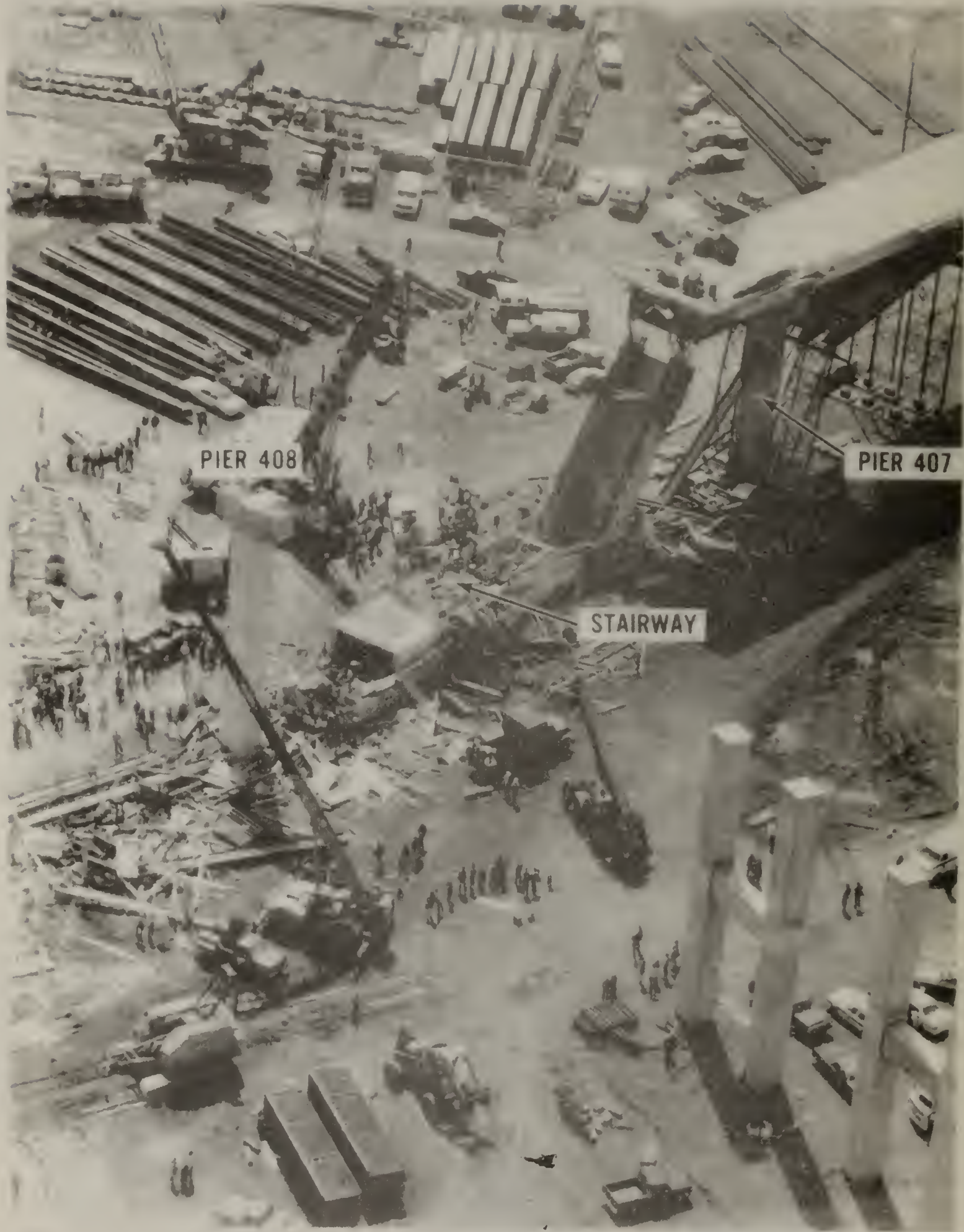

Figure 2.16 View of collapsed unit IV as seen from the northeast. (Courtesy of Post-Tribune, Gary Indiana) 


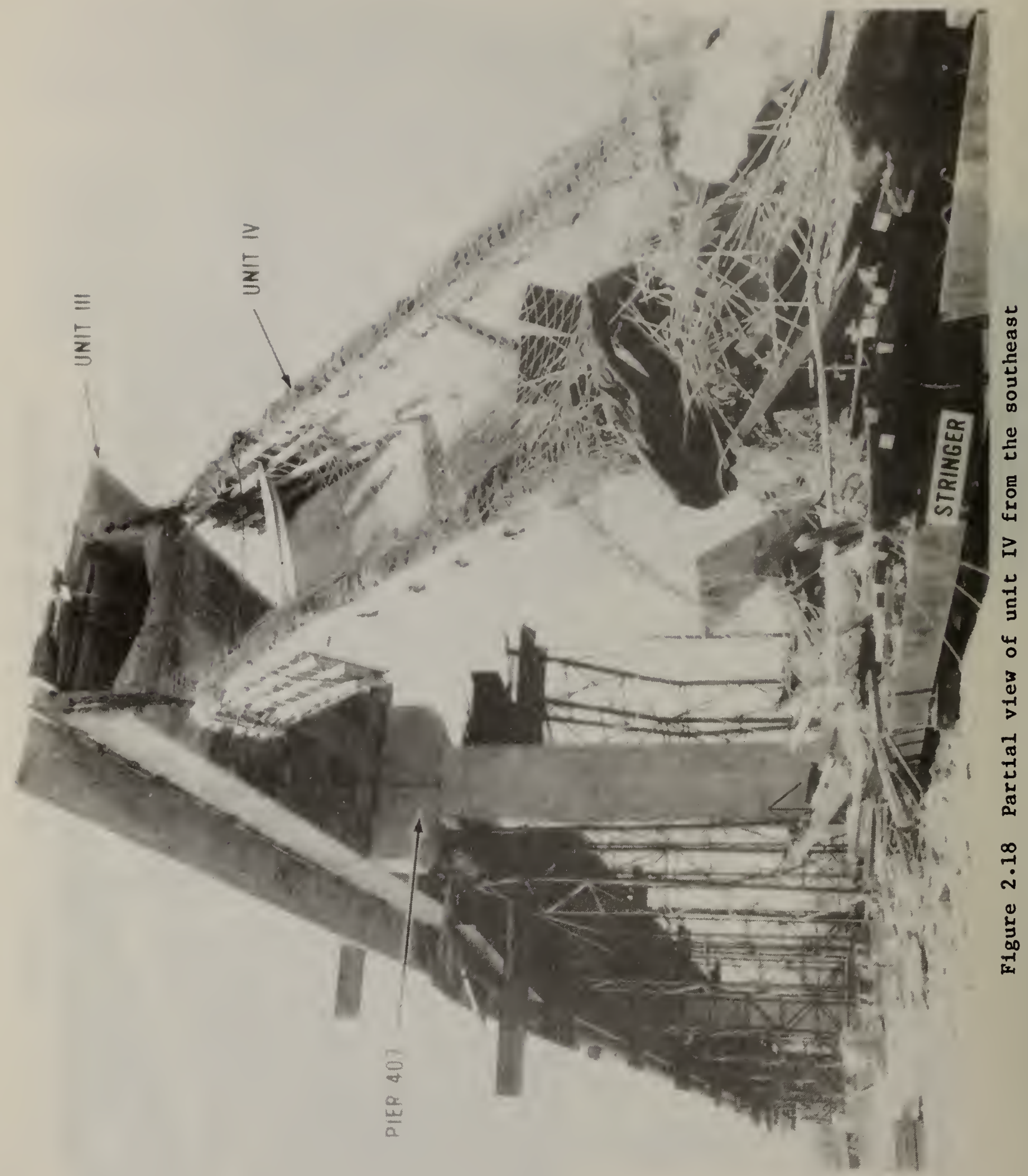




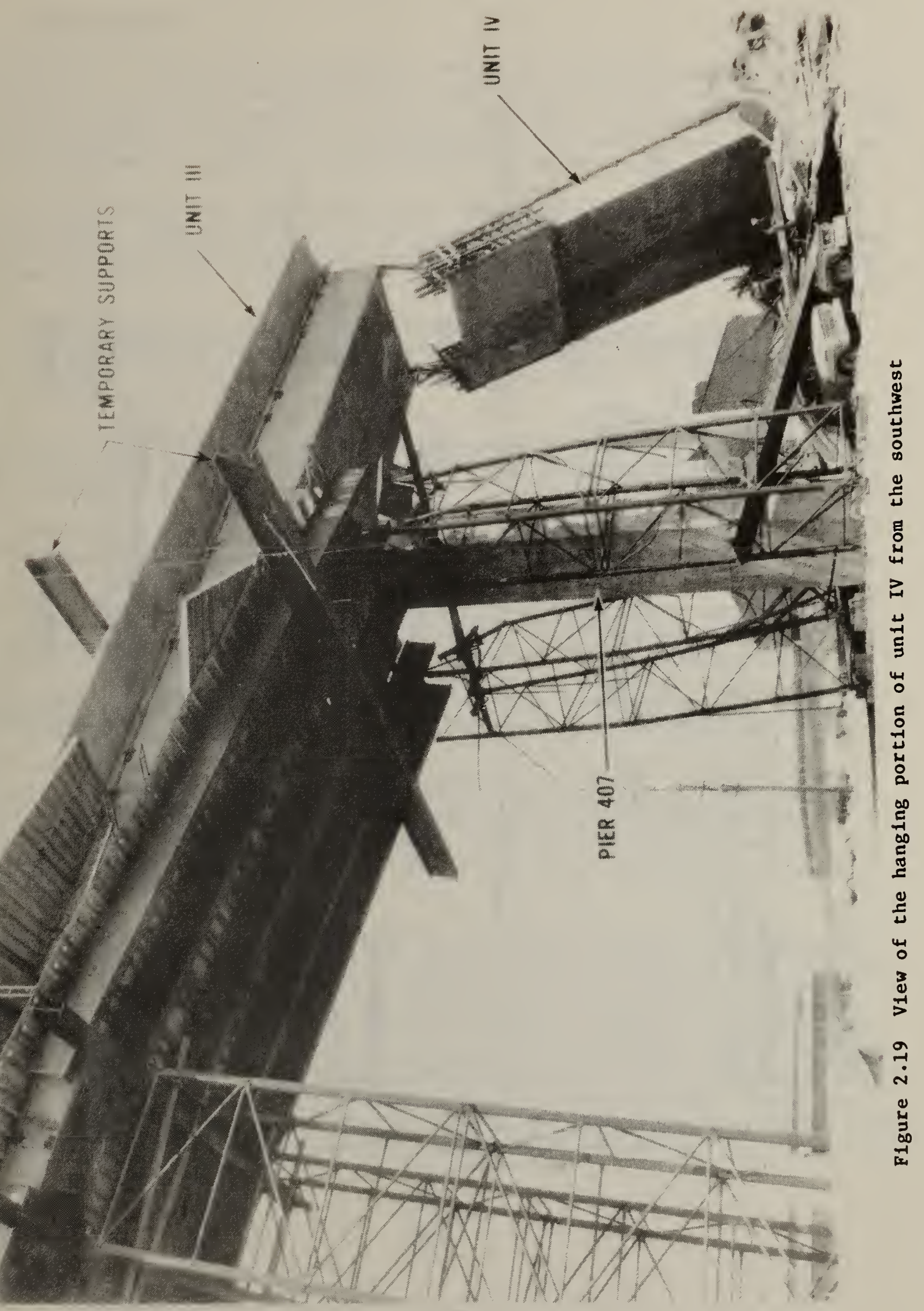




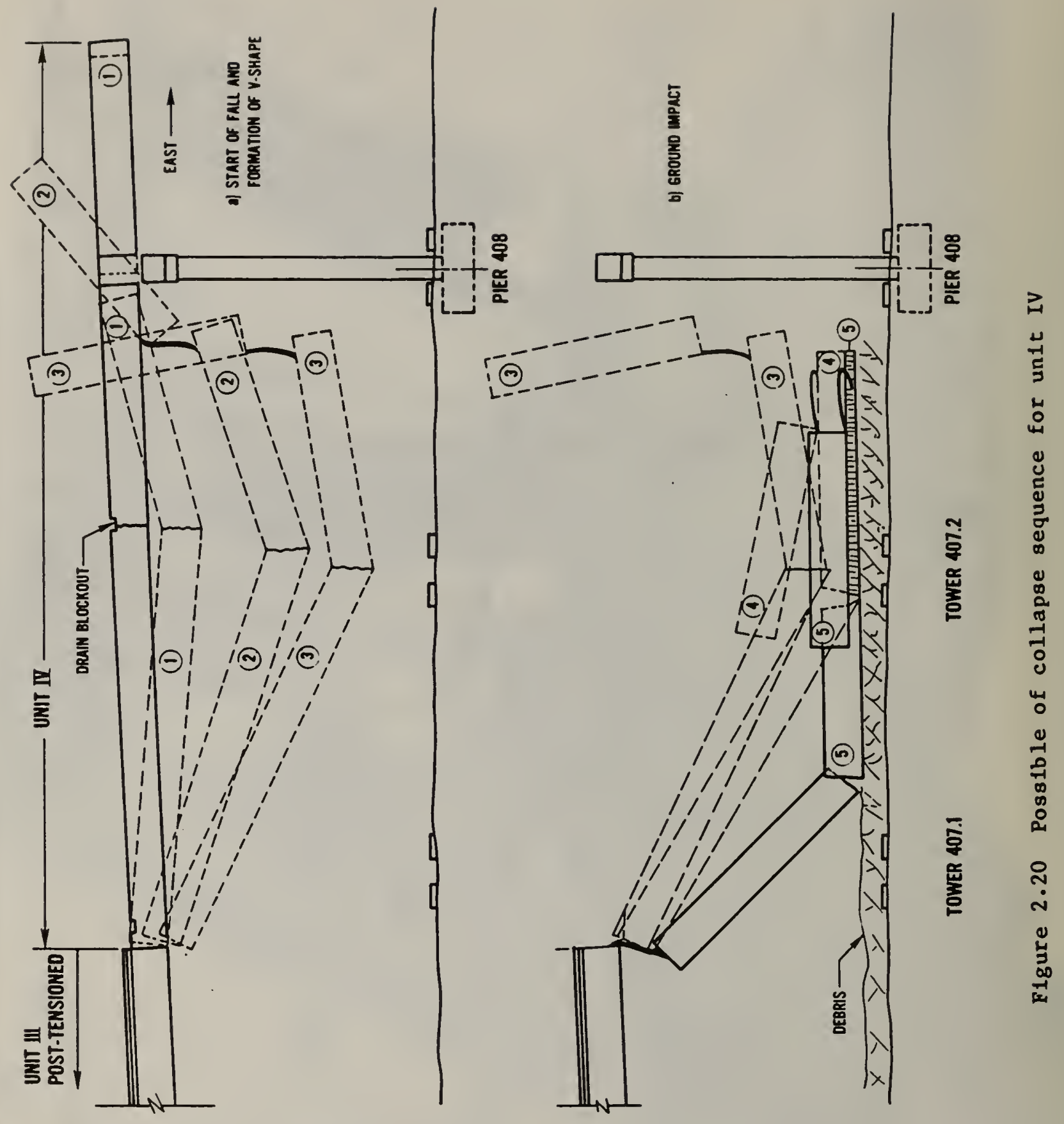




\section{FIELD INVESTIGATION}

\subsection{INTRODUCTION}

The purposes of the field investigation were to 1 ) establish as well as possible the conditions existing at the time of the collapse, and 2) examine the available evidence for possible clues as to the cause of the accident. For the reasons discussed in chapter 2, the emphasis of the field investigation was on the portion unit IV of Ramp C between piers 407 and 408 .

The field investigation consisted of site visits by members of the NBS/FHWA investigative team, examination of photographs taken by IOSHA personnel working out of a field office at the site, and examination of various documents secured for NBS by IOSHA. The following site visits were made:

1) Apri1 17-18, 1982 - preliminary field measurements, photographic documentation, prepared 11st of documents needed for the investigation, developed preliminary list of materials to be taken from the site for subsequent testing.

2) May 10-12, 1982 - photographic documentation of debris removal of units IV and $V$, close examination of falsework system in the uncollapsed portion of the ramp.

3) June 1-3, 1982 - photographic documentation of removal of unit IV debris, additional documentation of falsework system.

4) June 7-9, 1982 - measurements of dimensions of steel beams supporting unit IV formwork, photographic documentation of collapsed shoring towers, prepared final list of materials to be shipped to NBS for testing.

Additional visits were made as necessary to verify certain aspects of the investigation and to participate in the field load tests described in chapter 4.

The following documents were examined: structural drawings and calculations; copies of correspondence among the contractor, the designer and ISHC; shoring tower plans by the tower manufacturer; concrete test reports; materials delivery tickets; project engineer's dally records; local weather records; technical engineer's (surveyor's) notebook; and worker interview statements recorded by IOSHA.

Because of the critical nature of the falsework system, much of the effort was devoted to documenting the details of the falsework. Section 3.2 discusses the various components of the falsework, beginning with the conditions of the supporting soll and working up to the formwork. Also described are the locations of some of these components after the collapse. Figure 3.1 11lustrates the nomenclature used to identify the falsework support system between piers 407 and 408. The shoring tower locations are denoted as 407, 407.1, 407.2 and 408. At each location there is a north tower $(N)$ and a south (S) tower. Each tower has four support points denoted by the letters A-II. The reader is referred back to figure 2.8 for an elevation view of the shoring tower layout. 
Section 3.3 is a summary of worker interview statements recorded by IOSHA. Two topics are addressed in this summary: 1) eyewitness accounts of the collapse, and 2) previous construction problems.

Section 3.4 sumnarizes the findings.

\subsection{SITE INVESTIGATION}

Based on site visits and studies of photographs and construction documents, the conditions which existed at the time of the collapse were reconstructed as well as possible. The detalls of the falsework system received most of the attention, because of 1 ts critical nature in determining the most $11 k e l y$ cause of the fallure. In the following subsections, the falsework system is described in detall, starting with the soll supporting the towers and ending with the formwork for the topslab concrete. Much of the information was derived from the structural drawings and verified during the site visits. Discrepancies between the drawings and actual construction are noted.

\subsubsection{Subsurface Investigation}

Since the shoring towers rested on concrete pads which were in turn supported by the soil, it is important to investigate the types of solls at the site, their properties, and their load-deformation characteristics. Sheet 344 of the structural drawings indicate an allowable soll pressure of $3.24 \mathrm{kips} / \mathrm{ft}^{2}$ $\left(155 \mathrm{kN} / \mathrm{m}^{2}\right)$ for the concrete pads, although no documentation was found explaining the basis of this criterion.

No evidence was found indicating that soll borings were taken along Ramp C prior to construction. The closest borings taken along the Cline Avenue alignment varied from about 150 to $600 \mathrm{ft}(45$ to $180 \mathrm{~m})$ from Ramp C. The closest boring to Ramp $C$, showed about $3 \mathrm{ft}$ ( $1 \mathrm{~m}$ ) of gray fill, $3 \mathrm{ft}$ ( $1 \mathrm{~m}$ ) of dense brown gravely sand, followed by about $20 \mathrm{ft}(6 \mathrm{~m})$ of medium dense to dense black sand. Dense gray sandy loam was found below the black sand and the material below that was classified as stiff gray clay. The groundwater table was located about $1 \mathrm{ft}(0.3 \mathrm{~m})$ below the ground surface. Data from two other nearby borings indicated similar stratification of the subsoll. However, for a boring east of Ramp C, 1-ft $(0.3-\mathrm{m})$ thick layers of peat material existed at depths of about $9 \mathrm{ft}(3 \mathrm{~m})$ and $11 \mathrm{ft}(3.4 \mathrm{~m})$.

Soll test borings were made along Ramp C after some of the collapse debris had been removed, and the IOSHA provided NBS with the boring data. Soll borings were taken at each tower location from 403.2 to 409.2 as indicated in figure 3.2. In most instances, the soll test borings were $15 \mathrm{ft}(4.6 \mathrm{~m})$ deep and samples were taken at $2 \mathrm{ft}(0.6 \mathrm{~m})$ intervals using a $2-1 \mathrm{n}$ ( $51-\mathrm{mm})$ outside diameter split spoon sampler. Blow counts from the Standard Penetration Test (ASTM D 1586-67 (1974)) were obtained. Other holes were bored to a depth of $25 \mathrm{ft}(7.6 \mathrm{~m})$ or $35 \mathrm{ft}(10.7 \mathrm{~m})$ with the samples taken 1 n the same nanner. The samples were placed in sealed jars and stored at the project site.

The jar samples from locations 407.1 through 408 were inspected and classifled by a geotechnical engineer of the NBS team during a site visit in August, 1982. 
Figure 3.3 depicts the general subsoil condition derived from the sample examinations. It indicates that the ground is covered by a layer of fill 5 to $9 \mathrm{ft}(1.5$ to $2.7 \mathrm{~m}$ ) in thickness. The $\mathrm{f} 111 \mathrm{is}$ composed of dark brown and gray cinders and slag, sometimes mixed coarse sand and having an oily smell in places. Blow counts from the fill were scattered, and in some places refusal was marked on the field log indicating that difficulties were encountered during sampling. In some other holes, the blow counts were low $(<10)$ indicating that the fill was loosely placed. Below the fill and to a depth of 20 to $25 \mathrm{ft}(6.1$ to $7.6 \mathrm{~m})$ there is a layer of medium dense to dense brown fine to coarse sand. Pockets of saturated and highly compressible black organic silt and sandy silt, or dark brown sand with streaks of black organic material, were found just below the fill. The organic pockets were estimated to be 1 to $2 \mathrm{ft}$ $(0.3$ to $0.6 \mathrm{~m})$ in thickness and frequently had an oily smell. Below the sand layer, there is a layer of medium dense to dense brown fine silty sand to fine sand of 10 to $15-\mathrm{ft}$ ( 3 to $4.6-\mathrm{m}$ ) thickness underlain by a stiff brown-gray silty clay to the depth explored.

The subsoil condition adjacent to pier 408 is different from that just presented due to the excavation for the pile cap. The borings indicated that around the perimeter of the pile cap, the ground was backfilled by about $9 \mathrm{ft}(2.7 \mathrm{~m})$ of boiler slag. Blow counts indicated that the first $4 \mathrm{ft}(1.2 \mathrm{~m})$ of the material was medium dense to dense, probably due to the compaction by construction traffic; while the material below the first $4 \mathrm{ft}(1.2 \mathrm{~m})$ showed an extremely lcose condition with blow counts varying from 0 to 5 . The thickness of the boilerslag fill above the pile cap was estimated not to exceed $2 \mathrm{ft}(0.6 \mathrm{~m})$.

\subsubsection{Supports for Shoring Towers}

According to sheet 344 of the structural drawings, the shoring towers were to be supported by $5 \times 5 \times 1 \mathrm{ft}(1.5 \times 1.5 \times 0.3 \mathrm{~m})$ concrete pads set directly on the soil. The pads were to have nominal wire-mesh reinforcement. Field measurements confirmed the use of pads having the specified nominal dimensions in the region between piers 407 and 408. The structural drawings did not specify a compressive strength for the pad concrete. Based on workers' statements, it was learned that the pads were precast at the job site using concrete remaining from placements of various structural components of the ramp. Core samples were taken from the pads at 407.2 after removal of the collapse debris, and strength test results are presented in chapter 4. Among the engineering calculations, no record was found pertaining to the design of the concrete pads.

The lower screw jacks of the shoring towers did not bear directly on the concrete pads (see figure 3.4). According to the structural drawings, the jacks were to rest on circular, metal, sand boxes made of 16-in (41-mm) diameter pipe welded to a 1/4-in (6-mm) steel plate. Field inspections revealed that from tower locations 403.2 to 408.1 (N), the specified sand boxes were not used. Instead, the contractor substituted wood boxes made from ordinary $2 \times 4$ lumber and an aluminum sheet-metal base. Figure $3.4(\mathrm{~b})$ shows a wood sand box from location 406-H. At some tower locations wood cribbing of nominal $12 \mathrm{x}$ 12-in ( $305 \times 305-\mathrm{mm}$ ) cross section was used beneath the boxes. The cribbing was needed to achieve the correct elevation at the top of the shoring towers. 
As will be discussed in section 3.3, problems arose with the wood sand boxes and as a result metal banding, as seen in figure $3.4(\mathrm{~b})$, was added as a remedial measure. Banding was reportedly used to prevent the boxes from lifting off the cribbing and to prevent the boxes from spreading laterally during loading. In cases where the sand boxes rested directly on the concrete pads, the hold down was achieved by wedging two pieces of lumber between the bearing plate and two other pieces of lumber laid across the top of the box. In the region between piers 407 and 408, it was determined that cribbing was used only at tower $407.1(\mathrm{~S})$, and at the other locations the sand boxes rested directly on the concrete pads. Figure 3.5 is a view of location 407.1 as it appeared about one month before the accident. The photo was taken by an official of the Federal Highway Administration during an inspection of the construction in mid-March, 1982 .

During the NBS field visits, it was noted that between locations 403.2 and 406.2, there were 14 cracked concrete pads. It is not known when all these cracks developed. The surveyor's notebook indicates that at tower 405.2 (S), pads $C$ and $G$ cracked during the top-slab placement for unit II. The project engineer's records indicated that a pad at pier 407 cracked during the top slab placement of unit III. No additional records were available to document when other pads may have cracked.

In the course of the NBS investigation it was learned that tower leg settlements were monitored during the concrete placements. Settlement records were found in the surveyor's notebook and marked directly on some of the tower legs. Table 3.1 summarizes the available tower leg settlement data. The tower-leg settlements are due to settlement of the material in the sand boxes plus settlement of the soll beneath the concrete pad. Sheet 344 of the structural drawings stated: "maximum settlement when pouring top slab: 1/8-in." The data in table 3.1 indicate that the 1 imit was often exceeded.

Field examination revealed that fine slag (not boller slag) was used in most of the boxes. However, at the west end of the ramp (supports for unit I), the boxes contained what appeared to be ordinary river sand.

\subsubsection{Shoring Towers}

Figures 2.16, 2.18, and 2.19 show the appearance of the shoring towers used as temporary supports before each unit was pre-stressed. Each support location consisted of two shoring towers, a north (N) tower and a south (S) tower. The towers were constructed by bolting together prefabricated frames of standard dimensions. The prefabricated frames are $6 \mathrm{ft} 8 \mathrm{in}(2.03 \mathrm{~m})$ wide, and there are four standard nominal heights: $3 \mathrm{ft} 3$ in ( $1.02 \mathrm{~m})$; $6 \mathrm{ft} 6$ in ( $1.98 \mathrm{~m}) ; 13$ ft $(3.96 \mathrm{~m})$; and $19 \mathrm{ft} 6 \mathrm{in}(5.94 \mathrm{~m})$. Figure 3.6 shows the manufacturer's dimensions of the 6-ft 6-in and 19-ft 6-in frames. The elevation view is of the prefabricated frames, the side view shows the bolt-on tube members (referred to as truss braces in this report) used to join the frames and form a tower. The legs are made of $6-$ in $(152-\mathrm{m})$ square tubing with a nominal wall thickness of $0.25 \mathrm{in}(6.4 \mathrm{~mm})$. The horizontal and diagonal braces of the prefabricated frames are $2 \times 2 \times 0.11-i n(51 \times 51 \times 2.8-\mathrm{mm})$ squares tubes, which are welded to the legs. The manufacturer indicates that a 50-ksi (345-MPa) yield strength steel is used for the frames. 
The prefabricated frames are joined together by hollow tube members to form the truss bracing configuration shown in the "side view" of figure 3.6. The ends of the tubes are flattened and have a 13/16-in $(21-\mathrm{mm})$ hole. The tubes are attached to the frames with $3 / 4-i n(14-\mathrm{mm})$ bolts. Two tube sizes were used: 3 in $(76 \mathrm{~mm})$ and $2-1 / 2 \mathrm{in}(63.5 \mathrm{~mm})$ in diameter and with specified wall thicknesses of 0.188 in $(4.77 \mathrm{~mm})$ and 0.095 in $(2.4 \mathrm{~mm})$, respectively. The structural drawings did not specify the tube diameters to be used. However, in a letter from the design engineer to the contractor (dated March 27, 1981), it was recommended that the 3 -in tubes should be used.

To achieve the required tower height at each support location, various standard frames were stacked on top of one another. The frames were jointed by coupler pins as shown in figure 3.7. The coupler is made of a $1 / 2-i n(13 \mathrm{~mm})$ thick plate to which four vertical lugs are welded, which fit into the legs of the towers. Two 3/4-in (19-mm) high-strength steel bolts are specified for joining the legs to the coupler.

The top of each tower leg had a U-head, as illustrated in figure 3.8, to support the steel beams described in the next sub-section. The U-head is designed to pivot freely up to $8^{\circ}$ along one axis and incorporates a circular fit between the $2-i n(51-\mathrm{mm})$ top plate and the $2 \times 3-i n(51 \times 66-\mathrm{mm})$ post. Axial load is transmitted primarily by bearing between the top plate and the post, rather than through the $1-$ in $(25-\mathrm{mm})$ bolt. The post is welded to a $5 / 8-i n(16-\mathrm{mm})$ circular plate, which is in turn welded to a threaded bar forming the screw jack. The adjusting nut and bearing plate is similar to that used in the lower screw jacks (figure 3.4 ).

\subsubsection{Steel Beams}

The specified details are described first, and this is followed by a discussion of deviations noted during the investigation. The formwork was supported by means of a framing system composed of various steel beams which were in turn supported by the shoring towers. The details of how the steel beams were supported at the towers varied. Figure 3.9 shows the details specified in the structural drawings at typical tower locations XXX.2. The wood formwork is supported by five W36 x 194 stringers which are supported by W24 x 68 crossbeams, resting on the U-heads at the top of the towers. Short W36 $\times 194$ overlap beams are specified to fill the gap between the ends of adjacent stringers. Note that the shoring towers are oriented so that the truss bracing members span in the longitudinal direction of the ramp.

At the shoring towers adjacent to the construction joint, $1 . e .$, typical locations XXX.1, the details are as shown in figure 3.10 . In this case the crossbeams are supported by short W24 x 68 beams resting on the U-heads. Note that the orientation of the U-heads differs from that at tower locations XXX. 2 . At tower locations $\mathrm{XXX} \cdot 1$, the $\mathrm{U}$-heads can rotate to accommodate the longitudinal slope of the roadway; while at $\mathrm{XXX} \cdot 2$, the U-heads can rotate to accommodate the super-elevation (transverse slope) of the roadway. Wedges were specified to accommodate the slope perpendicular to the pivot direction of the U-heads. 
At the piers there was yet another configuration as shown in figures $3.11 \mathrm{a}$ and 3.11b. The details are similar to those at XXX.2, except that two special overlap beams are used around the pier cap (see figure $3.11 \mathrm{~b}$ ). These beams are intended to provide longitudinal stability to the entire falsework system. Field observations showed that the special overlap beams were not built as specified. As 1llustrated in figure 2.17, which shows an overlap beam in the foreground, only one set of triangular plates rather than the specified box section was welded to the overlap beam. As constructed, these special overlap beams would not be able to provide the same degree of longitudinal stability as the specifled beams. The $9-\mathrm{ft}(2.74 \mathrm{~m})$ spacing between the north and south towers at the piers is what was measured in the uncollapsed portion of Ramp C, while the plans specified a spacing of $8 \mathrm{ft} 6$ in $(2.59 \mathrm{~m})$.

Additional deviations were noted between the falsework details shown in the previous figures and the actual construction method. There was no evidence of the use of $1-$ in $(25-\mathrm{mm})$ bolts for tying stringers to crossbeams, and there was no evidence that wedges were used to accommodate the longitudinal and transverse slopes of the roadway. Among the documents made avallable to NBS, there are no indications that these modifications were approved by the ISHC.

Sheet 346 of the structural drawings indicates that whenever the shoring towers exceeded a height of $30 \mathrm{ft}(9.14 \mathrm{~m})$, the external guying system shown in figure $3.12 a$ was to be used to provide lontitudinal and transverse stability. However, an alternate construction scheme was approved by the ISHC. The alternate approach provides transverse stability by using the X-shaped guy system 111 strated in figure $3.12 \mathrm{~b}$. The guy wires are designed to resist a lateral load equal to 10 percent of the vertical load occurring during the placement of the bottom portion of the box girder. The required guy wire capacity varies with shoring tower heights, as shown in figure 3.12. Longltudinal stability was to be achieved by the special overlap beams wedged to the piers and the bolted connections indicated in figures $3.9-3.11$.

The guy wires provided for transverse stability were 5/8-in (16-mm) diameter steel cables. The towers were tied horizontally at the bottom with $2 \times 2 \times$ 1/4-in ( $51 \times 51 \times 6-\mathrm{mm})$ steel angles, but no horizontal tie was provided at the top. According to worker's statements, the guy wires were tensioned with a "come-along" and tied-off at each end with a cable clamp.

In place of the bolted connections between beams, the detall illustrated in figure 3.13 was adopted. No records were found indicating approval of this connection method. It is felt that the omission of the 1-in (25-mm) bolts reduced the stability of the falsework system, compared to the case if the bolts had been used. The consequences of this omission are discussed in chapter 6 .

As explained, the U-heads are designed to rotate in one direction only. Because the roadway slopes in both the longitudinal and transverse directions, wedges were called for as shown in figures $3.9-3.11$. The absence of wedges means that the top of the towers were subjected to eccentric loading. The consequences of the eccentric load is discussed in chapter 4. 
The dimensions of stringers and crossbeams in spans $7.1,7.2$, and 8.0 were measured during the field visits. Figure 3.14 shows the nomenclature adopted for identifying the various elements. Table 3.2 lists the dimensions of these members. A steel tape was used to measure the beam cross sections and hence the dimensions in table 3.2 are approximations of the actual values. Also given in the table are the standard dimensions of W24 x 68 and W36 x 194 shapes. It is concluded that the crossbeams employed are as specified, $1 . e \cdot, W 24 \times 68$, and the stringers in spans 7.1 and 8.0 are the W36 $\times 194$ shapes specified. However, the stringers in span 7.2 are heavier than specified; stringer 55 appears to be a W36 x 230, and the others could be W36 x 260 or W36 x 280 . Because of the longer length of the heavy beams in span 7.2 , overlap beams were not used at tower location 407.1 .

\subsubsection{Formwork for Top Slab}

As indicated in figure 3.9 , nominal $4 \times 6$-in $(100 \times 150 \mathrm{~mm})$ joists were laid across the stringers and 3/4-in (19-mm) plywood was placed on top of the joists. This provided the support for the box-girder formwork. As has been mentioned, the box girder was cast in two sections: 1) the bottom slab and side walls (webs); and 2) the top slab. The formwork for the bottom section was stripped before building the formwork for the top slab. In this section, the top-slab formwork is described since this was in place on unit IV at the time of the collapse.

Figure 3.15 shows the formwork details incorporated in the structural drawings and figure 3.16 shows some of the top-slab formwork remaining on unit III. No measurements were made to verify the specified dimensions. Figure 3.16 shows that frame scaffolding was used in place of single-post shores for the exterior supports. Note that the exterior shores are directly above the exterior stringers, and this affects the loading scheme for the structural analysis described in chapter 5 .

\subsubsection{Location of Falsework Components After the Collapse}

Following the collapse, the contractor was requested to carefully remove the collapse debris so as not to disturb the location of the falsework system components. The concrete and formwork of unit $V$ was removed first to expose the beams and towers. A detailed analysis of these components was not performed since it is known that the triggering mechanism for the collapse was not in this portion of the ramp. Removal of unit IV proved difficult because the hanging portion had to be lowered without harming unit III. In order to lower this portion, a slag berm was built up beneath it. The berm supported the hanging portion as the post-tensioning tendons were cut off. The slag was then removed and the remainder of the unit-IV concrete was removed. It was then possible to document the location of major falsework components between 407.1 and pier 408 .

Figure 3.17 shows the locations of stringers and crossbeams between piers 407 and 408. The drawing was reconstructed from photographic evidence and hence the locations shown are approximate. Of special significance is the location of crossbeam CU 7.2. During the collapse it was hurled from 407.2 towards 
pler 408 , and the north side travelled about $60 \mathrm{ft}(18 \mathrm{~m})$ eastward before hitting the ground. Also note that $C D 8.0$ landed on top of $C U 7.2$.

The location of the stringers offers a clue of a possible collapse sequence. The stringers between 407.2 and pier 408 (span 8.0) translated eastward, while those between 407.2 and 407.1 (span 7.2) translated westward. The stringers between 407.1 and pier 407 (span 7.1) also translated westward. This suggests that the stringers of spans 7.2 and 8.0 first lost support at 407.2 . After the ends at 407.2 had dropped down, support was lost at pier 408 for span 8.0 and at 407.1 for span 7.2. This would explain the opposite translation of the stringers in the two spans. This sequence also suggests that the stringers of span 7.1 were the last to fall. Thus, it appears that collapse of the falsework inftiated at 407.2. As will be discussed, this sequence is corroborated by an eyewitness to the collapse, and 1 t also agrees with the proposed collapse sequence of unit IV presented in figure 2.20. For this reason, the remaining description of the debris will concentrate on the shoring towers at 407.2 .

Figure 3.18 is an overview of location 407.2 after all the concrete debris had been removed; north is at the top of the photograph. From the photographs shown in figure 2.10 and 2.11 it had been determined that the shoring towers at 407.2 were each composed of two 19-ft 6-in (5.94-m) frames and a 6-ft 6-in (1.98-m) frame. Examination of the collapse debris confirmed this configuration. In figure 3.18, the bottom legs of the towers at 407.2 have been identified. It is seen that the tops of the lowermost frames of each tower fell toward the west. The top portions of the middle 19-ft 6-in (5.94-m) frames are also identified in figure 3.18. For example, the symbol "AMT" identifies the top of the A-leg of the middle frame. It is seen that the tops of the middle frames fell toward the east. Finally, figure 3.19 indicates the locations of the tops of the uppermost $6-\mathrm{ft}$ 6-in $(1.98-\mathrm{m})$ frames of each tower.

Based on the above evidence, it is concluded that the towers at 407.2 collapsed in a "jackknife" mode, that is, the towers folded at the coupler pin joining the 19-ft 6-in $(5.94-\mathrm{m})$ frames. The locations of the top 6-ft 6-1n (1.98-m) frames is consistent with the location of crossbeam CU 7.2. It appears that the top frame of the north tower separated from the rest of the tower and travelled eastward along with the crossbeam. The top frame of the south tower may not have separated until after impact with the ground.

Based on photographic evidence, such as figure 2.16, it was determined that the towers at pier 408 collapsed toward the east, and they were removed very soon after the accident to make way for emergency vehicles. That is why these towers are not seen in figure 3.19. The south tower at 407.1 (figure 3.20) also collapsed in a "jackknife" mode, except that the folding occurred such that the coupler joints moved toward the east. The north tower at 407.1 fell toward the west and apparently did not "jackknife" as no portions of the tower were found beneath unit IV. This tower was removed prior to placing the slag berm and it was not possible to document accurately its collapsed orlentation.

Examination of the lower screw jacks in the fleld indicated no evidence of their fallure. 
The location of the U-heads belonging to the towers at 407.2 were also documented. All of the heads were found to have separated from the top screw jacks at either the weld between the threaded bar and the round plate or between the rectangular post and the round plate (refer to figure 3.8). Seven heads and four screw jacks were found beneath the debris. An additional head and 1ts mating screw jack were found in a pile to the south of the collapse zone. The head was marked with the numbers " 7.2 ", and it had apparently been moved during the clean-up. Thus, all eight heads and five screw jacks belonging to 407.2 were located, and were shipped to NBS for study.

An attempt was made to determine to which tower leg each of the heads and top screw jacks belonged. To do this, the data in table 3.3 were used. The concrete pad elevations and top-of-plywood elevations were obtained from the surveyor's notebook. The lower screw jack extensions were measured at the site. In addition, the exposed lengths of threads of the five upper screw jacks were measured, and these lengths are shown in table 3.4. The identifying marks were put on these screw jacks by other investigators at the site.

The following procedure was used to locate the likely original positions of the top screw jacks.

1) Using the pad elevations and lower screw jack extensions, the relative elevations of the top of the towers were determined. It was assumed that the sand boxes contained the same thickness of slag, and that in a given frame the inner leg was at the same elevation as the outer leg. For example, leg $B$ was assumed to be at the same elevation as 1 eg $A$, and $\operatorname{leg} C$ the same as $D$, etc.

2) Using the top-of-plywood elevations given in table 3.3, the plywood elevations at the other leg positions were calculated by linear interpolation.

3) Using the relative top-of-tower elevations from (1) and the plywood elevations from (2), the required relative extensions of the upper screw jacks were determined.

4) The required relative extensions in (3) were compared with the measured lengths shown in table 3.4, from which the possible original locations of the screw jacks were determined.

5) In those cases where a screw jack had two possible locations, a comparison was made between the observed positions of the tops of the towers (figure 3.17 ) and those of the jacks. From this comparison the most 1ikely location was chosen as indicated in the last column of table 3.4 .

Figure 3.21 shows the positions of the four top screw jacks found in the debris, and the letters indicate to which tower leg each one belonged.

The fracture surfaces where the screw jacks separated from the heads were examined, from which it was possible to determine which head belonged with each screw jack. Figure 3.22 shows the locations of the heads along with the corresponding letter indicating the tower legs to which they belonged. Since the 
screw jacks at positions $A, G$, and $H$ were not recoverd, determination of which head belong to each postion was based on the locations of the heads within the debris. Note that the U-heads which supported cross-beam CD 7.2 are located near the concrete pads, while the U-heads which supported crossbeam CU 7.2 are located eastward of 407.2 .

From a study of the photographic evidence shown in figures 3.18-3.22, a possible collapse sequence of the falsework at 407.2 was reconstructed, and is illustrated in figure 3.23. This is not necessarily the failure sequence that actually occurred, but it conforms with the location and orientation of the various falsework components as they existed after the overlying debris was removed. All the concrete pads at 407.2 except D were cracked and in some cases it was evident that much of the cracking was a result of impact by fal1ing objects during the collapse. However, as illustrated in figure 3.24, some pads did not appear to have recelved heavy impact, because the tower frames and tube bracing lying on top of them were not severely crushed. It is very likely that the cracking of pads $F$ and $G$ was not a result of impact during the collapse. Figure 3.25 is a close-up view of the diagonal crack pattern for pad 407.2-G.

\subsection{INTERVIEW STATEMENTS}

In conjunction with other aspects of the field investigtion, officers of the Indiana Occupational Safety and Health Administration conducted interviews with workers and others who were involved either with the actual construction of the ramp or were in the vicinity of the collapse when it occurred. The statements obtained in the interviews provided valuable information which served as source documents in reconstructing the events prior to the collapse as well as the actual observed sequence of the collapse. This section summarizes the contents of the interviews which contained information considered relevant to the development of the collapse mechanism. It includes coverage of previous falsework construction problems and the description of the failure as observed at the site by eyewitnesses. In the following sections, the letter/ number combinations in parentheses refer to the designations assigned to the interview statements.

\subsubsection{Previous Construction Problems}

The questions directed to this portion of the interviews were made to determine the falsework construction practices not only in the collapsed sections but on the ramp project as a whole. As previously pointed out the superstructure is entirely dependent on the falsework for support until such time as the concrete is prestressed, so the temporary support system must be adequate to sustain all dead and construction live loads prior to the post-tensioning of the tendons.

One important element to the stability of the falsework is the ground on which the precast concrete pads rest. Of the workers interviewed who were involved in preparation of the ground prior to placing the concrete pads, all (S3, S10, $\mathrm{S} 13, \mathrm{~S} 16, \mathrm{~S} 19, \mathrm{~S} 21, \mathrm{~S} 22, \mathrm{~S} 24, \mathrm{~S} 25, \mathrm{~S} 26, \mathrm{H} 3)$ reported varlous methods of preparation ranging from none (pads placed directly on ground) to levelling with a front-end-loader. Some compaction with rollers or small tampers was reported 
(S13, S19, S22, S24) and two workers (S25, S26) stated that the section of ground in the vicinity of piers 407 and 408 would flood after a heavy rain. While one worker (S25) reported that most of the falsework was erected prior to November, 1981 and there was no frost in the ground in the area of the collapse, another (H3) stated there may have been some frost in the ground and one (S13) stated that fill material had been placed on frozen ground in the curved portion of the ramp.

Several workers interviewed (S1,S4,S6,S10,S16, S22) reported concrete pads supporting the shoring towers in the ramp falsework cracked as a result of the superstructure concrete being placed. Prior to the collapse of the ramp, one worker (S10) was informed that one of the concrete pads had cracked from the weight of the cast concrete deck in one section and the workers had felt the structure move. Another (S4) reported that he was told on one occasion, a pad had cracked and the deck dropped $1-1 / 2$ in $(38 \mathrm{~mm})$ on one side and raised 1-1/2 in on the other. The casting of the precast pads was reported (S13) to be made of concrete left over from concrete cast at the ramp site. Reinforcing mesh (S13, S19) was placed in the pads during their casting.

Wood sand boxes were used under the screw jacks at the base of the shoring tower legs initially, but these were reported (S10, S13, S16, S21, S22, S24) to pull apart at the corners when concrete was cast in the superstructure. After the problems with the wood boxes on the second or third superstructure concrete placements (S24), steel straps were nailed around the wood boxes to band them together (S10, S13, S22, S24). Wood cribbing between the banded wood sand boxes and the concrete pad was increased from 30-in (760- $\mathrm{mm})$ to $36-$ in $(910-\mathrm{mm})$ long to prevent the concrete pads from cracking (S22). One worker (S13) said that a switch from wood boxes to steel boxes was made somewhere in the area of the collapse while another (S10) stated that the change was made from pier 408 eastward. Two employees (S10, S16) stated they were aware that the wood boxes were not what was called for on the plans.

The shoring towers were set and erected by carpenters (S6, S17, M5) and any bent or damaged pieces were not used (S3, S13). The towers were guyed transversely on both sides with cables (S3, S8, S12, S13, S17) from the top outside leg of one tower to the bottom outside leg of the adjacent tower to form an Xshaped guy system. The guy cables were pulled up with a cable puller and clamped at the ends (S3, S13). These were the only guy cables used on the falsework (S12, S13). One worker (S12) stated that in some places the two towers were tied together with a piece of steel angle welded between them at the bottom in addition to the guy cables, while another (S13) stated that the towers were not tied in this manner while he was on the job. At the time of the interviews, one worker (S3) stated that the section that he was presently working on had cross bracing welded to the two towers but did not know if this was done on the sections that collapsed.

The steel comprising the falsework directly under the bottom of the concrete box girder and supported by the shoring towers consisted of new and used beams (S13). Several of the workers interviewed (S8, S13, S16, M3) stated that the longitudinal stringers spanning between the towers were not bolted directly to the crossbeams but were clamped together. The clamp consisted of a metal clip 
made from the flange of an old beam and 3/4-1n (19-mn) coil rod with a nut welded on the end of it (see figure 3.13). A 12-1n (300-mm) crescent wrench was used to tighten the clip (S13). One worker (S8) said that only 2 of the 5 longitudinal stringers were clamped in this manner while another (M3) knew of no $1-1 \mathrm{n}(25-\mathrm{mm})$ bolts used to tie the longltudinal stringers and crossbeams.

In contrast, it was reported (S17) that the stringers and crossbeams were bolted together with two 1 -in $(25-\mathrm{mm})$ bolts or larger at each intersection of the beams in the section that collapsed. On top of the longitudinal stringers, nominal $4 \times 6$-in $(100 \times 150 \mathrm{~mm})$ joists were layed and plywood was placed on top of the joists with approximately 6 to 8 nalls for each $4 \times 8-\mathrm{ft}(1.2 \times 2.4-\mathrm{m})$ sheet of plywood (S16, S23).

Approximately two to three weeks before the collapse, the construction site was hit by two heavy wind storms resulting in plywood deck-form panels being blown off the falsework of unit V(S4,S6,S11, S12,S21, M4, M5) and trailers being overturned (S21).

\subsubsection{Description of the Failure}

The description of the actual failure of Ramp $C$ contained herein recounts the event and sequence of the collapse as determined from eyewitness statements.

By all accounts of those people interviewed who were involved with the deck casting operation that day and were in the immediate vicinity of the initial collapse (S9, S12, S14, S15, S16, S17, S22, S24, S27, X1, X2, X3, H2, H4, H6, M2, M9, M10), nothing appeared unusual and the placement of the deck slab was proceeding smoothly.

One witness ( $\$ 24$ ) who was on the way down the stair scaffolding, on the south side of the structure and west of 407.2, was approximately 35 to $40 \mathrm{ft}$ (11 to $12 \mathrm{~m})$ from the ground, facing east and looking to the left, 1.e., looking in the direction of the span between towers 407.1 and 407.2. The first indication this witness had of the start of the collapse was a loud pop and he saw the longltudinal stringers on the north side of the ramp going down first, followed by a progression of longitudinal stringers collapsing from north to south. Eventually (S24), a collapsing beam struck the stair scaffolding causing it to topple to the north and land on the already fallen ramp debris. At this time, S24 and two other men who had ridden the stair scaffolding down were able to move away from the collapsed structure. It was reported (S24) that at this time the shoring towers east of pier 408 were bent in the middle and the concrete section on top of them "teetered" before that section of the ramp started collapsing approximately 5 minutes later. (Note: the time to the start of the collapse of the other portions of the ramp was reported as being anywhere from 3 to as long as 15 minutes, but the majority of witnesses reported an approximate average time of 5 minutes.)

Prior to the initial collapse, another worker (S15) awaiting a concrete bucket being lowered and standing next to the south side of the ramp midway between towers 407.1 and 407.2 heard a crack, followed by a low bass sound. This worker further stated that the structure began coming down between tower 407.2 and 
pier 408. On the other hand, a witness (M2) standing $10 \mathrm{ft}$ ( $3 \mathrm{~m}$ ) from the base of the stair scaffolding stated that the break occurred where the stairs were located, 1.e., slightly west of tower 407.2 .

A witness (H6) who came down with the initial collapse was standing on the deck-stee 1 rebar-mats $10 \mathrm{ft}(3 \mathrm{~m})$ east of pier 408 and was facing west, toward the span of the initial collapse. The point of collapse, according to this account, occurred approximately $30 \mathrm{ft}(9 \mathrm{~m})$ west of pier 408 , and concrete had been placed approximately half way up in the diaphragm of the box section over pier 408 but no concrete was being placed at this time. The sound of the collapse was described as "bars rolling on bars and a loud roar like thunder." While it was estimated (H6) that the concrete deck had been placed to within $30 \mathrm{ft}(9 \mathrm{~m})$ from pier 408 , another witness (S16) standing on top of the stair scaffolding at the time of the initial collapse estimated the deck placement to be about $20 \mathrm{ft}(6 \mathrm{~m})$ from pier 408 .

One worker (H2), who was under the ramp between piers 408 and 409 and stationed next to pier 408 when the collapse started, stated the first indication of the collapse was the sound of boards breaking and then he observed the peeling away of the boards from north to south. Other workers atop the first collapsed section of the ramp who went down with it stated that it was over as fast as it started (M9). Prior to the collapse, a worker (M10) standing on the rebar-mats ahead of the finishing machine heard no unusual sounds or felt any unusual vibrations except for wood cracking "split seconds" before the collapse. A worker (S9) located inside the box section of the superstructure in the vicinity of pier 408 reported the first sound heard resembled the hitting of a heavy metal beam with a sledge hammer, but prior to that no unusual sounds were heard or movement of the structure felt. This employee (S9) and another worker had made a check of the falsework and structure the day before the collapse and found nothing out of order.

From reports by witnesses on top of the other sections of the ramp that would eventually fall, a worker (S11) on top of pier $409 \mathrm{felt}$ the bridge move, then saw the first section collapse and start to fall. Another employee (MI) on the easternmost part of the ramp (approximately $300 \mathrm{ft}$ ( $90 \mathrm{~m}$ ) from pier 408) felt the ramp move east and then west, heard the sound of the collapsing structure (bumping noise of rallroad cars), then turned and saw the section between piers 407 and 408 go down. Prior to that, no unusual movements or vibrations of the deck had been felt, nor had any unusual noises been heard.

Generally, all witnesses reported that the second and third sections to collapse did so in a domino-like fashion, beginning with shoring tower 408.1 and proceeding eastward until the whole ramp east of piers 408 and 409 was on the ground. In the section between piers 408 and 409 , the west end of the ramp at the shoring tower would fall first followed by the east end of the same piece which was resting on the next tower, and so on (W30). East of pier 409, tower 409.1 was reported to have folded up (W30) in the progressing collapse. One witness (W18) standing approximately $1,100 \mathrm{ft}$ ( $335 \mathrm{~m}$ ) from the first section to collapse estimated that it took about 30 seconds for the remaining sections to come down completely. 
The position of the concrete buckets at the time of the initial collapse is somewhat obscure since there were conflicting accounts. The bucket on the south side of the ramp was reported to be going down (S15) while another (S14) said it was going up. From statements made by people on the deck of the first section to collapse, one (H6) said there were no buckets above the deck at the time of the collapse, while another (M9) said there was a bucket suspended just above the deck and was swinging in at the time the ramp broke. None of the witnesses in the area of the initial collapse knew of anything that had bumped or struck the falsework prior to the collapse (S14, S15, S17, S27, H4), and, as recounted previously, no one on the deck had felt any unusual vibrations or heard unusual noises before the collapse.

The general shape of the initial collapse was usually described as being a Vshape (an observance of the appearance of the initial vertical collapse of the span west of pier 408) and the point of the initial break reported by those who saw the collapse from a distance ranged from midpoint to three-fourths of the span length from pier 407.

\subsection{SUMMARY}

Based on observations made during field visits and the examination of documents secured by the IOSHA, a picture has emerged of the conditions as they may have existed prior to the collapse. The analysis of the soil samples indicated that the subsurface soils are stratified, but there are no marked differences between the soils which supported the towers at 407.1 and 407.2. The towers at pier 408 , on the other hand, were founded on boller slag having generally loose compaction.

The geometry of the falsework system in place between piers 407 and 408 is known, and table 3.5 summarizes the shoring tower configurations at locations $407.1,407.2$ and pier 408.

Comparison of field conditions with the structural drawings revealed deviations between what was specified and what was used in construction. For example, wood sand boxes were used in place of specified steel boxes; specified bolted connections between stringers and crossbeams were replaced with frictional clamps; the special overlap beams at the piers were not fabricated as specified; and specified wedges between crossbeams and stringers were omitted. In addition, a change was made in the guying system for the shoring towers. While the alternate $X$-shaped guying system was approved by the ISHC, it did not provide the same degree of stability to the towers as would have been provided had the external guying system been used which was indicated on sheet 346 of the structural drawings. The impact of these deviations on the performance of the structure will be discussed in subsequent chapters.

A review of the interview statements revealed that significant problems had been encountered during construction. Notable among these are the cracking of concrete pads and problems with the wood sand boxes.

A careful examination of the collapse debris was carried out in order to develop a tentative description of the collapse sequence. The location of the 
collapsed falsework components appears to indicate that the failure initiated at tower location 407.2. The testimony of eyewitnesses generally tends to confirm this conclusion. The testimony also indicates that the collapse of unit IV occurred suddenly without any apparent warning, and that it appeared to originate on the north side of the ramp.

While the field investigation yielded much information on the conditions prior to the collapse, the triggering mechanism was not identified. Thus, the experimental and analytical investigations described in the next chapters were required to determine why the accident occurred. 


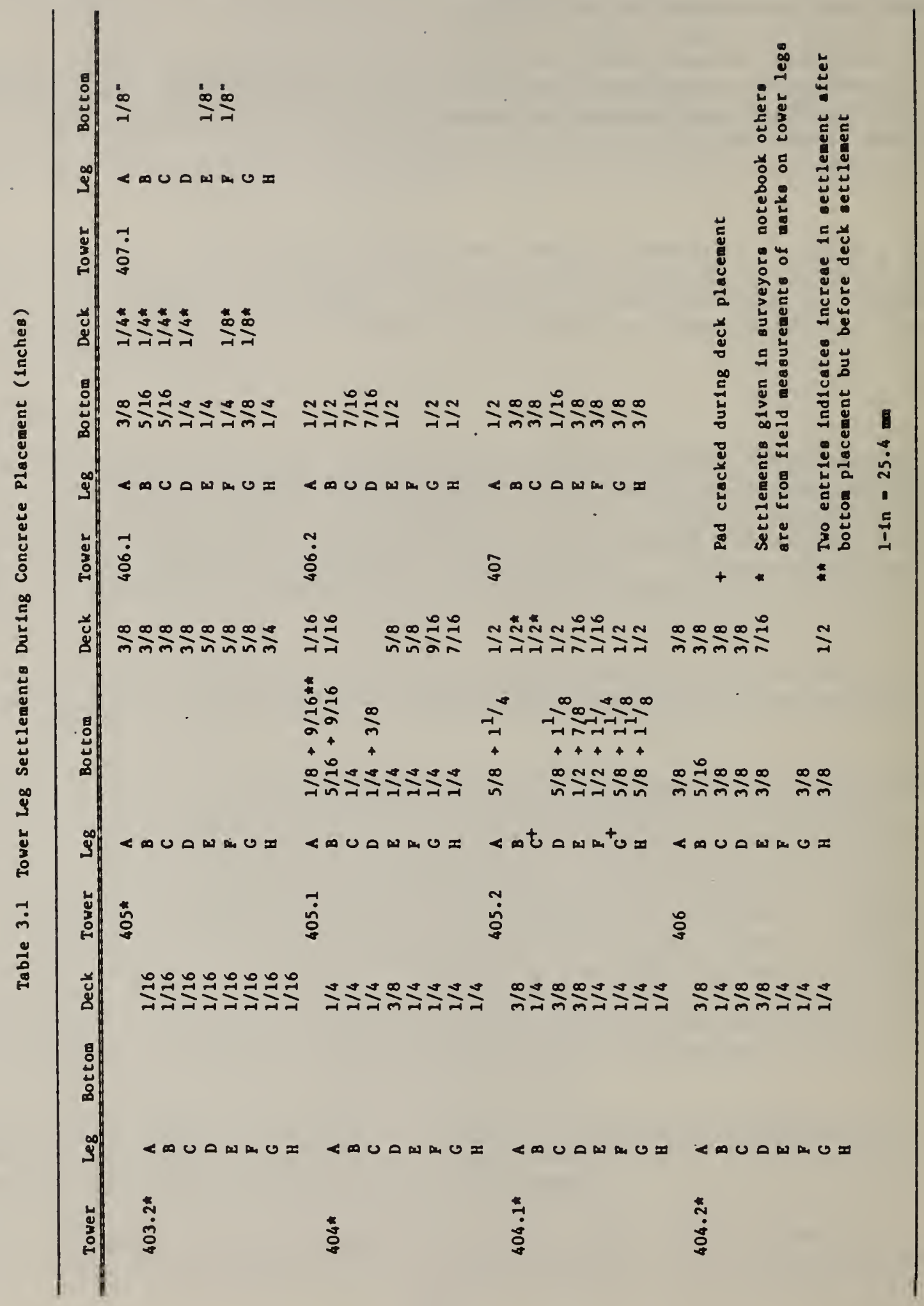


Table 3.2 Dimensions of Stringers and Cross-Beams Between Piers 407 and 408

\begin{tabular}{|c|c|c|c|c|c|c|}
\hline $\begin{array}{l}\text { Span } \\
====-=\end{array}$ & $\begin{array}{l}\text { Member } \\
==-==-=\end{array}$ & Length & Height & $\begin{array}{l}\text { Flange } \\
\text { Width } \\
====\end{array}$ & $\begin{array}{c}\text { Flange } \\
\text { Thickness } \\
=:=====\end{array}$ & $\begin{array}{c}\text { Web } \\
\text { Thickness } \\
===:===:===\end{array}$ \\
\hline 7.1 & $\begin{array}{ll}\text { CU } & 7.0 \\
\text { CD } & 7.1 \\
\text { S1 } & \\
\text { S2 } & \\
\text { S3 } & \\
\text { S4 } & \\
\text { S5 } & \end{array}$ & $\begin{array}{c}40^{\prime}-0^{\prime \prime} \\
39^{\prime}-2 " \\
55^{\prime}-3 " \\
55^{\prime}-4 " \\
-- \\
55^{\prime}-3 " \\
-\end{array}$ & $\begin{array}{l}23-3 / 4^{\prime \prime} \\
23-1 / 2^{\prime \prime} \\
36-11 / 16^{\prime \prime} \\
36-11 / 16^{\prime \prime} \\
36-1 / 2^{\prime \prime} \\
36-3 / 4^{\prime \prime} \\
36-1 / 2^{\prime \prime}\end{array}$ & $\begin{array}{l}9 " \\
9 " \\
12 " \\
12 " \\
12 " \\
12 " \\
12 "\end{array}$ & $\begin{array}{ll} & 5 / 8 " \\
& 5 / 8 " \\
1 & 3 / 8 " \\
1 & 3 / 8 " \\
1 & 1 / 4^{\prime \prime} \\
1 & 1 / 4^{\prime \prime} \\
1 & 1 / 4^{\prime \prime}\end{array}$ & $\begin{array}{c}7 / 16^{" ~} \\
7 / 16^{\prime \prime} \\
7 / 8^{\prime \prime} \\
13 / 16^{\prime \prime} \\
3 / 4^{\prime \prime} \\
3 / 4^{\prime \prime} \\
3 / 4^{\prime \prime}\end{array}$ \\
\hline 7.2 & $\begin{array}{ll}\text { CU } & 7.1 \\
\text { CD } & 7.2 \\
\text { S1 } & \\
\text { S2 } & \\
\text { S3 } & \\
\text { S4 } & \\
\text { S5 } & \end{array}$ & $\begin{array}{l}39^{\prime}-2 \text { " } \\
\quad-- \\
60^{\prime}-1 " \\
60^{\prime} \\
60^{\prime} \\
60^{\prime} \\
60^{\prime}\end{array}$ & $\begin{array}{l}24 " \\
23-3 / 4^{\prime \prime} \\
36-1 / 2 " \\
36-1 / 2 " \\
36-1 / 2 " \\
361 / 2 " \\
353 / 4 "\end{array}$ & 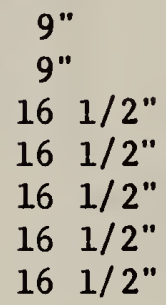 & $\begin{array}{ll} & 5 / 8 " \\
& 5 / 8 " \\
1 & 1 / 2 " \\
1 & 1 / 2^{\prime \prime} \\
1 & 1 / 2 " \\
1 & 1 / 2 " \\
1 & 1 / 4 "\end{array}$ & $\begin{array}{c}7 / 16^{\prime \prime} \\
7 / 16^{\prime \prime} \\
15 / 16^{\prime \prime} \\
15 / 16^{\prime \prime} \\
15 / 16^{\prime \prime} \\
7 / 8^{\prime \prime} \\
3 / 4^{\prime \prime}\end{array}$ \\
\hline 8.0 & $\begin{array}{ll}\text { CU } & 7.2 \\
\text { CD } & 8.0 \\
\text { S1 } & \\
\text { S2 } & \\
\text { S3 } & \\
\text { S4 } & \\
\text { S5 } & \end{array}$ & $\begin{array}{c}-- \\
-- \\
55^{\prime}-2 " \\
55^{\prime}-2 " \\
-- \\
55^{\prime} 2^{\prime \prime} \\
55^{\prime} 2^{\prime \prime}\end{array}$ & $\begin{array}{ll}23 & 3 / 4^{\prime \prime} \\
23 & 3 / 4^{\prime \prime} \\
36 & 3 / 4^{\prime \prime} \\
36 & 1 / 2 " \\
36 & 1 / 2^{\prime \prime} \\
36 & 1 / 2^{\prime \prime} \\
36 & 1 / 2^{\prime \prime}\end{array}$ & $\begin{array}{l}9 " \\
9 " \\
12 " \\
12 " \\
12 " \\
12 " \\
12 "\end{array}$ & $\begin{array}{ll} & 5 / 8 " \\
& 5 / 8 " \\
1 & 1 / 4 " \\
1 & 1 / 4 " \\
1 & 1 / 4 " \\
1 & 1 / 4 " \\
1 & 1 / 4 "\end{array}$ & $\begin{array}{l}7 / 16^{\prime \prime} \\
7 / 16^{\prime \prime} \\
3 / 4^{\prime \prime} \\
3 / 4^{\prime \prime} \\
3 / 4^{\prime \prime} \\
3 / 4^{\prime \prime} \\
3 / 4^{\prime \prime}\end{array}$ \\
\hline $\begin{array}{l}\text { STAND } \\
\text { W } 24 \\
\text { W } 36\end{array}$ & $\begin{array}{l}\text { R BEAMS } \\
68 \\
194\end{array}$ & & $\begin{array}{ll}23 & 3 / 4^{\prime \prime} \\
36 & 1 / 2^{\prime \prime}\end{array}$ & $\begin{array}{l}9 " \\
121 / 8 "\end{array}$ & $\begin{array}{ll}9 / 16^{\prime \prime} \\
1 \text { 1/4" }\end{array}$ & $\begin{array}{l}7 / 16^{\prime \prime} \\
13 / 16^{\prime \prime}\end{array}$ \\
\hline
\end{tabular}

1 in $=25.4 \mathrm{~mm}$

$1 \mathrm{ft}=0.305 \mathrm{~m}$ 
Table 3.3 Data Used to Deterulne Probable Positions of Upper Screw Jacks

\begin{tabular}{cccc}
$\begin{array}{c}\text { Leg } \\
\text { Postion }\end{array}$ & $\begin{array}{c}\text { Concrete } \\
\text { Pad } \\
\text { Elevation }\end{array}$ & $\begin{array}{c}\text { Top of } \\
\text { Plywood } \\
\text { Elevation }\end{array}$ & $\begin{array}{c}\text { Lower } \\
\text { Screw Jack } \\
\text { Extension }\end{array}$ \\
\hline A & $589.76^{\prime}$ & $644.23^{\prime}$ & $18-7 / 8^{\prime \prime}$ \\
D & $589.67^{\prime}$ & $643.88^{\prime}$ & $17-1 / 4^{\prime \prime}$ \\
E & $589.67^{\prime}$ & $644.61^{\prime}$ & $20-1 / 4^{\prime \prime}$ \\
H & $589.59^{\prime}$ & $644.20^{\prime}$ & $16-7 / 8^{\prime \prime}$ \\
\hline $\begin{array}{l}\text { in }=25.4 \mathrm{~mm} \\
1 \text { in }=0.305 \mathrm{~m}\end{array}$
\end{tabular}

Table 3.4 Exposed Thread Lengths and Probable Positions of Upper Screw Jacks at 407.2

\begin{tabular}{c|c|c|c}
$\begin{array}{c}\text { Ident1fying } \\
\text { Mark }\end{array}$ & $\begin{array}{c}\text { Thread } \\
\text { Length }\end{array}$ & $\begin{array}{c}\text { Possible } \\
\text { Position }\end{array}$ & $\begin{array}{c}\text { Probable } \\
\text { Position }\end{array}$ \\
\hline & & & \\
JT 33 & $31 / 2^{\prime \prime}$ & B, D & D \\
JT 34 & $45 / 8^{\prime \prime}$ & A, C & C \\
JT 37 & $31 / 2^{\prime \prime}$ & B, D & B \\
JT 38 & $91 / 2^{\prime \prime}$ & E, G & E \\
JT 39 & $71 / 2^{\prime \prime}$ & F & F \\
\hline
\end{tabular}

1 in $=25.4 \mathrm{~mm}$ 
Table 3.5 Summary of Shoring Tower Configurations

\begin{tabular}{l|c|c|c}
$\begin{array}{c}\text { Sharing } \\
\text { Tower }\end{array}$ & Cribbing & $\begin{array}{l}\text { Box } \\
\text { Box }\end{array}$ & \multicolumn{1}{|c}{ Frame Heights Used } \\
\hline $407.1(\mathrm{~N})$ & No & Wood & $2 @ 19^{\prime}-6^{\prime \prime}+1 @ 3^{\prime}-3^{\prime \prime}$ \\
407.1 (S) & 2 Layers & Wood & $2 @ 19^{\prime}-6^{\prime \prime}$ \\
$407.2(\mathrm{~N})$ & No & Wood & $2 @ 19^{\prime}-6^{\prime \prime}+1 @ 6^{\prime}-6^{\prime \prime}$ \\
$407.2(\mathrm{~S})$ & No & Wood & $2 @ 19^{\prime}-6^{\prime \prime}+1 @ 6^{\prime}-6^{\prime \prime}$ \\
$408(\mathrm{~N})$ & No & Wood & $2 @ 19^{\prime}-6^{\prime \prime}+1 @ 6^{\prime}-6^{\prime \prime}+1 @ 3^{\prime}-3^{\prime \prime}$ \\
$408(\mathrm{~S})$ & No & Wood & $2 @ 19^{\prime}-6^{\prime \prime}+1 @ 6^{\prime}-6^{\prime \prime}+1 @ 3^{\prime}-3^{\prime \prime}$
\end{tabular}

1 in $=25.4 \mathrm{~mm}$

$1 \mathrm{ft}=0.305 \mathrm{~m}$ 

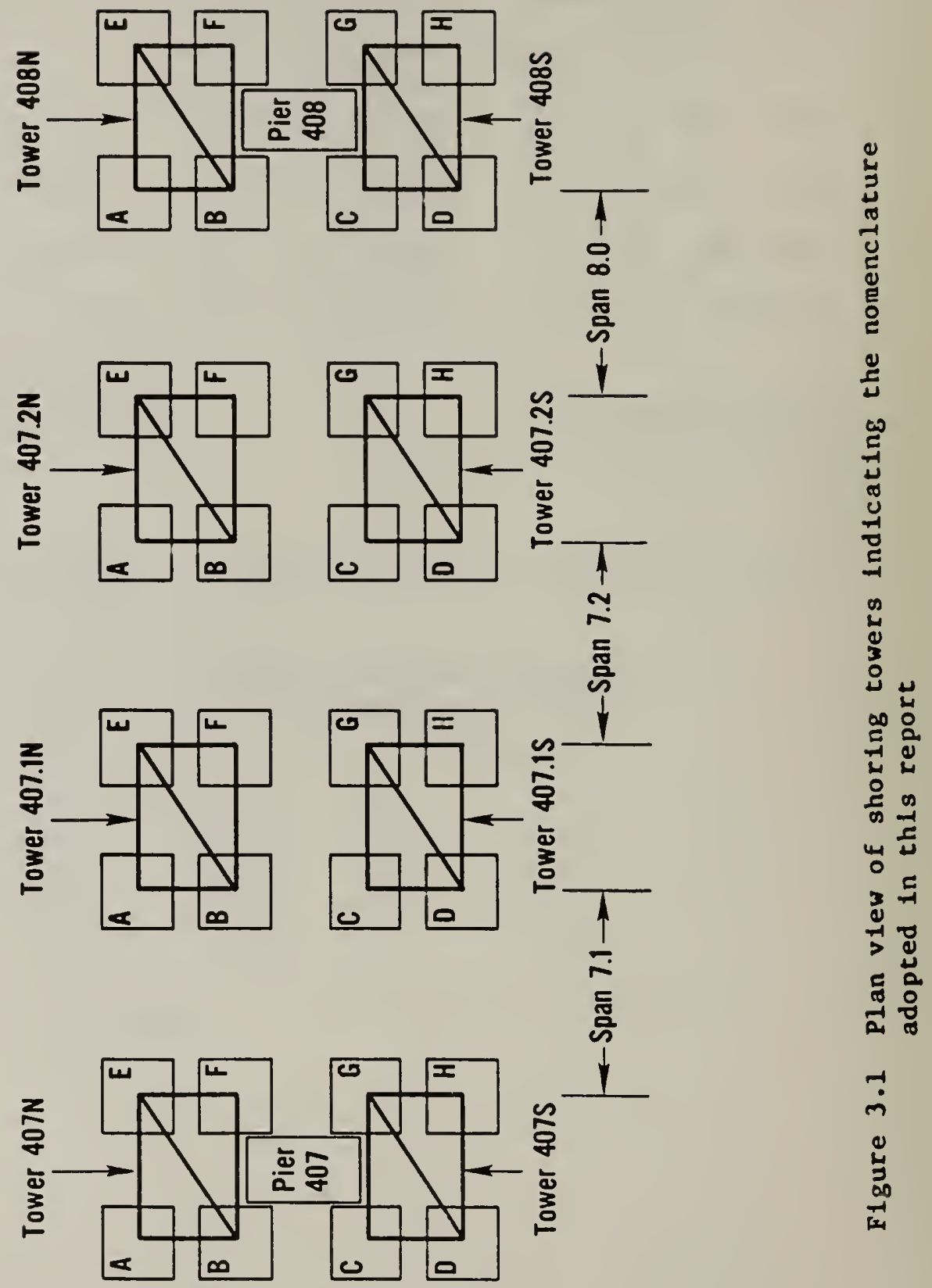

-1
0
$\frac{1}{3}$
$\frac{\infty}{14}$ 


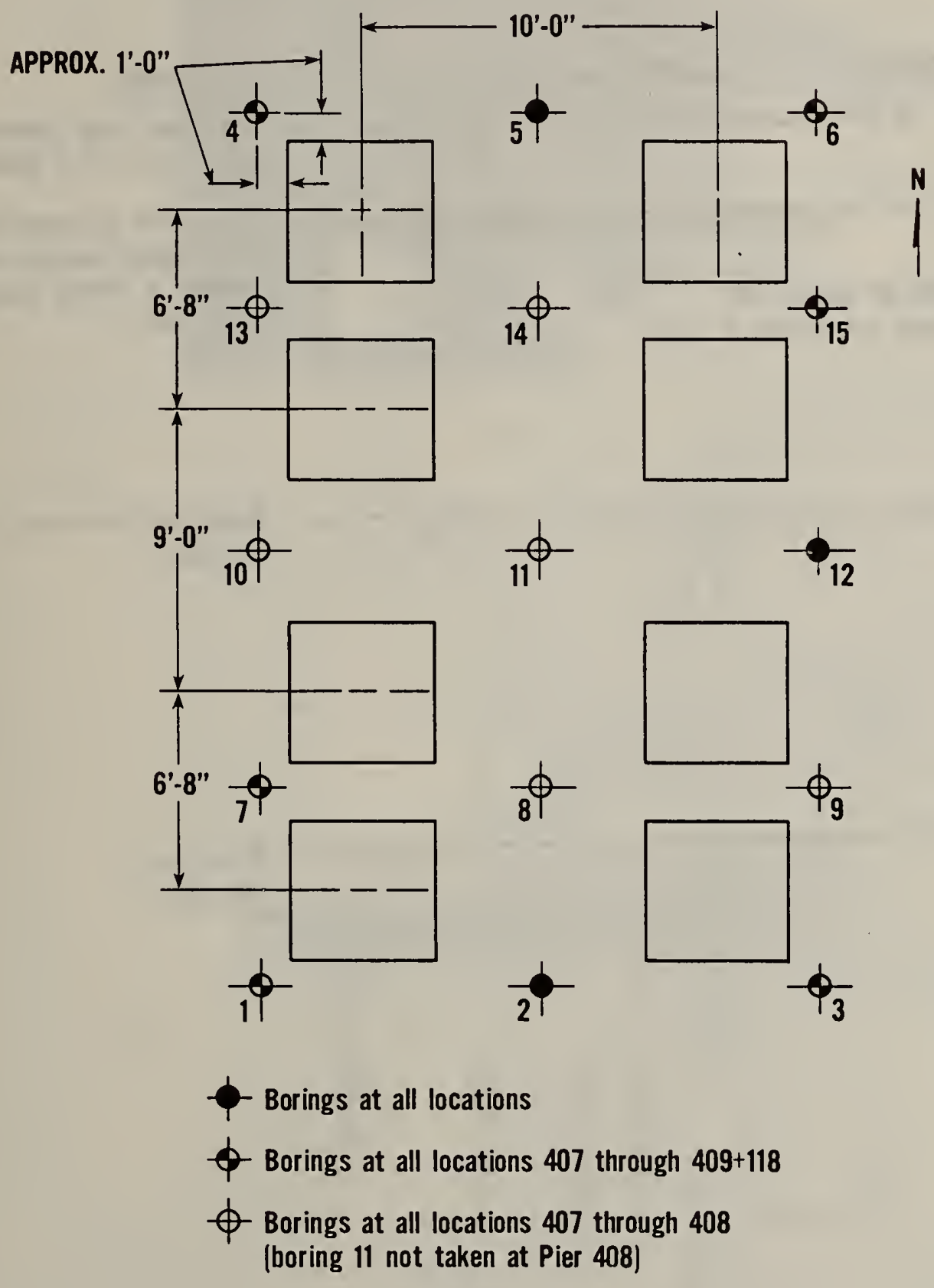

Figure 3.2 Position of soll borings at each tower location 


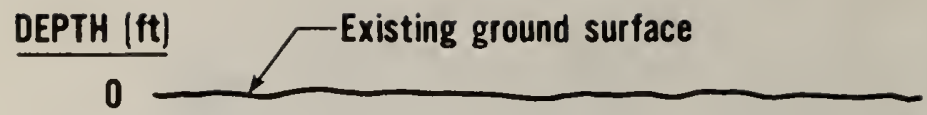

DESCRIPTION

Fill - sand, slag, cinders with oily smell in places

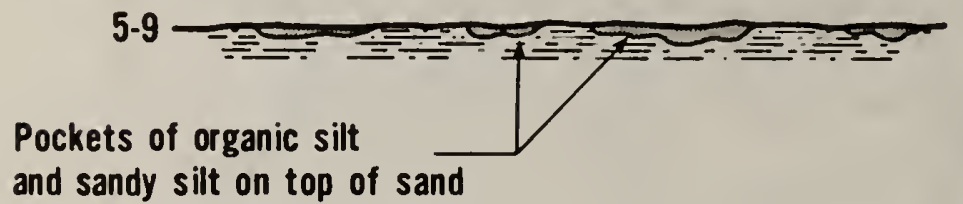

Brown fine to coarse sand with organic pockets and streaks in places, frequent oily smells

$20-25$

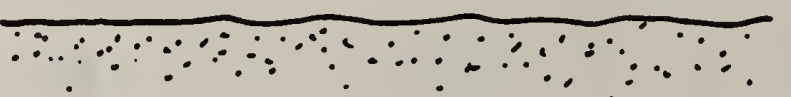

Brown fine silty sand to fine sand

35

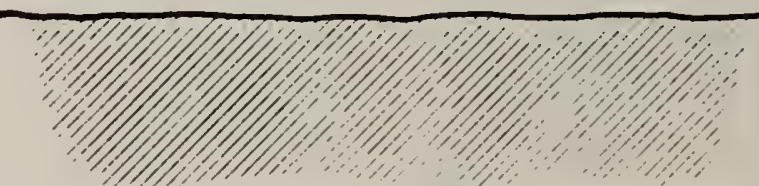

Brown gray

silty clay

Figure 3.3 Typical soil profile between tower locations 407.1 and 408 (except adjacent to pler 408) 

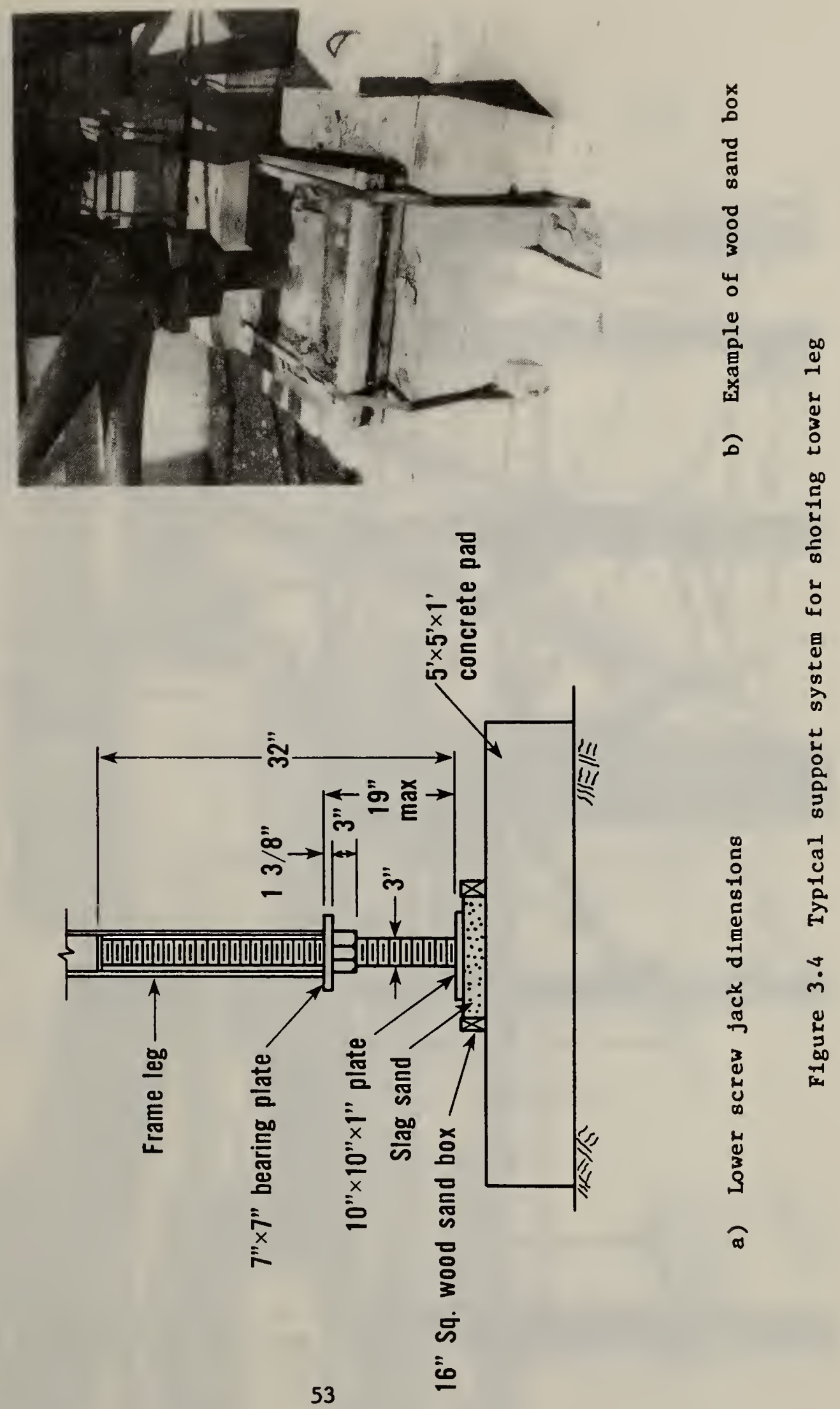


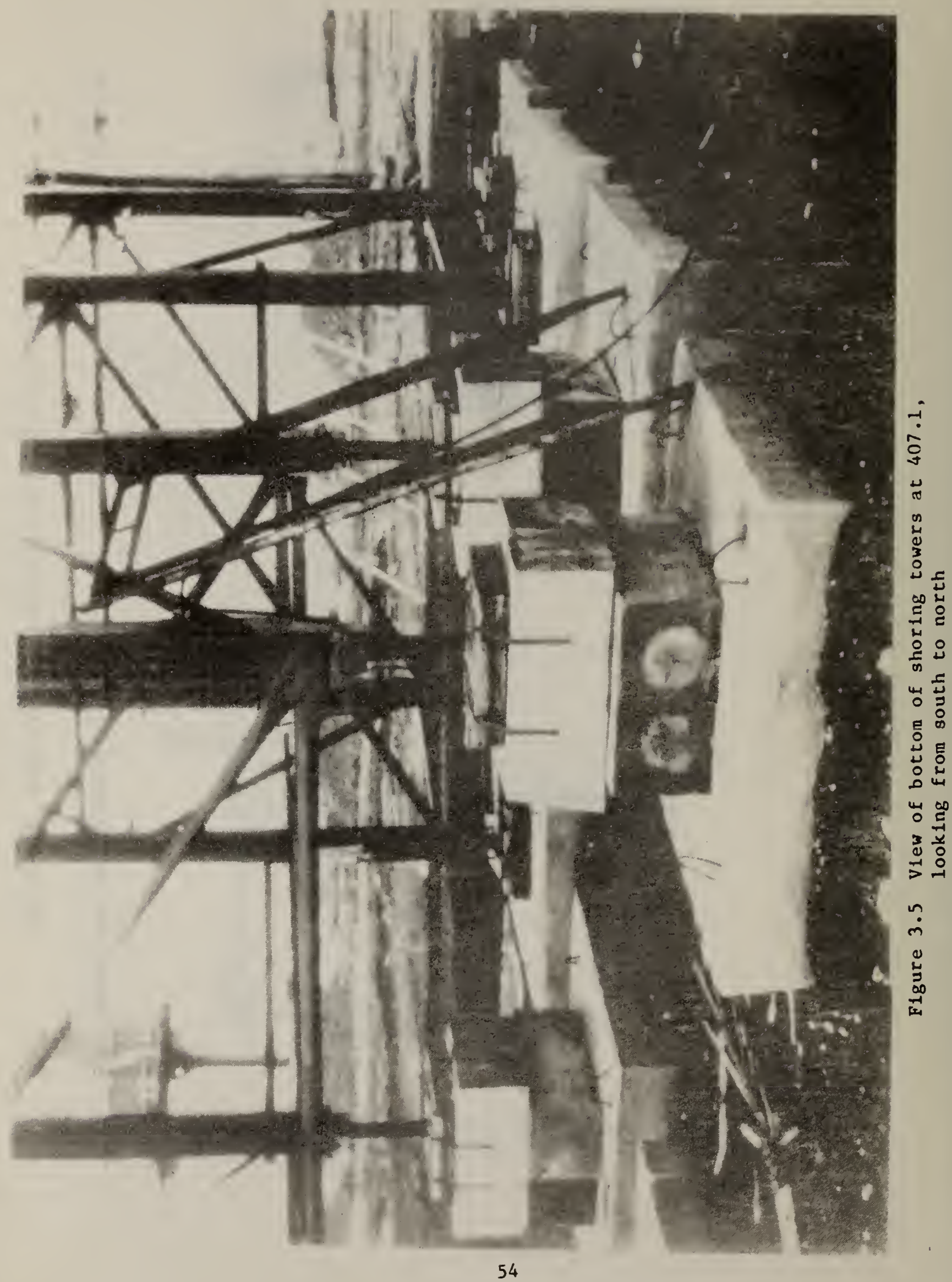



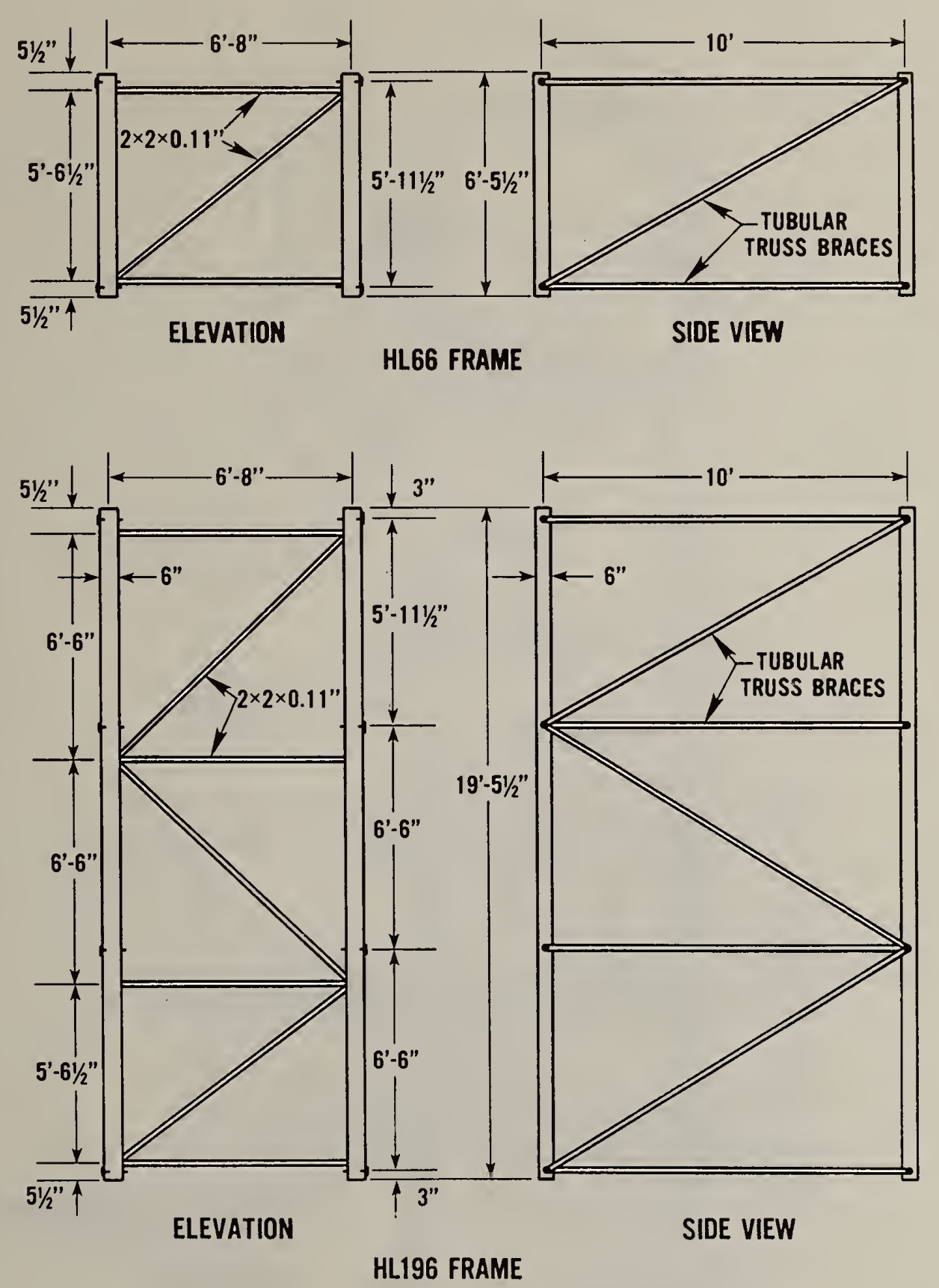

Figure 3.6 Dimensions of two of the standard-size frames used to construct the shoring towers 


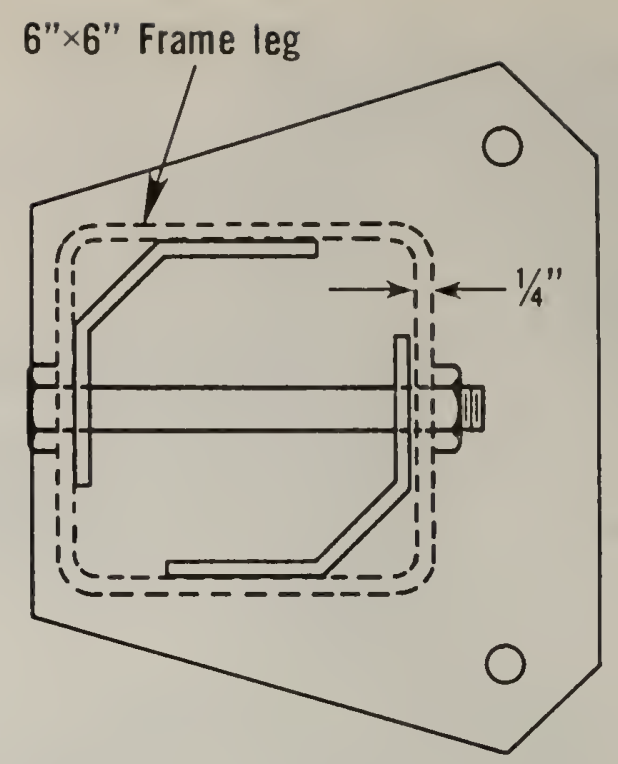

\section{PLAN}

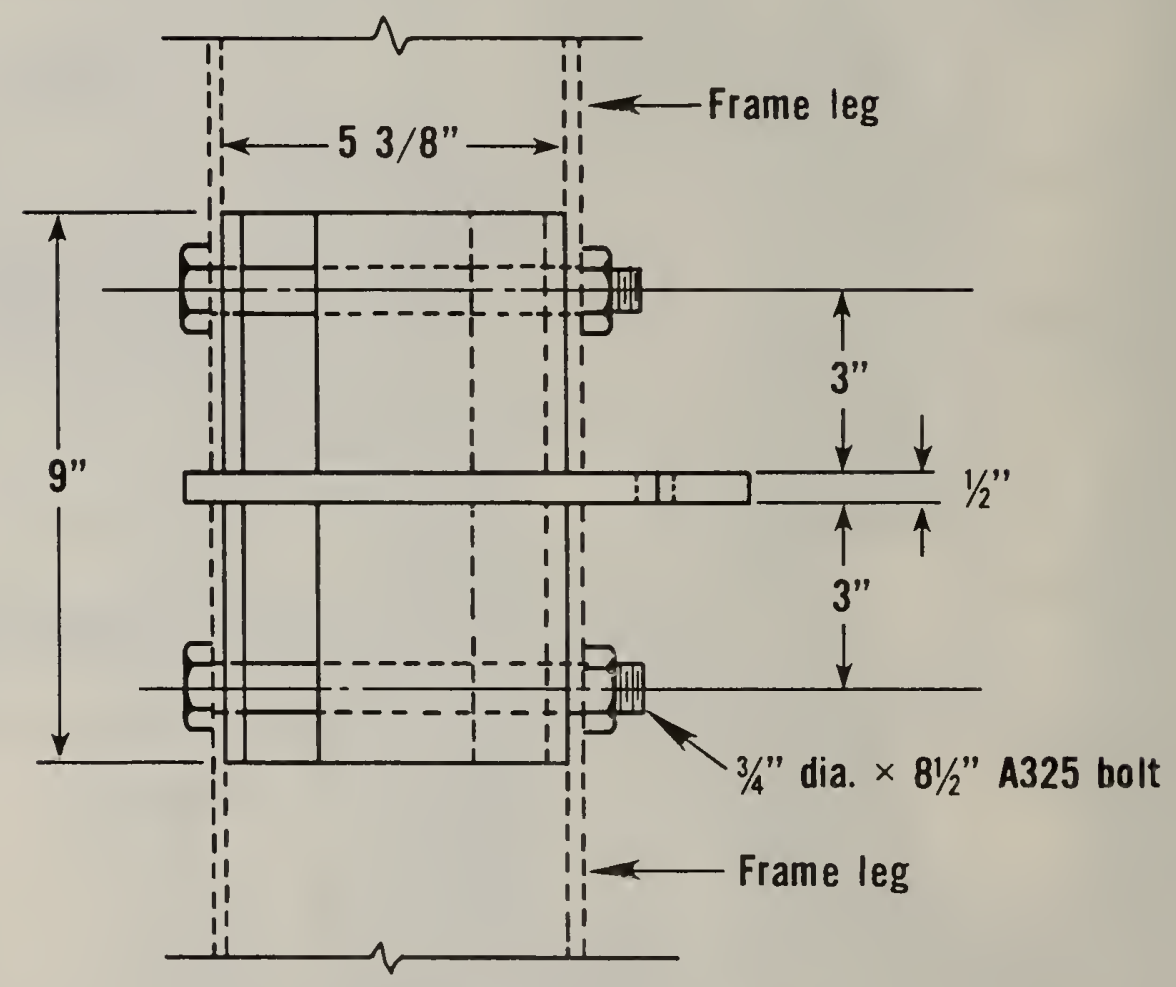

ELEVATION

Figure 3.7 Coupler pin used to join together tower sections 


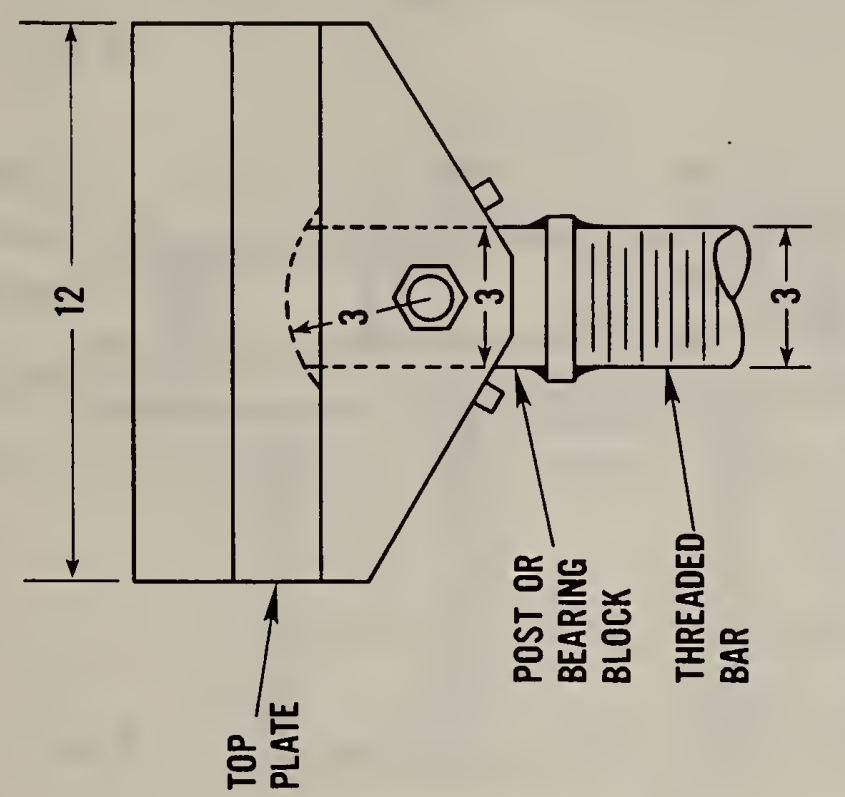

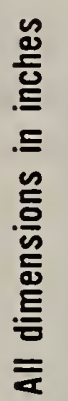

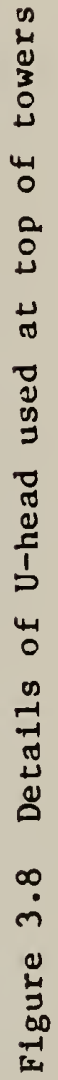

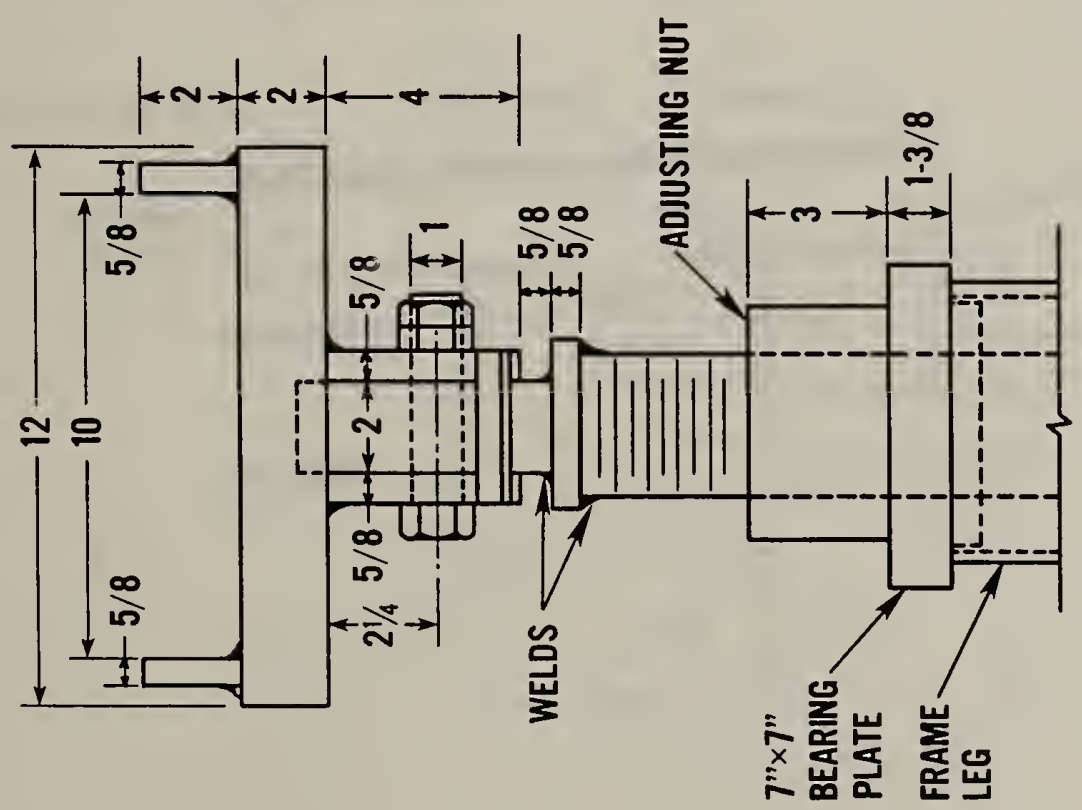



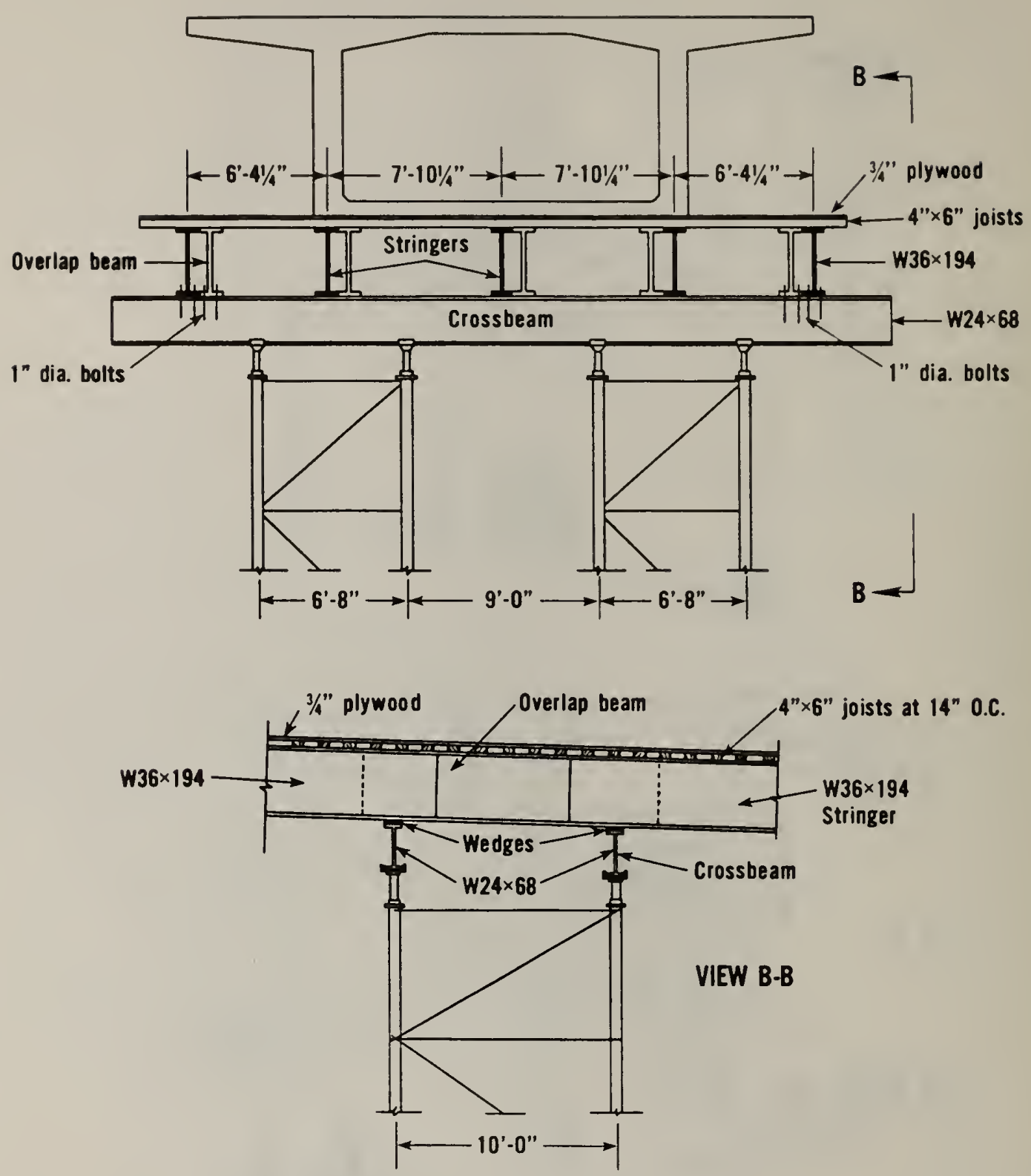

Figure 3.9 Detalls of the falsework system at shoring tower location XXX.2 

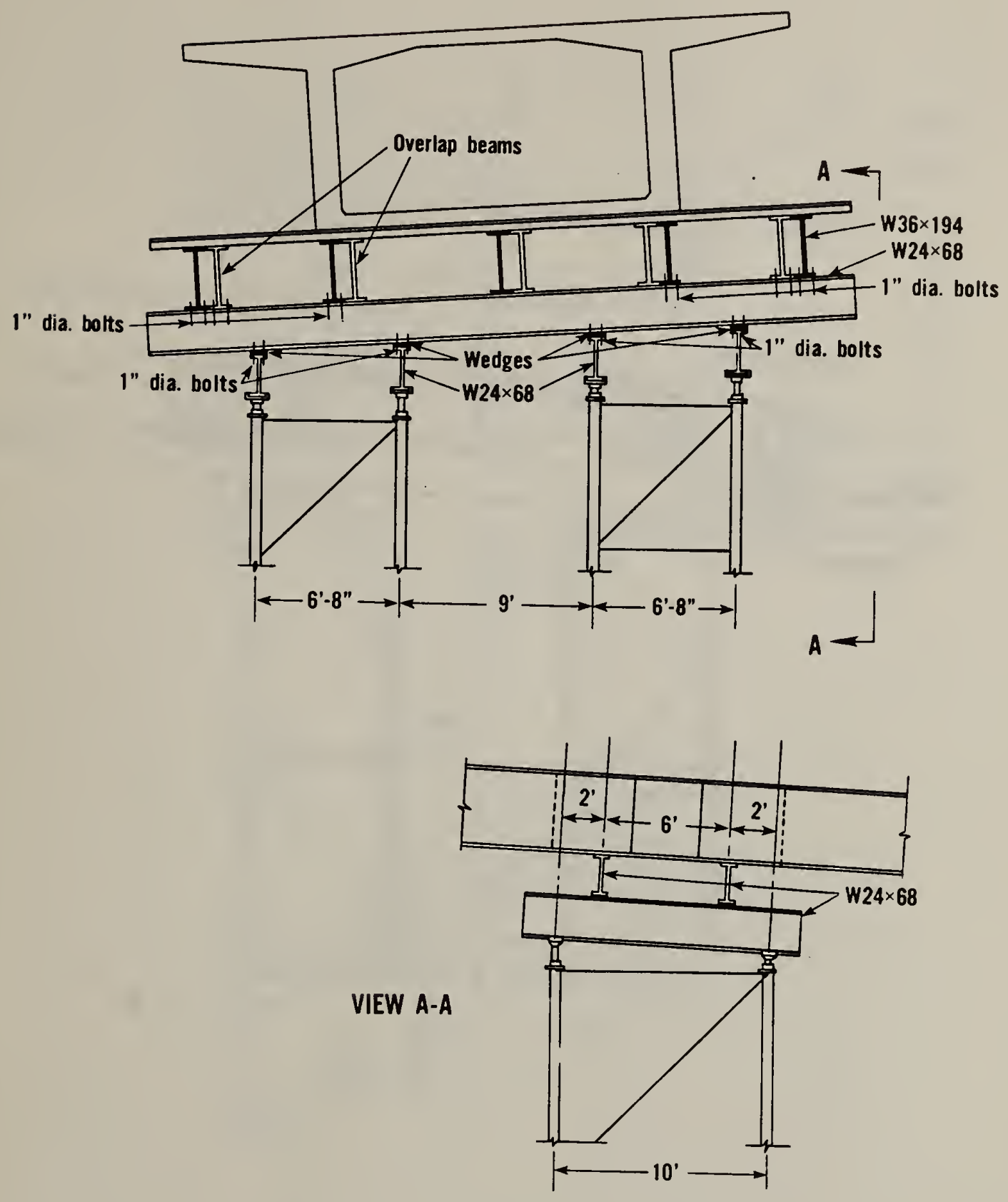

Figure 3.10 Detalls of falsework system at shoring tower location XXX.1 adjacent to construction joints 


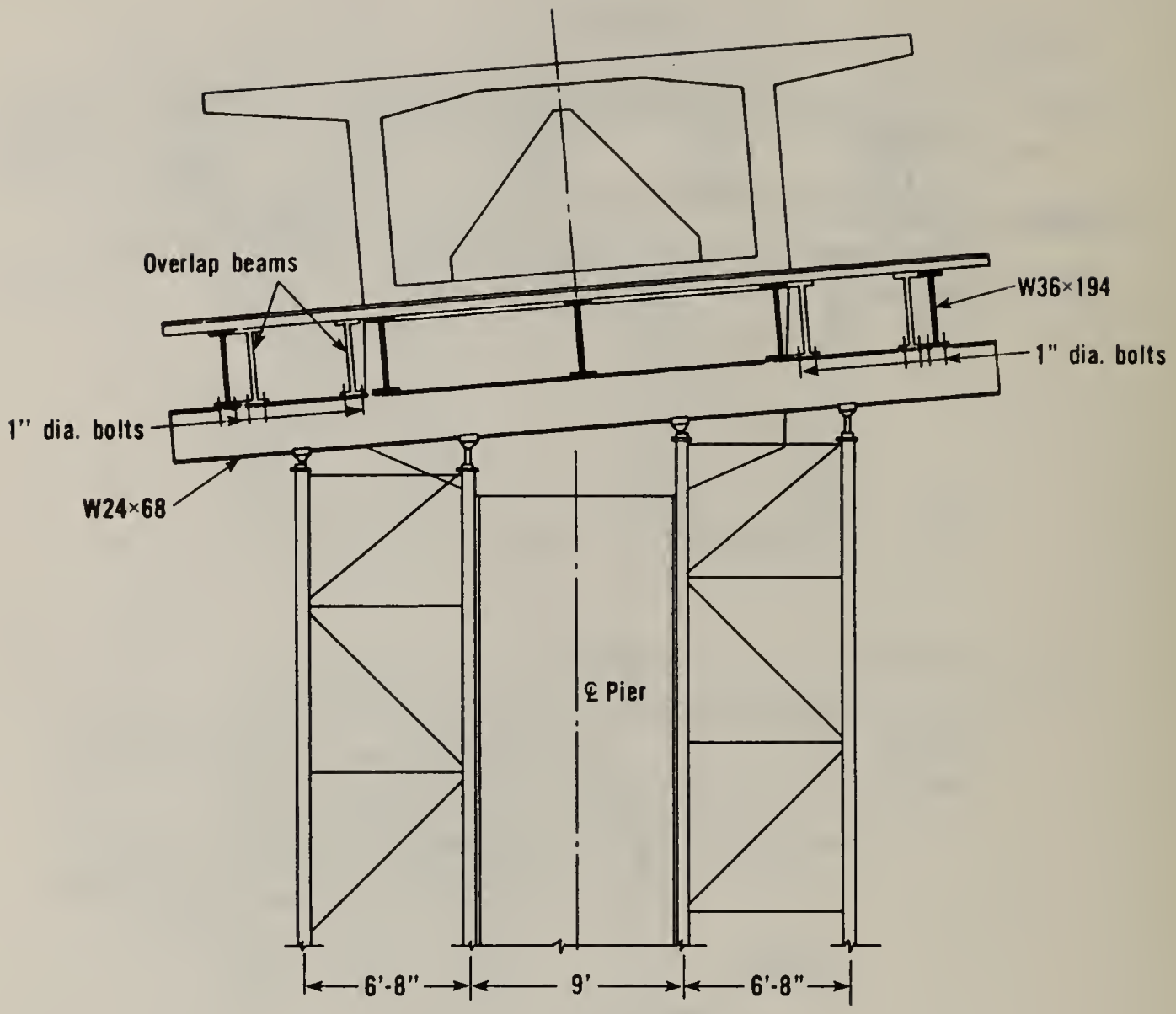

Figure 3.1la Detalls of falsework system at the shoring towers adjacent to the piers 

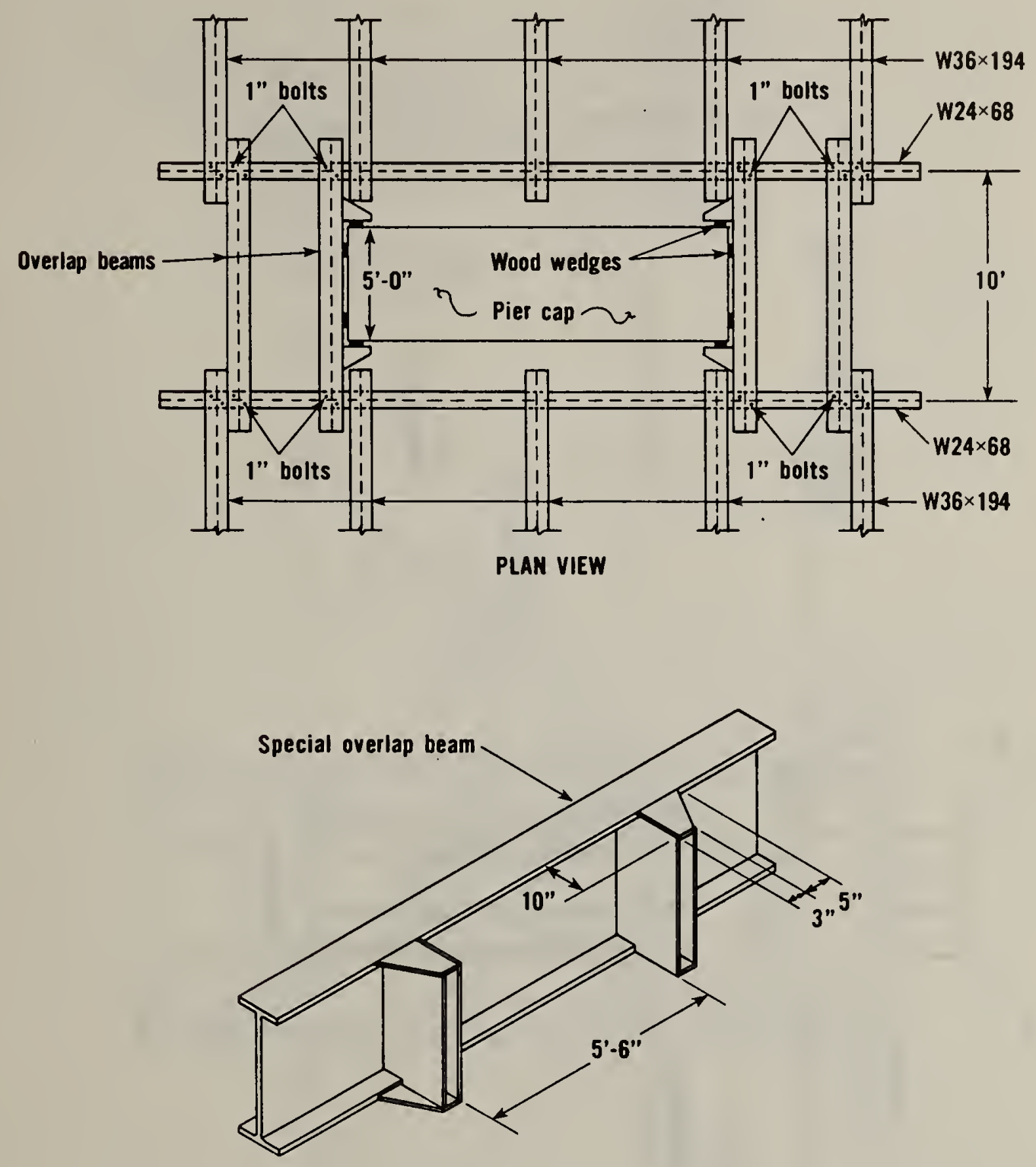

Figure 3.11b Detalls of falsework system at the shoring towers adjacent to the piers 


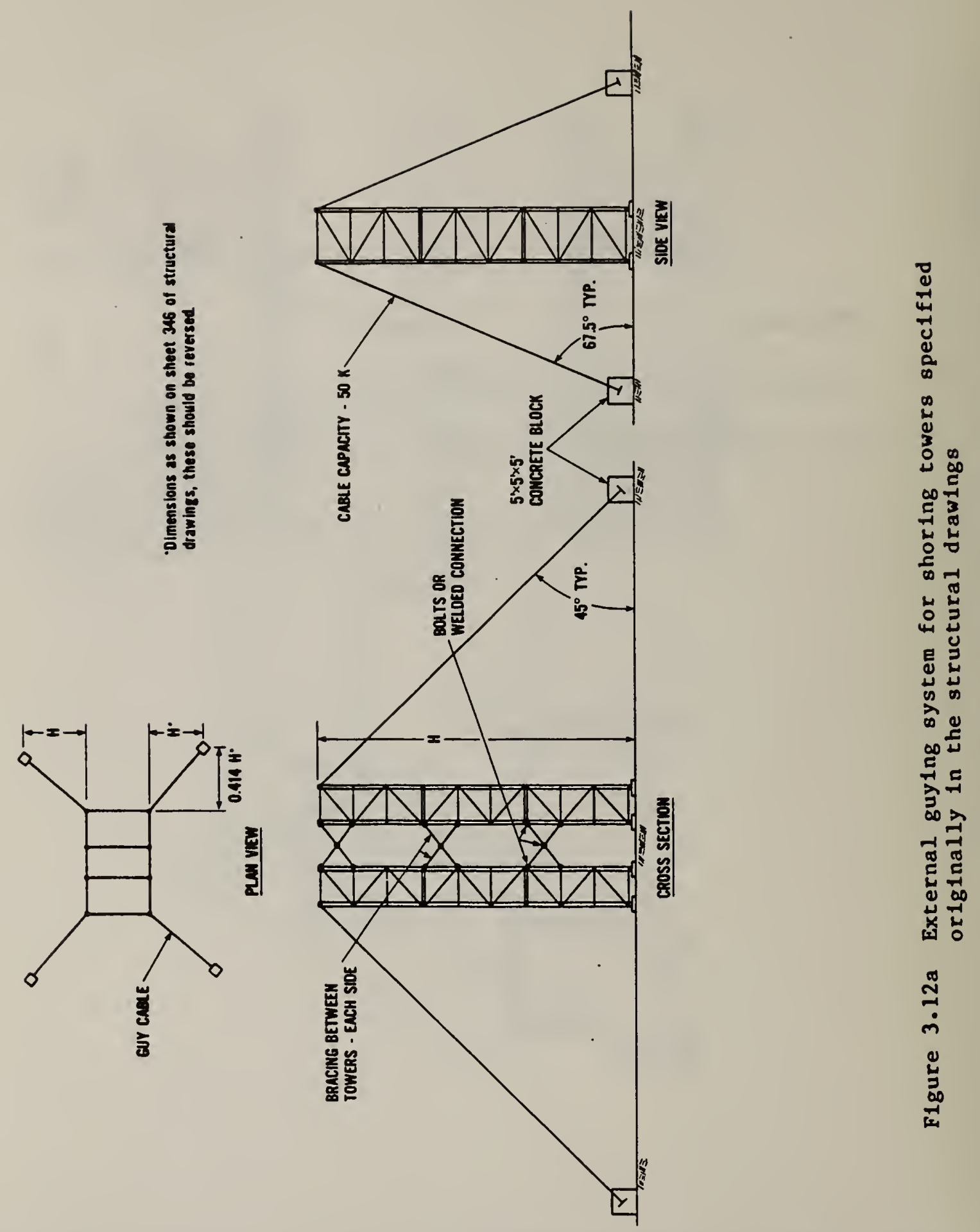



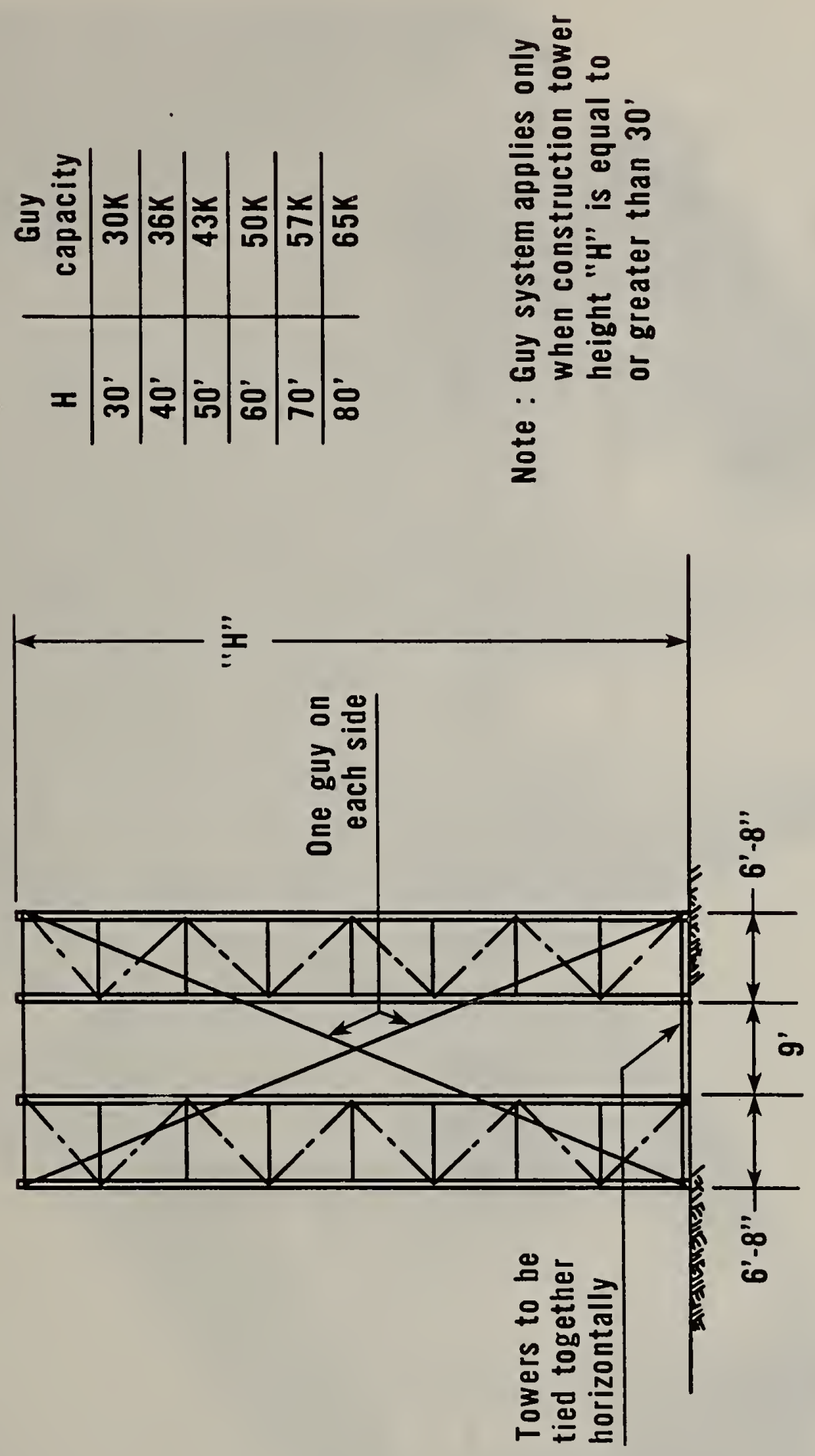

ป็ 


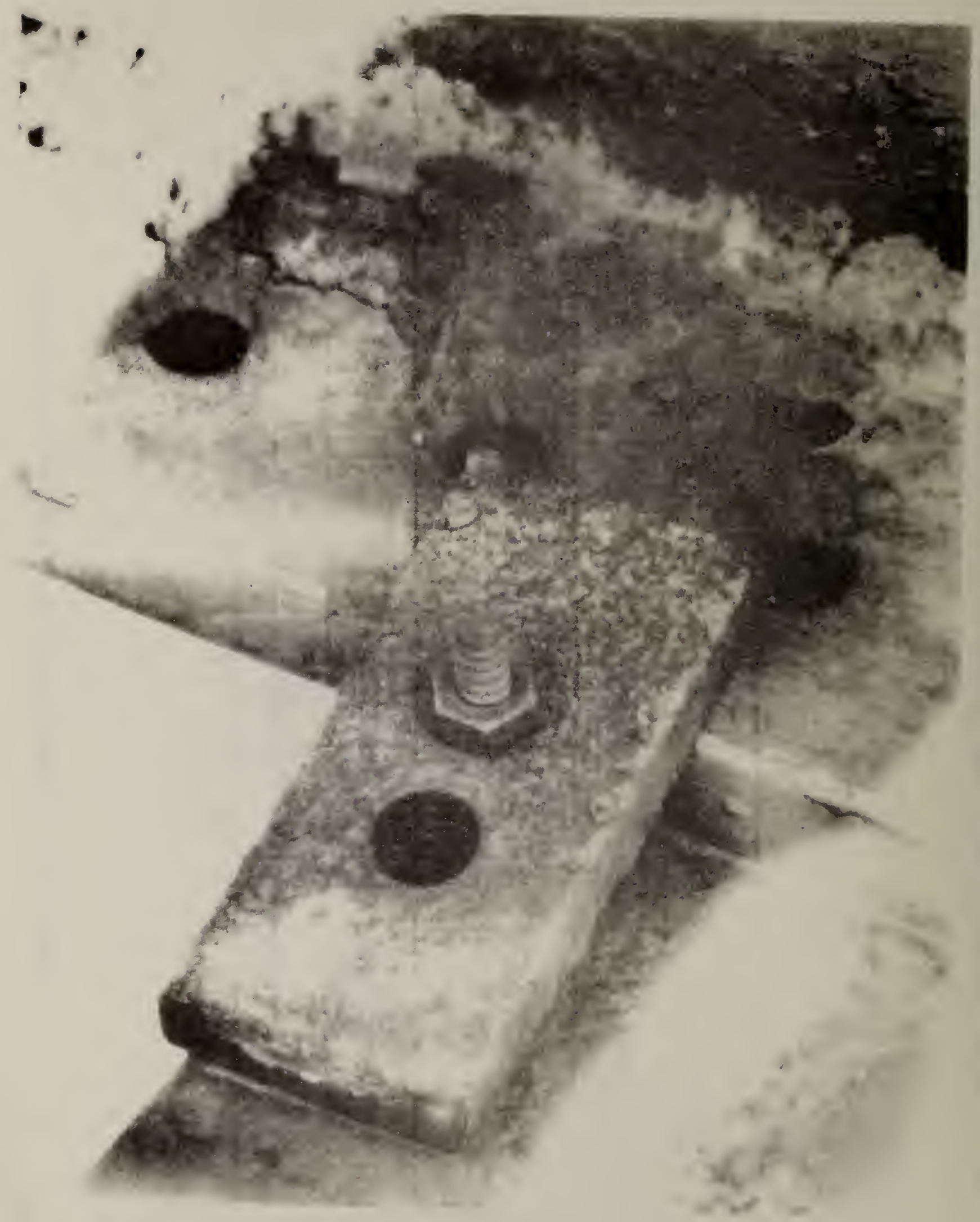

Figure 3.13 Connection detall employed in place of specified bolted connection 

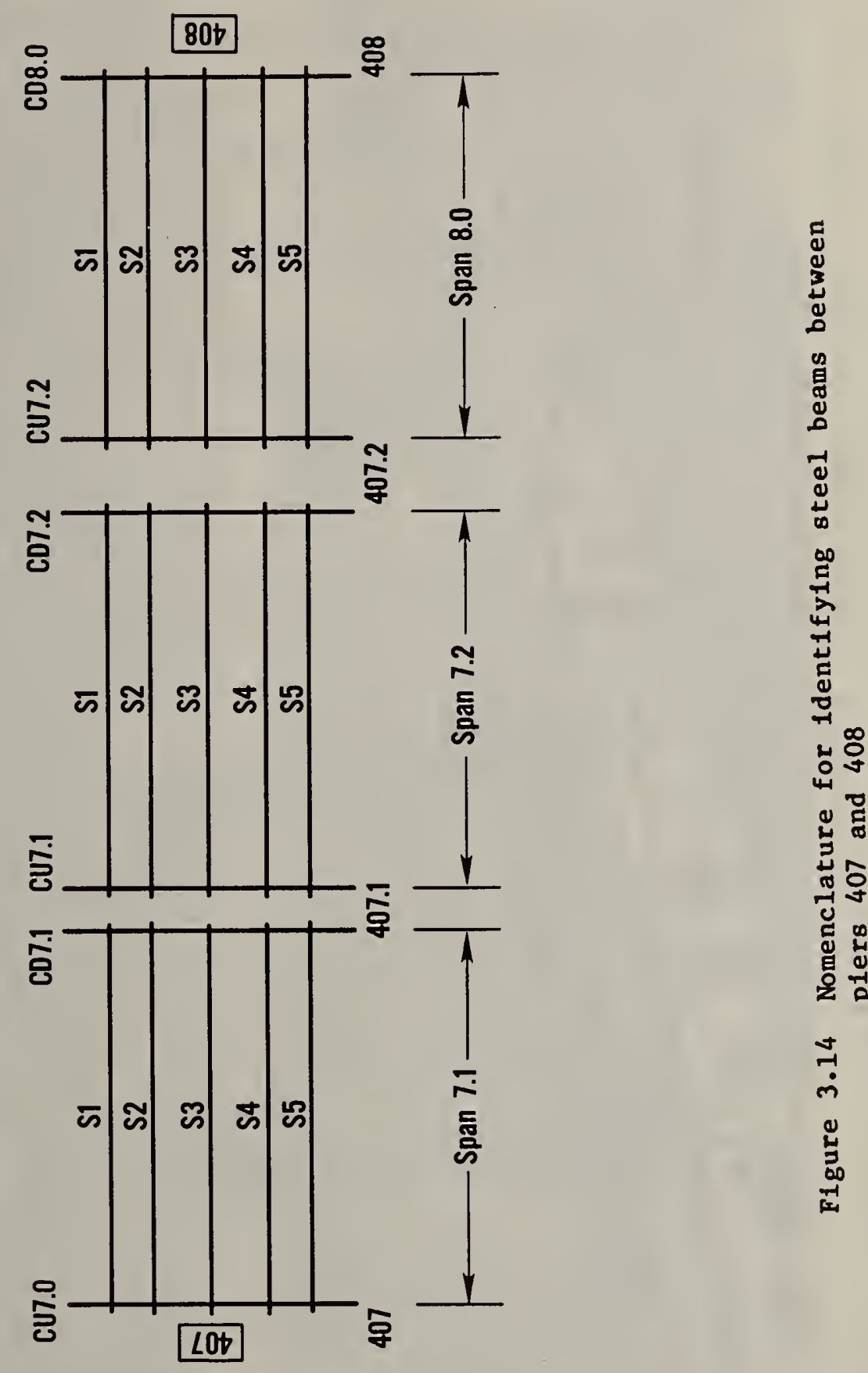


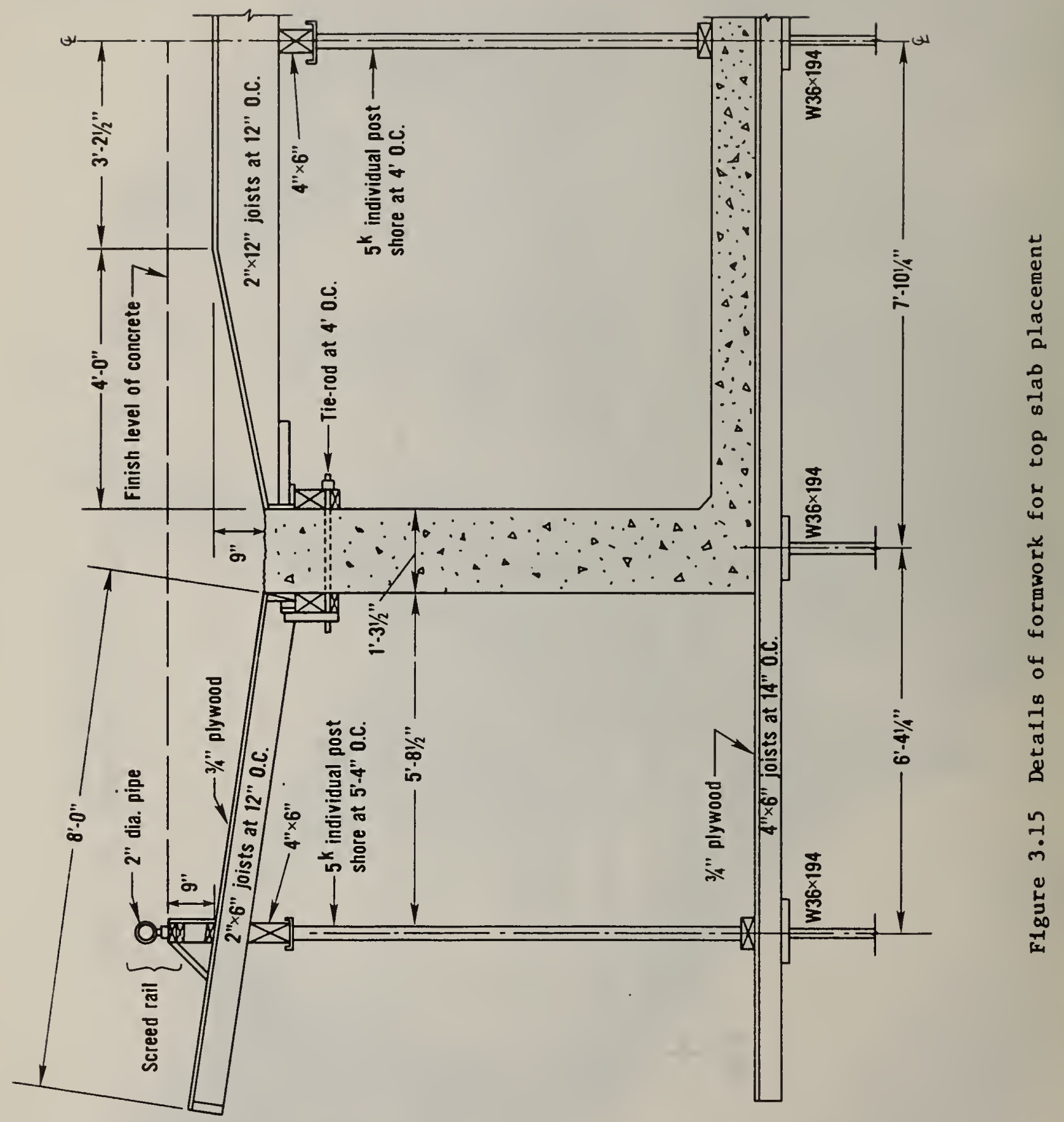




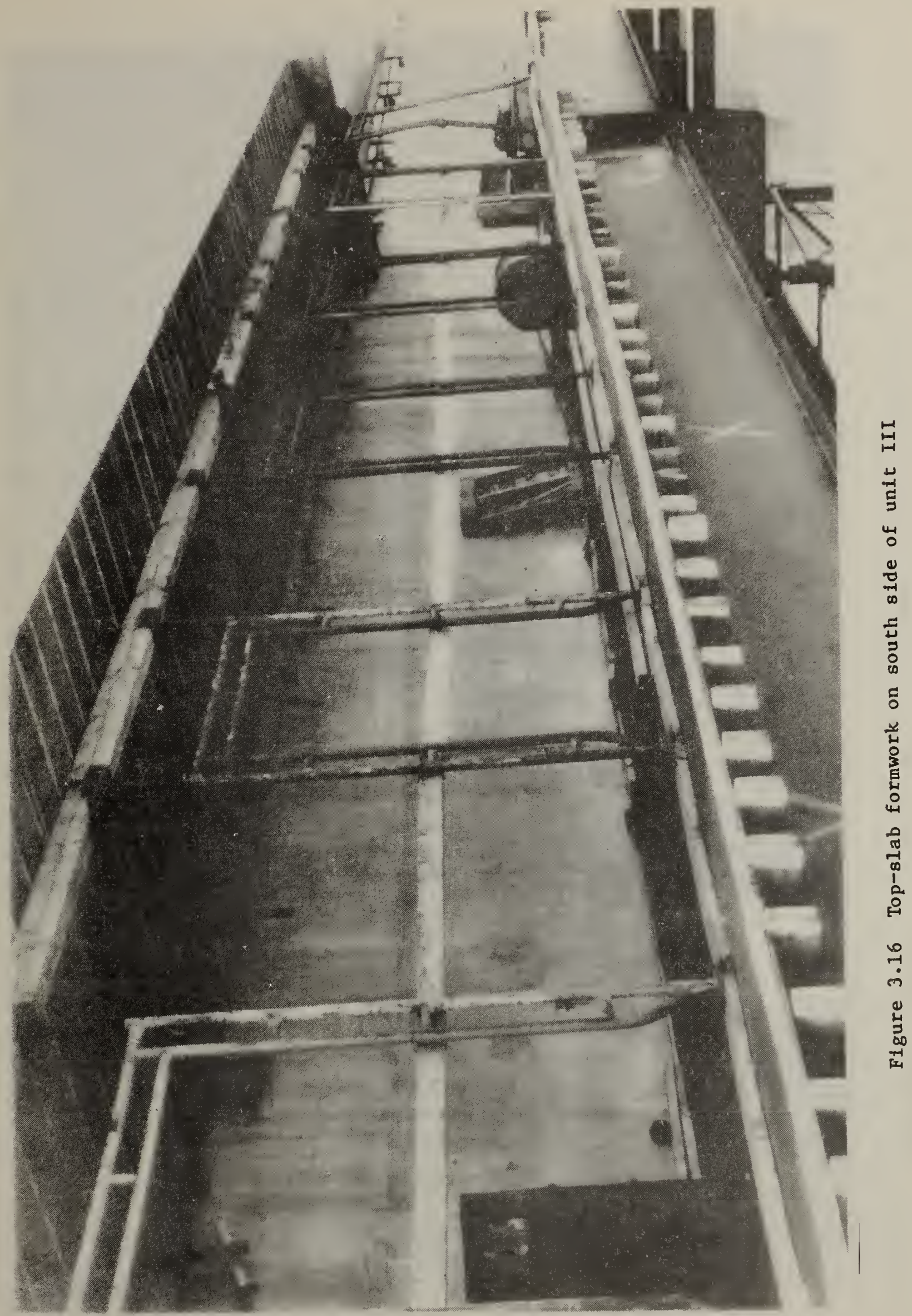




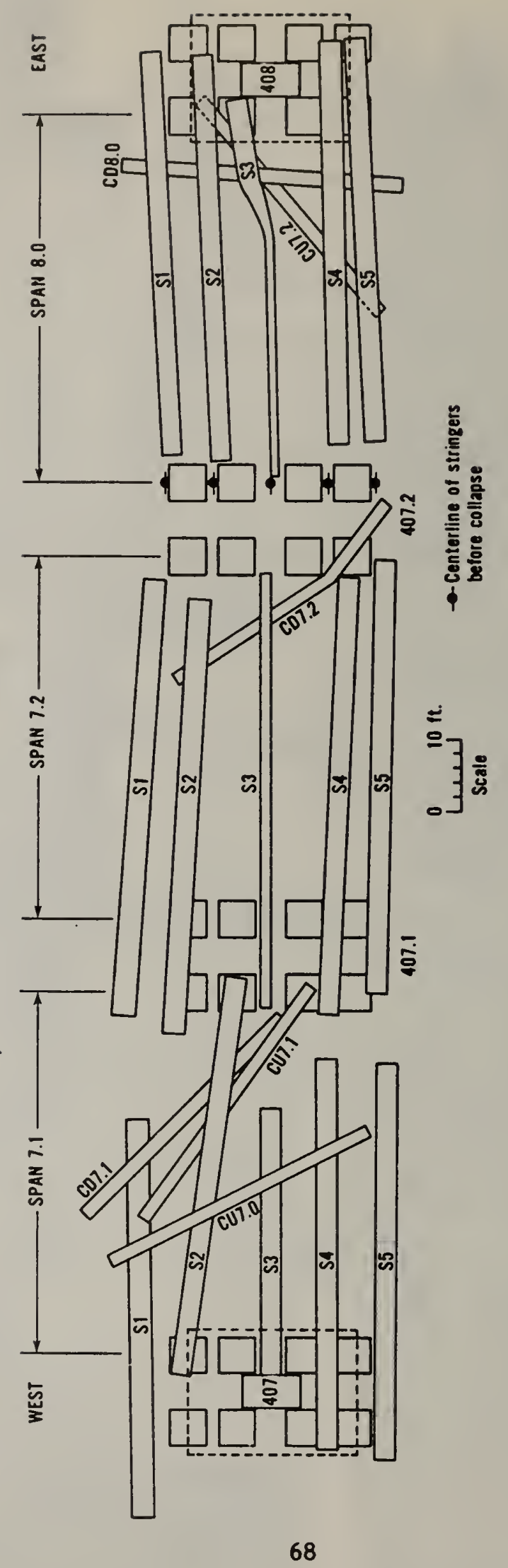

ป 


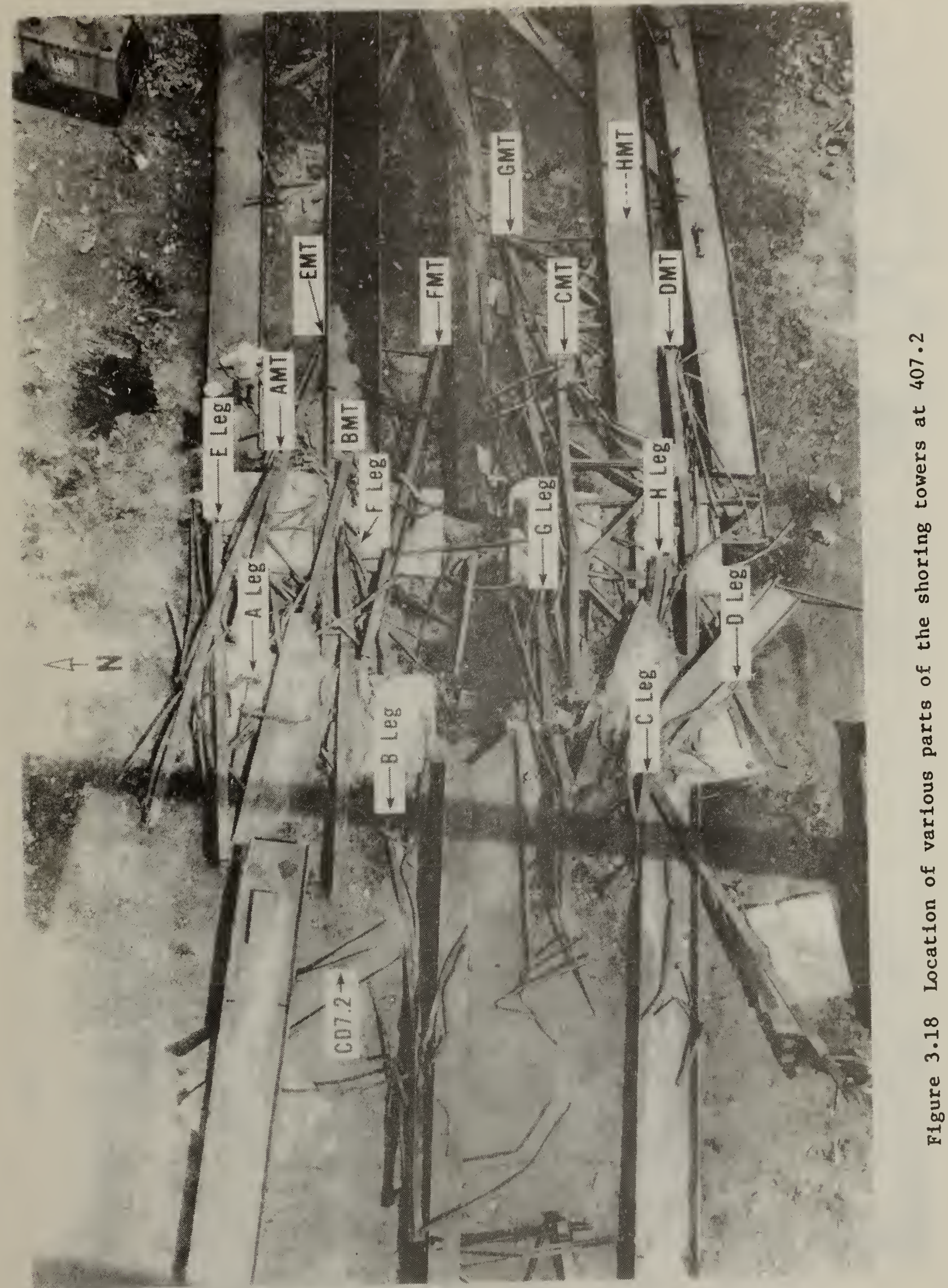




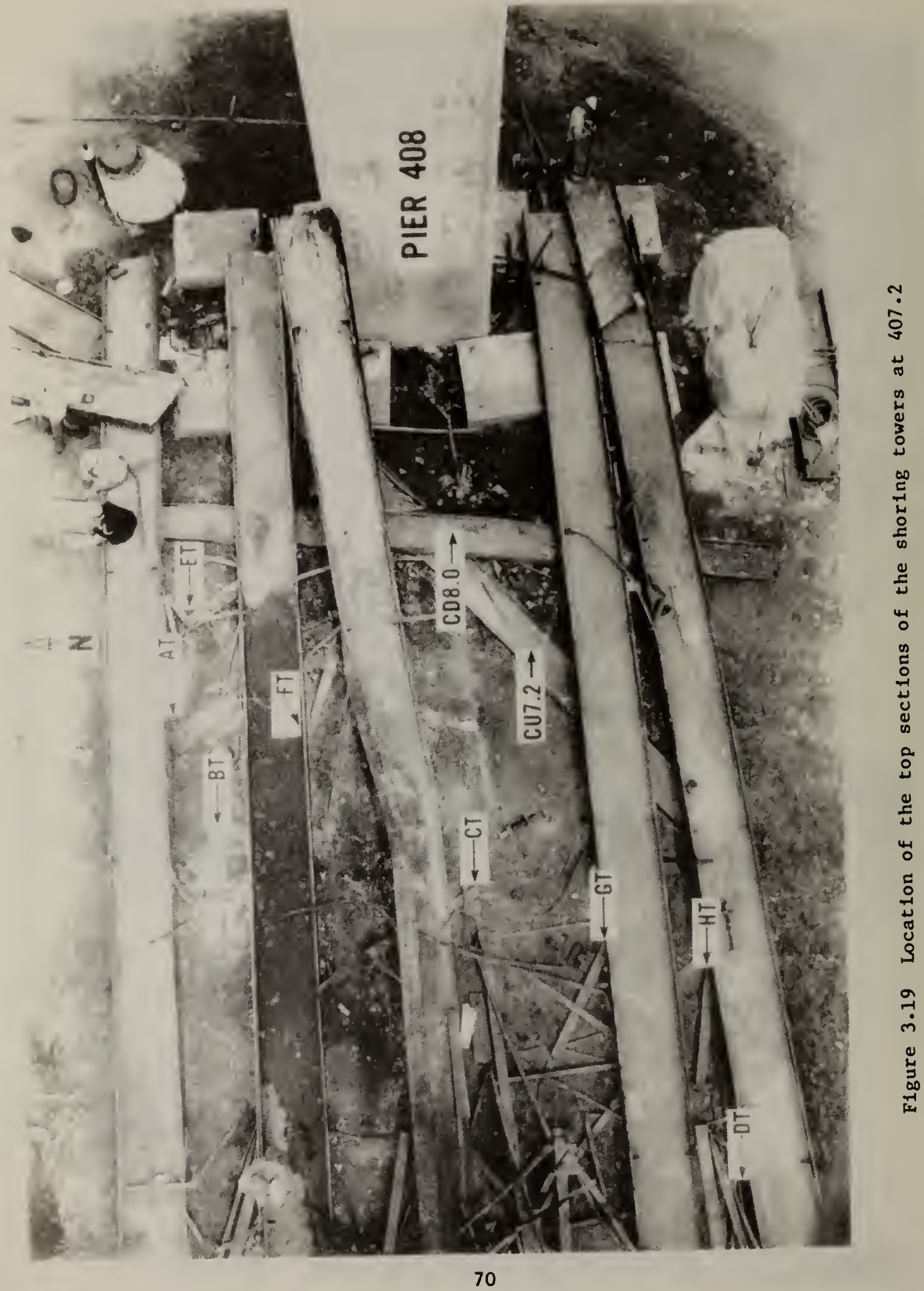




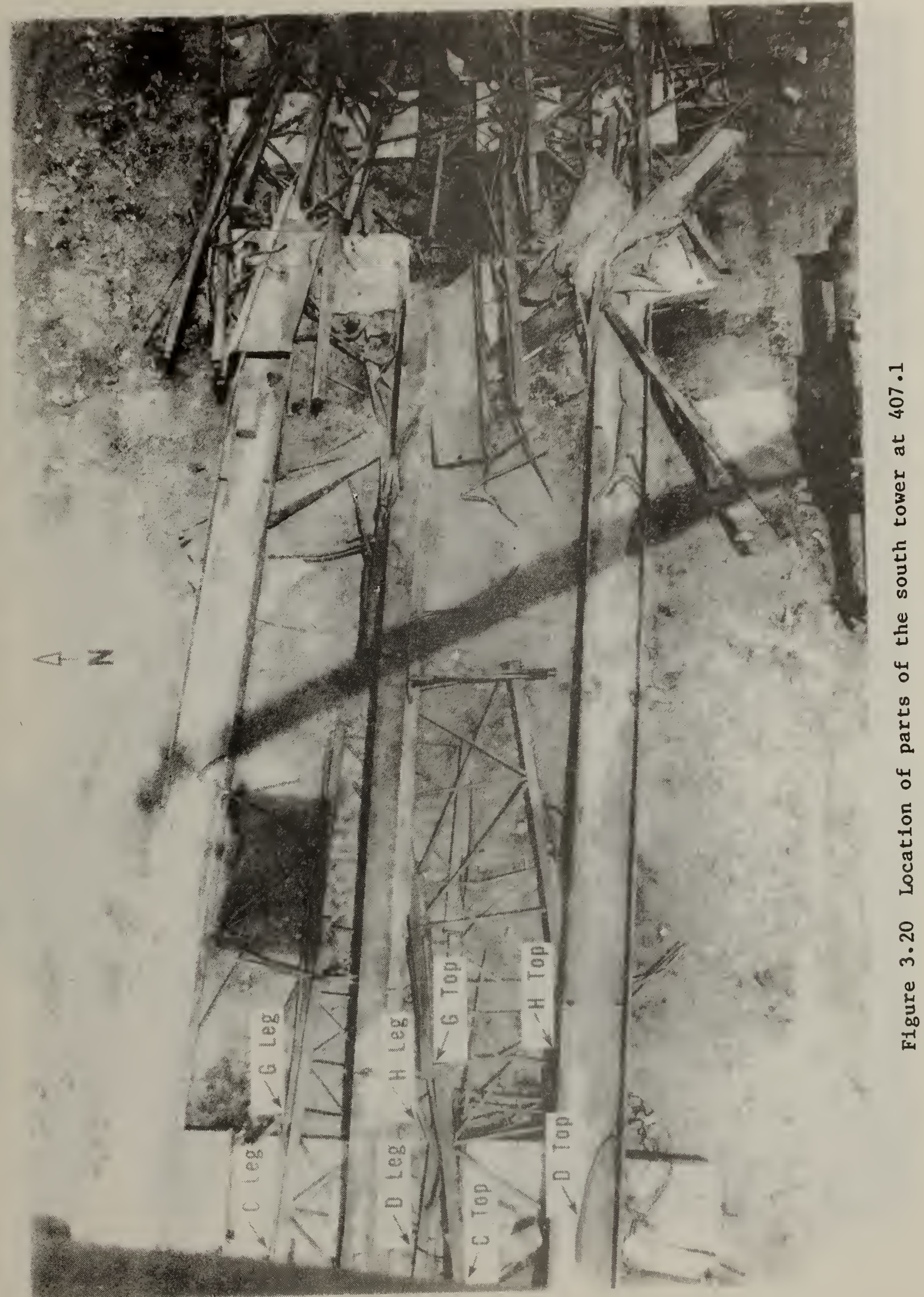




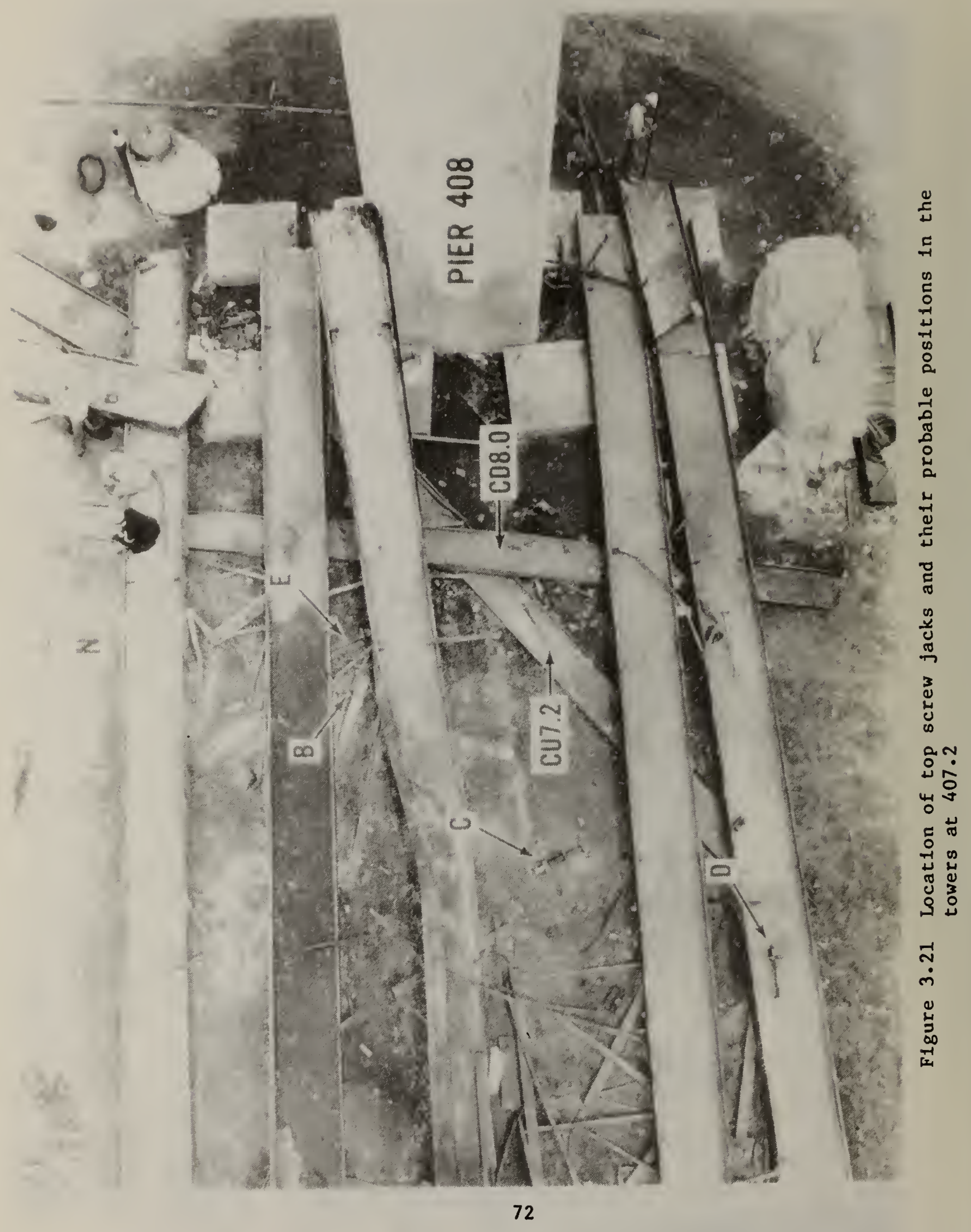




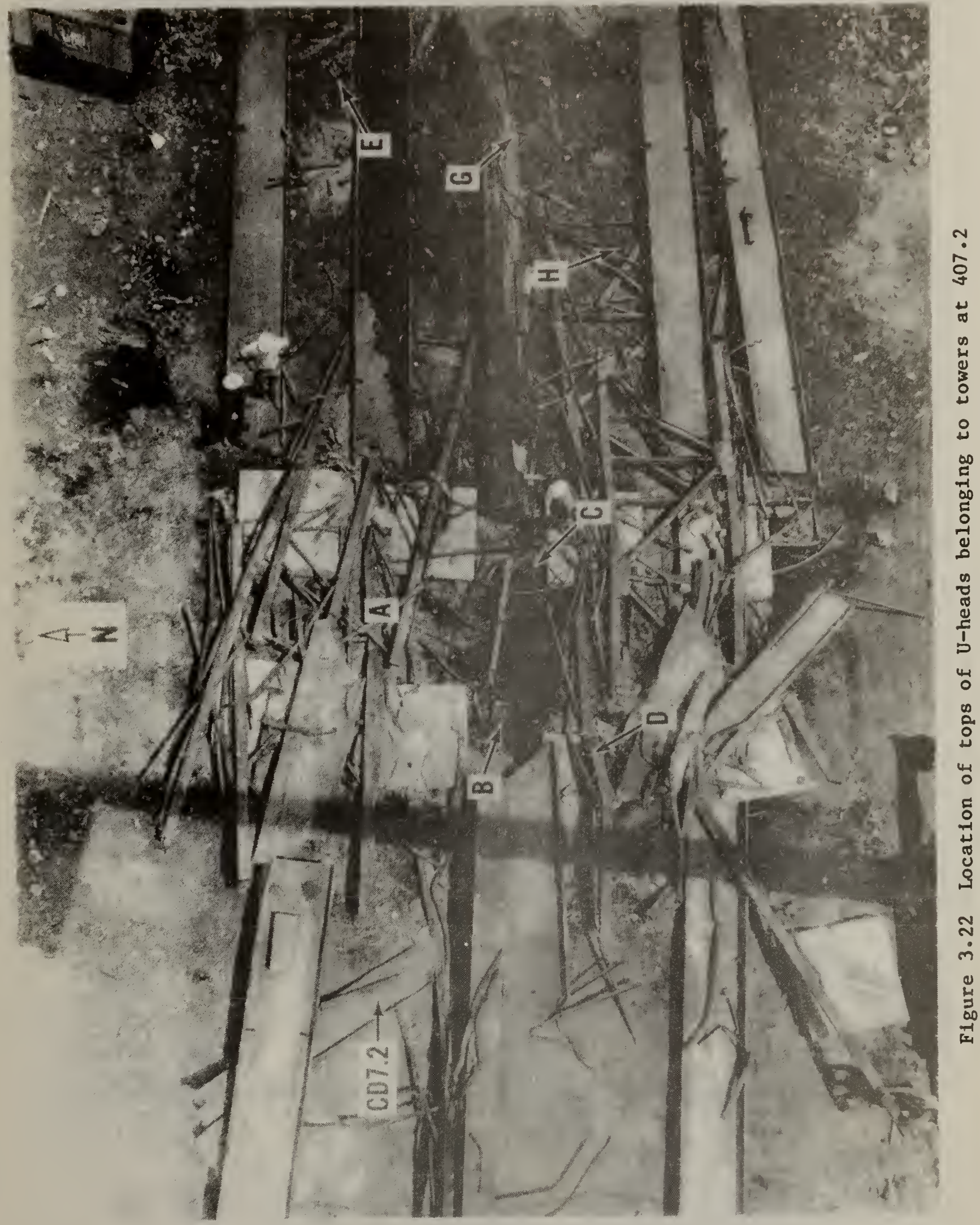




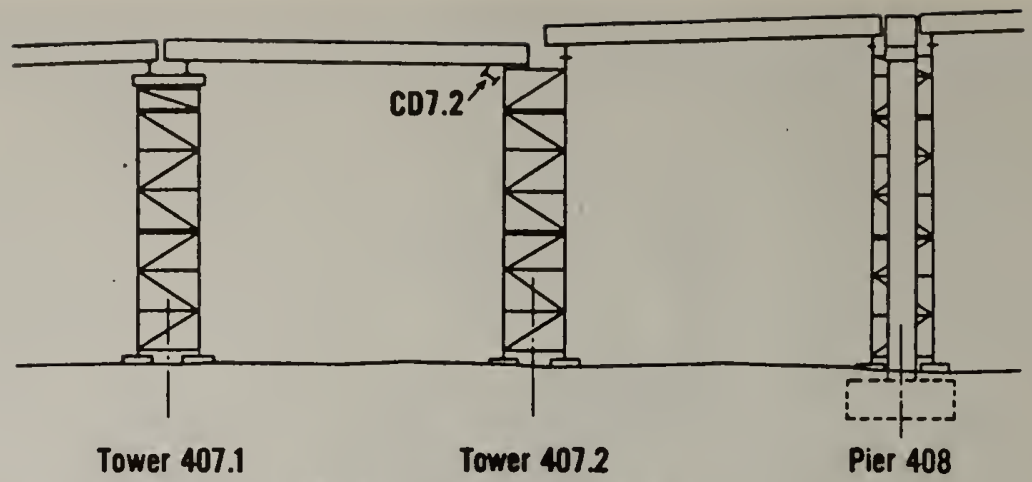

a. Cross-beam CD7.2 falls down, U-heads are broken off.

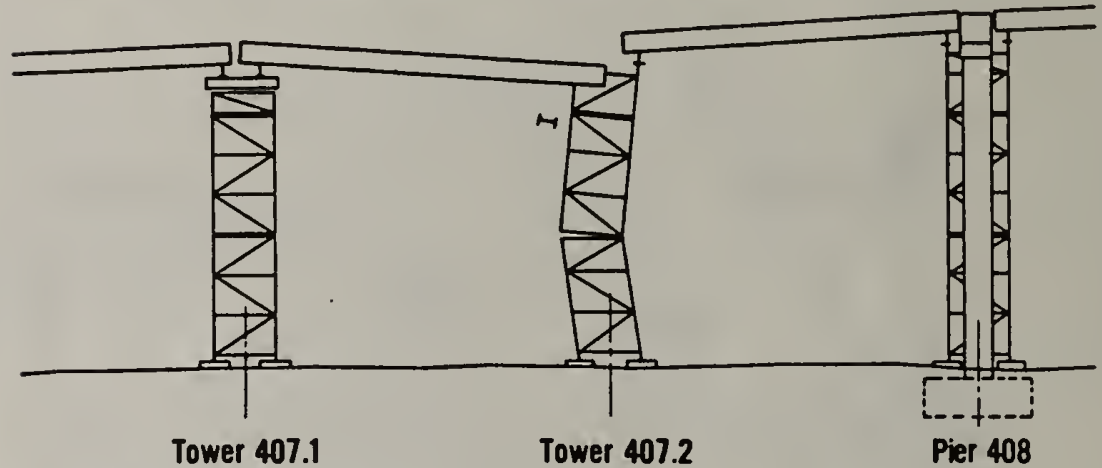

b. Tower starts to fold.

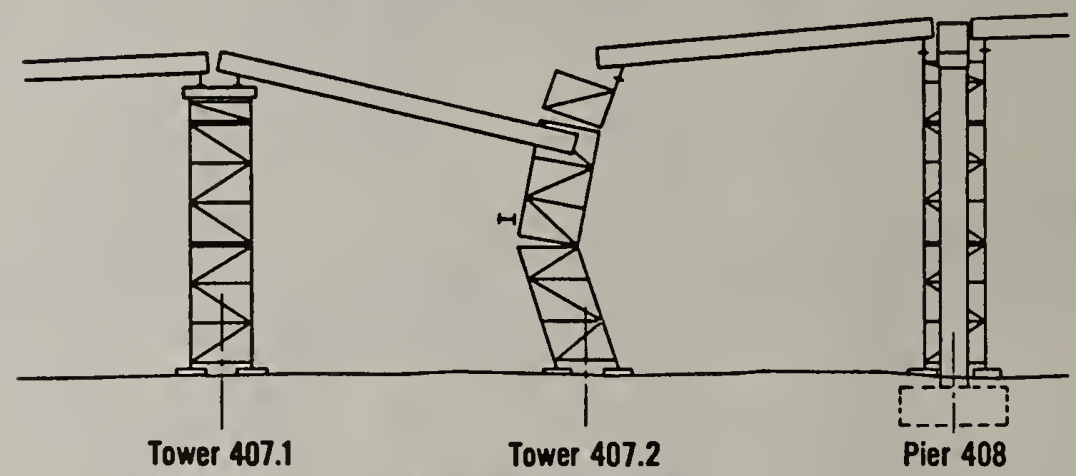

c. Top portion of north tower begins to separate

Figure 3.23 Posstble collapse sequence of falsework at 407.2 


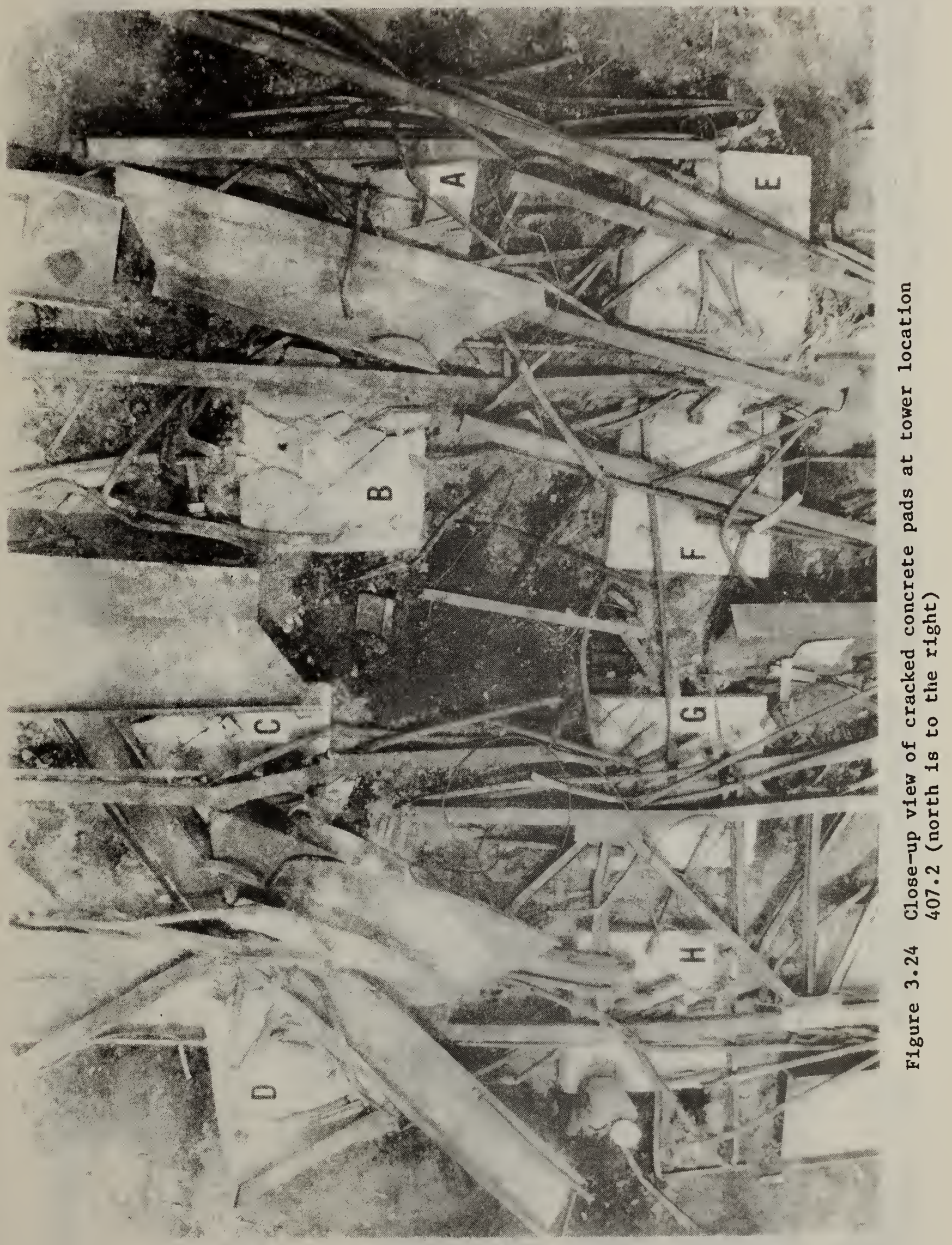




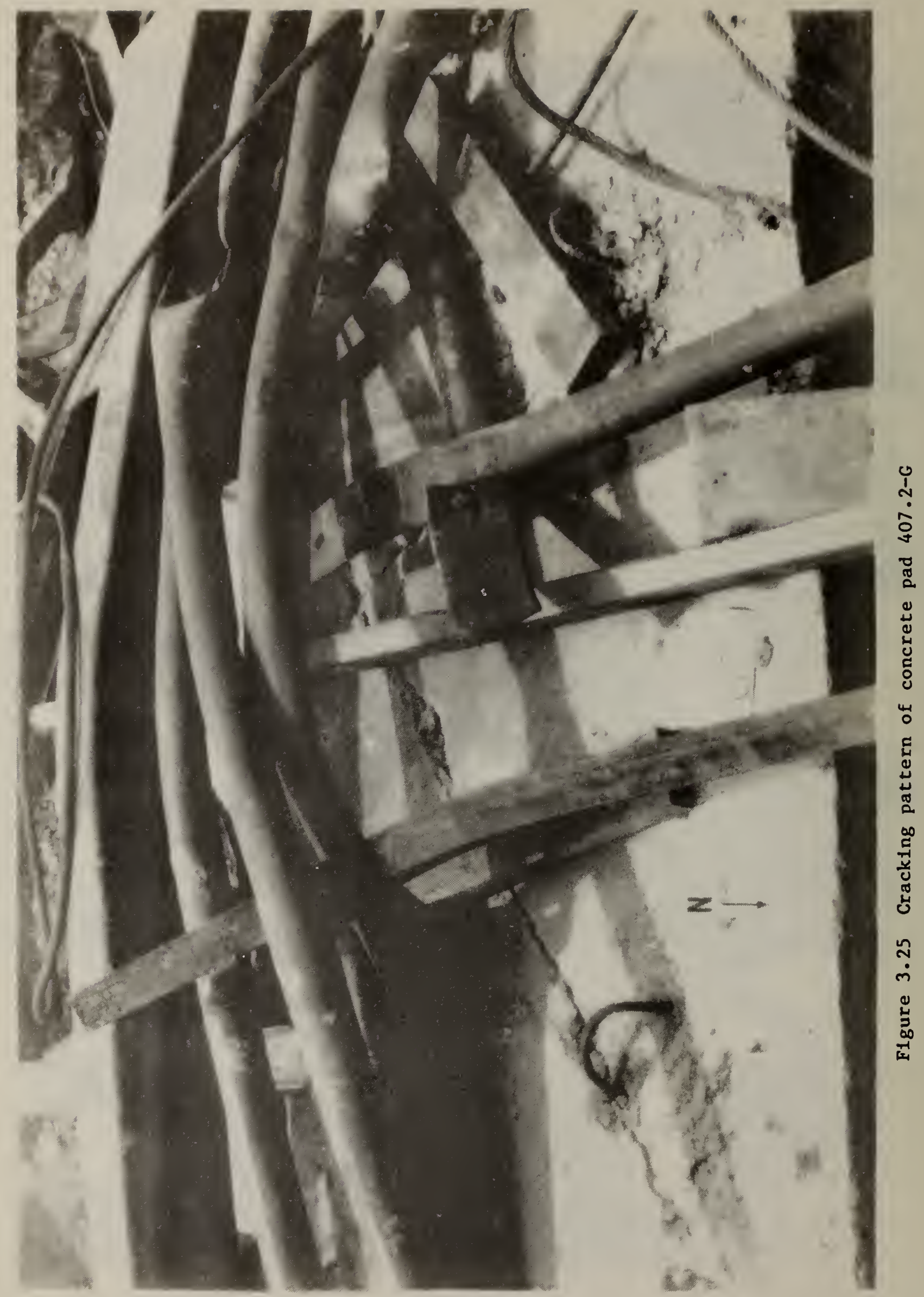




\section{EXPERIMENTAL INVESTIGATION}

\subsection{INTRODUCTION}

This chapter discusses the various laboratory and field tests conducted by NBS to establish the strength and deformation characteristics of key components of the falsework system. Such information is required in order to establish whether or not any of the components are possible candidates for the point of initial fallure which triggered the collapse of unit IV. In addition, certain information is needed for the structural analysis to be discussed in chapter 5 .

The materials tested were obtained from the construction site. However, because the falsework components for Unit IV were severely damaged during the collapse, tests were performed on materials similar to, but not necessarily identical to, those used in the falsework structure.

Section 4.2 reports the results of load tests on wood sand boxes in which different filler materials were used. Measurements were made to determine the extent of uplift and lateral spreading as the compressive load increased on a screw jack pad bearing on the filler in the box.

Section 4.3 discusses the results of tension tests on the screw jacks of unused U-heads obtained from the construction stockpile. After testing, the portion of each screw jack containing the welded joints was sectioned and subjected to metallographic examination. The purpose of the examination was to establish, in qualitative terms, the quality of the welds. The welded joints from four of the screw jacks recovered from the towers at 407.2 were also sectioned and examined. A comparison is made between the quality of the welds in the tested specimen and those recovered from the collapse debris.

Section 4.4 summarizes the results of tests on a falsework assembly that resembles, but does not duplicate, the configuration at the top of the towers at 407.2. These tests were designed to evaluate the behavior of the crossbeam$\mathrm{U}$-head assembly at the top of the towers when wedges were not inserted between the crossbeams and the inclined stringers.

Section 4.5 presents the results of compression and tension tests on tube members similar to the diagonal braces used in the towers at 407.2 .

Section 4.6 reports the results of three full-scale, load tests of concrete pads which were carried out at the construction site. The tests were performed in a cooperative effort among four groups of investigators of the collapse; NBS participated in the cooperative program. These tests were designed to obtain data on the settlement characteristics of the soll supporting the concrete pads, in addition, the tests furnished data on the breaking strength of the concrete pads.

Finally, section 4.7 summarizes the significant findings of the experimental investigations. Some of the test results are used as input data to the structural analysis discussed in chapter 5, and in chapter 6 some of the data are compared to the results of the structural analysis. 
As discussed in the previous chapter, there were indications that sand boxes caused some problems in the early stages of construction. For this reason, tests were conducted to evaluate the performance of wood sand boxes. Specifically it was desired to have information on the load versus deformation relations and on the fallure mechanisms.

Nine sand boxes were recovered from the site and shipped to NBS for testing. Some boxes had damaged or missing metal base plates. These boxes were repalred with aluminum sheet metal similar to that of the intact boxes. NBS obtained a sample of slag similar to that used to fill the boxes during construction. In addition, NBS obtained a sample of the boller slag, known as "black beauty," which was used as a levelling course beneath the concrete pads and as a fill around the piers.

The tests were performed using a bottom screw jack obtained from the site. Figure 4.1 shows an overall view of the test setup. The screw jack is attached to a short plece of the square tube of a shoring tower leg fastened to a universal testing machine. A sand box was placed on a concrete pedestal and the screw jack was pushed into the box. A.dial gage was used to measure the downward displacement of the crosshead of the testing machine, by which the load displacement relationships were obtained. In addition to measuring the vertical displacement, dial gages were also used to measure the upward lift of the corners of each box tested. Figure 4.2 is a closeup view to 1llustrate the dial gage arrangement. In some tests, two other gages were used to measure the lateral spreading of the boxes.

The following variables were considered: 1) type of filler; 2) degree of compaction prior to testing; and 3 ) the molsture content of the filler. The compaction procedure involved filling a box in three layers and hand-tamping each layer with a wood block. No attempt was made to carefully control the degree of compaction. The tests were performed without the wedging system employed during construction. A total of 10 sand boxes were tested, 1 and the conditions of each test are summarized in table 4.1. In some tests the load was sustained at a constant level in order to gain information on the effects of time on the deformation.

The results of the tests are summarized in terms of load-deformation curves. First, the tests using slag filler will be discussed. Figure 4.3 shows the relations between load and displacement of the testing machine crosshead. The data were plotted so that a load of $2 \mathrm{klps}(8.9 \mathrm{kN})$ corresponded to zero displacement. The times shown on the figures indicate the extents of the constant load periods. The four tests using the slag filler placed loosely in the boxes had consistent behavior. When the slag was compacted during filling of the boxes, the resulting head-displacement was about one-half of that with loose slag. The measured average uplift of the four corners of the boxes is shown in

1 One box was built in the laboratory and is 1dentified as "new". 
figure 4.4. The sand boxes with compacted slag displayed less uplift than the boxes with loose slag.

In all the tests, there were no cases in which an ultimate load was reached followed by increasing deformations with decreasing loads. Prior to testing, it was anticipated that some of the boxes would burst during loading due to the lateral pressure exerted by the slag filler. However, the tests revealed that the lateral pressures which developed were very small, especlally when loose slag was used. In fact, it was possible to remove the slag between the sides of the box and the pad of the screw jack without affecting the load carrying ability of the slag beneath the pad. This is 1llustrated in figure 4.5 which shows that after the slag was removed with a vacuum cleaner, a load of $160 \mathrm{kips}$ ( $712 \mathrm{kN}$ ) could still be maintalned by the pad (test 407-G). When compacted slag was used, higher lateral pressures developed because some of the slag between the sides of the box and the pad became densily compacted during the test so that it was not readily removed by the vacuum cleaner. This behavior is illustrated in figure 4.6 , which resulted when mo1st, precompacted slag was used (test 9.0 ).

Tests were also carried out with boller-slag filler and with ordinary, concrete-sand filler. The test results are summarized in figures 4.7 to 4.9 . The crosshead displacements, as shown in figure 4.7 , were greater than in the slag-filler tests. The shapes of the load-displacement curves in figure 4.7 appear to indicate a bearing fallure of the sand and the dry botler-slag. The measured uplifts, as shown in figure 4.8, were also greater than in the slag tests. Flgure 4.9 shows the uplift of the box which occurred during one of the tests with boiler-slag filler. However, even in these tests there were no "fallures" because the load versus crosshead displacement curves all had positive slopes (figure 4.7 ).

Figure 4.10 shows the lateral spreading of the boxes which was measured in some of the tests. Two dial gages on opposite sides of the box were used for this measurement (see figure 4.2). The largest spreading occurred in the test with compacted dry slag, which turned out to have the least value of uplift (figure 4.4). This inverse relation between uplift and lateral spreading is confirmed in the behavior of the sand and boller-slag tests, which displayed high uplift and low spreading.

Finally, figure 4.11 shows the results of the sustained load tests. The crosshead displacements are plotted as a function of the logarithm of time. The behavior was similar for all tests.

Based on the results of these tests, a clearer picture emerged of the mechanism by which load is transmitted from the screw jack base to the concrete pad. When loose-slag, boiler-slag, or concrete-sand is used, the load is transmitted straight down through the filler. In these cases there was significant uplift of the boxes and very little lateral spreading. With compacted slag, the load travelled downward and also laterally through the slag. This resulted in less uplift but more lateral spreading of the boxes. 
The test results indicate that significant lateral pressures do not develop as the leg load increases. Apparently, the sand boxes experlenced large uplift during construction as in the tests with concrete-sand filler, and this may have caused the contractor to take measures to prevent uplift. The lateral banding was probably just a precautlonary measure. As has been mentloned, slag was used in the boxes except for unft I where a sand simflar to the concrete sand was used.

Another significant finding of these tests is the variation in the magnitude of the settlement of the filler material. For the slag filler, the settlement was reduced by compacting the slag in the boxes before testing. The magnitude of the settlement at $80 \mathrm{klps}(356 \mathrm{kN})$ with compacted slag was about 0.5 in $(13 \mathrm{~mm})$. The compacted concrete-sand and boller-slag tests resulted in greater settlements than the compacted-slag tests by about 0.5 in (13 mm).

\subsection{EXAMINATION AND TESTS OF UPPER SCREW JACKS}

As discussed in subsection 3.2.6, all the U-heads of the towers at 407.2 separated at the welds of the screw jack (refer to figure 3.6). Visual exam1nation of the fallure surfaces at the site indicated that some of the welds might be of poor quality. Thus, some of the falled welds were subjected to metallographic examination. In addition, unused U-heads were obtalned from the contractor's supply yard and subjected to strength testing as well as metallographic examination.

The approach chosen for measuring the strength of the unused screw jack welds was to perform unlaxial tension tests. The top-plate was removed from the screwjacks and a testing $\mathrm{jlg}$ was bullt to enable tensile testing. Figure 4.12 shows the testing arrangement. A dial gage was attached to the threaded bar to measure deformation over a $10-1 \mathrm{n}(254 \mathrm{~mm})$ gage length. Three spectmens were tested, and the results are given in figure 4.13, in which load is plotted against nominal strain (dlal gage reading divided by the gage length).

Specimens $\# 3$ and $\# 5$ could not be tested to their ultimate capac1ty, because the $1-$ in $(25-\mathrm{mm})$ diameter bolts falled in shear at loads of 140 and $145 \mathrm{k} 1 \mathrm{ps}$ (623 and $645 \mathrm{kN})$, respectively. Specimen 非 falled at an ultimate load of $97 \mathrm{k1ps}$ $(432 \mathrm{kN})$. The low strength of specimen 非 18 attributed to a large defect in the weld between the "post" and the clrcular plate: about $1 / 2-1 \mathrm{n}$ (12-mm) of weld was missing.

After testing, the welded portions of the screw jacks were cut and prepared for subsequent metallographic examination. Figure 4.14 shows the portions of the screw jacks prior to sectioning. Note that specimens \#3 and 5 were sectioned along a diagonal of the post. After sectioning and polishing, the specimens were 1mmersed in an etching solution to bring out differences in the microstructural features of the metal. Figures $4.15,4.16$, and 4.17 show the appearance of the specimens under no magnification. The features to note in these photographs is the weld size and the appearance of the heat-affected-zone (dark area) in the base metal. The lack of a heat-affected-zone can be interpreted as a poor quality weld in which little or no fusion occurred between the weld metal and the base metal. 
Figure 4.15 is the appearance of the diagonally-cut cross section of specimen \#3. The weld between the threaded bar and the clrcular plate appears to be of good quality. On the other hand, the welds at the corners of the rectangular post are of poor quality. The same conclusion can be drawn for specimen 非 as shown in figure 4.16. Note that in both specimens, gaps exist between the c1rcular plate and the two other components. These gaps existed prior to testing, as they were visible in X-ray photographs taken before testing. Figure 4.17 is the cross-section of speclmen \#9 which falled by fracture of the weld between the post and the circular plate. The weld within the rectangle in figure 4.17 was examined at a 7.5 magniflcation and 18 shown In flgure 4.18. It appears that complete fusion did not occur at the weld between the threaded bar and the circular plate. The other welds that are shown in flgure 4.17 appear to be of good quality.

In order to relate the measured capacitles of the tested screw jacks to the capacities of the screw jacks that were in-place at 407.2 , metallographic examinations were performed on the recovered screw jacks. Figure 4.19 shows the portions of screw jacks A, B, C, and D prior to sectioning. The threaded bar for screw jack $A$ was not recovered and only the rectangular post could be examined. Note that specimen $D$ was quartered.

Figures $4.20,4.21$, and 4.22 show cross sections of screw jacks $B, C$, and $D$. The cross section of screw jack B (figure 4.20) does not display a well-defined heat-affected-zone in the threaded bar and this may explain why the separation occurred without no apparent fracturing of the weld metal. Figure 4.21 is a cross section of screw jack $C$. In thls case, fracture occurred in the weld between the post and the circular plate, which would indicate adequate fusion. However, the weld-throat th1ckness 18 less than 1/4-1n (6-mm). Both screw jacks $B$ and $C$ show evidence that the fracture began on the east side and that the post tops were bent toward the west. Figure 4.22 is quarter section of screw jack $D$, and it appears that there is no fusion of the weld metal to the threaded bar.

Based on the metallographic analyses, it is concluded that there is a difference between the weld quality of the examined screw jacks from 407.2 and the unused screw jacks tested in the laboratory. There are evidences that there was lack of fusion between the weld metal and the threaded bars of the screw facks from 407.2 , and this would account for the "clean" separation of some threaded bars from the remainder of the screw jacks. In some cases the size of the weld between the post and the circular plate was small and this may also help explain why some fallures occurred in the welds.

\subsection{FALSEWORK ASSEMBLY TESTS}

In subsection 3.2 .4 , the configuration of the top portions of the falsework system was described. It was pointed out that at locations such as 407.2, the U-heads are oriented so that they cannot freely pivot to accommodate the longitudinal roadway slope of 0.03569 . The structural plans specify the use of wedges between the crossbeams and the stringers (see figure 3.7) so that concentric loads would be applied to the U-heads. The fleld investigation revealed that wedges were not used and this raises the question of the consequences of 
their omission. Thus, tests were performed to determine experimentally the forces generated on a U-head under the condition of no wedges between crossbeams and stringers.

The test arrangement is illustrated in figure 4.23 . Figure 4.24 is a photograph of the actual laboratory setup. A single 3-ft 3-in (1-m) shoring frame was placed with one leg concentric with the loading head of a universal testing machine and with the other leg supported by the laboratory floor. The frame legs were supported by lower screw jacks. A U-head was placed at the top of the leg positioned in the testing machine. A 30-in (0.76-m) long section of a $W 24 \times 68$ beam was placed on the U-head. A short plece of a W24x92 beam was bolted to the top loading head of the testing machine, using wedges so that the bottom flange was inclined approximately at a slope of 0.036 . The testing machine is of the screw-type so that loading is achieved by moving the top cross-head downward at a constant displacement rate.

Instrumentation was provided to measure various forces and deformations. The total vertical load transmitted through the $U$-head was measured by the testing machine weighing table and by a load cell beneath the unloaded leg (see $\mathrm{fig}$. 4.23). The screw jack of the U-head was instrumented with three electrical resistance strain gages, spaced $120^{\circ}$ apart along the circunference of the threaded bar. These gages were used to compute the bending moment and axial force in the upper screw jack. Figure 4.25 is a closeup view of a U-head showing one of the strain gages along the circumference of the threaded bar. A pair of strain gages were also attached to frame braces in order to compute the forces in the braces. In addition, dial gages were used to measure the displacements of the crossbeam, the top-plate of the U-head and the frame leg. Some of these dial gage locations are shown in figure 4.26 .

The purpose of the tests was to gain information on the force-deformation characteristics of the assembly. It was not the intent to replicate the conditions in the actual structure, as this would have required a much larger and complex testing arrangement. The plane of the frame was placed perpendicular to the crossbeam, so that the force in the diagonal brace would correspond to the forces in the diagonal truss braces in the actual shoring towers.

Two tests were performed. In test $\# 1$, the diagonal brace was oriented opposite to the direction shown in figure 4.23. During the first test it was found that the forces which developed during the test tended to displace the loading-head of the testing machine because of its flexibility. Therefore, for test \#2, the loading-head was braced to increase its rigidity.

The two most significant results of the tests are the variation of the bending moment in the screw jack and of the forces in the braces as the vertical load was increased on the U-head. Figure 4.27 shows the variations of the bending moment magnitude and of the bending axis direction in the screw jack as the load was increased in test $\# 2$. The plotted load is the load measured by the testing machine. The direction and magnitude of the moment were calculated from the strain gage readings using the assumptions that plane sections remained plane and that the material was linear elastic with a modulus of $30 \times 10^{3} \mathrm{ks}$ $(206.9 \mathrm{GPa})$. The numbers 1,2 , and $3 \mathrm{in}$ the figure refer to the strain gages 
Figure 4.15 is the appearance of the diagonally-cut cross section of specimen \#3. The weld between the threaded bar and the circular plate appears to be of good quality. On the other hand, the welds at the corners of the rectangular post are of poor quality. The same conclusion can be drawn for specimen 5 as shown in figure 4.16. Note that in both specimens, gaps exist between the c1rcular plate and the two other components. These gaps existed prior to testing, as they were visible in X-ray photographs taken before testing. Figure 4.17 is the cross-section of specimen \#9 which falled by fracture of the weld between the post and the circular plate. The weld within the rectangle in figure 4.17 was examined at a 7.5 magnification and 18 shown in figure 4.18. It appears that complete fusion did not occur at the weld between the threaded bar and the circular plate. The other welds that are shown in figure 4.17 appear to be of good quality.

In order to relate the measured capacitles of the tested screw jacks to the capacities of the screw jacks that were 1n-place at 407.2, metallographic examinations were performed on the recovered screw jacks. Figure 4.19 shows the portions of screw jacks A, B, C, and D prior to sectioning. The threaded bar for screw jack $A$ was not recovered and only the rectangular post could be examined. Note that specimen $D$ was quartered.

Figures $4.20,4.21$, and 4.22 show cross sections of screw jacks B, C, and D. The cross section of screw jack B (figure 4.20) does not display a well-defined heat-affected-zone in the threaded bar and this may explain why the separation occurred without no apparent fracturing of the weld metal. Figure 4.21 is a cross section of screw jack $C$. In this case, fracture occurred in the weld between the post and the circular plate, which would indicate adequate fusion. However, the weld-throat thickness is less than 1/4-in (6-mm). Both screw jacks $B$ and $C$ show evidence that the fracture began on the east side and that the post tops were bent toward the west. Figure 4.22 is quarter section of screw jack $D$, and it appears that there is no fusion of the weld metal to the threaded bar.

Based on the metallographic analyses, it is concluded that there is a difference between the weld quality of the examined screw jacks from 407.2 and the unused screw jacks tested in the laboratory. There are evidences that there was lack of fusion between the weld metal and the threaded bars of the screw jacks from 407.2 , and this would account for the "clean" separation of some threaded bars from the remainder of the screw jacks. In some cases the size of the weld between the post and the clrcular plate was small and this may also help explain why some fallures occurred in the welds.

\subsection{FALSEWORK ASSEMBLY TESTS}

In subsection 3.2.4, the configuration of the top portions of the falsework system was described. It was pointed out that at locations such as 407.2 , the U-heads are oriented so that they cannot freely pivot to accommodate the longitudinal roadway slope of 0.03569 . The structural plans specify the use of wedges between the crossbeams and the stringers (see figure 3.7 ) so that concentric loads would be applied to the U-heads. The fleld investigation revealed that wedges were not used and this ralses the question of the consequences of 
their omission. Thus, tests were performed to determine experimentally the forces generated on a U-head under the condition of no wedges between crossbeams and stringers.

The test arrangement is 11lustrated in figure 4.23. Figure 4.24 is a photograph of the actual laboratory setup. A single 3-ft 3-in (1-m) shoring frame was placed with one leg concentric with the loading head of a universal testing machine and with the other leg supported by the laboratory floor. The frame legs were supported by lower screw jacks. A U-head was placed at the top of the leg positioned in the testing machine. A 30-in (0.76-m) long section of a W24x68 beam was placed on the U-head. A short plece of a $W 24 \times 92$ beam was bolted to the top loading head of the testing machine, using wedges so that the bottom flange was inclined approximately at a slope of 0.036 . The testing machine is of the screw-type so that loading is achieved by moving the top cross-head downward at a constant displacement rate.

Instrumentation was provided to measure various forces and deformations. The total vertical load transmitted through the $U$-head was measured by the testing machine weighing table and by a load cell beneath the unloaded leg (see fig. 4.23). The screw jack of the U-head was instrumented with three electrical resistance strain gages, spaced $120^{\circ}$ apart along the circumference of the threaded bar. These gages were used to compute the bending moment and axial force in the upper screw jack. Figure 4.25 is a closeup view of a U-head showing one of the strain gages along the circumference of the threaded bar. A pair of strain gages were also attached to frame braces in order to compute the forces in the braces. In addition, dial gages were used to measure the displacements of the crossbeam, the top-plate of the U-head and the frame leg. Some of these dial gage locations are shown in figure 4.26 .

The purpose of the tests was to gain information on the force-deformation characteristics of the assembly. It was not the intent to replicate the conditions in the actual structure, as this would have required a much larger and complex testing arrangement. The plane of the frame was placed perpendicular to the crossbeam, so that the force in the diagonal brace would correspond to the forces in the diagonal truss braces in the actual shoring towers.

Two tests were performed. In test $\|_{1}$, the diagonal brace was oriented opposite to the direction shown in figure 4.23. During the first test it was found that the forces which developed during the test tended to displace the loading-head of the testing machine because of its flexibility. Therefore, for test 非, the loading-head was braced to increase its rigidity.

The two most significant results of the tests are the variation of the bending moment in the screw jack and of the forces in the braces as the vertical load was increased on the U-head. Figure 4.27 shows the variations of the bending moment magnitude and of the bending axis direction in the screw jack as the load was increased in test $\# 2$. The plotted load is the load measured by the testing machine. The direction and magnitude of the moment were calculated from the strain gage readings using the assumptions that plane sections remained plane and that the material was linear elastic with a modulus of $30 \times 10^{3} \mathrm{ksi}$ $(206.9 \mathrm{GPa})$. The numbers 1,2 , and $3 \mathrm{in}$ the figure refer to the strain gages 
on the perimeter of the threaded bar, and the north direction corresponds to that in the actual ramp structure. Also shown in figure 4.27 is the line which indicates the ratio of axial load to bending moment which produces a zero stress at a point on the perimeter of the threaded bar. Combinations of axial force and bending moment below this line would produce tensile stresses In the threaded bar. Two important observations are noted. First of all, at the start of the test, tensile stresses exist in the threaded bar, but they disappear at higher loads. Second, the direction of the bending moment changes throughout the test. The maximum load was $135 \mathrm{kips}(600 \mathrm{kN})$ in test which point, the crossbeam started to undergo inelastic bending in the web, as evidenced by the flaking of whitewash applied to the crossbeam surfaces. Beyond the maximum vertical load, high tensile strains were recorded on one side of the threaded bar, but because the bar was undergoing compressive yielding on the opposite side it was not possible to readily compute the bending moment. Therefore, figure 4.27 does not show the descending branch which existed.

The other major finding of the test is the variation of the forces in the braces of the frame. Figure 4.28 shows the computed forces in the horizontal and diagonal braces of test $\$ 2$ as a function of the load measured by the testing machine. These forces were calculated from strain gage readings assuming a $2 \times 2 \times 0.11-$ in $(50.8 \times 50.8 \times 2.8-\mathrm{mm})$ tube cross section and an elastic modulus of $30 \times 10^{3} \mathrm{ksi}(206.9 \mathrm{GPa})$. Also shown is the force recorded by the load cell beneath the other frame leg. The force in the diagonal brace is tensile, and all other forces are compressive. This figure shows that the absence of wedges between the crossbeam and stringers not only introduces bending into the screw jack, but it also introduces a lateral force to the $\mathrm{U}$-head which must be resisted by the braces. Note that the brace forces vary linearly with the applied vertical load before the maximum load is reached, and that they increase rapidly near the maximum load.

Further insight into the cause of the above behavior may be gained by considering the deflected shape of the crossbeam-U-head assembly, which is shown schematically in figure 4.29. The top flange of the crossbeam rotates and makes full contact with the inclined stringer. Because of the compatability of deformation between the $U$-head and the lower flange of the crossbeam, a horizontal force and bending moment is imparted to the U-head. Forces are set up in the braces of the frame to resist the horizontal force and bending moment. If the braces are pin-connected to the legs, as they would be in the shoring towers, the diagonal brace becomes a critical member. If the diagonal reaches its ultimate capacity, the top of the frame leg would rotate toward the east (for the actual ramp orfentation), and the crossbeam would tip over.

Figure 4.30 and 4.31 show the bending moment and brace-force variation for test \#1. In this case, the frame diagonal was oriented so that it developed a compressive load. The ultimate load was $120 \mathrm{kips}(534 \mathrm{kN}$ ) and fallure was also by bending in the web of the crossbeam. Comparing figure 4.30 with 4.27 , one sees a similar pattern of behavior. The primary difference is the direction of the bending axis. It is belleved that this is a result of a difference in the contact-point location, through which the load is transferred from the topplate to the post of the screw jack. Imperfections in the circular bearing 
surfaces of these two components would affect the actual point of force transfer. Comparing figure 4.31 with 4.28 reveals that the variation of forces in the diagnonal braces follows a simflar pattern independent of the brace orfentation. The force in the horizontal brace was not monitored in the first test.

In summary, these tests have highlighted the behavior when wedges are not used between the crossbeam and the inclined stringers. A significant horizontal force is imparted to the U-head, which in the actual structure would tend to rotate the frame leg toward the east. Stability of the frame leg is provided by the diagonal braces. In addition, a bending moment is imparted to the Uhead. The horlzontal force and bending moment will also introduce additional compressive load into the opposite frame leg.

\subsection{DIAGONAL BRACE TESTS}

The diagonal braces which join together the prefabricated frames are critical structural elements in determining the ability of the shoring towers to accommodate any differential settlements of the legs and to accommodate the horizontal forces discussed in the previous section. No data were avallable for the strength of the dlagonals used in the towers. Thus, tests were performed by NBS on six braces obtained from the site. The braces all had welded external couplers which joined two tube sections to form the completed brace. This type of dlagonal brace was observed to have been used at 407.2 and elsewhere in the structure. Three braces were tested in compression and three in tension.

F1gure 4.32 shows the testing arrangement for the compression tests. The braces were attached to small pieces of frame legs using $3 / 4-1 \mathrm{n}(19-\mathrm{mm})$ diameter bolts which were also obtalned from the site. The frame legs were positioned concentrically in the universal testing machine and loaded to the ultimate capacity of the braces. After testing, two coupons were cut from each brace, one from each half of the brace, and the wall thicknesses were measured.

Table 4.2 summarizes the results of the tests. Braces 1 1 and 12 buckled out of plane, while brace 非 3 buckled in the plane of the brace. The different buckling mode and lower capacity for brace $\|_{3}$ is attributed to a corroded zone near the coupler as shown in figure 4.33. Apparently there was enough local reduction of the cross section due to rusting to significantly reduce the buckling strength.

The arrangement for the tension tests is shown in figure 4.34. Short sections of frame legs were utilized as spacers so that the same type of bolts could be used as were used in the compression tests. Braces $\$$ 非 and 5 falled by bearing fallure and tearing out at one end, as shown in figure 4.35. In the test of brace 非, fallure occurred as a shear fallure in the threaded section of the bolt. This test was repeated two additional times and shear fallure of the bolt occurred in all cases. After testing, coupons were cut from the braces for thlckness measurements.

Table 4.2 also summarizes the dimensions of the tested braces. It is seen that

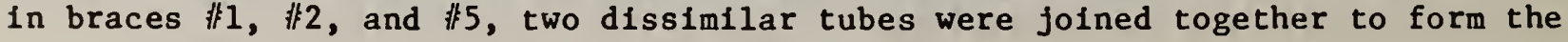


complete brace. In brace \#6, both halves were tubes with large wall thickness and this accounts for the bolt-shear fallure when this brace was tested. The manufacturer's specifications indicate that the $2-1 / 2-1 \mathrm{n}(63.5-\mathrm{mm})$ diameter braces should have a wall thickness of 0.095 in $(2.4 \mathrm{~mm})$.

\subsection{FIELD LOAD TESTS OF CONCRETE PADS}

The most direct method to evaluate the settlement characteristics of the foundation supporting the tower legs and to determine the breaking strength of the concrete pads is to conduct full-scale load tests at the site. Four load tests were performed from August 30 to September 17, 1982. The tests were designed and carried out in a cooperative effort among four groups of invest1gators including NBS. Locations of the load tests are given in figure 4.36 . Test 1 was a four pad test located at the north tower at 407.2 , and the four pads were positioned at the original locations of the north tower supports. Test 1 evaluated the load-displacement characteristics of a previously loaded subgrade. Test 2 was also a four-pad test located at the north side of the ramp midway between tower locations 407.2 and 408 . Test 2 evaluated the loaddisplacement characteristics of the subgrade in a relatively undisturbed area. Test 3 was another four-pad test located at the north side of pler 408 and the pads were also positioned at the original support locations on the boller-slag f111. Test 4 was a single-pad test located in line with the northernmost concrete pads and at the centerline of pler 408. All concrete pads used for the tests were obtained from the tower locations east of pler 408 .

The general load test layout is shown in figure 4.37. Figure 4.38 provides an overall view (from west to east) of the load test at the site. Approximately 800 kips ( $3.56 \mathrm{MN}$ ) of steel plates were placed above the W36 x 194 steel beams as counter weights for loading. The loading assembly for each concrete pad is shown in figure 4.39. Slag in its natural molsture condition was placed in each sand box in three layers, which were hand compacted using the $10 \times 10-$ in $(250 \times 250-\mathrm{mm})$ plate of the screw jack. A hydraulic ram of $220 \mathrm{klps}(980 \mathrm{kN})$ capacity was provided for loading each pad. A $200 \mathrm{kip}$ (890-kN) capacity load cell was positioned between each ram and the steel beams. Figure 4.40 provides a closeup view of the loading assembly. The hydraulic line from each ram was connected to a manifold so that all four pads could be loaded simultaneously. Figure 4.39 illustrates the positions of the dial gages used for the displacement measurement of each pad. The corner dials (dials \#1 through \#4) were located approximately 6 in $(150 \mathrm{~mm})$ from the pad edges and dials 非 through 非 were located near the corners of the sand box. Dial \#9 was placed on top of the steel plate of the screw jack, and was used to measure the total settlement of the subsoll below the pad plus that of the slag in the sand box.

The original test procedures called for two loading cycles for each test location: 1) loading to $80 \mathrm{kips}(356 \mathrm{kN}$ ) and unloading (cycle 1); 2) reloading to $160 \mathrm{kips}(712 \mathrm{kN}$ ) and unloading (cycle 2). However, due to pad cracking prior to $160 \mathrm{kips}(712 \mathrm{kN}$ ) the original plan was not carried out. In load cycle 1 , all pads were loaded simultaneously in increments of $8.5 \mathrm{kips}$ ( 37.8 $\mathrm{kN}$ ) up to a maximum load of about $85 \mathrm{kips}(378 \mathrm{kN})$ per pad. At each increment, the load was held constant for a period of 15 to 30 minutes and the dial readings were monitored to observe the rate of settlement. A settlement rate 
of $0.01 \mathrm{in}(0.25 \mathrm{~mm})$ per hour was set as the criterion to declde whether the holding period should be extended prior to increasing the load. Once the nominal 85-kip ( $378 \mathrm{kN}$ ) load was reached, the load was maintained for 12 to 13 hours, and the settlement readings were taken hourly after the first hour to evaluate the time-settlement characteristics of the subsoil. The unloading cycle was accomplished in three steps with a 28.3-kip (126 kN) reduction in load in each step. Load cycle 2 was conducted in a manner simflar to load cycle 1 with the exception that (1) a settlement rate criterion of 0.02 in $(0.51 \mathrm{~mm})$ per hour was used and (2) the load 1ncrement was $17 \mathrm{klps}$ (76 kN).

Table 4.3 presents the measured average pad settlement for all the pads during load cycle 1. Except for pad 1 of Test 1, which cracked 73 minutes after the start of the holding perfod, the settlement data used in the tabulation were taken at the end of the holding period. Pad 2 of Test 3 cracked at a load of $77 \mathrm{klps}(343 \mathrm{kN})$. During testing, the response of the load cell at pad 4 was used to monitor the load at each increment. The actual load on each pad varied slightly as indicated in Table 4.3. The measured settlements were thus corrected for the load differences by using a linear load-displacement relationship as indicated by the load-displacement plots which will be presented later in this section.

Several observations can be made from table 4.3. Under a load of $85 \mathrm{kips}$ $(378 \mathrm{kN})$, the settlement of the soll under the pad is expected to be less than $0.3 \mathrm{in}(8 \mathrm{~mm})$. The settlements of the soll during loading in Test 1 were smaller than those in Test 2; however, the difference is less than 0.1 in $(2.5 \mathrm{~mm})$. The results also indicated that the pads within each test settled rather uniformly, and the maximum differences in settlement among pads were $0.061 \mathrm{in}(1.6 \mathrm{~mm})$ for Test 1 and $0.050 \mathrm{in}(1.3 \mathrm{~mm})$ for Test 2. The pads on boller slag at 408 settled much less uniformly with settlements varying from about 0.2 to $0.5 \mathrm{in}(5$ to $13 \mathrm{~mm}$ ) to yleld a maximum differential settlement among pads of about $0.3 \mathrm{in}(7 \mathrm{~mm})$. Dial $\$ 9$ measured the total settlement of the screw jack which includes the settlement of the slag placed in the sand box plus that of the soll. The net settlement of the slag in the sand box was obtained by subtracting the average readings of dials \#1 through \#8 from the dial 非 readings. As shown in table 4.3, the settlement of the slag varied from about 0.4 to 0.7 in ( 10 to $18 \mathrm{~mm}$ ). The average slag settlement is remarkably close to the values obtalned from the laboratory sand box tests as shown in figure 4.3. The table also indicates that the maximum difference in total screw jack settlements among four pads for all load tests conducted did not exceed 0.3 in $(7 \mathrm{~mm})$.

Al1 pads cracked during load testing and the breaking strength of the pads varled from $77 \mathrm{kips}(343 \mathrm{kN})$ to $178 \mathrm{kips}(792 \mathrm{kN})$, as shown in table 4.4 . Table 4.4 also indicates the load magnitude after each pad cracked and the magnitude of screw jack settlement caused by cracking. Generally, two types of crack pattern were observed. The first type is a diagonal crack as shown in figure 4.41, and the second is a transverse crack along either direction across the pad as shown in figure 4.42. For most of the pads, two cracks were formed. The observed crack patterns are indicated in table 4.4 . 
Three concrete cores were taken from each pad used in Tests 1 and 2 and were sent to NBS for compression testing. Table 4.5 gives the results of the core tests. It is seen that the pad thicknesses, as Indicated by the "as-recelved" core lengths, and the core compresslve strengths varled among the pads. These two variables must be taken into account when interpreting the fallure loads shown in table 4.4. For comparison purposes, two cores were taken from each of the concrete pads which orfginally supported the shoring towers at 407.2. Table 4.6 presents the dimensions and strengths of these cores. Note the varlations in as-recelved core lengths and compressive strengths.

Load-displacement curves for the first pad to crack during each test are given in figures 4.43 through 4.45 , for Tests 1, 2, and 3, respectively. The data presented in these figures were the readings recorded at dial 非, which measured the total settlement of the subsoll and the compacted slag in the sand

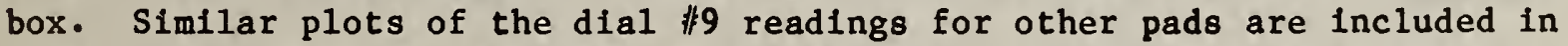
Appendix A. The circles are the data for load cycle 1 and the squares are for load cycle 2 .

Common features which can be observed from Tests 1 and 2 are summarized as follows: for practical purposes the loading portion of load cycle 1 can be approximated as a straight line in the load range from 30 to $85 \mathrm{kips}$ (134 to $378 \mathrm{kN}$ ). The loading curves of cycle 1 from Test 1 , conducted in the area which had been precompacted during construction, indicated about 30 percent greater stiffness than from Test 2 which was conducted in an area of less previous compaction. Another common observation is that the pads could take additional load even after they had cracked. This, however, was not the case for pad 2 of Test 3, whose load-displacement curve is given in figure 4.45. In this case, and also for the other pads in Test 3, the pad could not support additional load once it had cracked. This is attributed to bearing failure of the shallow boiler slag layer underneath the pad. The boller-slag would simply be pushed away by the cracked pad when the load was being re-applied and the pad continued to sink into the boller slag. The loading portion of load cycle 1 for pad 2 of Test 3 also indicated an approximately linear relationship between the load and displacment; however the foundation was more compressible than observed in Test 2 .

Foundation stiffness values obtalned from the linear portions of the load-displacement curves for the loading portion of load cycle 1 are also summarized in table 4.4. It can be seen that the values from Test 1 varied in a narrow range from 140 to $154 \mathrm{kips} / \mathrm{ln}$ ( 25 to $27 \mathrm{kN} / \mathrm{mm}$ ). The stiffness values of Test 2 were found to be in an even narrower range from 112 to $119 \mathrm{klps} / \mathrm{in}$ ( 20 to $21 \mathrm{kN} / \mathrm{mm}$ ), or about 78 percent of the stiffnesses from Test 1 . The stiffnesses from Test 3 were lower than those obtained from Test 2 indicating that the boiler-slag fill is more compressible than the surrounding soil.

Table 4.4 also gives the duration of the constant load period when the pad cracked. Most pads cracked less than 10 minutes into the holding period. Three of the pads had a sudden failure as the load was being increased, and one pad (pad 1 of Test 2) cracked after the load had been maintained for more than one hour. Two factors are offered in an attempt to explain this delayed failure. Figure 4.46 shows the time-settlement curve obtained from pad 1 in Load 
Test 2. This curve shows that the settlement experienced by the screw jack did not occur instantaneously. The time-dependent component of the settlement 18 a function of load level and the foundation materials. In addition, there may be a difference between the settlement around the peripheral area of the pad and the central portion of the pad. Table 4.7 summarizes the accumulated settlements during the first 60 minutes while the pads were loaded to the values given in table 4.3. Column 3 of the table shows the average values of dials \#1 through \#4, and column 4 shows the averages for dials \#5 through \#8. Although in most cases the difference 18 small, the trend consistently indicates that the inner portion of the pad experienced a higher settlement than the outer portion. These two observations may be interpreted to mean that the soll pressure distribution changes with time causing the central part of the pad to settle more than the perimeter. This would in turn increase the flexural tensile stresses in the bottom of the pad, and could result in delayed cracking of the pad.

The results from the single pad test of Test 4 are not used in the analysis since the load-displacement curve in load cycle 1 indicated a rather high stiffness value at $119 \mathrm{kips} / \mathrm{in}(21 \mathrm{kN} / \mathrm{mm})$. This outcome is attributed to compaction of the underlying boller slag by the overlapping stress fields developed during the loading of the adjacent pads: once during construction and twice during loading cycles 1 and 2 of Test 3 .

In summary, the full-scale load tests of the four-pad groups indicate a low value for the maximum differential settlement of the screw jack plates. Most of the observed differences can be attributed to differences in the settlement of the slag filler in the sand boxes, rather than to differences in settlement of the underlying soil. In addition, about two-thirds of the screw jack settlements can be attributed to the settlement of the slag in the sand boxes. There were significant differences among the foundation stiffnesses at the three test locations. As expected, Test 1 (preloaded location) resulted in greater foundation stiffness than Test 2 (location without preload), because of the higher degree of precompaction at 407.2. For the purpose of subsequent structural analyses, the average of the results from Test 2 are used to represent the foundation stiffnesses for the shoring towers originally at 407.1 and 407.2 , that is, a value of $115 \mathrm{kips} / \mathrm{ln}(20 \mathrm{kN} / \mathrm{mm})$ is used. For the towers resting on boller-slag fill at pler 408 , a foundation stiffness of $95 \mathrm{kips} / 1 \mathrm{n}$ $(17 \mathrm{kN} / \mathrm{mm})$ is used. This value is the average of the two lower values from Test 3. The reason for using this lower value, rather than the measured average foundation stiffness at 408 of $105 \mathrm{kips} / \mathrm{in}(19 \mathrm{kN} / \mathrm{mm})$, is because the average value is for precompacted boller-slag fill. During the original loading of the towers, the foundation stiffness at 408 would have been lower than the Test 3 results. It is not justified to lower the average foundation stiffness from Test 3 by the ratio of the average stiffness of Test 1 to the average stiffness of Test 2 because of the different subsurface condition at 408 . For the structural analysis, it is is felt that using a value of $95 \mathrm{kips} / \mathrm{in}$ $(17 \mathrm{kN} / \mathrm{mm})$, rather than some lower value, for the stiffness at 408 would underestimate the load effects at 407.2 , and this is a conservative approach as far as the fallure analysis is concerned. 


\subsection{SUMMARY}

Based on the results of the experimental investigation, the following major conclustons are drawn concerning the performance of various components of the falsework system.

1. None of the tested sand boxes experienced fallure by attaining an ultimate load capacity. Some boxes were tested to a load of $160 \mathrm{kips}(712 \mathrm{kN})$. The load-settlement behavior of the filler was affected by the degree of precompaction prior to testing. Lateral pressures on the sides of the box were greatest with compacted slag-filier, but were not enough to cause lateral bursting of the boxes. Uplift was greatest when boller-slag and concrete-sand were used as fillers. With compacted slag filler the vertical settlement at $80 \mathrm{kips}(356 \mathrm{kN})$ was about $0.5 \mathrm{in}(13 \mathrm{~mm})$.

2. Metallographic examination of screw jack welds from U-heads recovered from 407.2 indicated lack of fusion in some of the welds. The unused screw jacks tested in the laboratory had better weld quality, but they still had welding defects.

3. Tests of a falsework assembly, modelling the interaction between crossbeam and $U$-head when wedges were not used, revealed that a horizontal force and a bending moment were introduced into the U-heads.

4. Compression tests of three diagonal tube braces resulted in an average buckling load of $6.3 \mathrm{kips}(28 \mathrm{kN})$. In the tension tests two braces experienced bearing fallure and subsequent tearing out at the bolted connection. The average fallure load for the two braces was $12.8 \mathrm{kips}$ $(57.0 \mathrm{kN})$. A third brace tested in tension resulted in shear failure of the bolt. The average failure load for three bolts was $17.8 \mathrm{kips}$ $(79.2 \mathrm{kN})$. The wall thickness of the tubes, joined to form the complete braces, varied considerably, but it was not lower than specified in the manufacturer's specifications.

5. The compressive strength of cores taken from the concrete pads at 407.2 were variable from pad to pad, and in some cases were variable from bottom to top within a single pad. The pad thicknesses, as measured by the core lengths, were also varlable. Pad E had the lowest thickness, 11-1/2-in $(292-\mathrm{mm})$; and pad $\mathrm{C}$ had the largest thickness, 13-1/2 in (343 $\mathrm{mm}$ ).

6. The results of the full-scale field tests of concrete pads revealed insignificant differential settlements among the screw jacks in each fourpad group. The major cause of the screw jack settlement was the settlement of the slag in the sand boxes rather than subsoil settlement. A significant difference was noted between the foundation stiffness of the boiler-slag fill around pier 408 and that of the surrounding soil.

7. The breaking strengths of the concrete pads varied from 77 to $178 \mathrm{kips}$ ( 343 to $792 \mathrm{kN}$ ), and some of this variation can be attributed to differences in pad thickness and concrete strength. A majority of the pads cracked while the load was being held constant and it is suggested that 
the delayed failure 18 due to a time-dependent redistribution of the underlying soil pressures.

90 
Table 4.1. Summary of Sand Box Tests

\begin{tabular}{|c|c|c|c|c|c|}
\hline I.D. & Filler & $\begin{array}{l}\text { Molsture } \\
\text { Condition } \\
\end{array}$ & Compaction & $\begin{array}{l}\text { Bottom } \\
\text { Plate } \\
\end{array}$ & $\begin{array}{l}\text { Sustalned } \\
\text { Loading }\end{array}$ \\
\hline New & Slag & Moist & Loose & New Box & No \\
\hline $407-G$ & Slag & Mo1st & Loose & Original & No \\
\hline $407-F$ & slag & Moist & Loose & Original & $2.5 \mathrm{hr} @ 160 \mathrm{k}$ \\
\hline 8.1 .1 & Slag & Moist & Loose & Original & $7.5 \mathrm{hr} @ 80 \mathrm{k}$ \\
\hline 9.0 & Slag & $\begin{array}{l}\text { Moist } \\
(5 \%)\end{array}$ & Hand Tamping & Original & $\begin{array}{l}18.5 \mathrm{hr} @ 40 \mathrm{k}, \\
8.5 \mathrm{~h} @ 80 \mathrm{k}\end{array}$ \\
\hline 8.1 .2 & Slag & Dry & Hand Tamping & Original & $\begin{array}{l}2.25 \mathrm{hr} @ 40 \mathrm{k}, \\
23.3 \mathrm{hr} @ 80 \mathrm{k}\end{array}$ \\
\hline $407-\mathrm{H}$ & $\begin{array}{l}\text { Boiler } \\
\text { Slag }\end{array}$ & Dry & Hand Tamping & New & $1.5 \mathrm{hr} @ 40 \mathrm{k}$ \\
\hline 407-E & $\begin{array}{l}\text { Boiler } \\
\text { Slag }\end{array}$ & $\begin{array}{l}\text { Moist } \\
(8 \%)\end{array}$ & Hand Tamping & New & $1 \mathrm{hr} C 40 \mathrm{k}$ \\
\hline 408-E & $\begin{array}{l}\text { Concrete } \\
\text { Sand }\end{array}$ & Dry & Hand Tamping & New & No \\
\hline 9.1 & $\begin{array}{l}\text { Concrete } \\
\text { Sand }\end{array}$ & $\begin{array}{l}\text { Mo1st } \\
(5 \%)\end{array}$ & Hand Tamping & Original & No \\
\hline
\end{tabular}




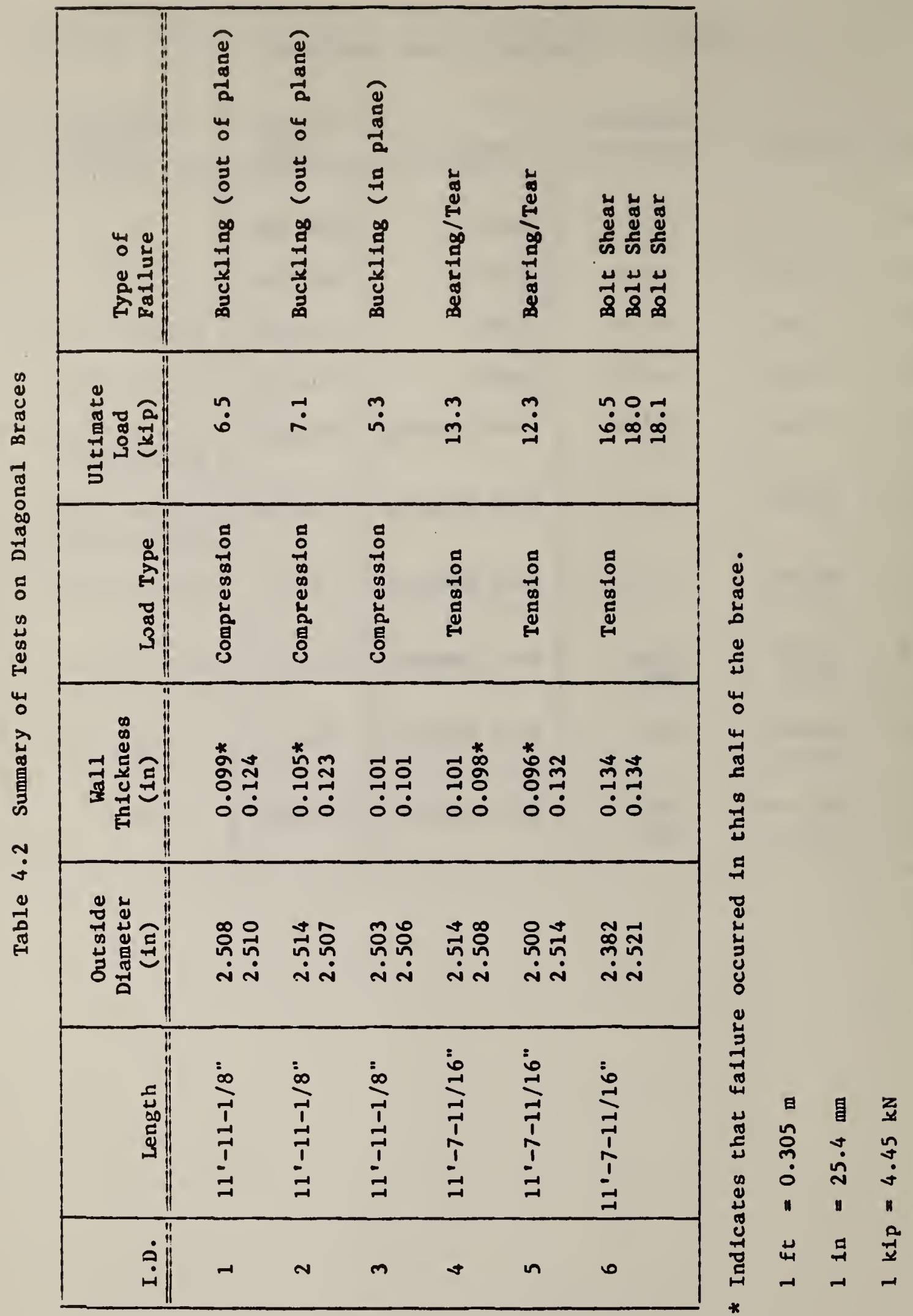




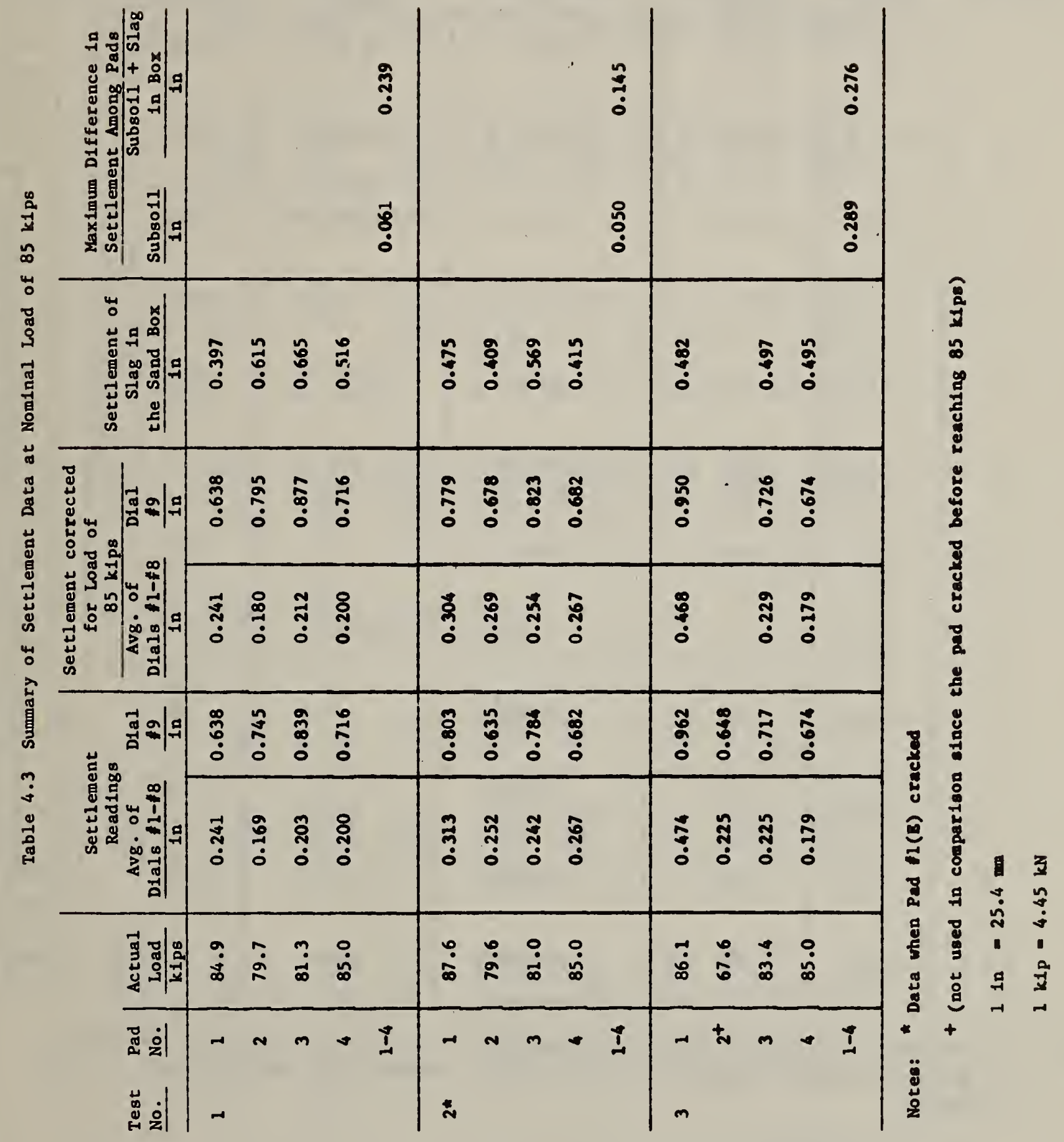


Table 4.4 Values of Pad Fallure Loads and Foundation Stiffness for Screw Jacks

Test Fallure Load After Drop of Screw Duration of Foundation Crack No. Pad No. Load Cracking Jack Plate Load Held St1ffness Pattern

\begin{tabular}{|c|c|c|c|c|c|c|c|}
\hline & & k1ps & $\mathrm{kIps}$ & In. & min. & $\mathrm{klps} / \mathrm{ln}$. & $+N$ \\
\hline \multirow[t]{4}{*}{1} & 1 & 112 & 101 & 0.64 & 0.5 & 145 & \\
\hline & 2 & 132 & 120 & 0.33 & 2.0 & 154 & \\
\hline & 3 & 178 & 168 & 0.25 & Information & 146 & \\
\hline & 4 & 154 & $?$ & 0.19 & 0 & 140 & \\
\hline \multirow[t]{4}{*}{2} & 1 & 88 & 74 & 0.46 & 73.0 & 112 & \\
\hline & 2 & 115 & 102 & 0.25 & 5.0 & 115 & \\
\hline & 3 & 153 & 151 & 0.14 & 0 & 112 & \\
\hline & 4 & 168 & 144 & 0.72 & 10.0 & 119 & \\
\hline \multirow[t]{4}{*}{3} & 1 & 135 & 40 & $>0.941 /$ & 0 & 98 & \\
\hline & 2 & 77 & 21 & $>0.371 /$ & 1.0 & 93 & \\
\hline & 3 & 104 & 74 & $>0.57 \underline{1 /}$ & 3.0 & 115 & \\
\hline & 4 & 102 & 74 & $>0.431 /$ & 3.0 & 112 & \\
\hline
\end{tabular}

Note: 1. Fallure load could not be re-applled and held by the pads, thus the drop of support under the load should exceed the values given in the table.

$1 \mathrm{kIp}=4.45 \mathrm{kN}$

$11 \mathrm{n}=25.4 \mathrm{~mm}$ 


\begin{tabular}{|c|c|c|c|c|c|c|c|c|}
\hline 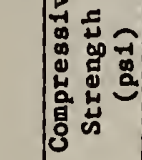 & 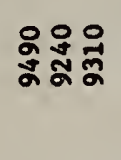 & 送总 & 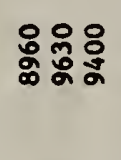 & 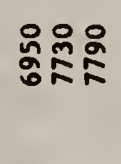 & : & 옳옹용 & 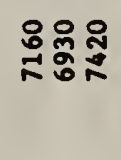 & 递总员 \\
\hline 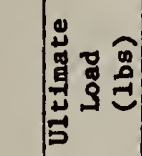 & 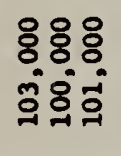 & 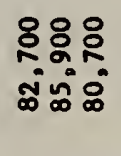 & 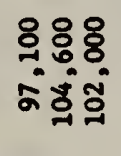 & 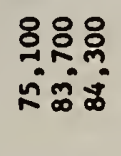 & 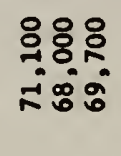 & $\begin{array}{l}800 \\
500 \\
100\end{array}$ & $\begin{array}{r}8 \% \\
\vdots 0 \\
200 \\
200\end{array}$ & 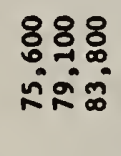 \\
\hline 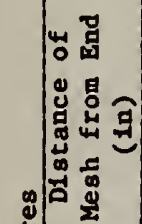 & 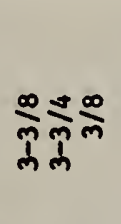 & NN N & ํㅗㄹำ & 㤐罢器 & $\sum_{n=1}^{\infty}=$ & 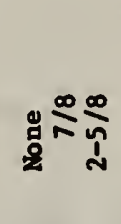 & 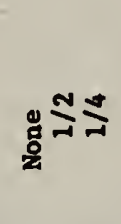 & $\stackrel{\infty}{\circ}$ \\
\hline 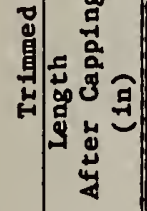 & 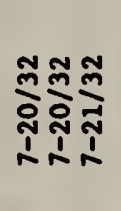 & 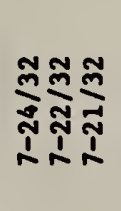 & 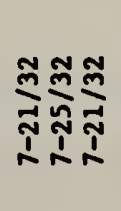 & 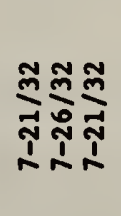 & 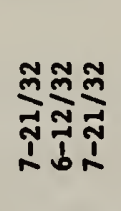 & 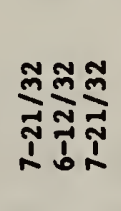 & 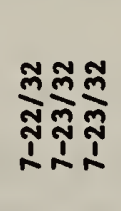 & 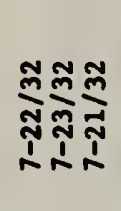 \\
\hline 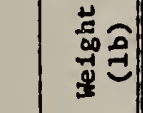 & 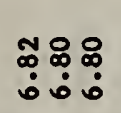 & 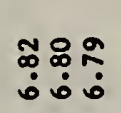 & 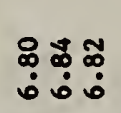 & 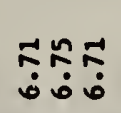 & 11 & 111 & & \\
\hline 卷 & 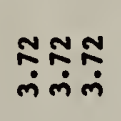 & 管紫 & 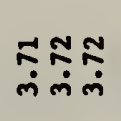 & $\begin{array}{l}\vec{i} \\
\dot{\varphi}\end{array} \overrightarrow{\dot{m}}$ & 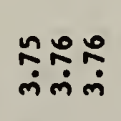 & 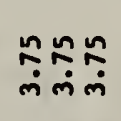 & 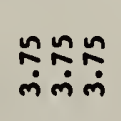 & 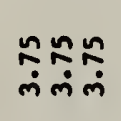 \\
\hline 䓀 & 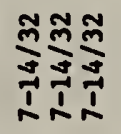 & 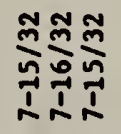 & 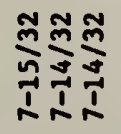 & 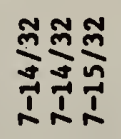 & 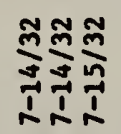 & 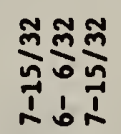 & 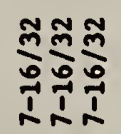 & 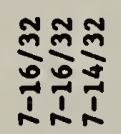 \\
\hline 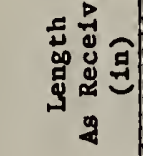 & 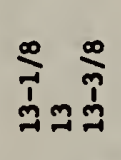 & 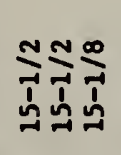 & 施施 & 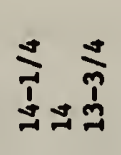 & 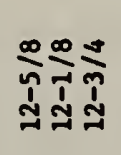 & 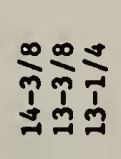 & 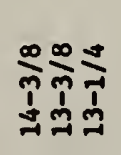 & 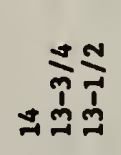 \\
\hline ن. & 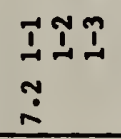 & 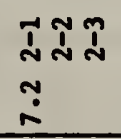 & 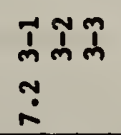 & 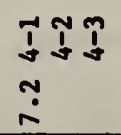 & $\underset{N}{ \pm \pm I}$ & ลี & ปิ่ & ป⿻ \\
\hline
\end{tabular}

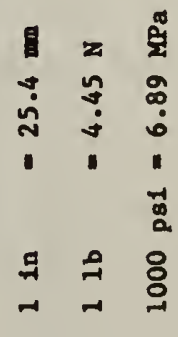




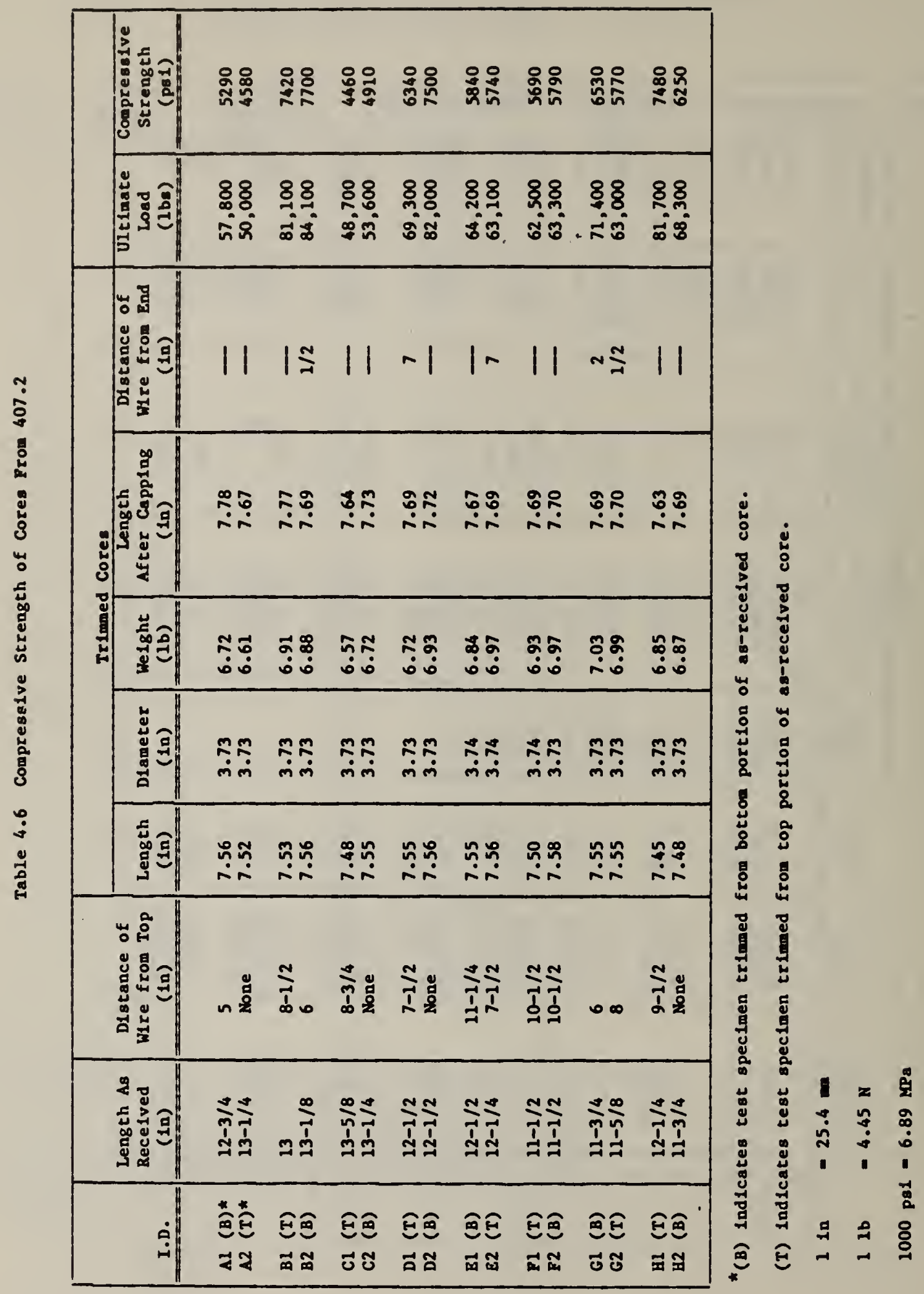


Table 4.7 Accumulated Settlement During the F1rst 60 Minutes When the Pads Were Loaded Under $85 \mathrm{klps}$ Nominal Load

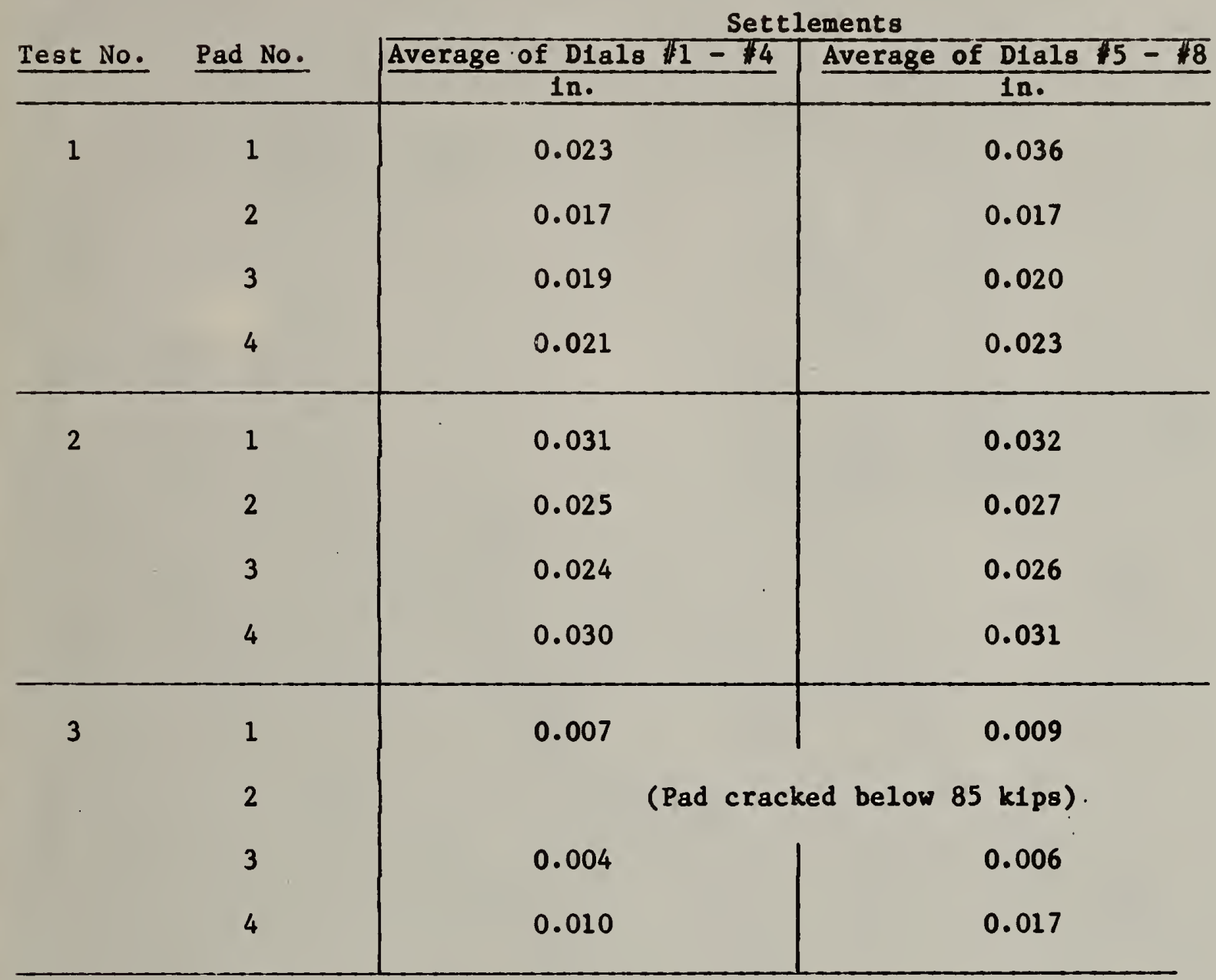

1 in $=25.4 \mathrm{~mm}$ 


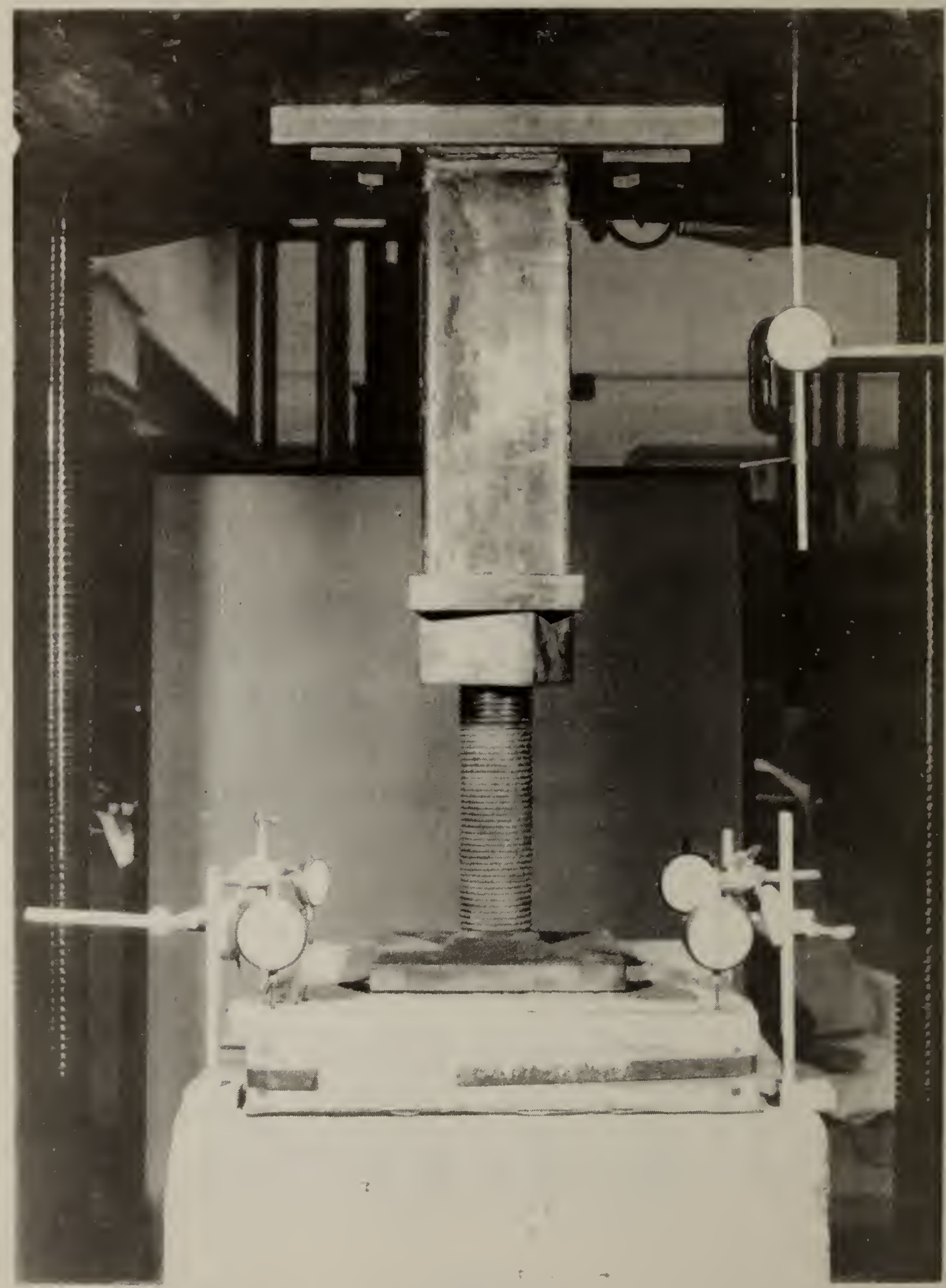

Figure 4.1 Over-all view of arrangement for the sand-box tests 


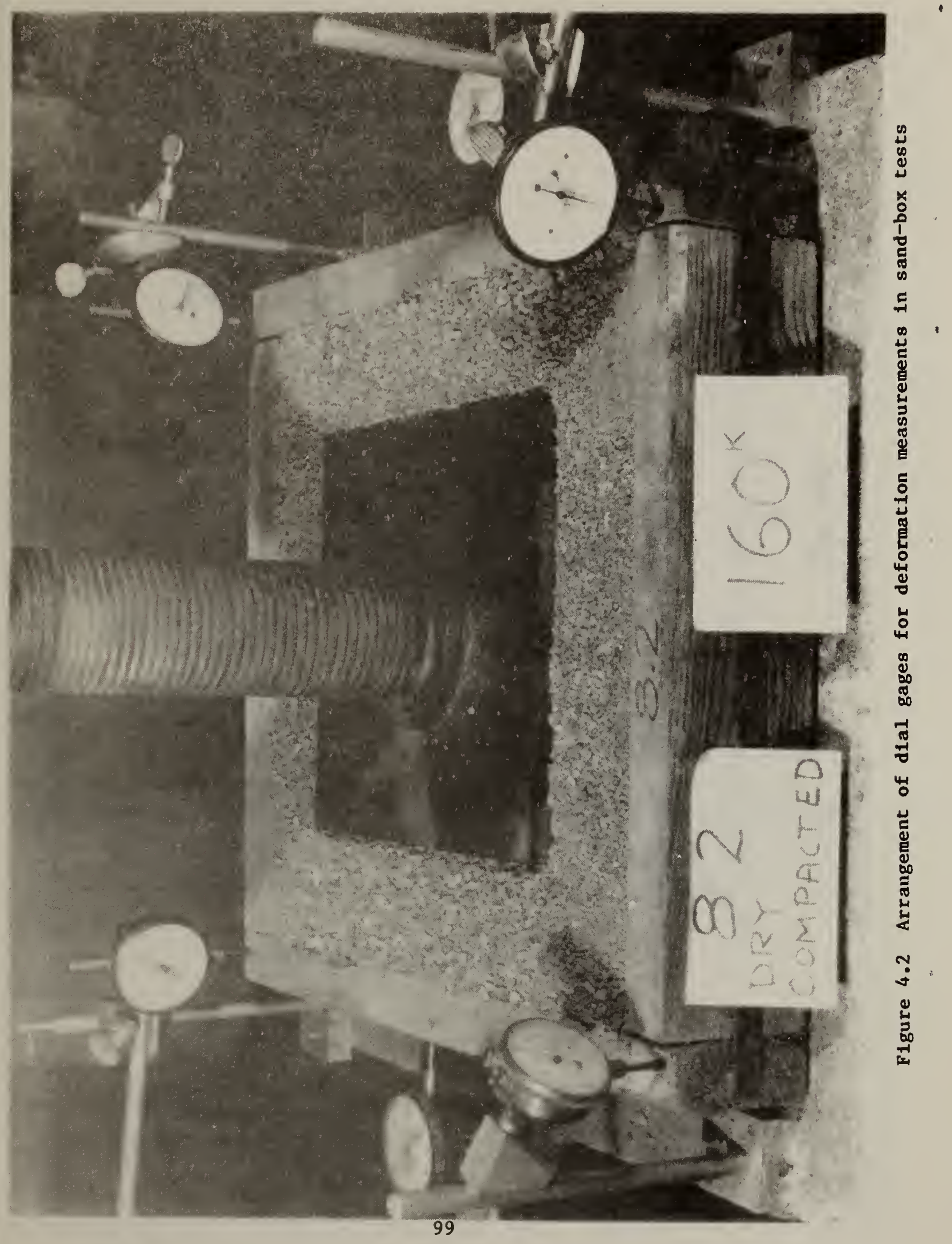




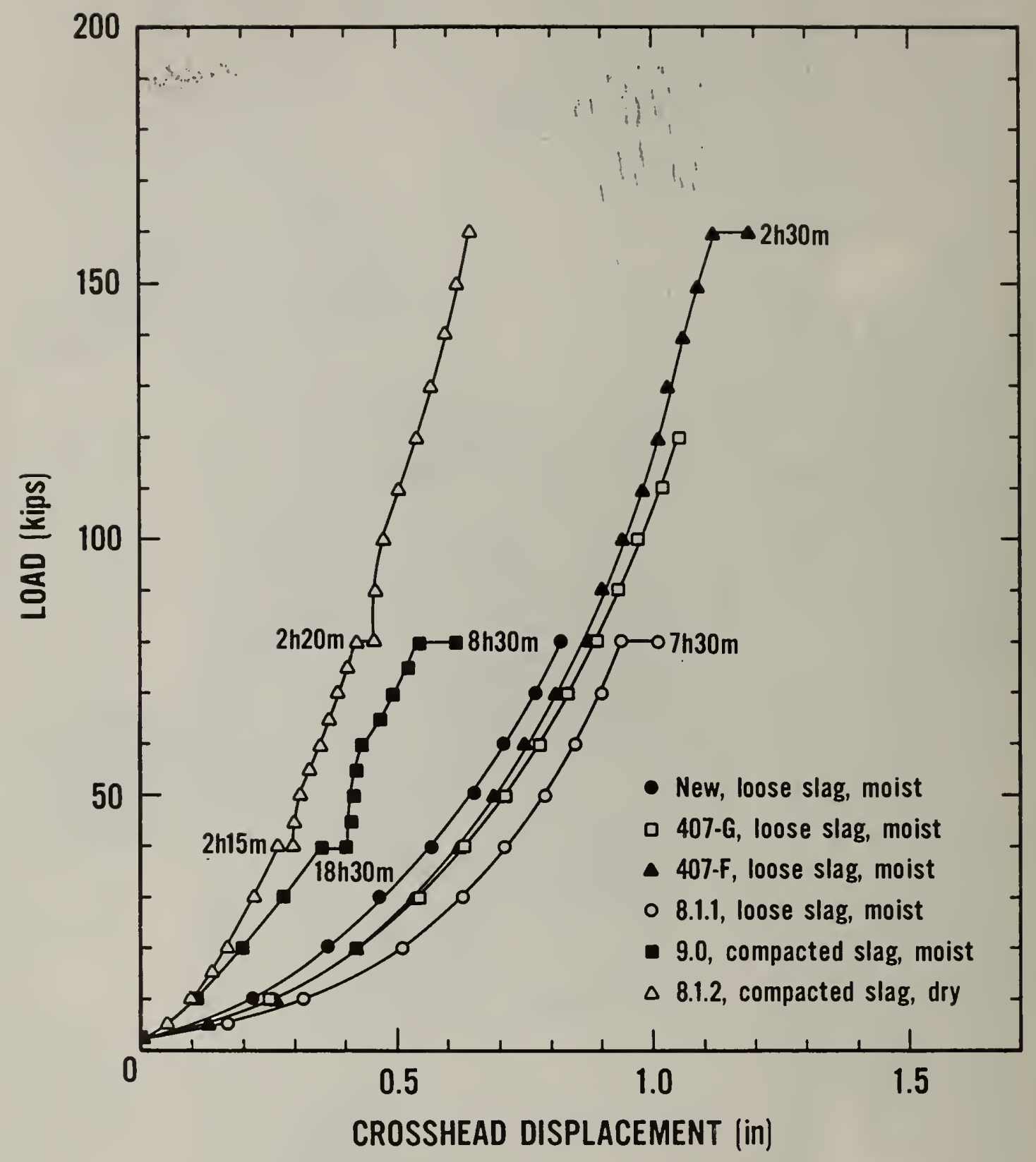

Figure 4.3 Load versus crosshead displacement for sand-box tests with slag filler 


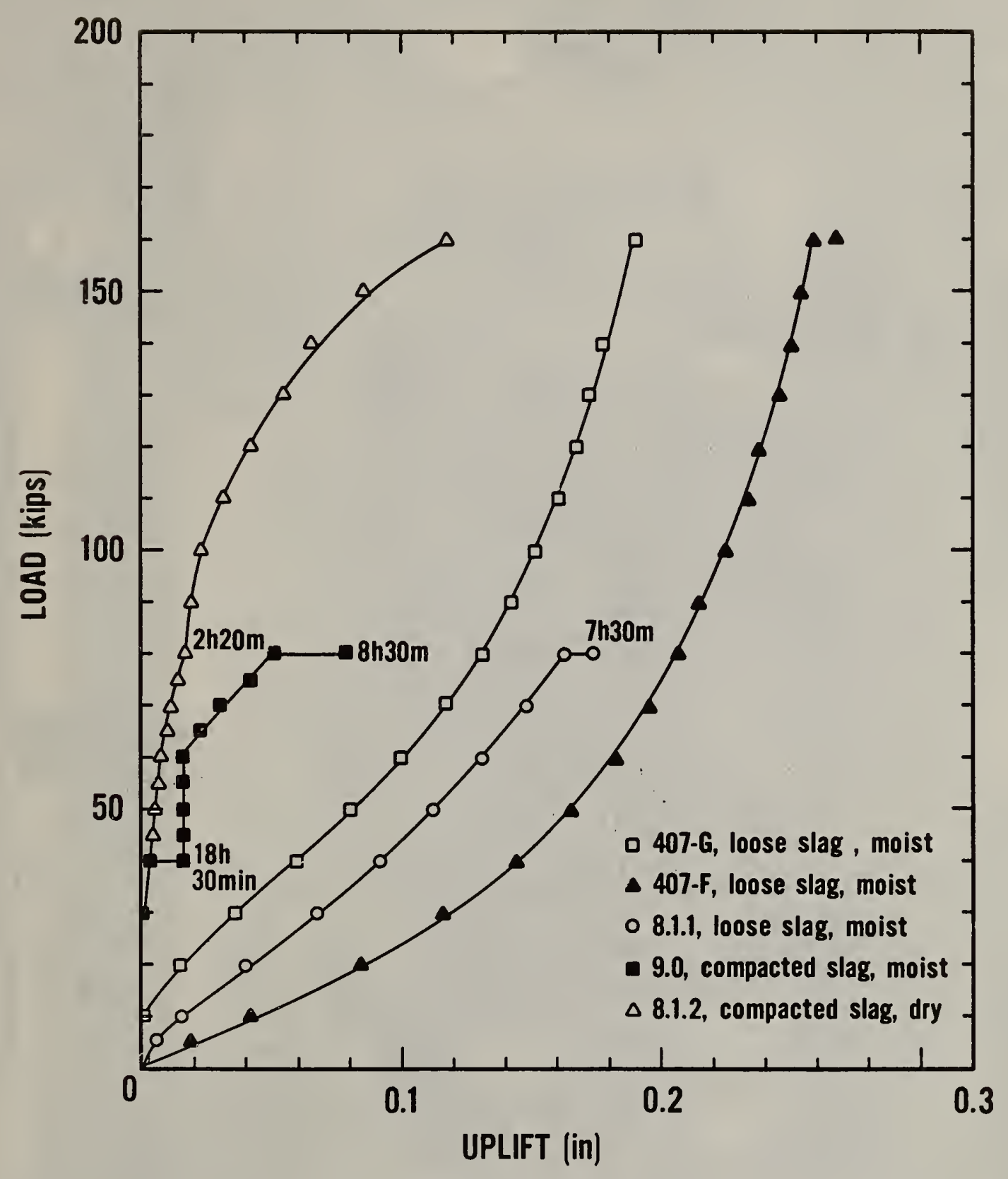

Figure 4.4 Load versus uplift for sand-box tests with slag filler 


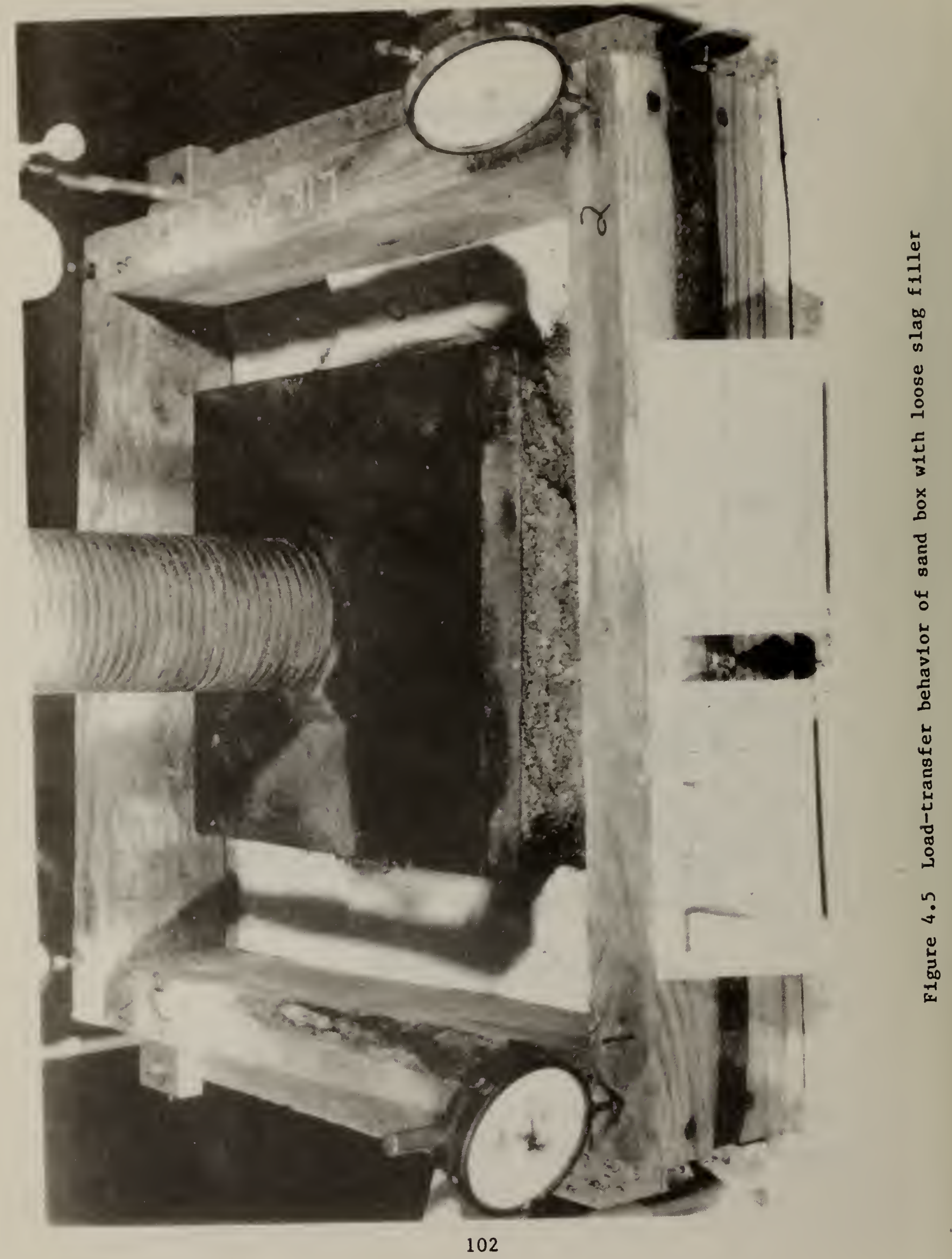




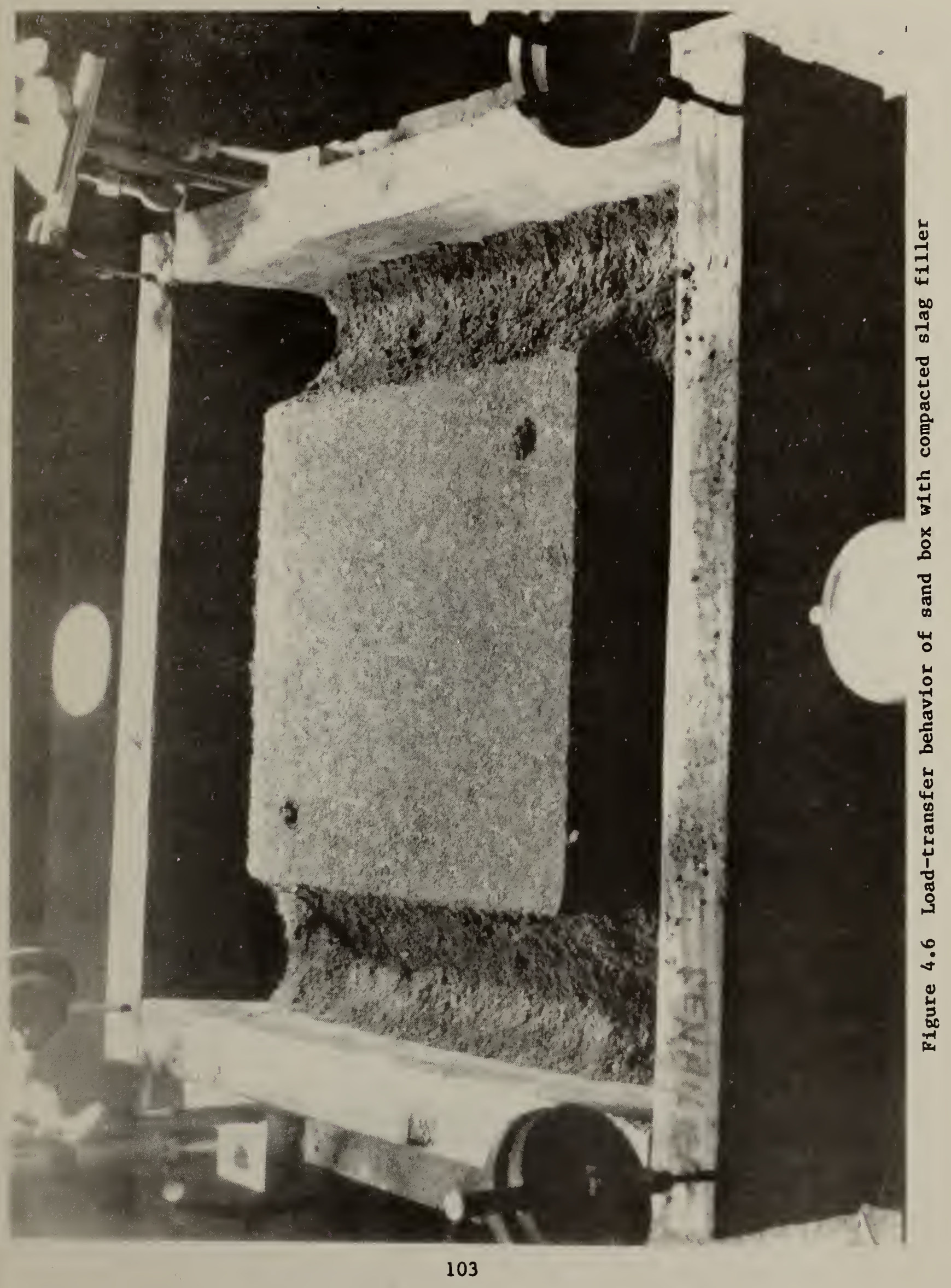




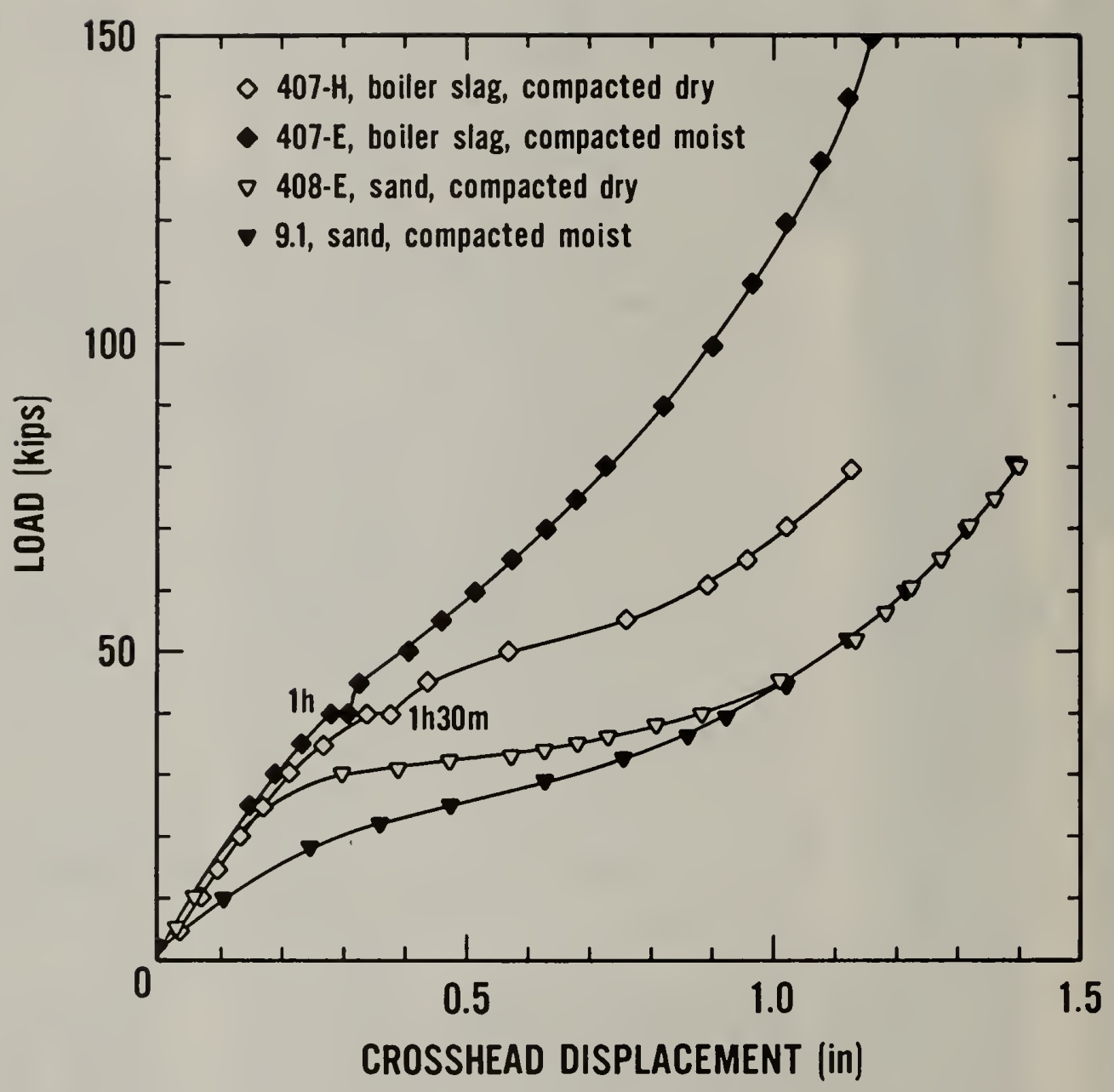

Figure 4.7 Load versus crosshead displacement for sand-box tests with boller-slag and concrete-sand fillers 


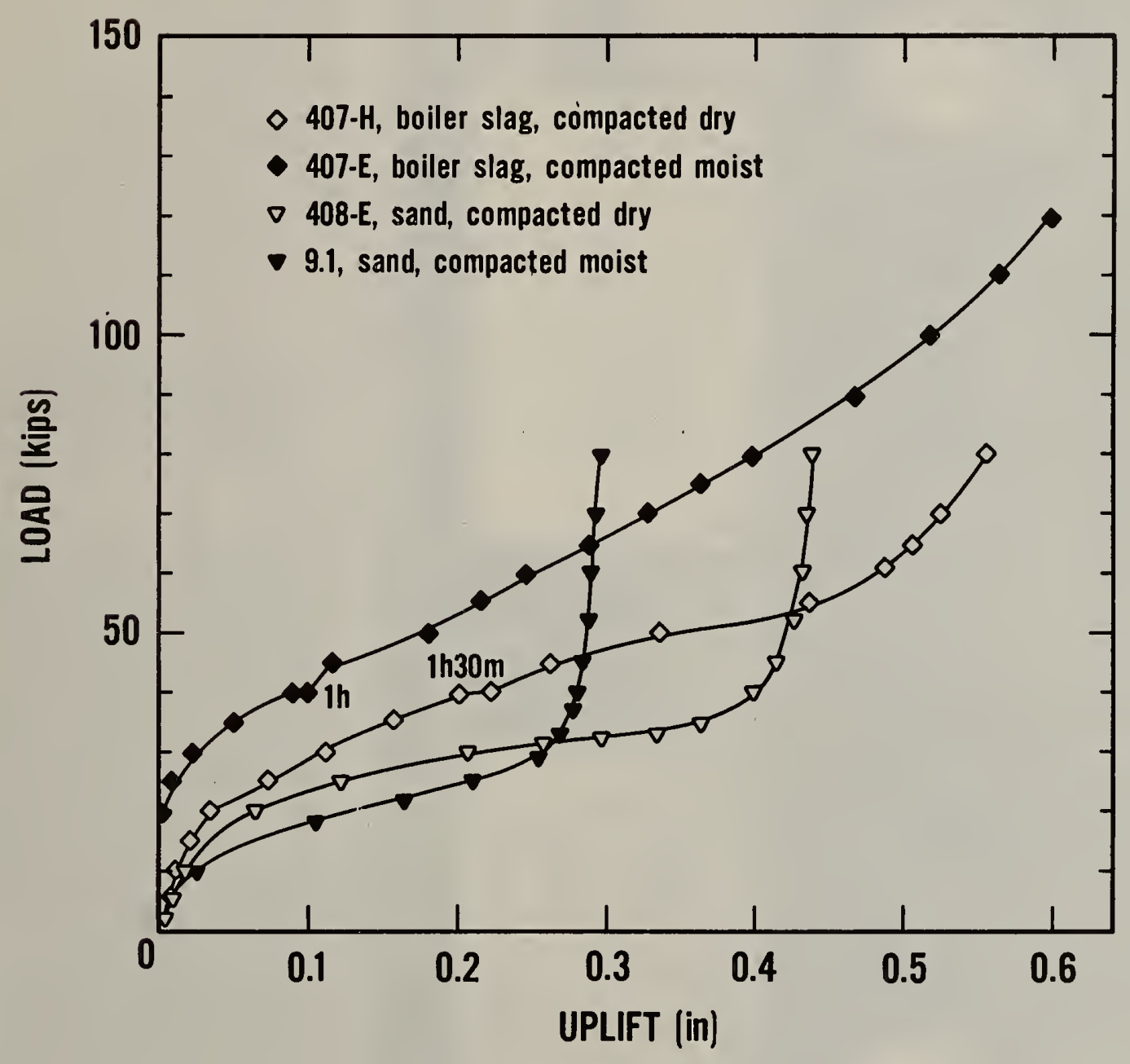

Figure 4.8 Load versus uplift for sand boxes with boiler-slag and concrete-sand fillers 


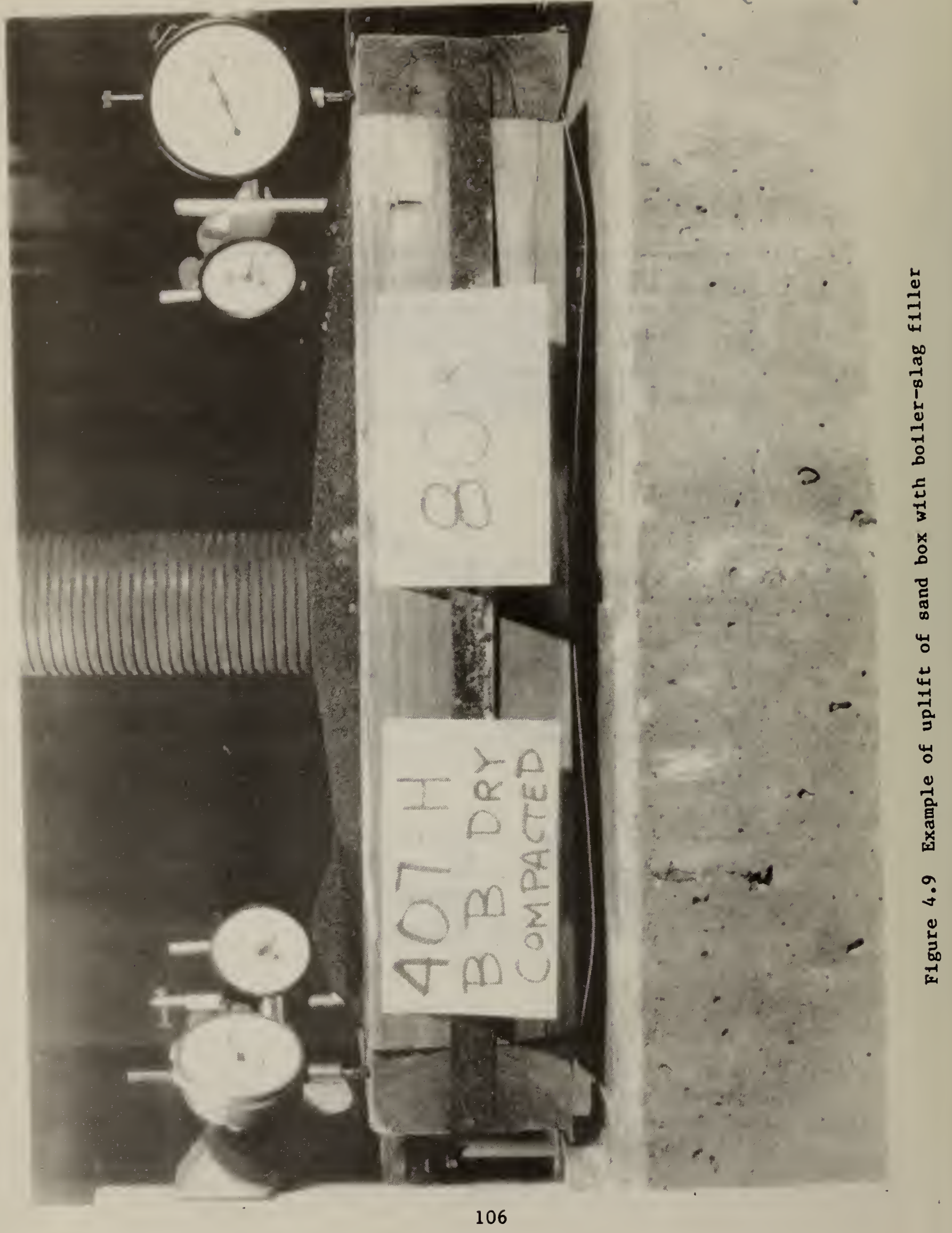




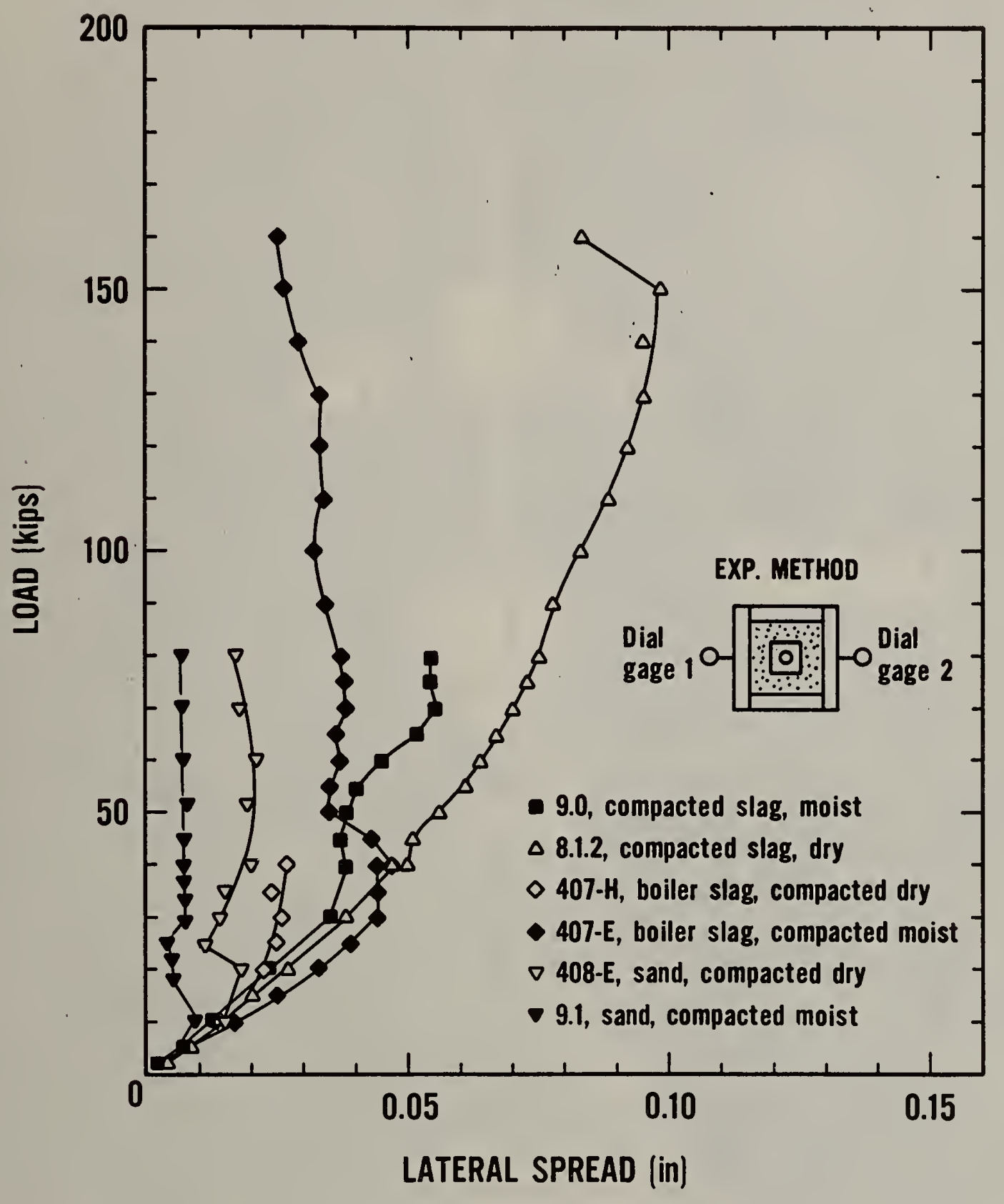

Figure 4.10 Load versus lateral spreading of sand boxes 


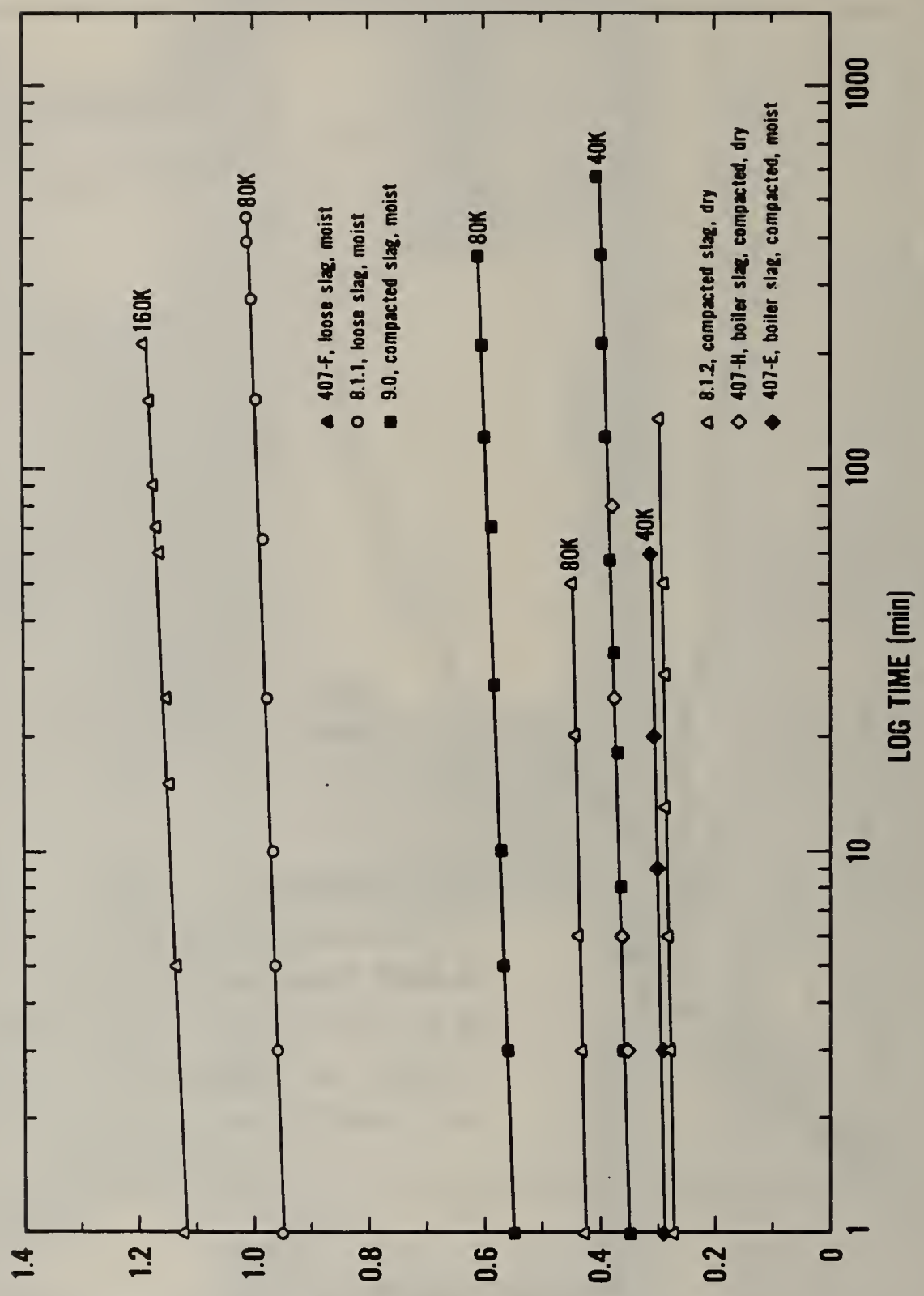

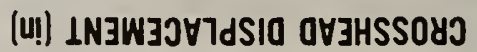




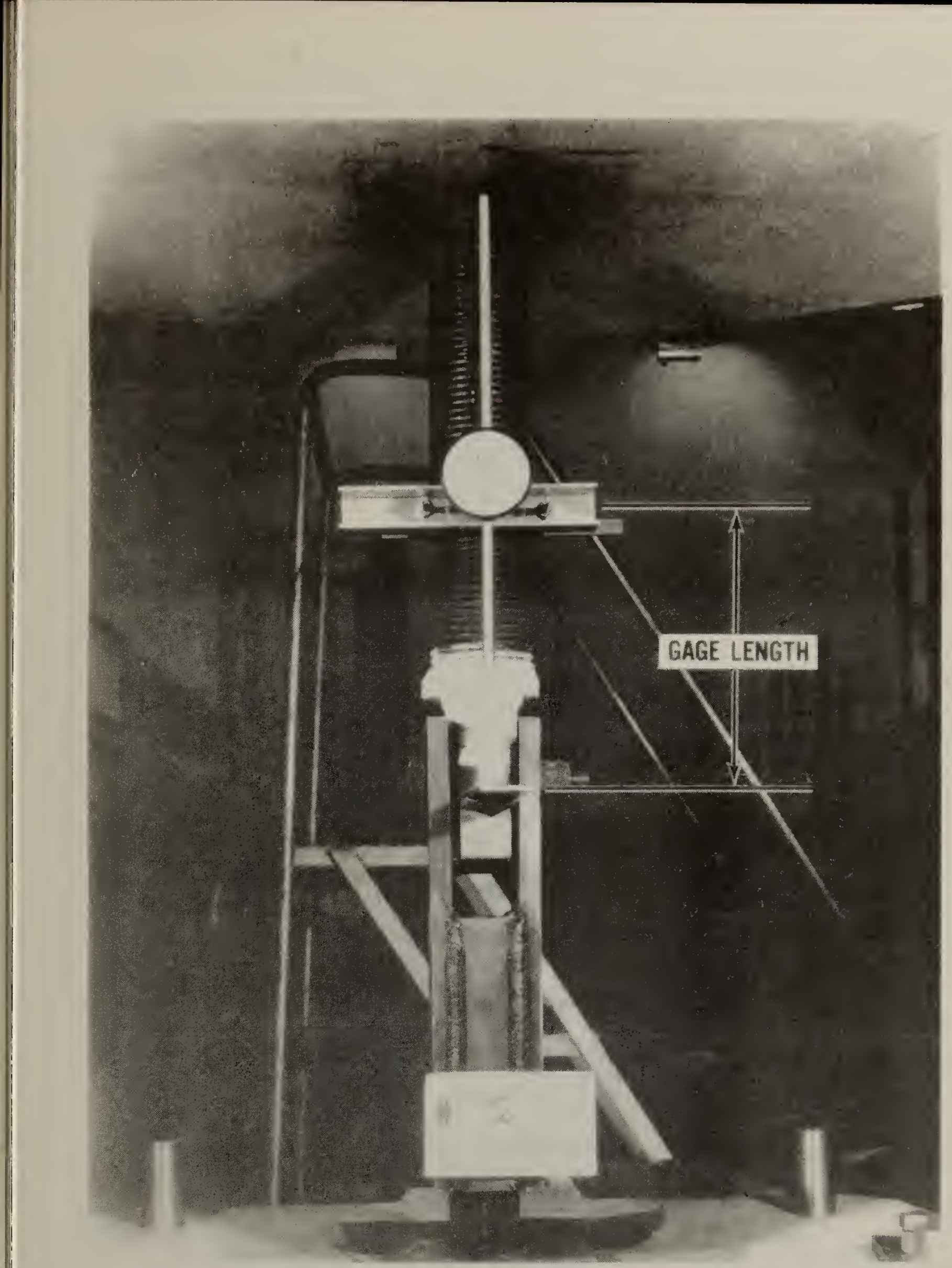

Figure 4.12 Arrangement for tension tests of unused screw jacks 


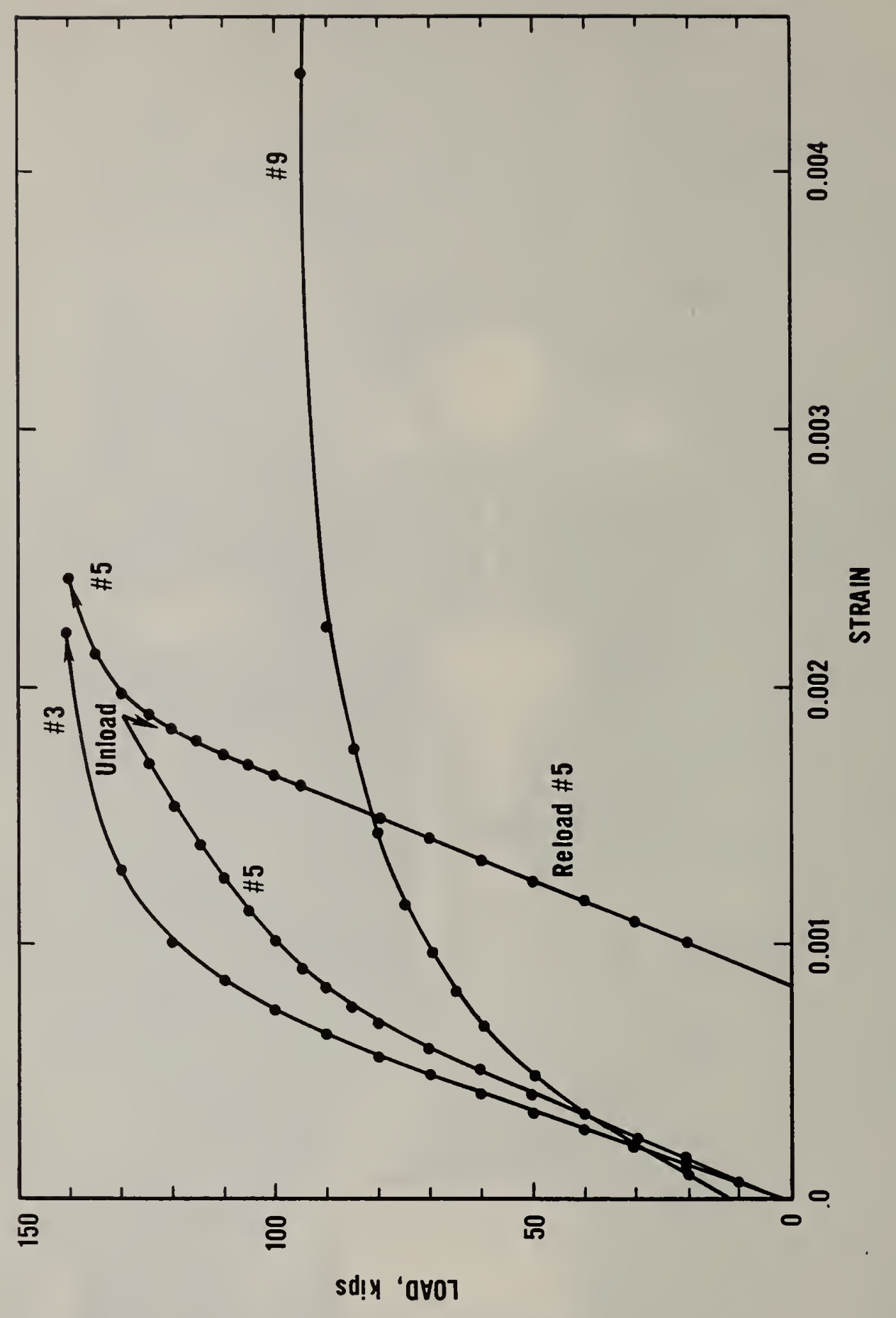

ป 


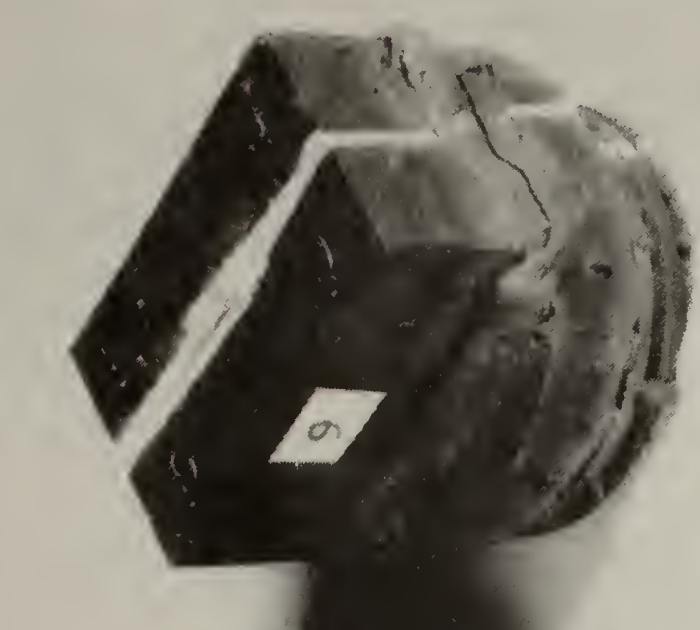

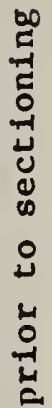

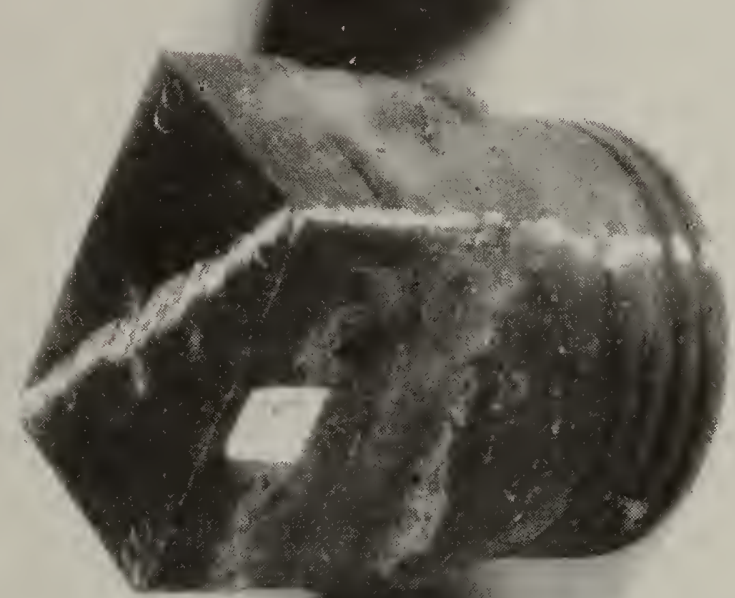

ปั

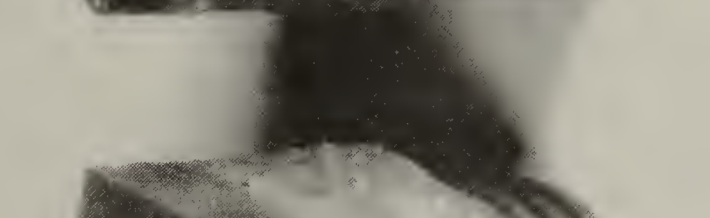

مُ

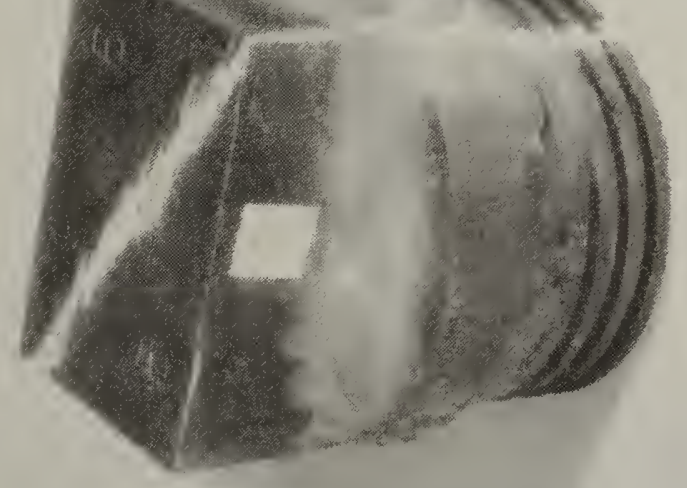

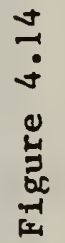

1 


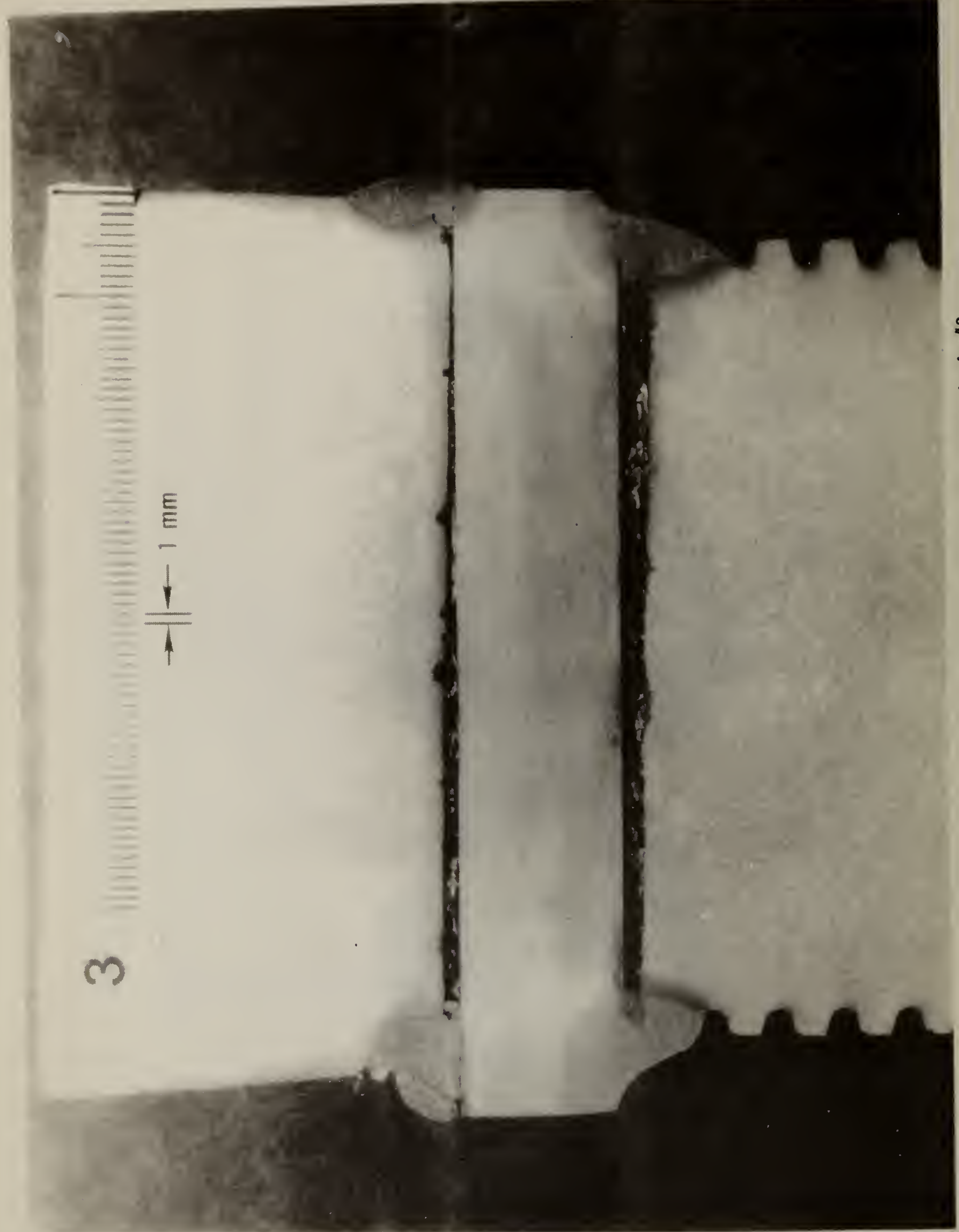

m

है

总 㟧 品 4

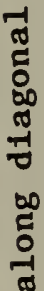




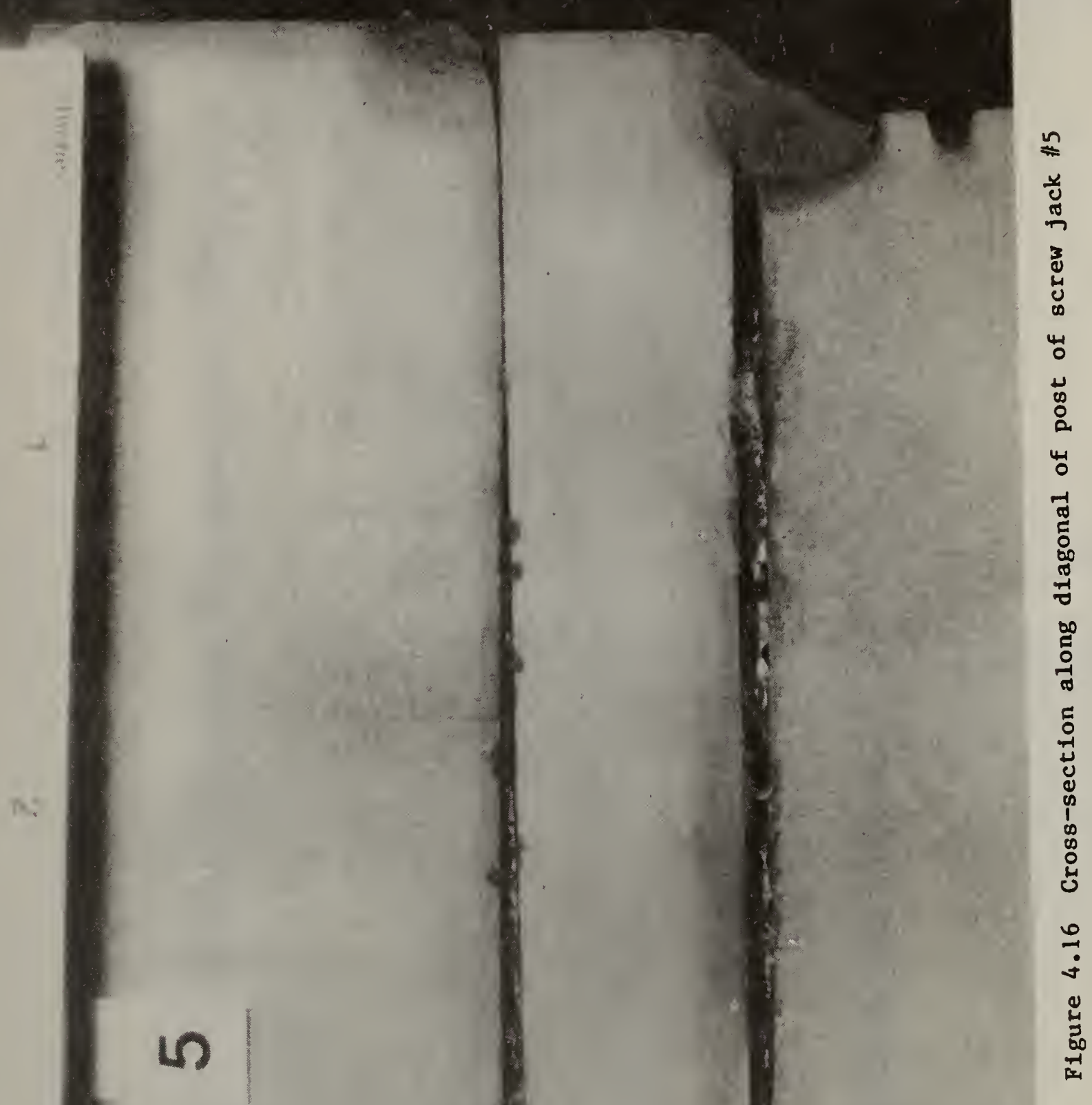




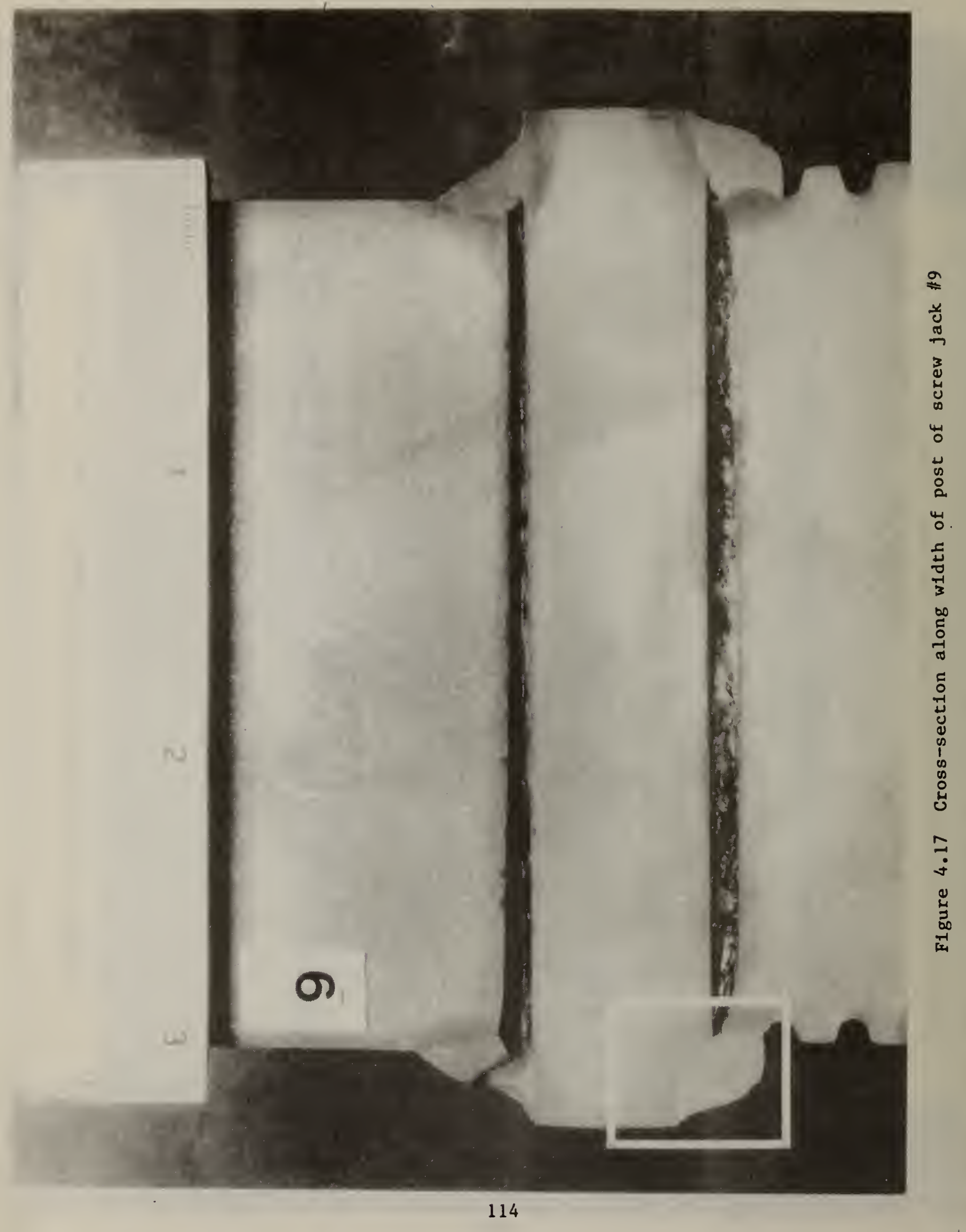




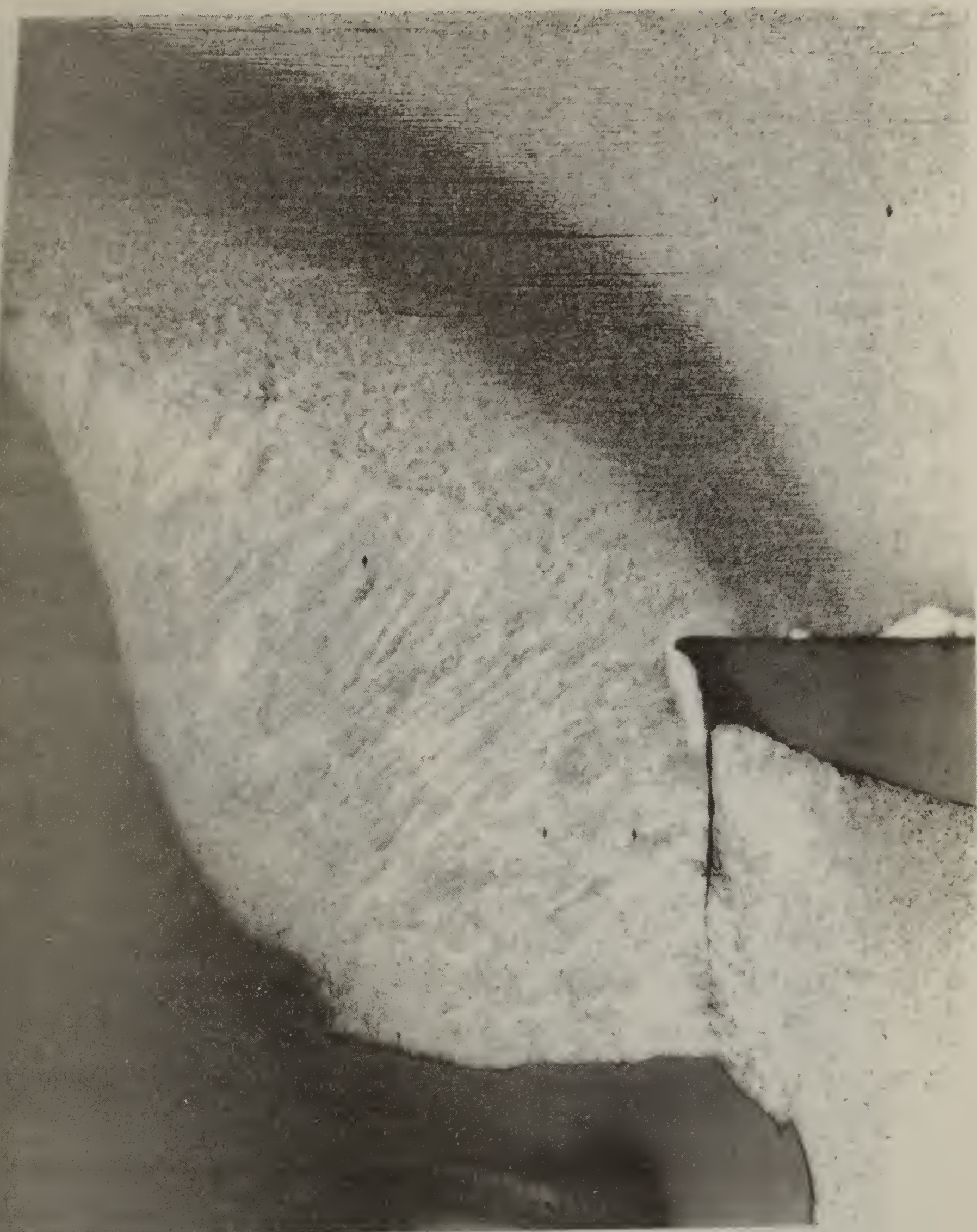

Figure 4.18 iagnified view of area within rectangle in figure 4.17 

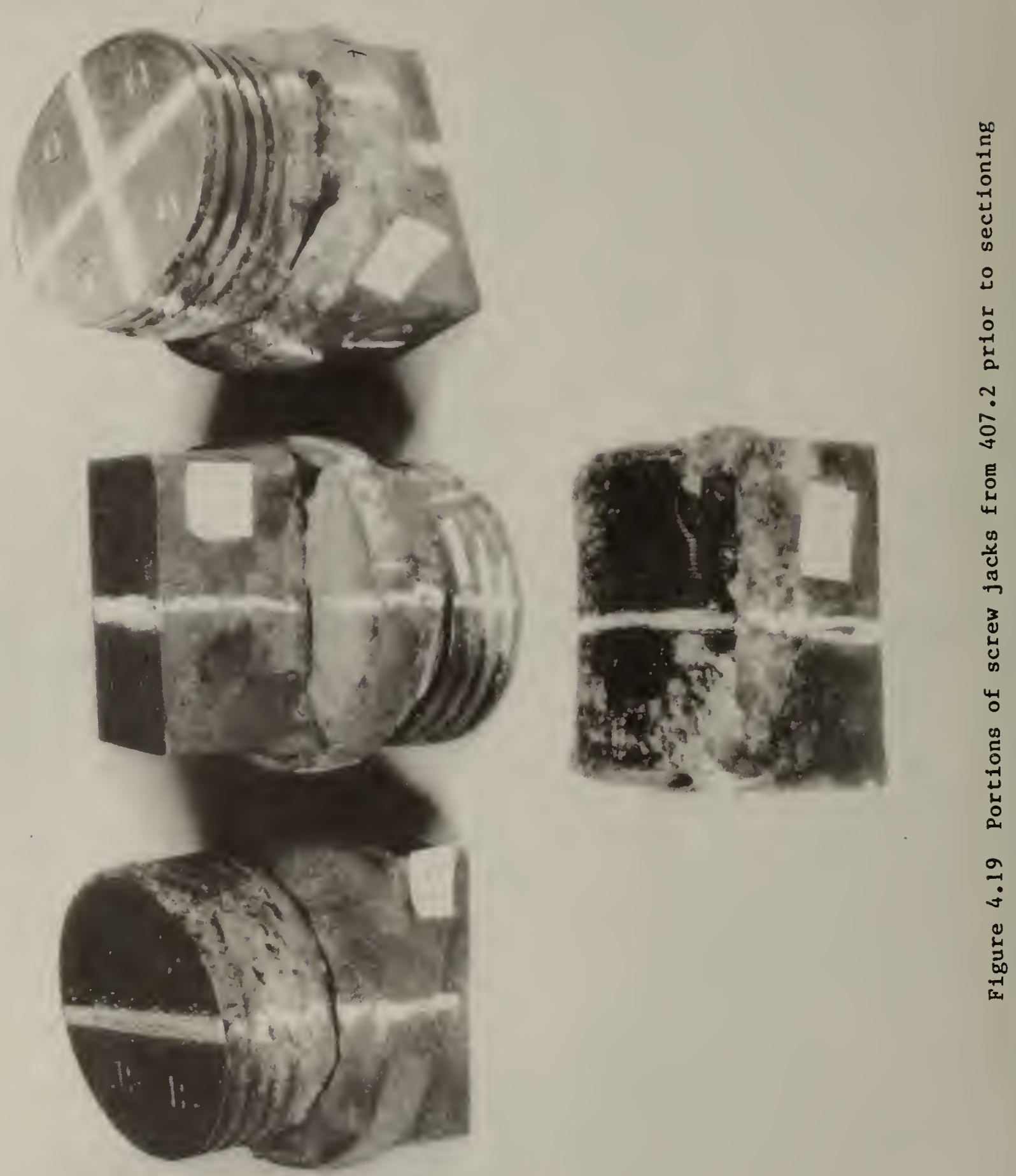


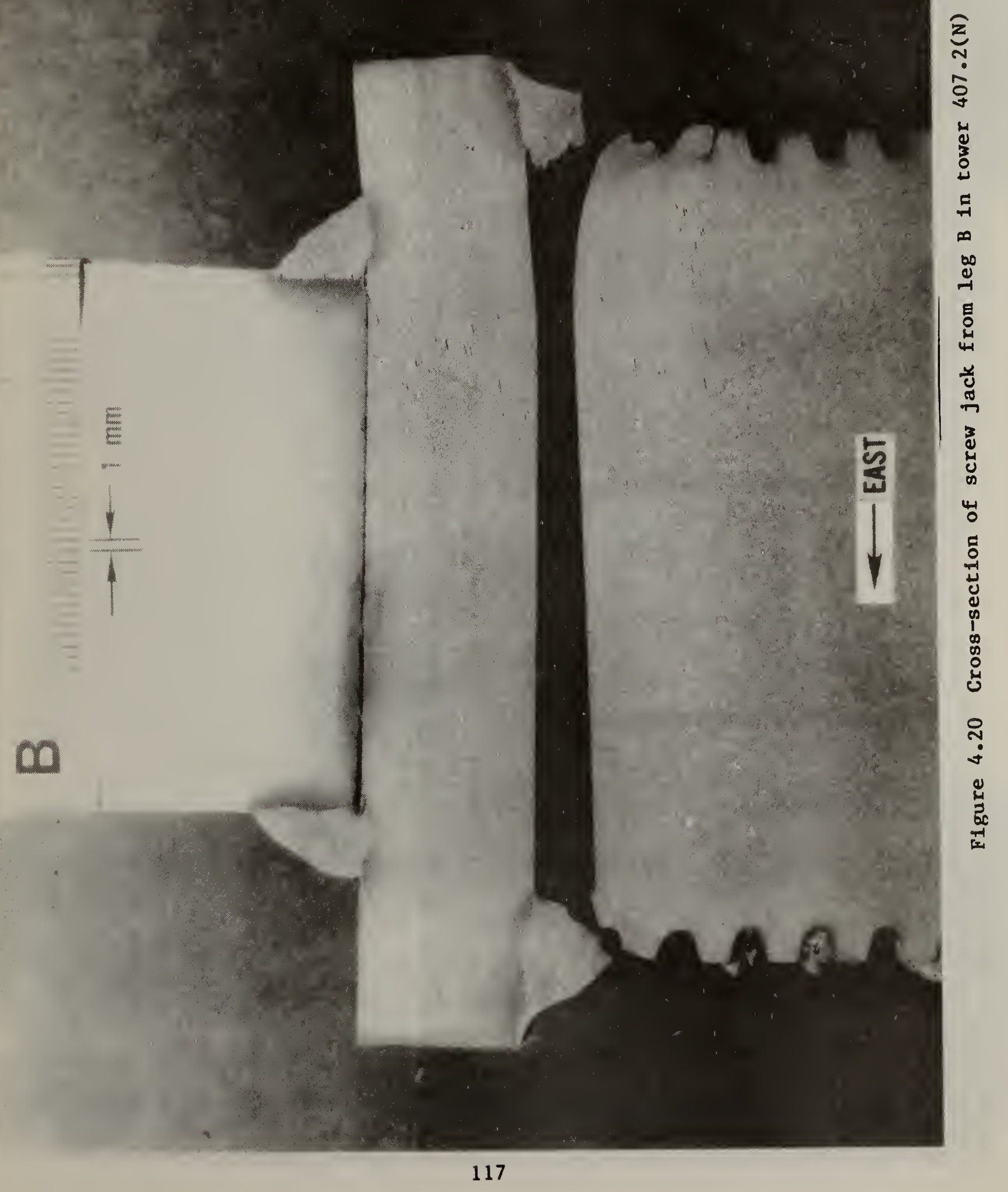




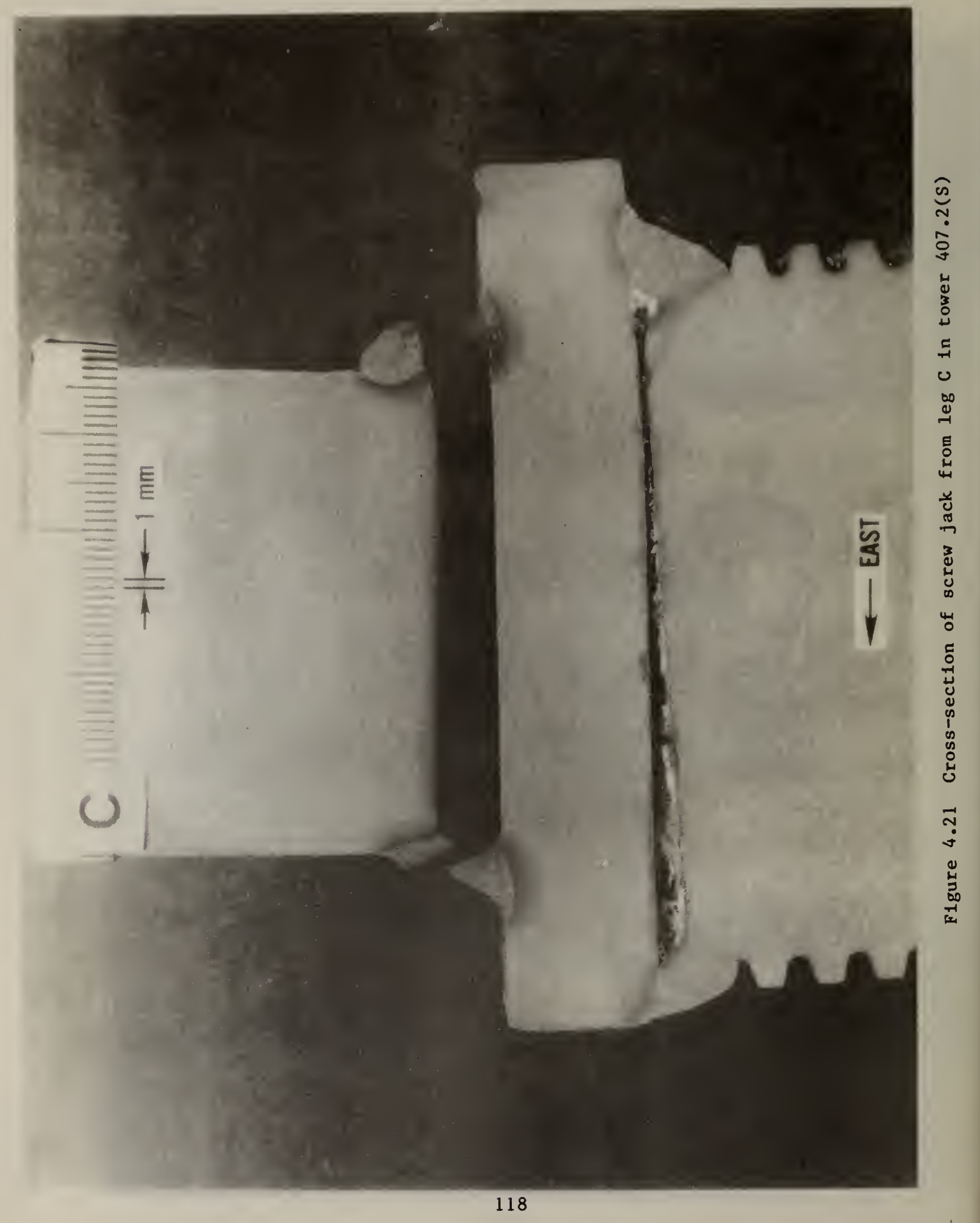




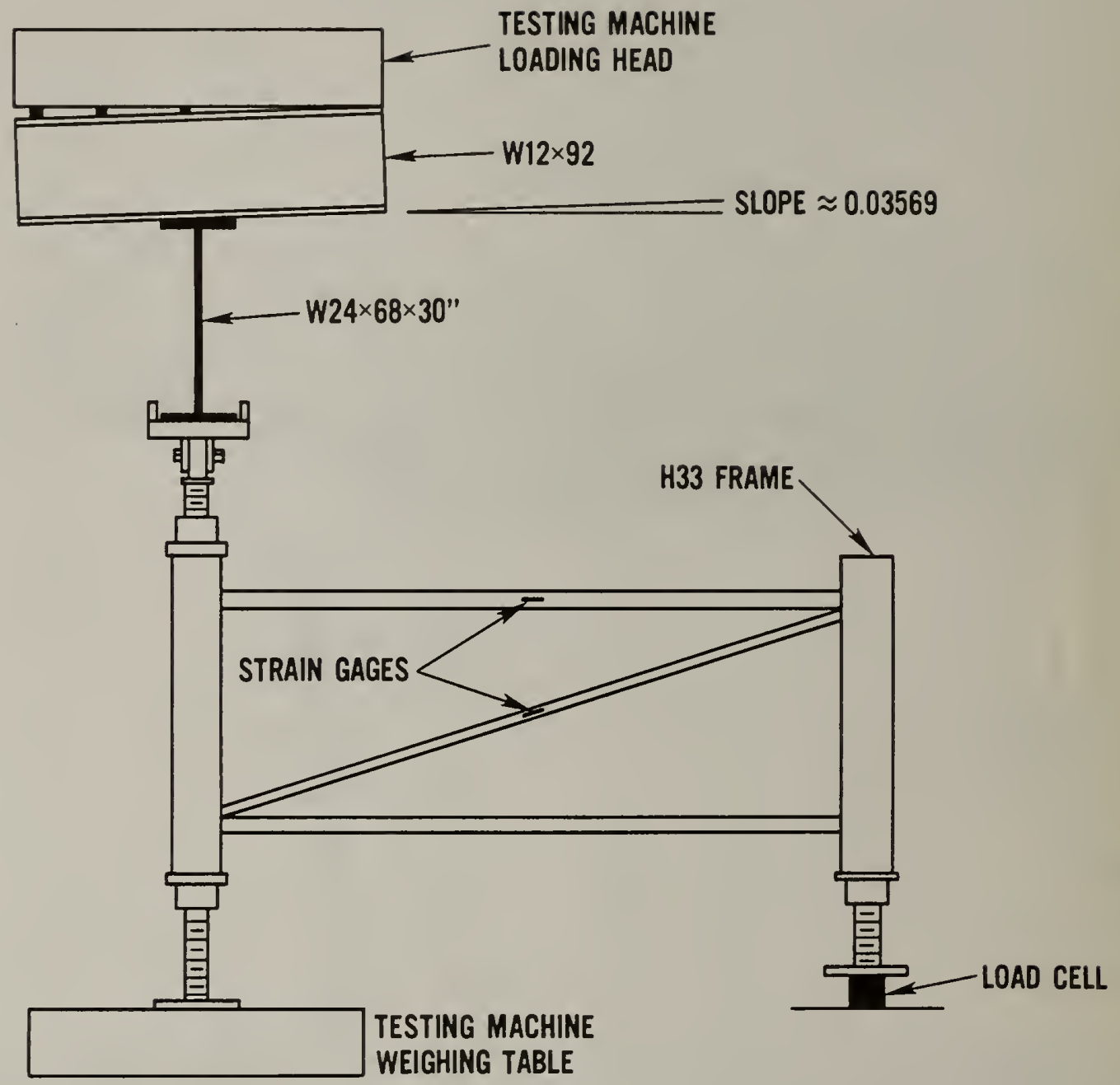

Figure 4.23 Schematic of arrangement for test of falsework assembly 


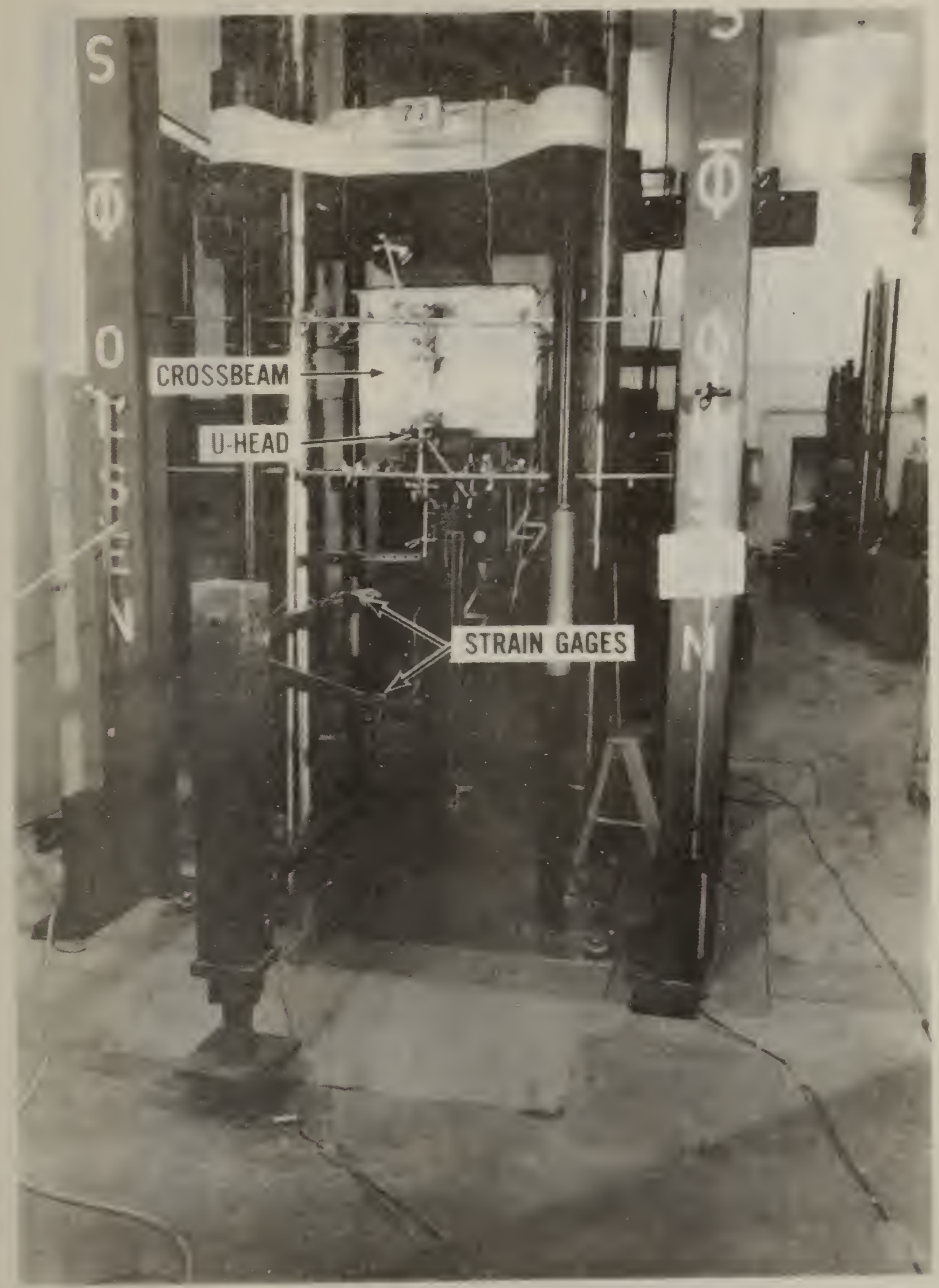

Figure 4.24 Laboratory set-up for falsework assembly test 非 


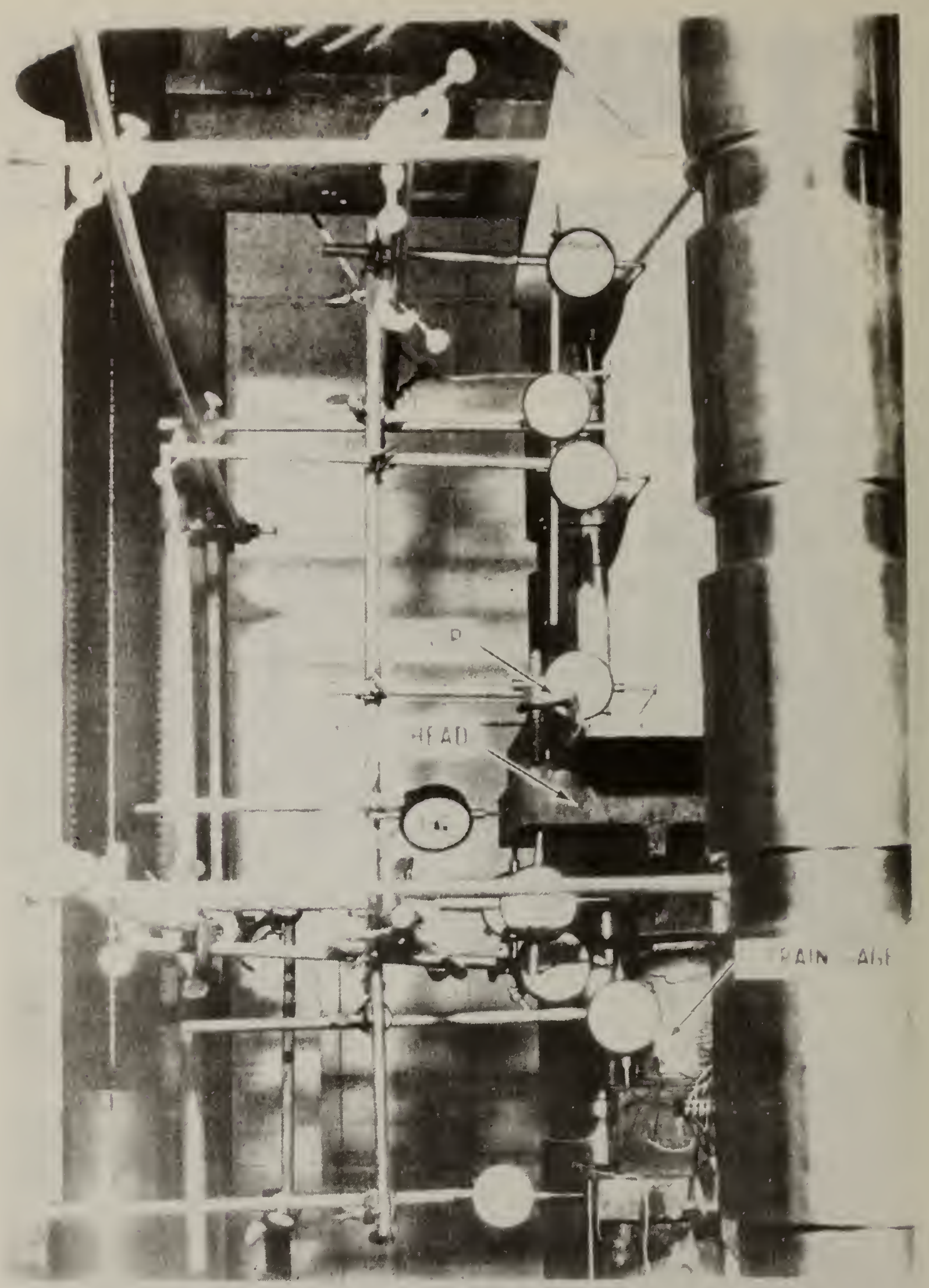

Figure 4.25 Close-up view of U-head and instrumentation used in tests of falsework assembly 

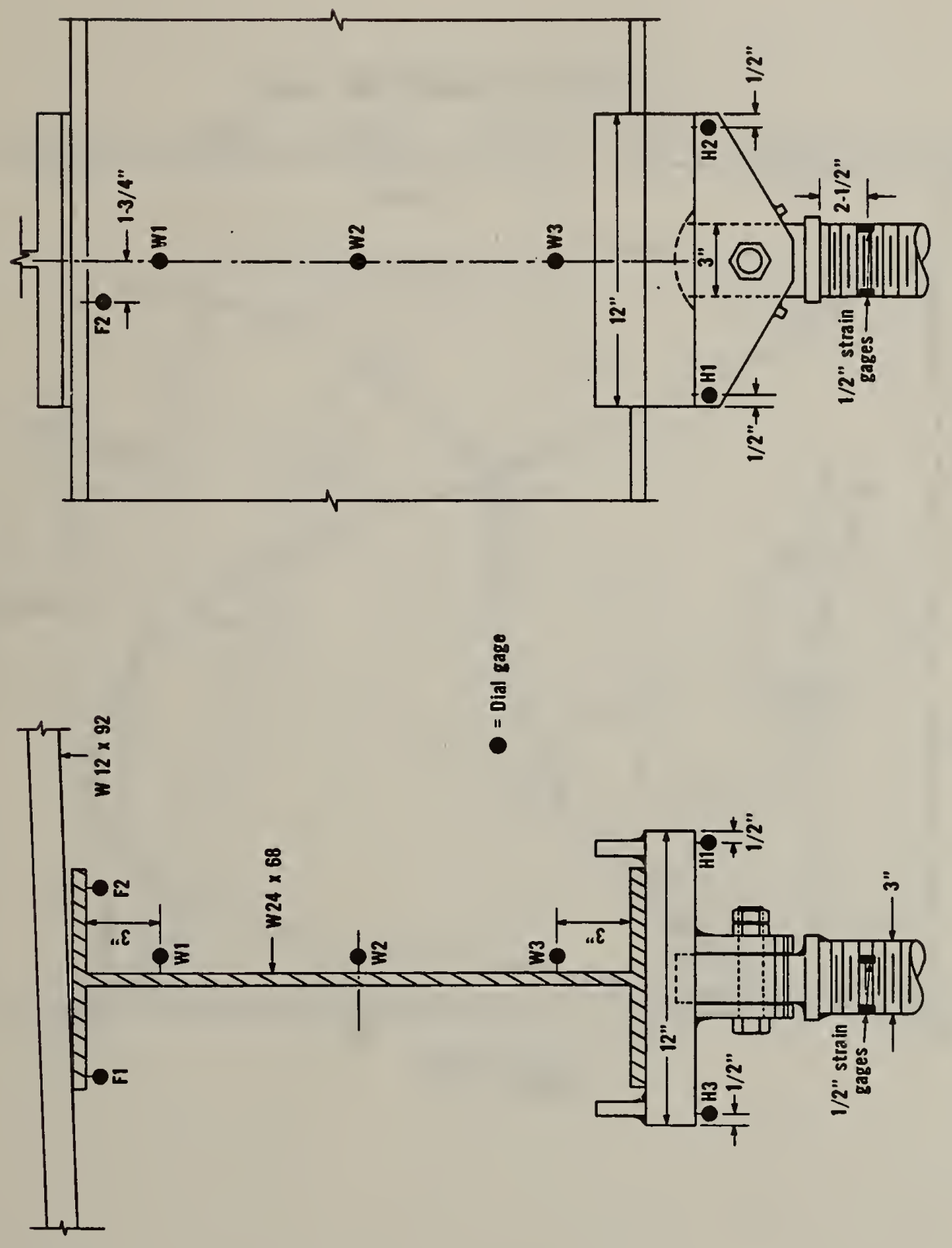

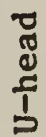

हี

8

范 


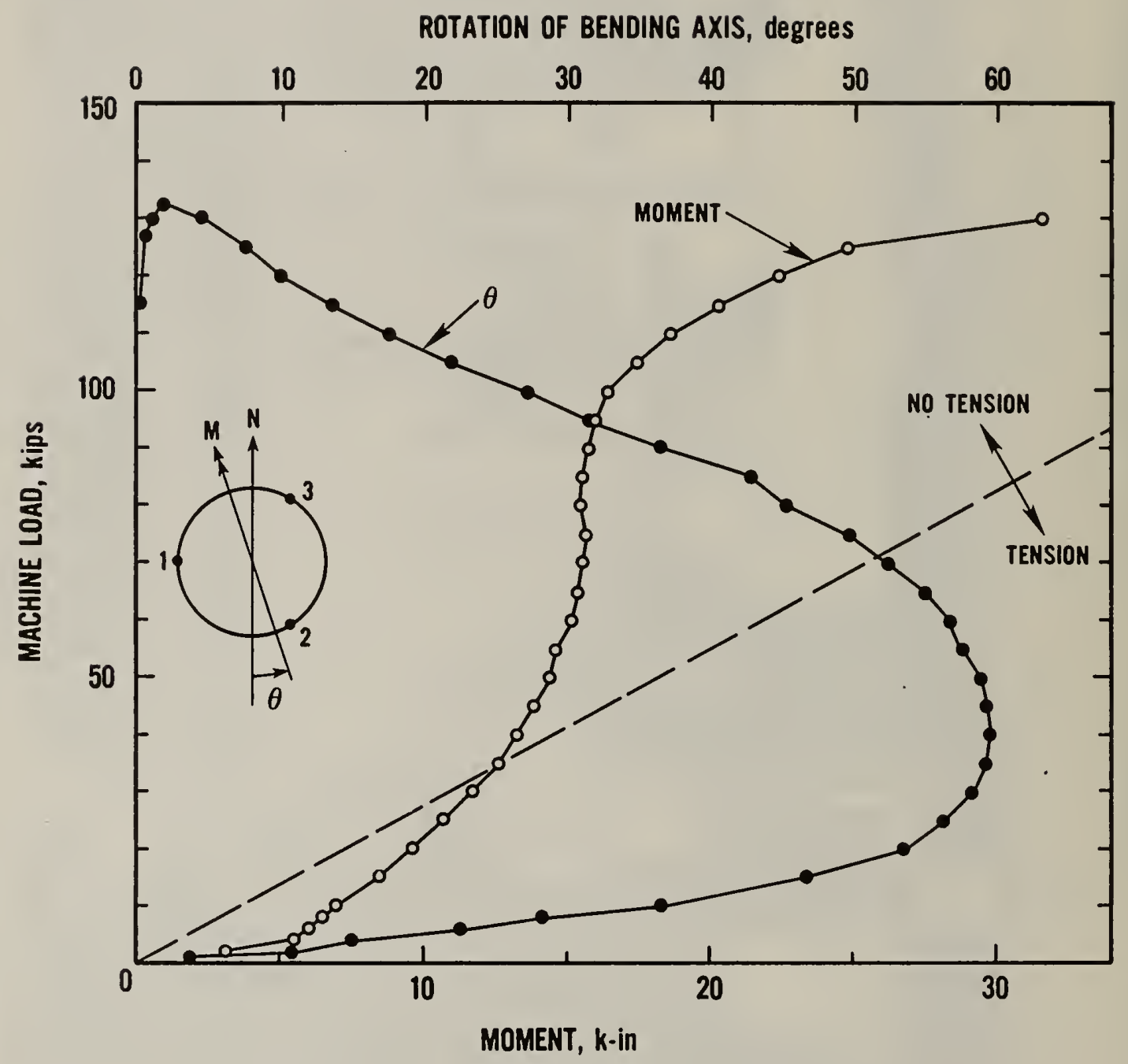

Figure 4.27 Variation of the magnitude and direction of the bending moment in the screw jack as a function of the vertical load (test $\#_{2}$ ) 


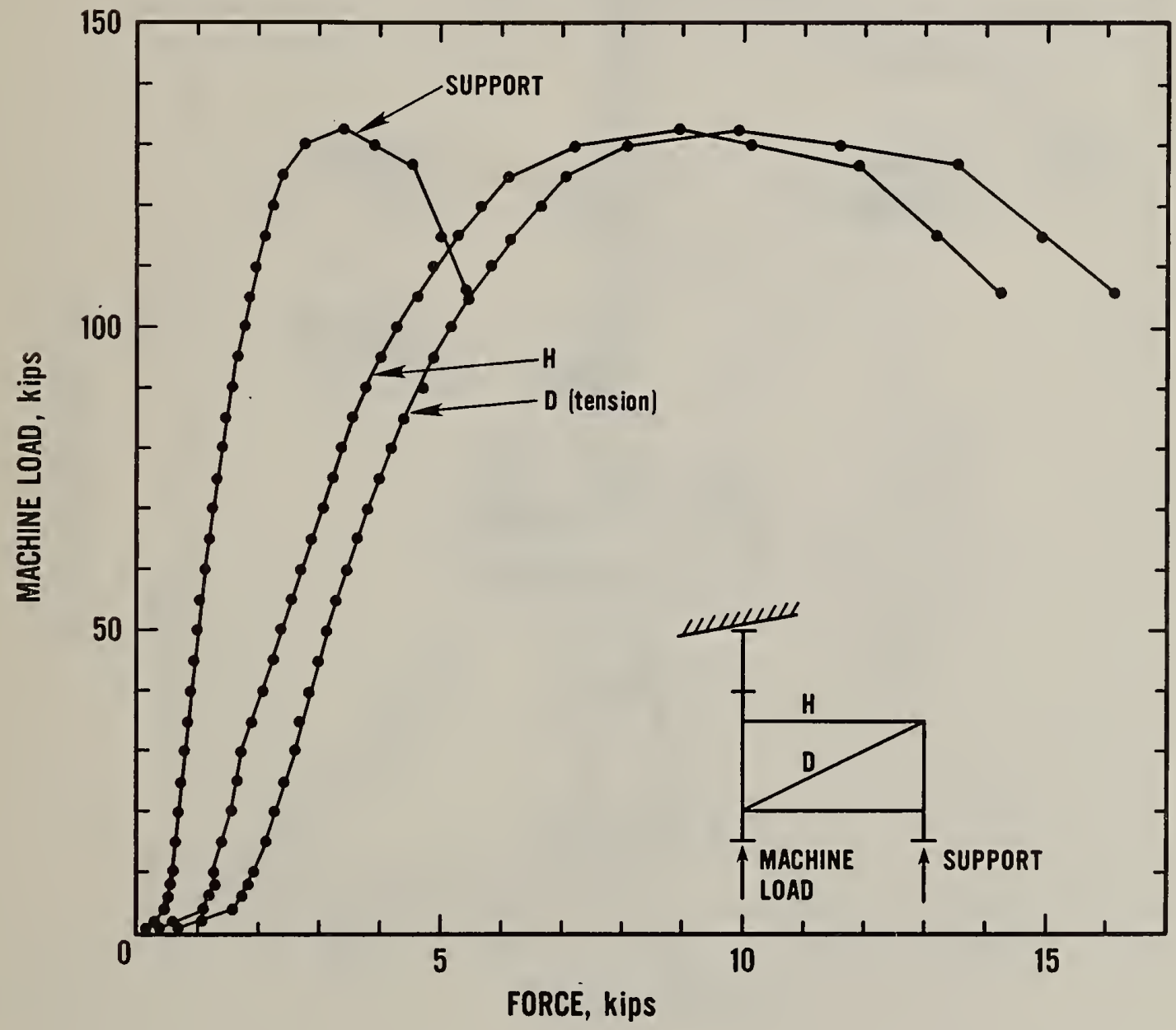

Figure 4.28 Variation of brace forces and support reaction as a function of vertical load (test $\# 2$ ) 


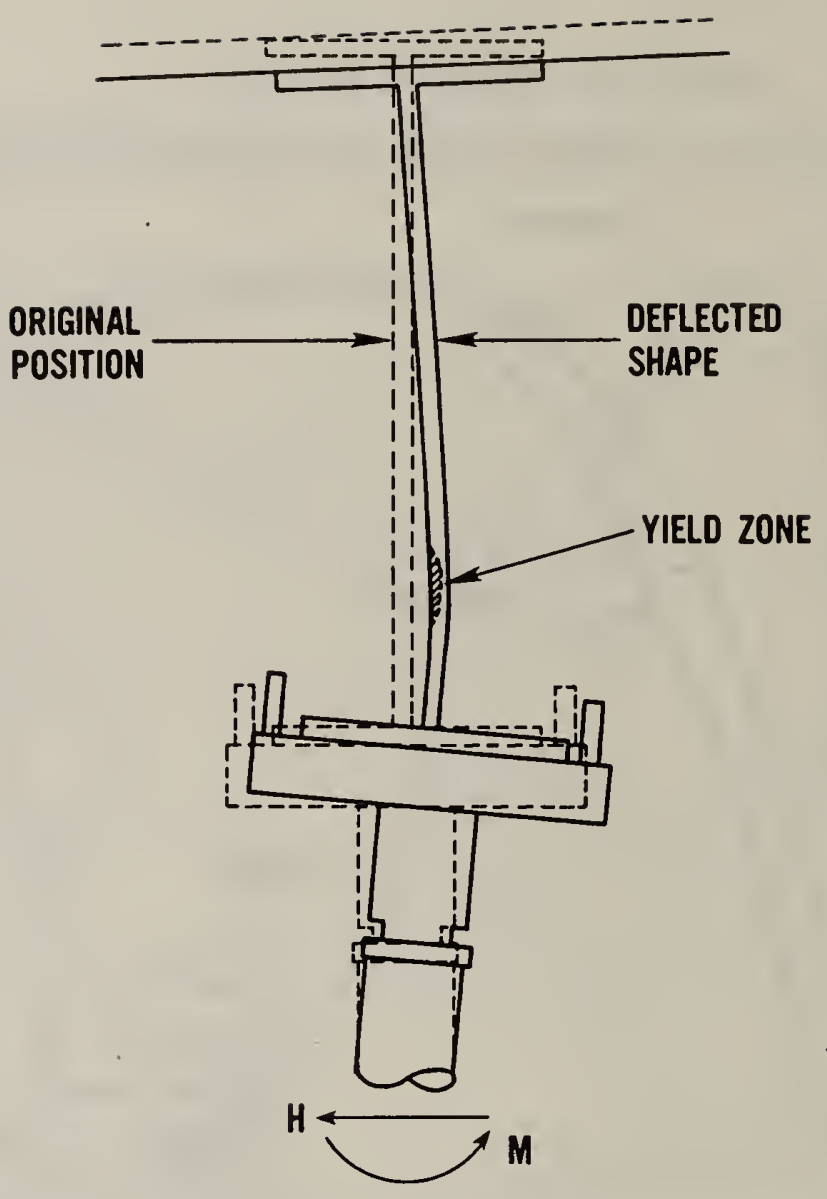

Figure 4.29 Schematic of deflected shape of crossbeam and top of U-head when wedges are not used between stringer and crossbeam 


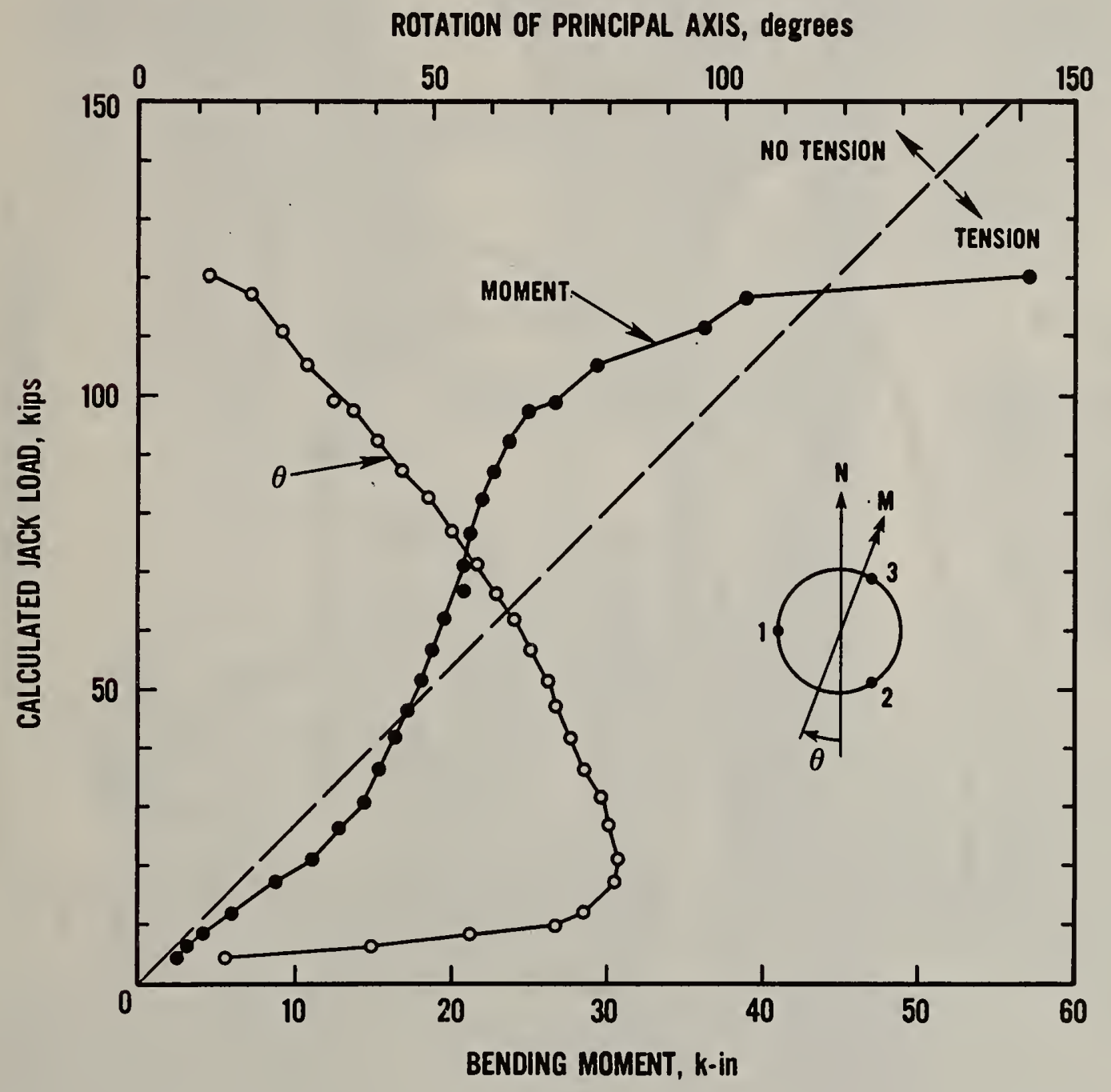

Figure 4.30 Variation of the magnitude and direction of the bending moment in the screw jack as a function of the vertical load (test \#1) 


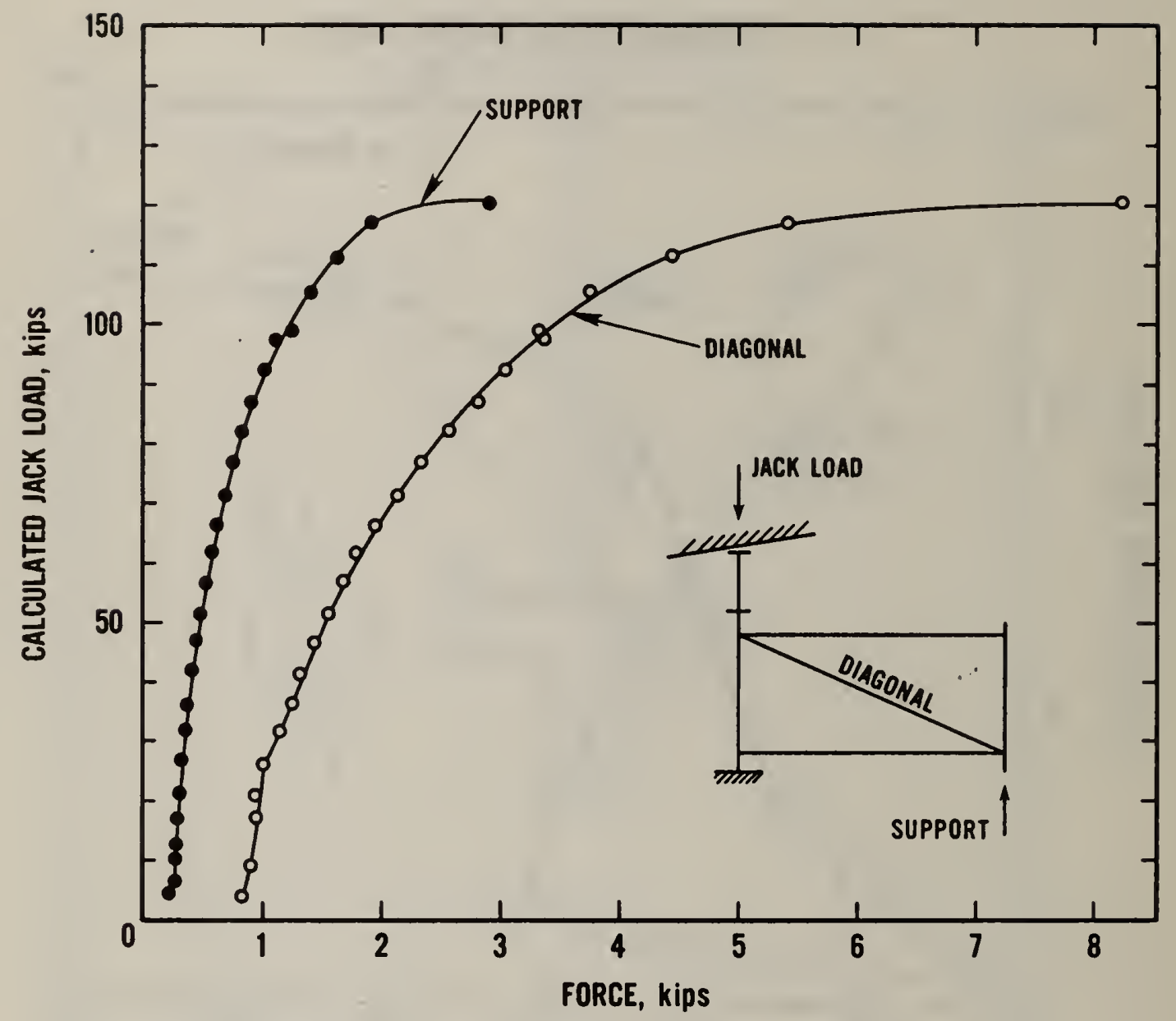

Figure 4.31 Varlation of brace force and support reaction as a function of vertical load (test \#1) 


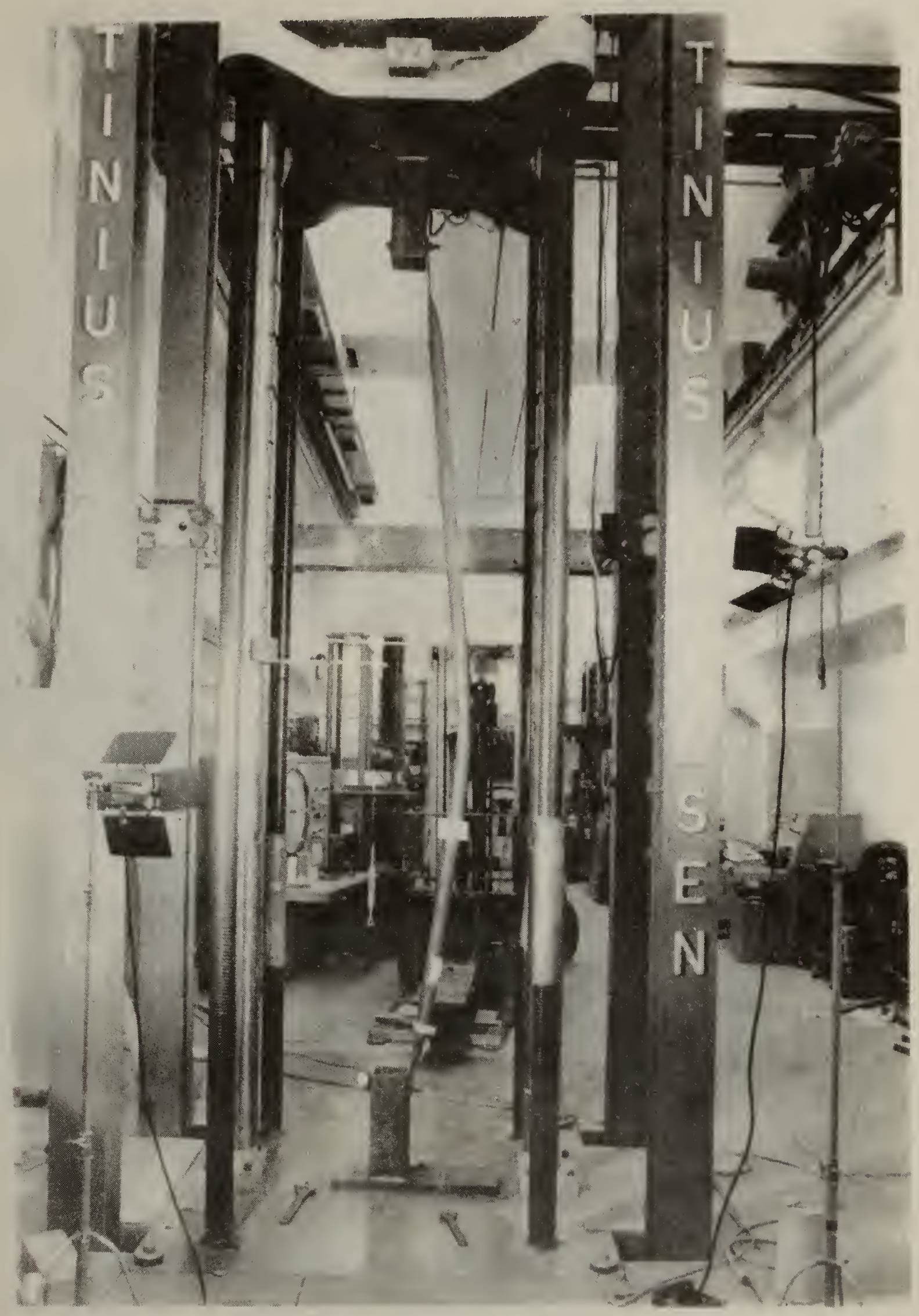

Figure 4.32 Arrangement for compression tests of diagonal braces 

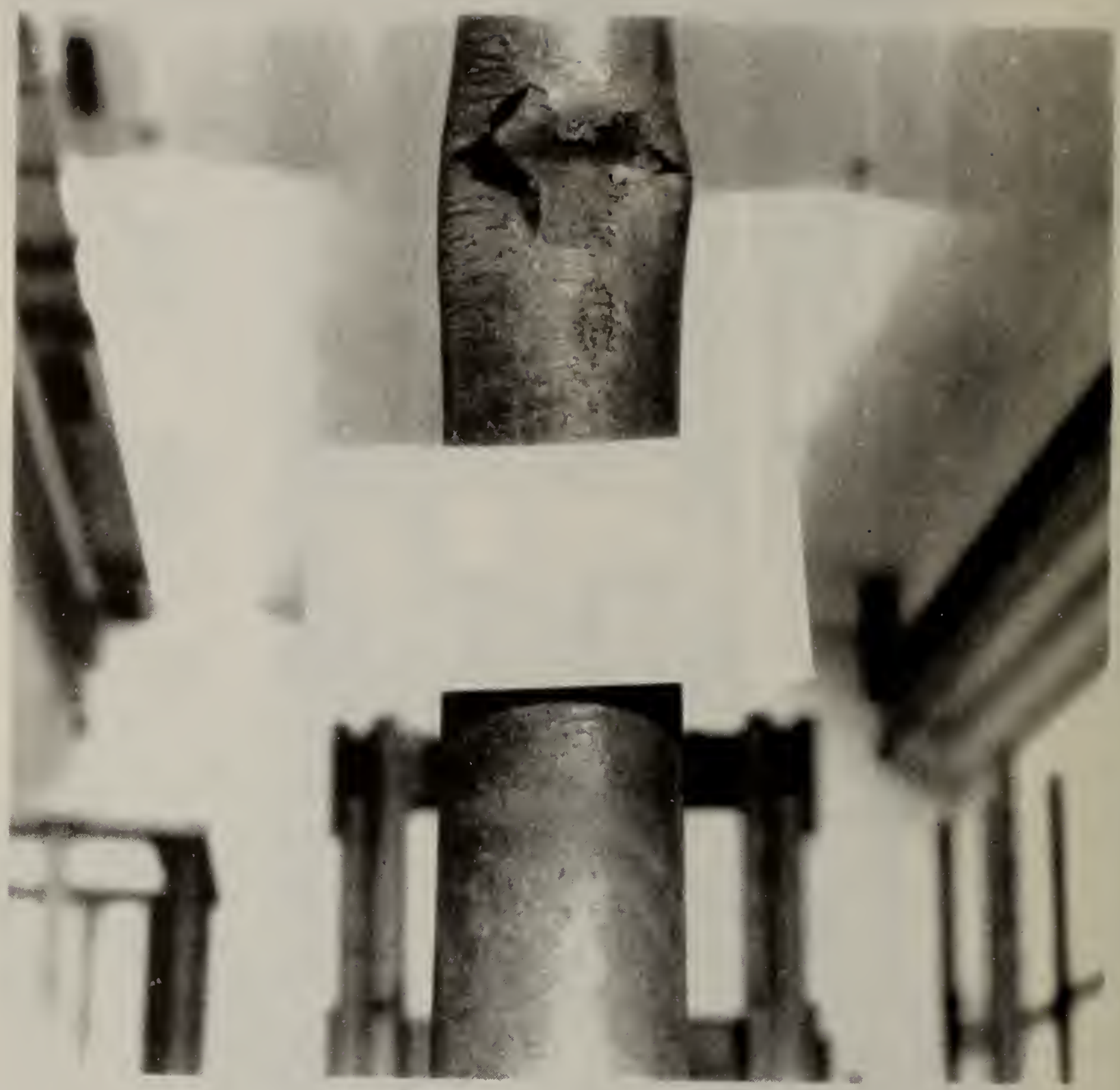

F1gure 4.33 Close up view of corroded region near coupler of brace 非 


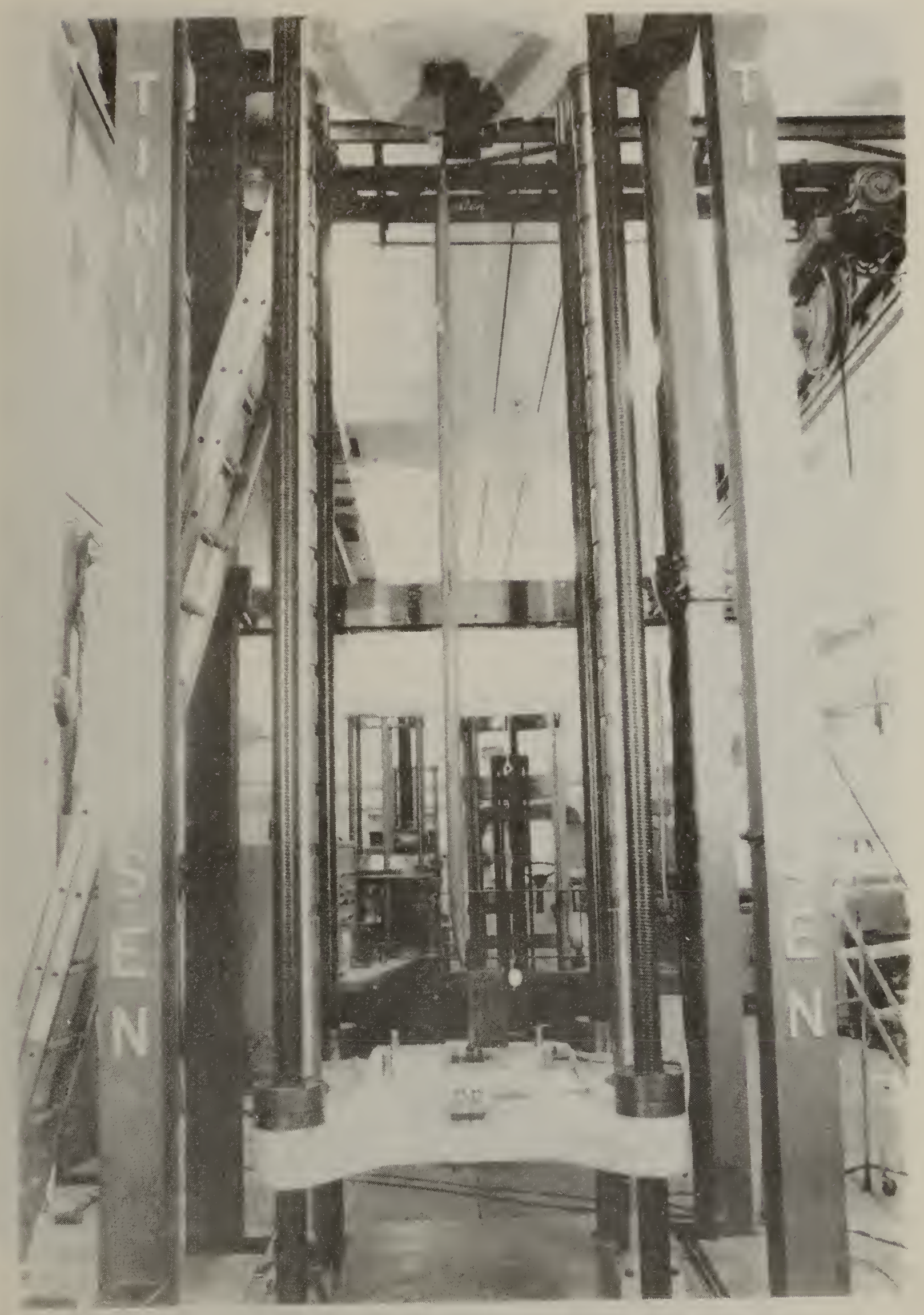

Figure 4.34 Arrangement for tension tests of diagonal braces 


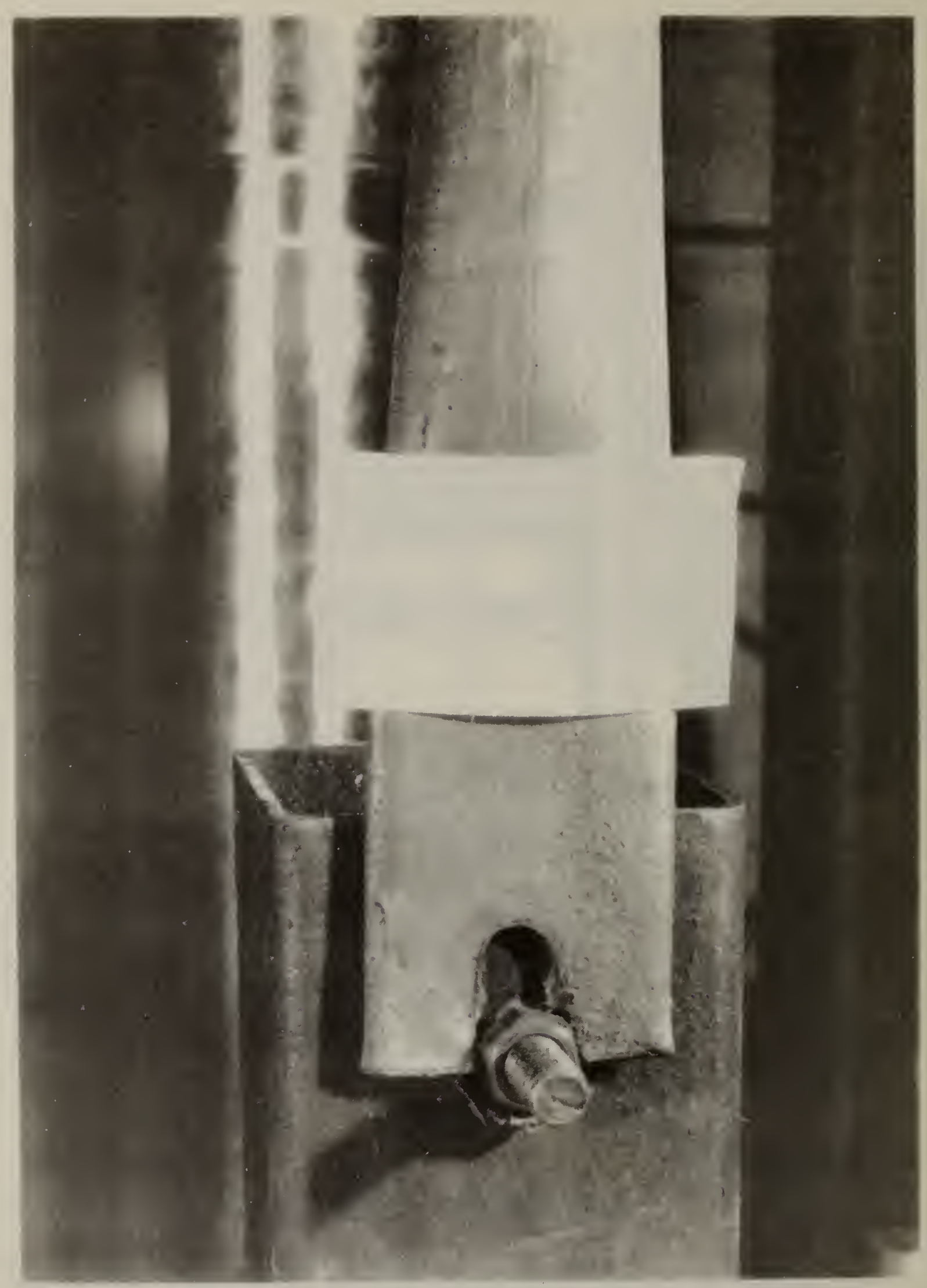

Figure 4.35 Tearing fallure at bolt connection of brace $\$ 5$ 
407.2

$i$

LOAD TEST \#1

4
$(A)$

1
$(E)$

\section{3}

(B)

\begin{tabular}{c}
2 \\
$(\mathbf{F})$ \\
\hline
\end{tabular}

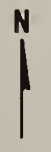

LOAD TEST \#2

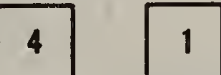

3

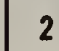

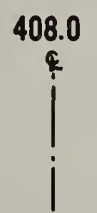

$\left[\begin{array}{l}\bar{C} \\ -\end{array}\right]\left[\begin{array}{l}-\bar{G} \\ {[-}\end{array}\right]$

$\left[\begin{array}{ll}-\bar{C} \\ 0\end{array}\right]$<smiles>CCCC</smiles>

$\approx 50^{\prime}$
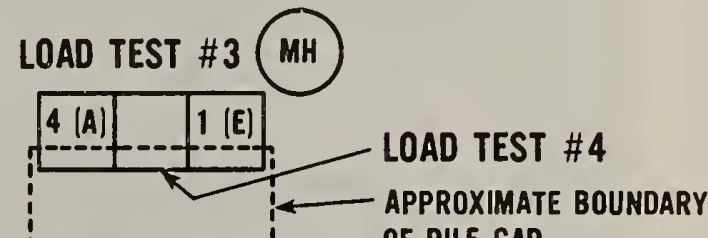
OF PILE CAP EXISTING PIER

NOTES:

1. $\square$ CONCRETE PADS FOR LOAD TEST

2. ? INDICATE THE LOCATIONS OF THE REMAINING PADS IN THE ORIGINAL LAYOUT

3. LETTERS MARKED ON THE PADS IDENTIFY THE LEGS OF THE SHORING TOWER

4. NUMBERS GIVEN TO THE PADS WERE THOSE USED DURING FIELD LOAD TESTING

Figure 4.36 Locations of full-scale load tests 

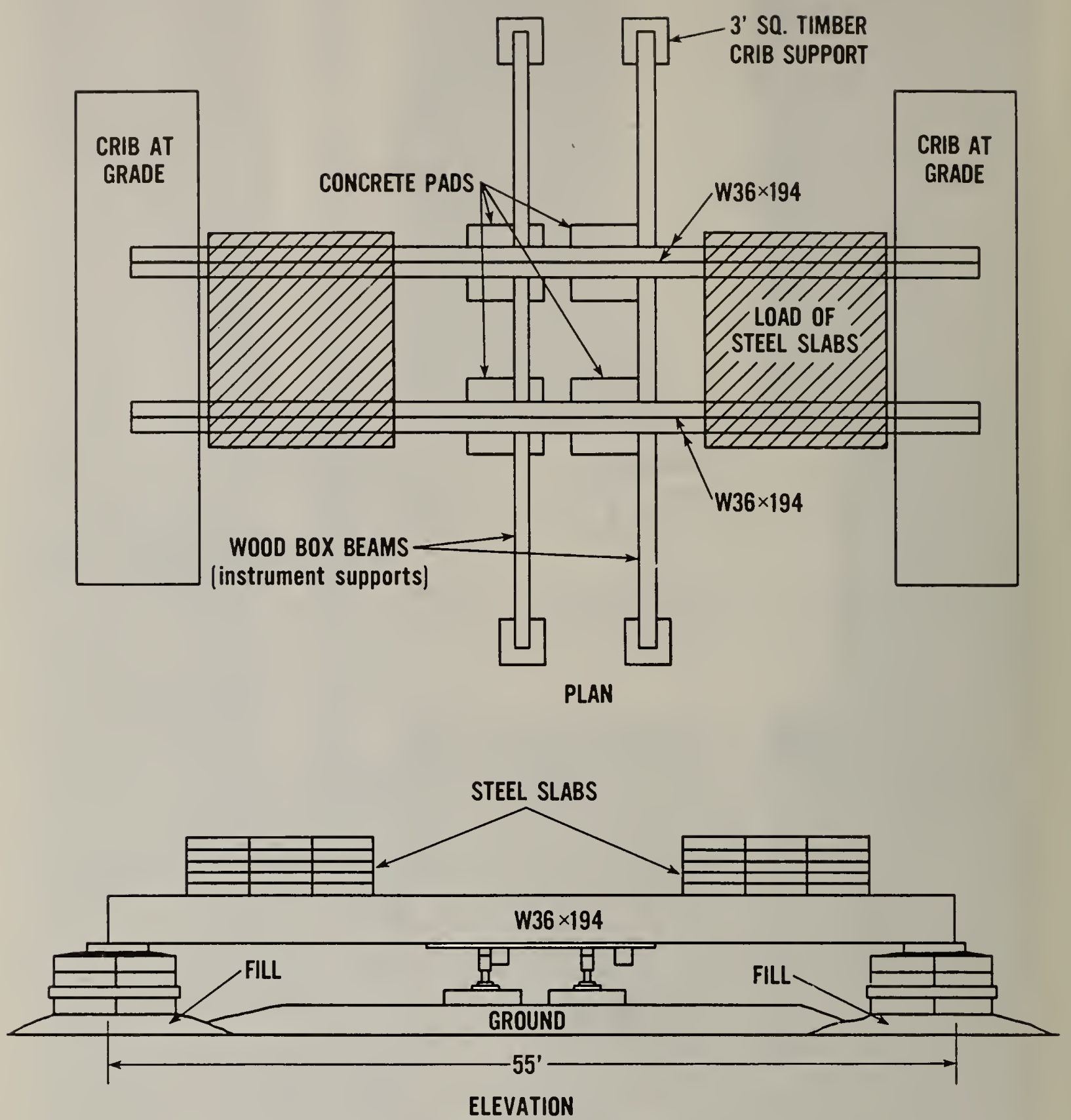

Figure 4.37 Layout of field load tests of concrete pads 


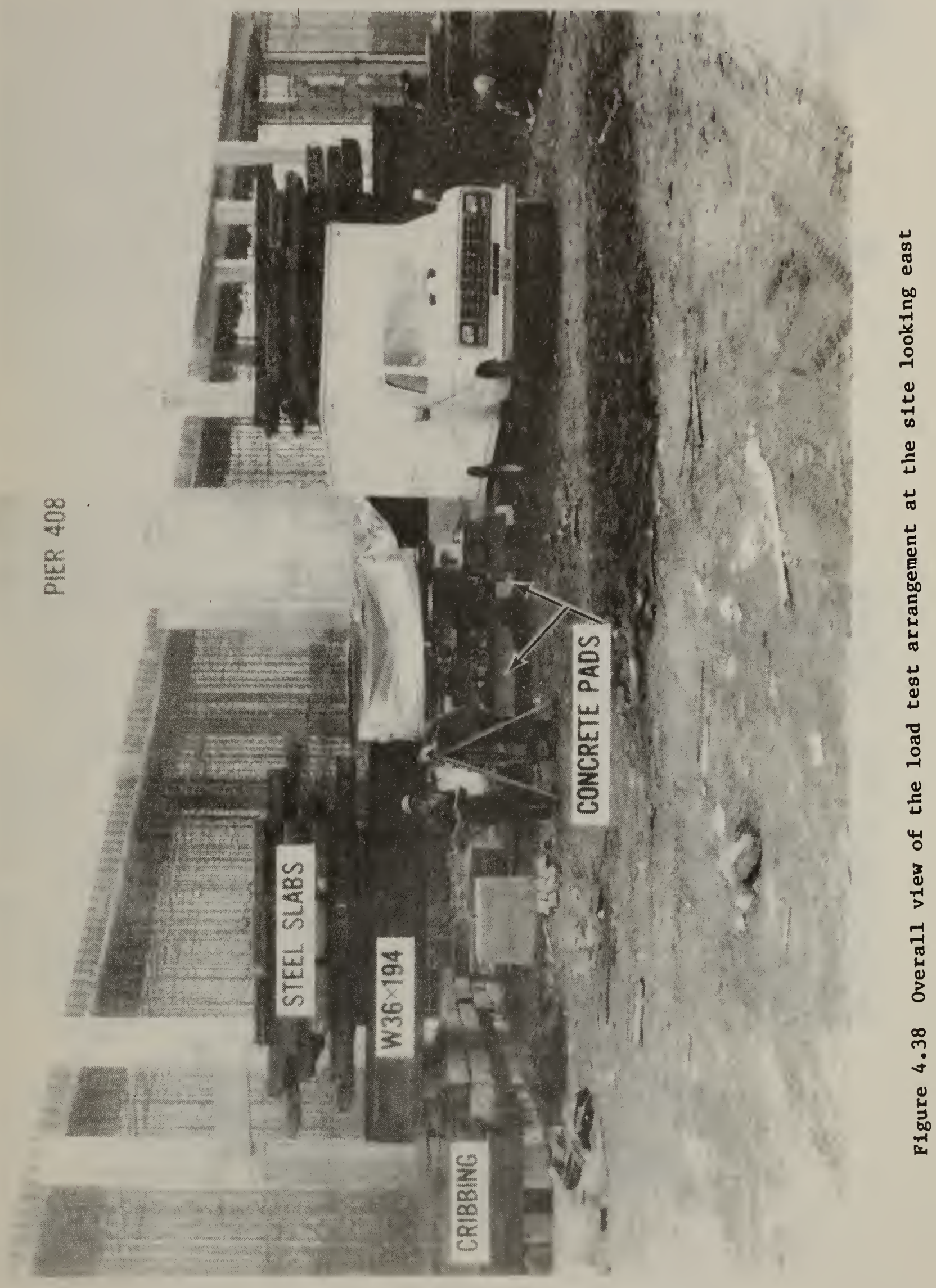



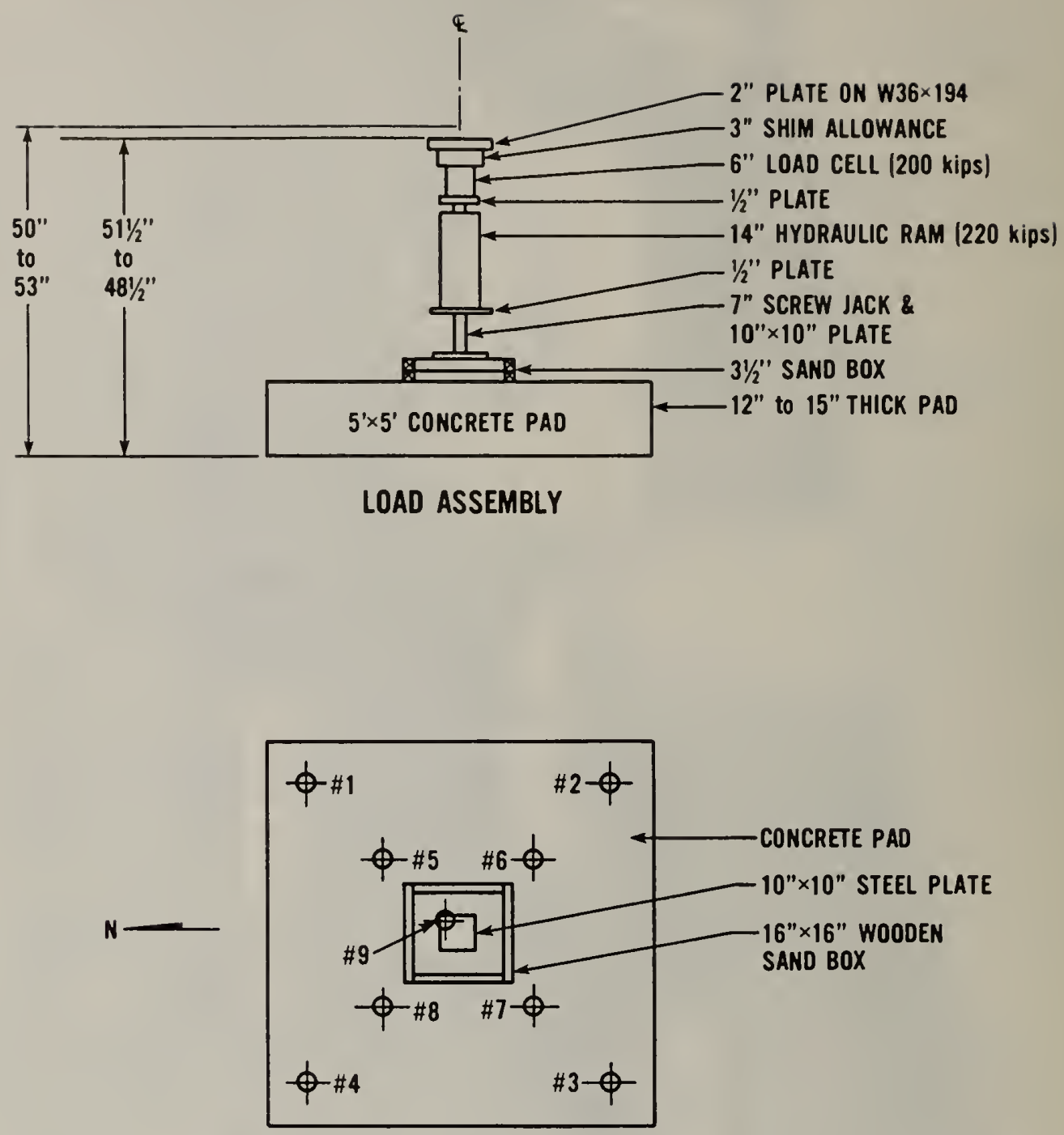

LAYOUT OF DIAL GAUGES

Figure 4.39 Load assembly and layout of dial gages on the concrete pad 


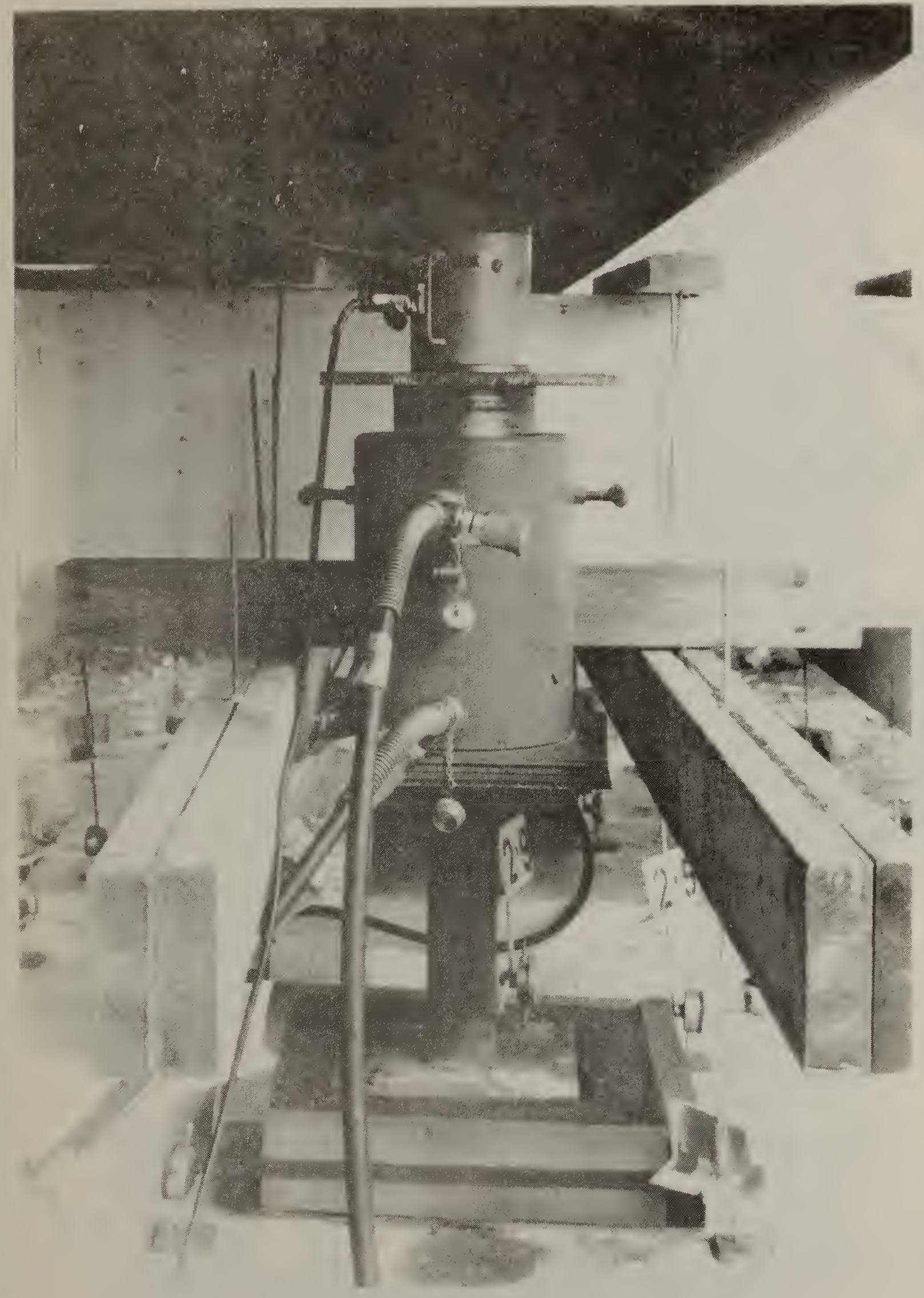

Figure 4.40 Close-up view of the load assembly 


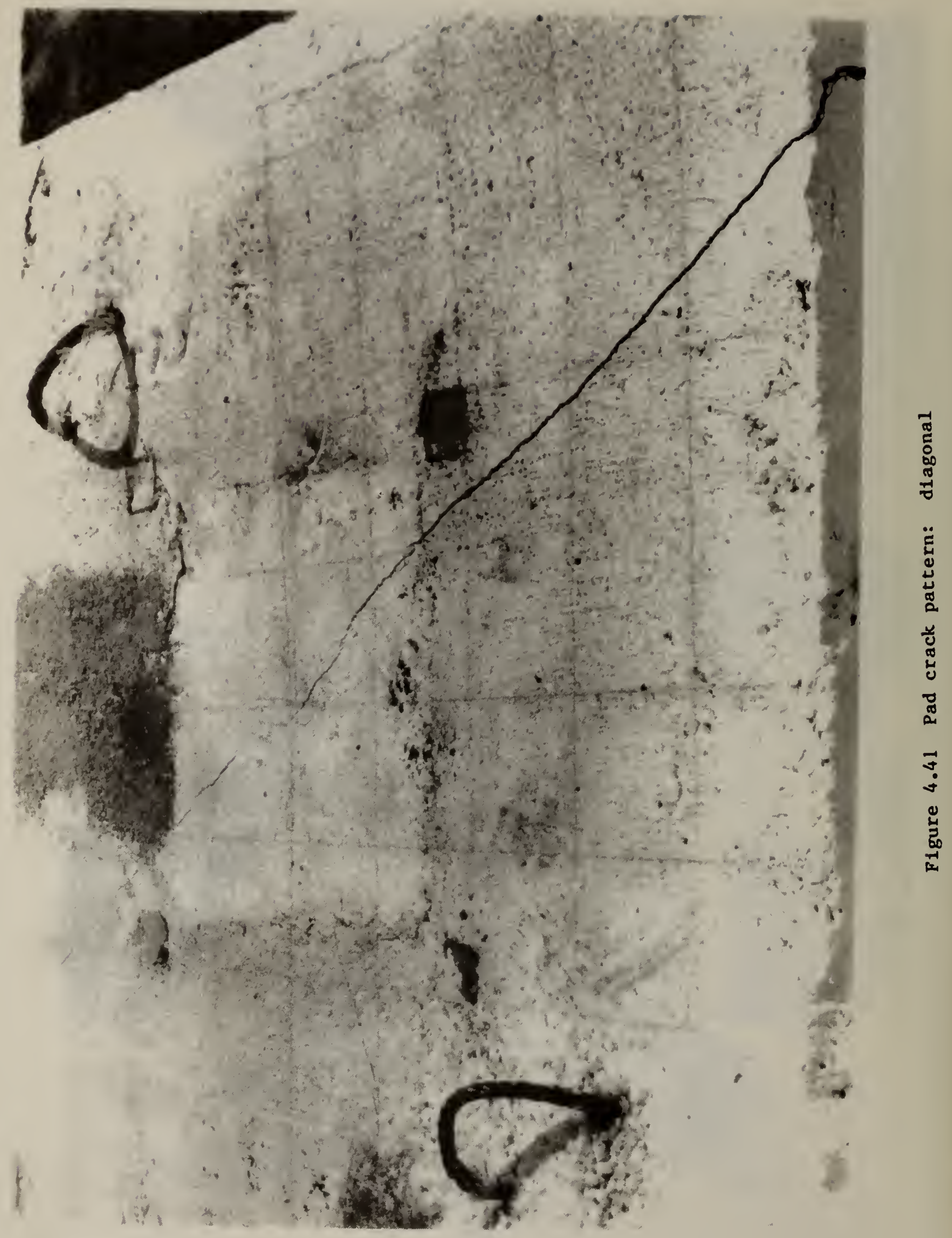




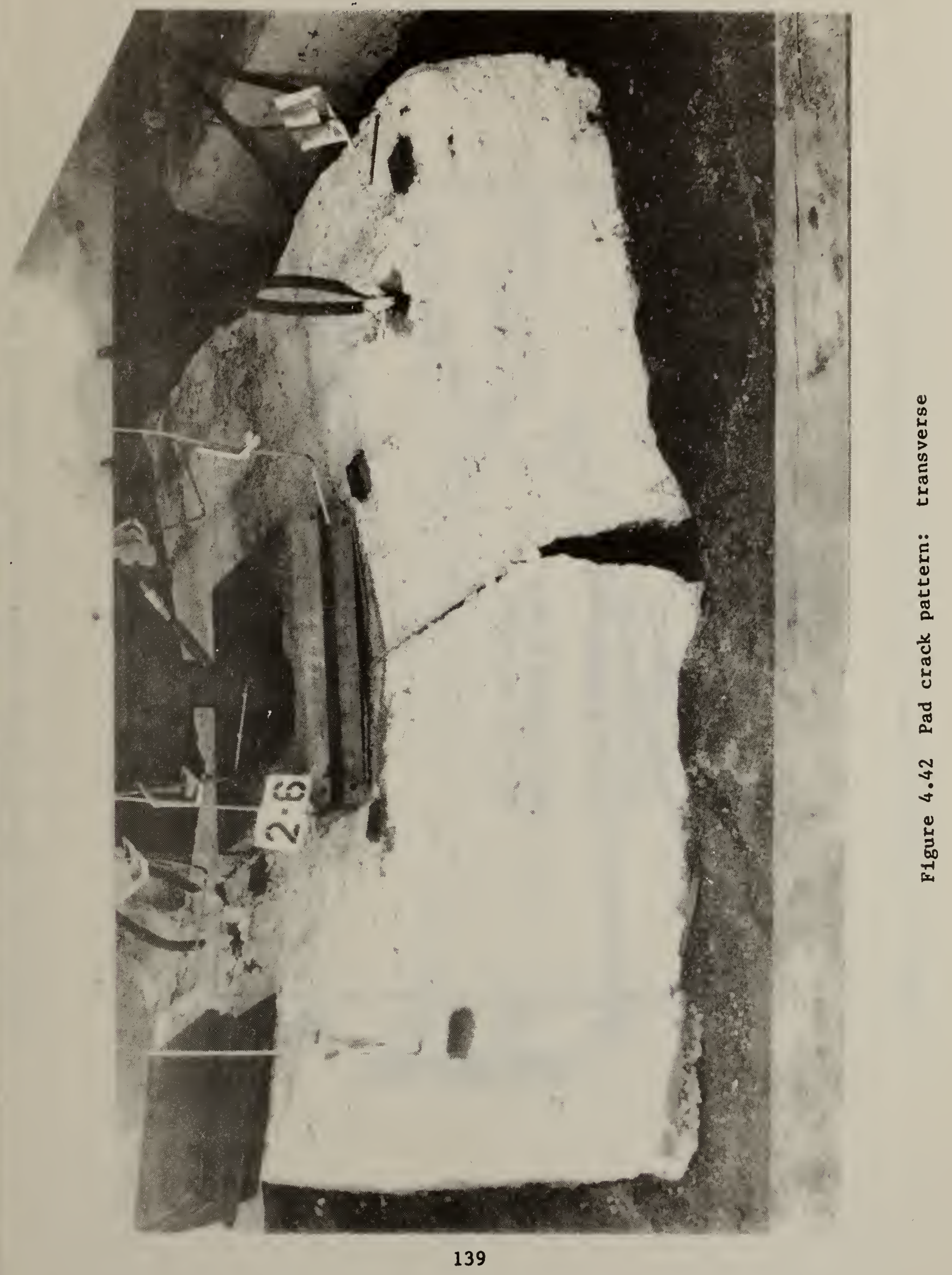




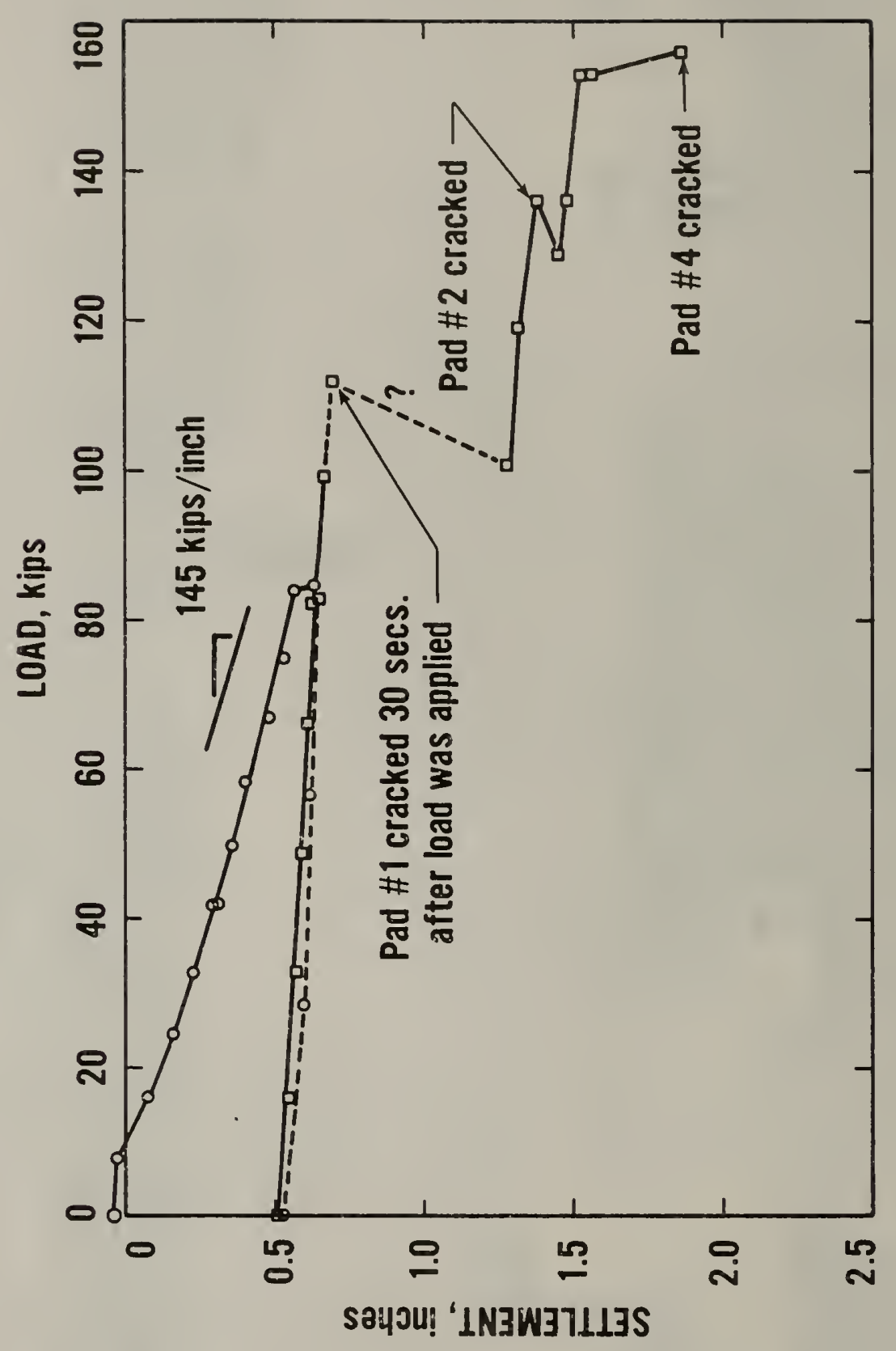

ت 


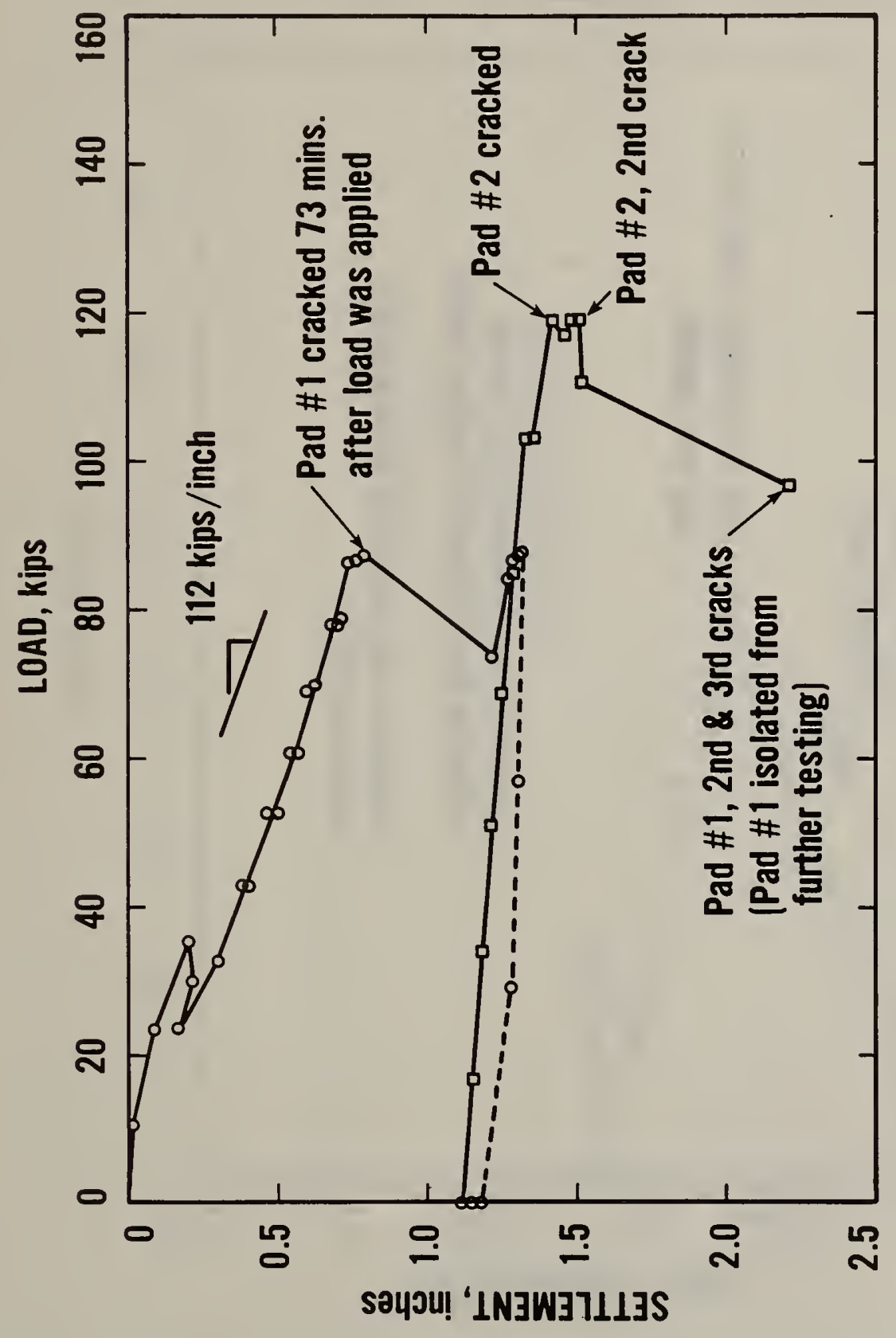

م 


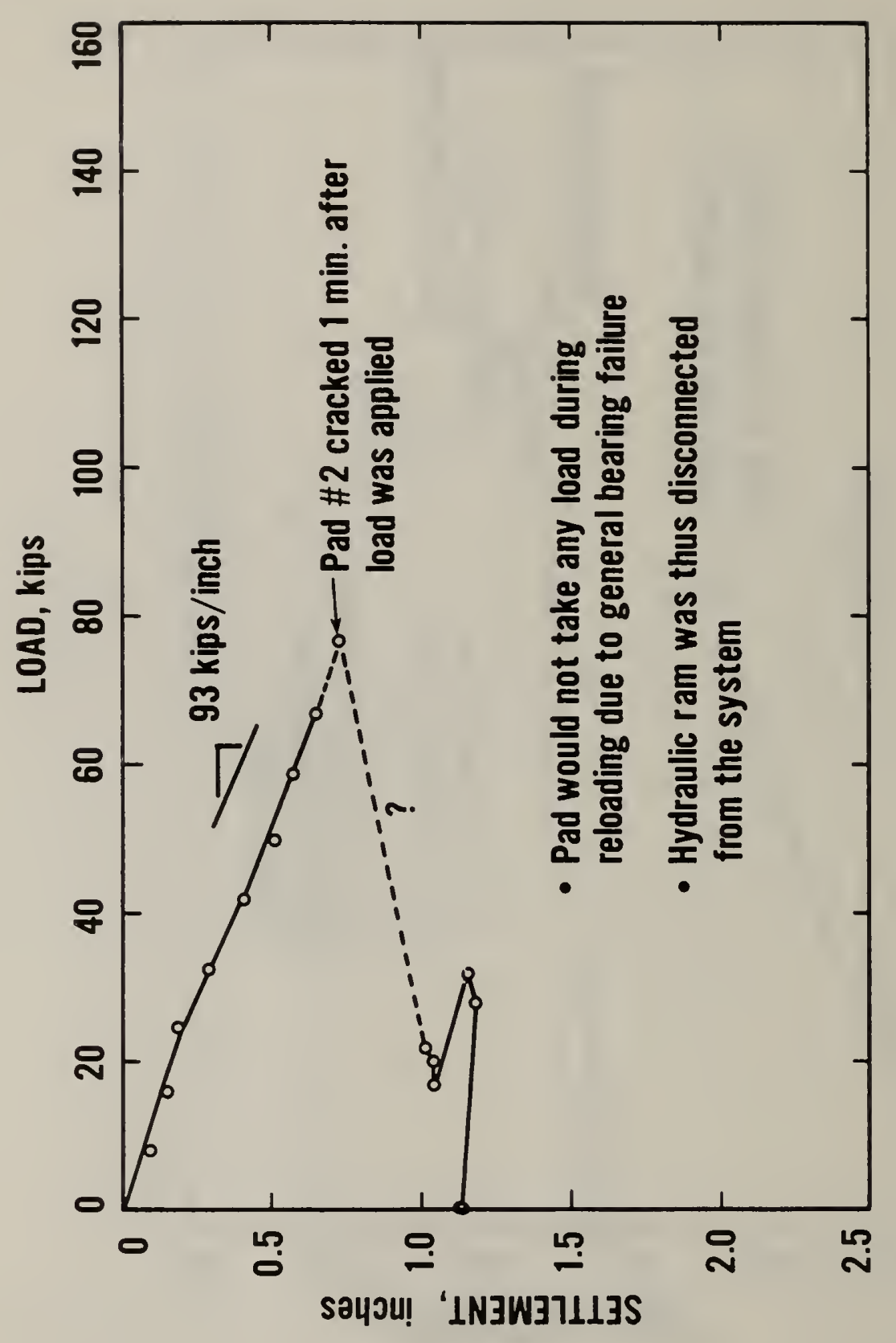

m 


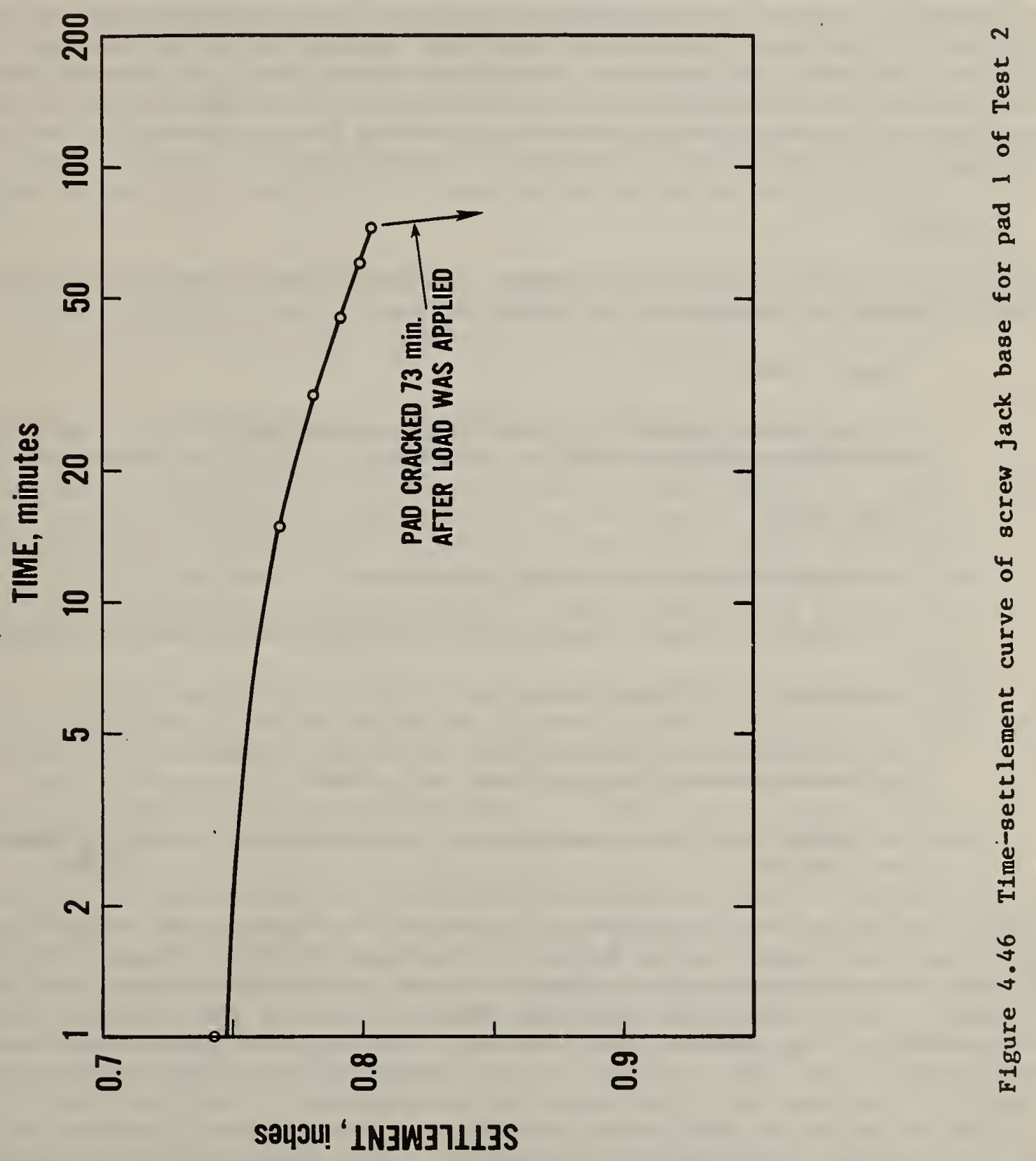




\section{ANALYTICAL INVESTIGATION}

\subsection{INTRODUCTION}

This chapter presents the analytical investigation of unit IV under conditions estimated to be existing at the time of the collapse. The results of the analyses are used in chapter 6 to determine the most likely trigger of the collapse. Chapter 6 also presents the results of additional analyses performed to explain a likely failure sequence leading to the total collapse of unit IV. Section 5.2 defines the structural loadings and the basis used in their calculation. . The basis for selecting the method of analysis and the detalls of the computational model are presented in section 5.3. The results of the analysis are presented and explained in section 5.4. A summary of the major findings in this chapter is presented in section 5.5 .

\subsection{LOADS}

The following list identifies possible sources of loading on unit IV and on the falsework at the time of collapse:

1. Impact loads.

2. The weight of construction workers and equipment (i.e., generators, screeding machines, etc.)

3. Wind loads.

4. The weight of steel shoring towers.

5. The weight of steel longitudinal stringers and transverse crossbeams.

6. The weight of timber formwork.

7. The weight of hardened concrete and reinforcement in the walls (webs) and bottom slab (flange) of the box girder.

8. The weight of fresh concrete and reinforcement in the top slab of the box girder.

Impact loads due to the placement of concrete are significant only if concrete is being discharged from the bucket to the formwork at the time of the collapse. It has been established that concrete was not being discharged at the time of collapse. In fact, worker testimony indicates that at the time of collapse, all members of the construction team on unit IV were taking a break on the east side of pier 408, and that no work was being done. This also indicates that any live load due to the construction personnel -- estimated at $3 \mathrm{kips}$ $(13 \mathrm{kN}$ ) -- would be transferred directly to the crossbeam CU 8.0 on the towers at 408. Location of the screeding machine and portable generators (estimated at $2 \mathrm{kips}(9 \mathrm{kN})$ load) were determined to be approximately $10 \mathrm{ft}(3 \mathrm{~m})$ behind the limit of concreting at the time of collapse. 
The prevalling wind was estimated at $15 \mathrm{mph}$ ( $24 \mathrm{kph}$ ) approximately from the south based on weather reports from a nearby industrial plant. This corresponds to a wind load of only $1.1 \mathrm{kips}(4.9 \mathrm{kN})$ along the entire length of unit IV. Compared to the gravity loads of $1611 \mathrm{kips}$ (7.17 MN), the effect of such a wind on the structural behavior is not significant and therefore it was not included in the analytical study.

The self welght of the shoring towers was calculated based on an assumed steel density of $.000283 \mathrm{k1ps} / \mathrm{In}^{3}\left(7.83 \mathrm{Mg} / \mathrm{m}^{3}\right)$. This value was input directly into the computational model along with individual member cross-sectional areas. The longitudinal steel stringers were ascertained to be comprised primarily of W36 $\times 194$ sections and the transverse crossbeams were determined to be W24 x 68 sections. A notable exception to the above values was the heavier stringers in span 7.2 between towers 407.1 and 407.2. These had an estimated weight of 260 $1 \mathrm{bs} / \mathrm{ft}(4 \mathrm{kN} / \mathrm{m})$.

The timber formwork was comprised primarily of nominal $4 \times 6-1 \mathrm{n}(100 \times 150 \mathrm{~mm})$ joists together with $3 / 4-1 \mathrm{n}(19-\mathrm{mm})$ plywood decking. A density of $351 \mathrm{bs} / \mathrm{ft}^{3}$ $\left(560 \mathrm{~kg} / \mathrm{m}^{3}\right)$ (k1ln dried $\left.\mathrm{fir}[5.1]\right)$ was assumed in the calculation of formwork loads.

Based on the mixture proportions documented in the testing laboratory reports of the Indiana Department of Highways and based on the unit welghts of air-dry cores taken from units IV and $V$, it is estimated that the unit weight of fresh concrete being placed in the top slab of unit IV was $1491 \mathrm{bs} / \mathrm{ft}^{3}\left(2390 \mathrm{~kg} / \mathrm{m}^{3}\right)$. For the air-dry concreţe in the bottom "U"-section of unit IV a unit welght of $145 \mathrm{lbs} / \mathrm{ft}^{3}\left(2320 \mathrm{~kg} / \mathrm{m}^{3}\right)$ was used. Based on estimated steel quantities shown on the structural drawings, the reinforcing steel load was estimated at 5 $1 \mathrm{bs} / \mathrm{ft}^{3}\left(80 \mathrm{~kg} / \mathrm{m}^{3}\right)$.

Because of the two-phase method of construction (see chapter 2.3), the above mentioned loads are percelved by the structural system in two distinct sets. The first phase is the casting of the webs and bottom flange of the box girder, and figure 5.1 shows the manner in which the load is distributed down through the longitudinal stringers. Because the concrete is fluld at this stage, the load is carried directly to the formwork as a pressure load. The formwork then distributes the load to the stringers in the manner shown in figure 5.1. Continuity of the plywood and wood joists across the longitudinal steel stringers is taken into account. Wall forms for the box girder webs were not included in this analysis since they were not present at the time of collapse. For the same reason the unit weight of concrete in the "U"-section was assumed to be $1451 \mathrm{bs} / \mathrm{ft}^{3}\left(2320 \mathrm{~kg} / \mathrm{m}^{3}\right)$ since this was the estimated air-dry weight of the hardened concrete at the time of collapse. Note that the loads given in figure 5.1 are loads per longitudinal foot of deck.

For the first placement (Case I), the structural system for unit IV can be viewed as a discontinuous system of simply supported beams resting on towers $407,407.1,407.2,408$, and 408.1. Since the longitudinal stringers are simply supported at their ends on the crossbeams, all Case I loads can be reduced to equivalent point reactions on the six crossbeams of the towers at $407.1,407.2$, and 408 using the simple method of tributary areas. The contribution to the 
towers at 407.1 from the fresh concrete of unit IV supported by stringers between 407 and 407.1 can be computed on the basis of an equilibrium analysis. Likewise, the reactions at the towers at 408 from that portion of unit IV cast between 408 and 408.1 can be calculated on the basis of equilibrium. The crossbeam reactions for the towers at 407.1, 407.2, and 408 under the Case I loading are presented in figure 5.2.

Figure 5.3 illustrates the manner in which the welght of fresh concrete during the casting of the upper deck is carried down through the structure. From a static equilibrium analysis, the load transmitted via the wing form shoring posts to the outer stringers was calculated to be $0.51 \mathrm{kips}$ per longitudinal foot $(7.44 \mathrm{kN} / \mathrm{m})$ of deck. The load carried by the box-girder web consists of three components: a contribution of $0.626 \mathrm{kips} / \mathrm{ft}(9.14 \mathrm{kN} / \mathrm{m})$ of deck from the wing forms and concrete (calculated via static equilibrium); a contribution of $0.298 \mathrm{kips} / \mathrm{ft}(4.35 \mathrm{kN} / \mathrm{m})$ of deck from the concrete over top of the web; and a contribution of $0.46 \mathrm{kips} / \mathrm{ft}(6.71 \mathrm{kN} / \mathrm{m})$ of deck from the center forms and concrete based on an equilibrium analysis which assumes the center forms to act as a continuous unit aross the center shoring posts. The center shoring posts carried a load equal to $1.26 \mathrm{kips} / \mathrm{ft}(18.4 \mathrm{kN} / \mathrm{m})$ of deck, which includes both the weight of the forms and the fresh concrete.

During Case II -- the casting of the upper deck of the box girder - the loads will be transferred in a very different manner to the supporting towers than for Case I. This is because the hardened concrete in the lower "U"-section of the box girder acts as a continuous beam over the tops of the shoring towers. A continuous beam will yield significantly different results for the reactions at the tower supports than would be calculated using the simply supported beam analysis of Case I, particularly if there is differential settlement between any of the three tower groups in unit IV -- 407.1, 407.2, and 408. Furthermore, the stiffness of the box girder "U"-section [estimated at $E_{c} I_{c}=1.1(10)^{8}$ $\mathrm{kip}-\mathrm{ft}^{2}\left(4.5(10)^{7} \mathrm{kN}-\mathrm{m}^{2}\right)$ ] is more than nine times as stiff as the supporting stringers. For analysis, the loads applied to the "U"-section during the casting of the box girder deck can be assumed to be carried solely by the hardened "U"-section of the box girder with the stringers serving only to transfer bearing reactions to the crossbeams.

\subsection{METHOD OF ANALYSIS}

For cast-in-place structures utillzing high load capacity steel shoring, it has been shown [5.2] that a large redistribution in the axial load carried by the tower legs will take place if even a minor amount of differential leg settlement takes place. This situation is amplified in the case of unit IV where, due to the continuity of the structure attained from the box girder " $U$ "section, differential settlement of a tower can increase the load carried by adjacent towers. An accurate structural analysis would thus have to consider the behavior of unit IV and its supporting structure under various stages of construction, rather than simply an analysis of a single shoring tower under an assumed loading based upon tributary area calculations. For these reasons, two analytical models were developed and their results superimposed to obtain the structural load distribution prior to the collapse. A 1inear-elastic finite element program, the Sperry Univac implementation of ICES-STRUDL-II [5.3], was used for the analysis. 


\subsubsection{Case I Mode1}

Figure 5.4 shows the three-dimensional space frame/truss for shoring towers at 407.1, 407.2, and 408. The designations HL196, HL66 and HL33 refer to frame heights of $19 \mathrm{ft} 6$ in $(5.94 \mathrm{~m}), 6 \mathrm{ft} 6$ in $(1.98 \mathrm{~m})$ and $3 \mathrm{ft} 3$ in $(1.02 \mathrm{~m})$, in that order. The relative elevations of the towers, the longitudinal and lateral positioning, and superelevations were all taken from the surveyor's notes and the structural plans. The configuration of the tower units and the orientation of frame and truss bracing was determined from the analysis of photographs taken prior to the collapse (see section 2.4) and from fleld investigation of the wreckage. These data are presented in schematic form on the finite element model for tower 407.2 detailed in figures 5.5 to 5.8. Similar data for the towers at 407.1 and 408 are presented in appendix B. The cross-sectional dimensions and properties of the frame and truss bracing members, as well as the main compression legs were as indicated in the manufacturer's engineering drawings of the hi-load shoring towers. Field observations indicated some variation in the truss and frame braces: certain truss braces were joined at the middle via welded inner or outer sleeves; some frame units had been reinforced with 4-in $(100-\mathrm{mm})$ channels welded to the vertical sides of the square tubular frame braces; and some random variation in the diameters of the truss braces were noted on varlous towers. While these variations may affect the ultimate strengths of the members in tension or compression, they produce very little change in the load distribution characteristics of the towers and hence were not considered in the analysis. Some frame members had additional $1.25-$ in $(32-\mathrm{mm})$ O.D. crossbraces welded into place and these were included in the analysis. Also included in the structural model of the towers were the horizontal diagonal braces that were used at the junctions of the frame units. The nominal cross-sectional tower member properties used in the analysis are listed in table 5.1. As shown in figures 5.5 through 5.8 , the truss braces occupied positions in the eastwest vertical plane, while frame braces were orlented in the north-south vertical planes. The coupler joints between the prefabricated shoring tower frames were assumed to provide translational (shear), but no rotational (bending) restraint.

Because of the lack of wedges between the longitudinal stringers and the supporting crossbeams, it has been determined from tests (see chapter 4) that horizontal forces are introduced into the upper screw jacks at the bottom of the crossbeams. As illustrated in figure 4.28, the magnitude of this horizontal force increases fairly linearly with increasing axial load until the onset of ylelding in the web of the crossbeam. For a vertical load of $100 \mathrm{kips}$ the horizontal force component was equal to at $2.4 \mathrm{kips}(10.7 \mathrm{kN})$. This force, due to the geometry of the contact surface as evidenced in the deflected shapes of the tests (figure 4.29), would be directed parallel to the longitudinal axis of the bridge in an easterly direction (for unit IV). To account for this additional force in the analytical study, a mechanistic model as show in figure 5.10 was employed. This transforms the vertical stringer reaction into an equivalent vertical load at the screw jack top, plus a horizontal component derived from a linear approximation of the experimentally measured loads. In falsework assembly test 非 2 the horizontal force was measured indirectly by the various strain gage and load cell elements which monitored forces in the horizontal and diagonal braces. The horizontal force at the screw jack was back 
calculated via a computer structural analysis of the test specimen and the consideration that equilibrium of internal forces and external reactions must be maintained. This gave the approximate variation of the horizontal force (H) with the applied vertical stringer load (P) as shown in Fig. 5.10b. An 1mplic1t assumption in the computer model, as 1 llustrated in Fig. $5.10 \mathrm{c}$, is that longitudinal (to the east or west for unit IV) deformation in the structural system is restricted to the shoring towers: the box girder and superstructure formwork are assumed to undergo no longitudinal translation. This can be visualized as follows: due to the rotation of the crossbeams at the towers at 407.2 and at 408, horizontal forces acting towards the east are introduced into the shoring towers. The reactions acting on the superstructure are directed to the west, and thus will be resisted by direct bearing of unit IV with unit III. Given the small magnitude of these horizontal forces, the axial deformation of the superstructure was assumed to be negligible. The effect of crossbeam rotation was not included for the 407.1-towers, because for this case the U-heads were orlented so that they accommodated the roadway slope and the horizontal force would not exist, see figure 3.10. Any transverse horizontal forces which might have existed at 407.1 due to the superelevation were neglected in the analysis because of the low value of the superelevation (the transverse slope) in unit IV (see fig. 2.2).

For the Case I analysis the loading configuration shown in figure 5.1 is used in conjunction with the dead weight of the tower elements. The support stiffnesses, as determined from the fleld load tests described in chapter 4, are given in table 5.2 .

\subsubsection{Case II Model}

During the casting of the upper deck, the hardened box girder "U"-section carries the majority of the live load from the fresh concrete and transfers it to the underlying shoring towers via direct bearing through the stringers and the crossbeams. The stringers themselves are assumed to carry none of the live load along their span during this construction phase. The box girder was modeled using rectangular overlapping plate bending (type BPR) and membrane (type PSR) finite elements. These elements are described in reference [5.3]. The finite element mesh used to define the box girder "U"-section and its relative connectivities with the support towers is shown in figure 5.9. A number of assumptions were made in defining the boundary conditions and element connectivities for the analytical model in Case II. Because the construction joint to unit III had been cast two days prior to the collapse, it was assumed that translational, but not rotational, restraint was present there at the time of the collapse. The translational elastic restraints were defined as follows: In the $Z$ direction (positive to the east, along the longitudinal axis of the roadway) a spring support was assumed with a stiffness equal to the axial deformation of unit III under a unit load of $1 \mathrm{klp}(4.45 \mathrm{kN})$; in the Y-direction (vertical, or elevation, positive up) the spring stiffness was equal to the vertical deflection of the east end of unit III under an applied load of $1 \mathrm{kip}$, with unit III assumed to act as a propped cantilever fixed at pier 406 . In a like manner the X-direction (transverse, positive north) spring stiffness was calculated from the application of a transverse 1-kip ( $4.45 \mathrm{kN}$ ) load to the propped cantilever structure defined above. The elastic stiffness of the 
supports at the base of the shoring towers were the same as for Case I (table 5.2).

For simplification of the model, the box girder "U"-section was attached to the crossbeams by means of short $(0.1 \mathrm{ft}(0.03 \mathrm{~m}))$, stiff connecting members which simulated the manner in which load was carrled via bearing, down through the W36 stringer to the W24 crossbeams. Because in the actual structure no tensile vertical forces (generated by uplift of the box girder) can be supported by the stringers and crossbeams a no-tensile force criterion was employed for the connecting members between the box girder and the crossbeams.

As with the Case I analysis, the joints between the shoring tower frames were assumed to provide translational, but not rotational restraint. The loading configuration for Case II (as shown in flgures 5.3 and 5.9 ) consists of two components: that carried directly by the box girder "U"-section, and that transferred to the outer stringers by the exterfor shoring posts. These latter loads are subsequently applied to their respective crossbeam reaction points as concentrated forces. The former are applied as line loads to the webs and centerline of the bottom flange of the hardened box girder.

The superposition of the member forces and deflections calculated for Case I and Case II above will yleld the structural forces in the falsework system supporting unit IV.

\subsection{RESULTS}

The force distribution in the falsework system of unit IV was calculated via superposition of the Case I (first casting plus the self weight of the shoring towers) and the Case II (second casting) loadings described in the preceding sections. For this analysis all concrete pads are assumed to be uncracked and all other components of the falsework system retained their structural

integrity.

\subsubsection{Support Reactions}

Table 5.3 lists the support reactions for the towers at $407.1,407.2$ and 408 . Two important conclusions can be drawn from these data. First, the towers at 407.2 carry nearly 50 percent more load than the towers at 407.1 and 408 . The majority of this difference is introduced during the casting of the box girder deck (Case II). It can also be seen that for each shoring tower system ( 407.1 , 407.2, and 408.) the easternmost set of legs ( $E, F, G, H)$ carries more load than the western set $(A, B, C, D)$. From this analysis it can be seen that the two most heavily loaded supports were legs $F$ and $G$ of the towers at 407.2 , each carrying a load of $90 \mathrm{kips}(400 \mathrm{kN})$. The construction joint with unit III is shown to carry a vertical load of $81 \mathrm{kips}(360 \mathrm{kN})$, which is well below its capacity based upon the specifled concrete strength. 


\subsubsection{Crossbeam and Stringer Reactions}

Figure 5.11 shows the stringer and crossbeam reactions at the 407.2 -towers. The greatest stringer reactions occur at beams beneath the box girder web. Stringers S2 and S4 on the west side of the 407.2-towers (span 7.2) each transfer a load of $117 \mathrm{klps}(516 \mathrm{kN})$ to crossbeam CD 7.2. The greatest crossbeam reactions (loads tranferred to the U-heads) were $86 \mathrm{klps}(378 \mathrm{kN}$ ) and occurred at the U-heads for tower legs $B$ and $C$. The slightly higher stringer and crossbeam reactions on the $A-B-C-D$ side of the towers resulted from the Case II (continuous box girder) analysis during which the horizontal forces developed from the crossbeam rotation gave rise to greater support deflections on the E-F-G-H side, and hence a slight unloading of the stringers supported by CU 7.2 .

\subsubsection{Truss Brace Loads}

Truss braces are those bracing elements lying in the east-west (longitudinal) vertical plane which were bolted into place at the time the tower units were assembled. These are to be distinguished from the frame braces which were shop welded to the tower legs and were oriented in the north-south (transverse) vertical plane. Frame and truss brace designations for the towers at 407.2 and defined in figures 5.5 through 5.8 .

Because of the strength of the welded connections, the greater cross sectional area of the frame braces, and the relatively small forces set up in the northsouth vertical planes, the welded frame braces (usually $2 \times 2-1 \mathrm{n}$ ( $51 \times 51-\mathrm{mm}$ ) square tubing) are not of particular concern to the fallure analyses of unit IV. The truss braces, however, are of considerable interest. Due to the horizontal forces induced at the tops of the shoring towers, significant forces are set up in the truss braces. These forces are further increased by any differential settlement which may occur at the tower supports, either through soll settlement or cracking of a concrete pad. The test results detalled in chapter 4 indicate low buckling loads for the diagonal truss braces (between 5.3 and $7.1 \mathrm{kfps}(24$ to $32 \mathrm{kN})$ ) and tensile fallure loads between 12.3 and $13.3 \mathrm{kfps}$ (55 $\mathrm{kN}$ and $59 \mathrm{kN}$ ).

Fig. 5.12 gives the truss brace forces for the intact towers at 407.2 . As previously pointed out, in the discussion of the support reactions, the towers at 407.2 carry substantlally higher loads than the towers at 407.1 and at 408 . The truss brace forces for these latter towers are thus considerably smaller than those for the 407.2-towers. Thus, and truss brace forces for the towers at 407.1 and 408 are not presented here.

Figure 5.12 depicts the truss brace forces for the towers at 407.2. From this figure, it is seen that the inner truss panels (FB, GC) are slightly more heavily loaded. The maximum values in tension are $5.6 \mathrm{kfps}(25 \mathrm{kN})$ for brace $72 \mathrm{EA} 2$ and $5.5 \mathrm{kfps}(24 \mathrm{kN})$ for braces $72 \mathrm{FB} 2$ and $72 \mathrm{GC} 2$. The maximum values in compression are $-5.4 \mathrm{kips}(-24 \mathrm{kN})$ for braces $72 \mathrm{FB} 9$ and $72 \mathrm{GC} 9$. 


\subsection{SUMMARY}

Because of the two-stage construction method, it was necessary to develop a series of analytical models which would accurately reproduce the response of unit IV and its supporting structure under varlous states of loading. Furthermore, the three-dimensional nature of the problem, and the structural interaction of widely separated components, required a three-dimensional analysis.

Two cases were analyzed and their results superimposed to obtain the member forces and support reactions:

Case I: The shoring towers are modeled as independent units with support stiffnesses derived from the full-scale fleld tests of concrete pads. Since the falsework assembly tests revealed that significant horizontal loads were transmitted to the U-heads, this force was included in the tower models via a discrete mechanical linkage model. The vertical stringer-to-crossbeam reactions were calculated on the basis of tributary area considerations and equilibrium analyses for all loads acting above the crossbeams at the time of the casting of the bottom flange and web sections of the concrete box girder. The self welght of shoring tower components were also included in this analysis.

Case II: At the time of the casting of the box-girder deck, the majority of the additional load applied to the structure was carried by the hardened "U"section of the box girder rather than by the stringers. This comprises a distinctly different structural system than that defined in Case $I$. The hardened "U"-section of the box girder formed a continuous member over the towers at $407.1,407.2$, and 408, and 1t was physically joined to unit III by means of a construction foint. To analyze this case, the box girder was modeled using overlapping plate bending and membrane finite elements which were linked to the Case I model. The construction joint support to unit IV was modeled as a series of translational spring restraints based on the calculated stiffness of unit III.

The analysis indicated that the towers at 407.2 were the most critically loaded substructures in unit IV. Support reactions of $90 \mathrm{kips}(400 \mathrm{kN}$ ) were calculated at legs $F$ and $G$. The maximum stringer bearing reaction was found to be $117 \mathrm{kips}(516 \mathrm{kN})$ for stringers $\mathrm{S} 2$ and $\mathrm{S} 4$ resting on crossbeam CD 7.2. The maximum load transferred to the U-head was $86 \mathrm{kips}(378 \mathrm{kN}$ ) for tower legs B and $C$. The maximum truss brace forces were $5.6 \mathrm{klps}(25 \mathrm{kN})$ in tension at brace $72 \mathrm{EA} 2$ and $-5.4 \mathrm{kips}(-24 \mathrm{kN})$ in compression at braces $72 \mathrm{FB} 9$ and $72 \mathrm{GC} 9$. In the next chapter the loads computed above will be compared to the structural capacities of the varlous falsework components. 
Table 5.1 Tower Member Propertles

\begin{tabular}{|c|c|c|c|}
\hline Member & $\begin{array}{c}\text { Nominal Dimensions } \\
\text { (Inches) }\end{array}$ & $\begin{array}{c}\text { Area } \\
A_{x}\left(\ln ^{2}\right)\end{array}$ & $I_{x}=I_{y}\left(1 n^{4}\right)$ \\
\hline $\begin{array}{l}\text { Maln compression } \\
\text { legs }\end{array}$ & $\begin{array}{l}6 \times 6 \times 0.25 \\
\text { (square tube) }\end{array}$ & 5.54 & 29.9 \\
\hline Frame braces & $\begin{array}{l}2 \times 2 \times 0.11 \\
\text { (square tube) }\end{array}$ & 0.832 & 0.497 \\
\hline $\begin{array}{l}\text { Extra frame } \\
\text { bracing (optional) }\end{array}$ & $\begin{array}{l}1.250 . D_{.}, 1.03 \text { I.D., } \\
\text { (round tube) }\end{array}$ & 0.394 & .065 \\
\hline Truss braces & $\begin{array}{l}2.50 . D_{.}, 2.31 \text { I.D. } \\
\text { (round tube) }\end{array}$ & 0.718 & -- \\
\hline $\begin{array}{l}\text { Upper and lower } \\
\text { screw jack legs }\end{array}$ & $2.910 . D .($ solid) & 6.61 & 3.47 \\
\hline
\end{tabular}

Table 5.2 Support Stiffnesses for Unit IV (kips/inch)

Leg Tower 407.1 Tower 407.2 Tower 408.

$\begin{array}{llll}\text { A } & 115 . & 115 . & 95 . \\ \text { B } & 115 . & 115 . & 95 . \\ \text { C } & 115 . & 115 . & 95 . \\ \text { D } & 115 . & 115 . & 95 . \\ \text { E } & 115 . & 115 . & 95 . \\ \text { F } & 115 . & 115 . & 95 . \\ \text { G } & 115 . & 115 . & 95 . \\ \text { H } & 115 . & 115 . & 95 .\end{array}$

$1 \mathrm{kip} / \mathrm{inch}=0.175 \mathrm{kN} / \mathrm{mm}$ 
Table 5.3 Unit IV Vertical Support Reactions Immediately Prior to Collapse (Units Kips)

\begin{tabular}{|c|c|c|c|c|}
\hline $\begin{array}{c}\text { Tower } \\
\text { Leg }\end{array}$ & $\begin{array}{c}\text { Case IA } \\
\text { (FIrst Cast) }\end{array}$ & $\begin{array}{l}\text { Case IB } \\
\text { (Deadload) }\end{array}$ & $\begin{aligned} \text { Case II } \\
\text { (Second Cast) }\end{aligned}$ & $\begin{array}{c}\text { Total } \\
\text { Reaction }\end{array}$ \\
\hline 407.1 & $\begin{array}{l}22.07 \\
22.11 \\
22.18 \\
21.7 \\
43.79 \\
43.87 \\
44.38 \\
43.66\end{array}$ & $\begin{array}{l}1.80 \\
1.76 \\
1.71 \\
1.67 \\
1.8 \\
1.76 \\
1.70 \\
1.66\end{array}$ & $\begin{array}{l}18.99 \\
18.89 \\
19.01 \\
19.01 \\
21.91 \\
21.76 \\
21.99 \\
22.13\end{array}$ & \begin{tabular}{r}
43 \\
43 \\
43 \\
42 \\
68 \\
67 \\
68 \\
67 \\
\multicolumn{4}{c}{41.}
\end{tabular} \\
\hline $407 \cdot 2$ & $\begin{array}{l}31.83 \\
36.59 \\
36.72 \\
32.01 \\
48.68 \\
53.55 \\
53.63 \\
48.43\end{array}$ & $\begin{array}{l}1.83 \\
1.83 \\
1.84 \\
1.84 \\
1.83 \\
1.83 \\
1.83 \\
1.83\end{array}$ & $\begin{array}{l}33.25 \\
31.87 \\
31.85 \\
33.16 \\
35.69 \\
34.41 \\
34.29 \\
33.46\end{array}$ & $\begin{array}{r}67 \\
70 \\
70 \\
67 \\
86 \\
90 \\
90 \\
\Sigma \\
\quad 66 \\
626\end{array}$ \\
\hline 408 & $\begin{array}{l}29.35 \\
33.96 \\
34.25 \\
29.41 \\
48.1 \\
52.73 \\
52.71 \\
47.89\end{array}$ & $\begin{array}{l}2.04 \\
2.03 \\
2.0 \\
1.98 \\
2.02 \\
2.01 \\
1.99 \\
1.98\end{array}$ & $\begin{array}{r}20.61 \\
15.65 \\
15.61 \\
20.74 \\
13.90 \\
8.06 \\
7.95 \\
13.98\end{array}$ & $\begin{array}{r}52 \\
52 \\
52 \\
52 \\
64 \\
63 \\
63 \\
64 \\
462 .\end{array}$ \\
\hline \multirow[t]{2}{*}{$\begin{array}{c}\text { Unit III } \\
\text { Constructio } \\
\text { Joint }\end{array}$} & 0. & 0. & 82 & 82 \\
\hline & & & $\begin{aligned} \text { Total Loa } & \text { Untt IV }\end{aligned}$ & $\begin{array}{l}1611 \\
\text { k1ps. }\end{array}$ \\
\hline
\end{tabular}

$1 \mathrm{kip}=4.45 \mathrm{kN}$ 


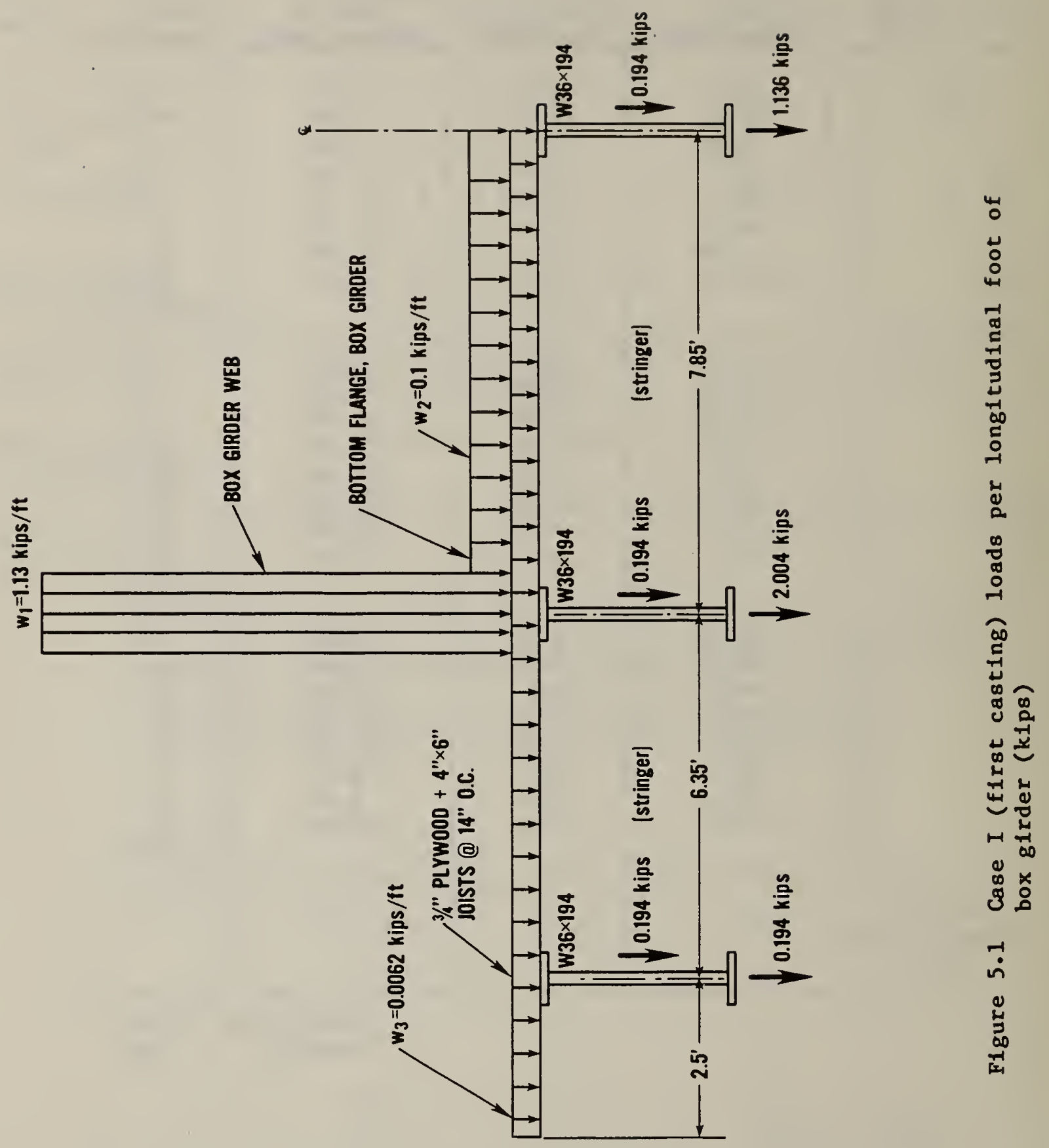




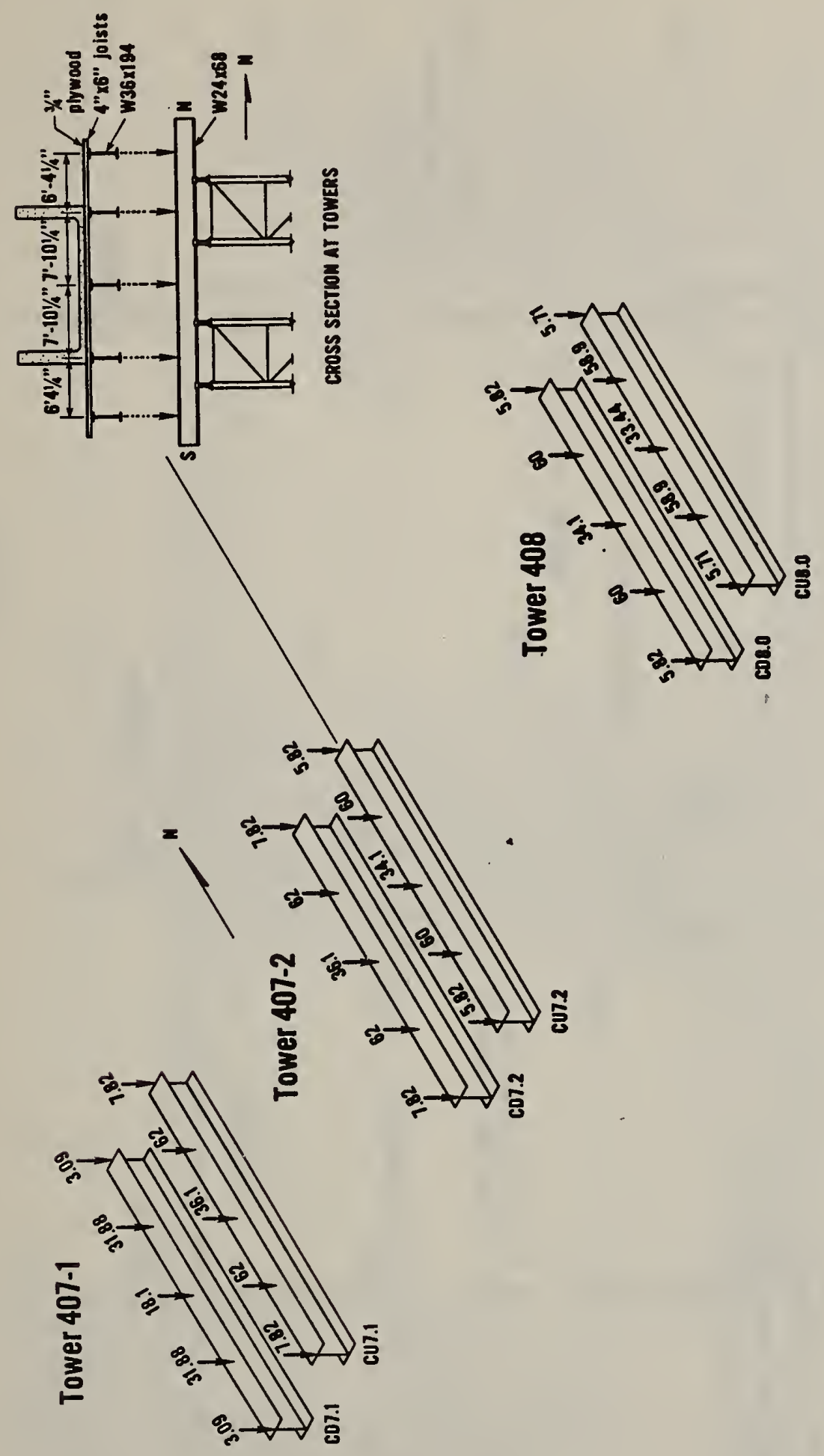

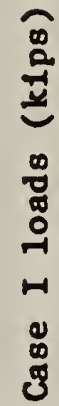

욘

芒

ก

峁 


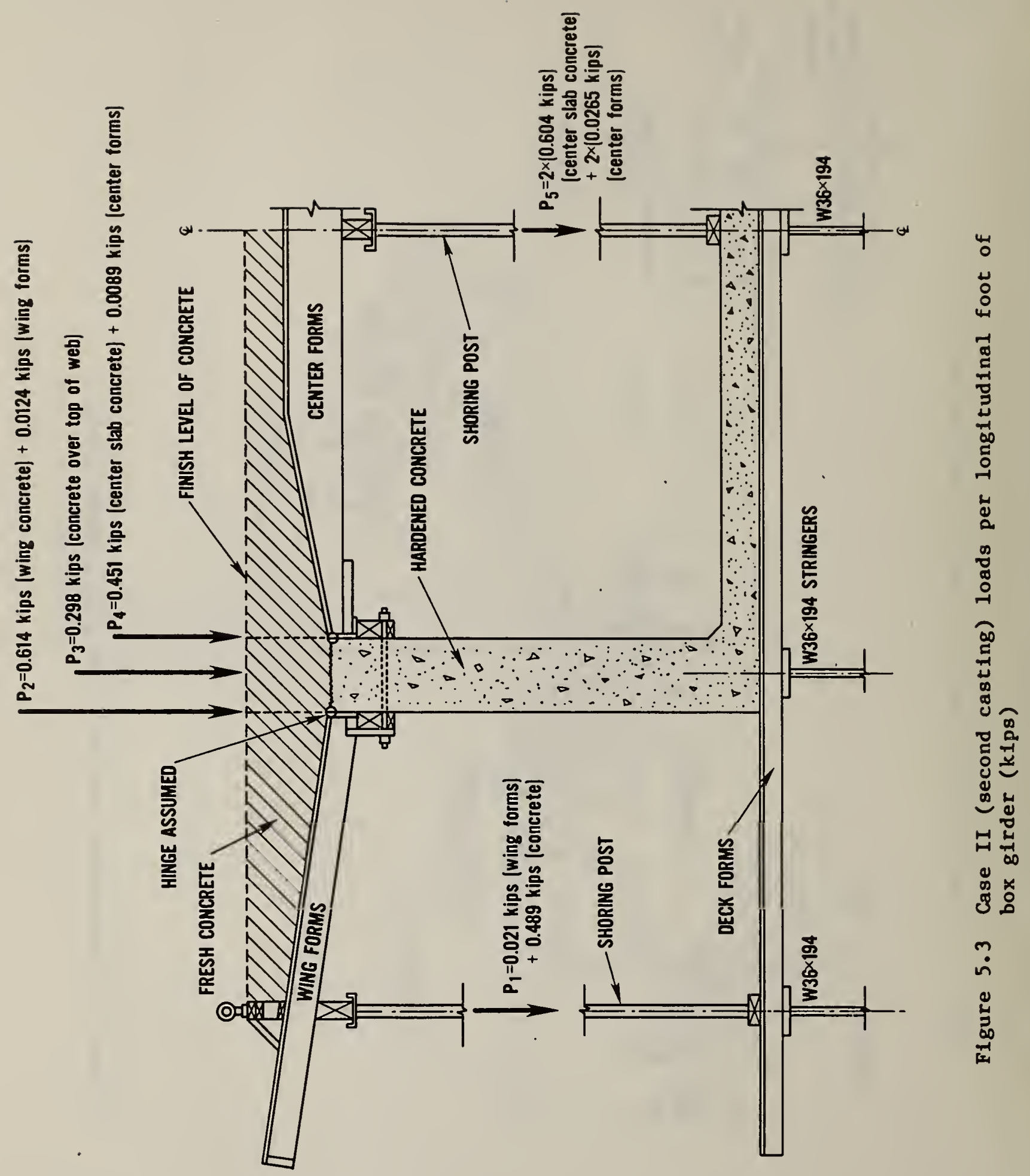




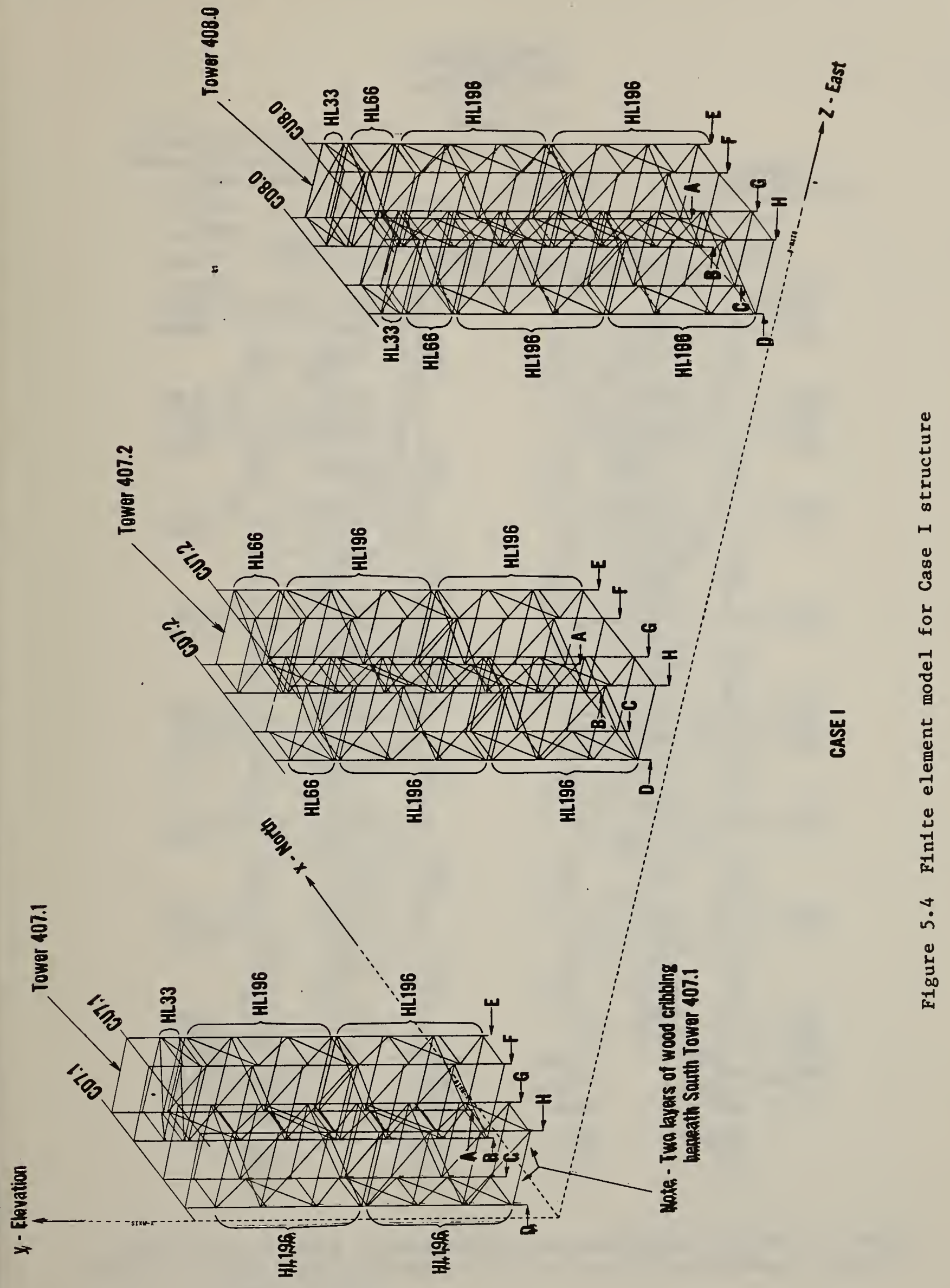




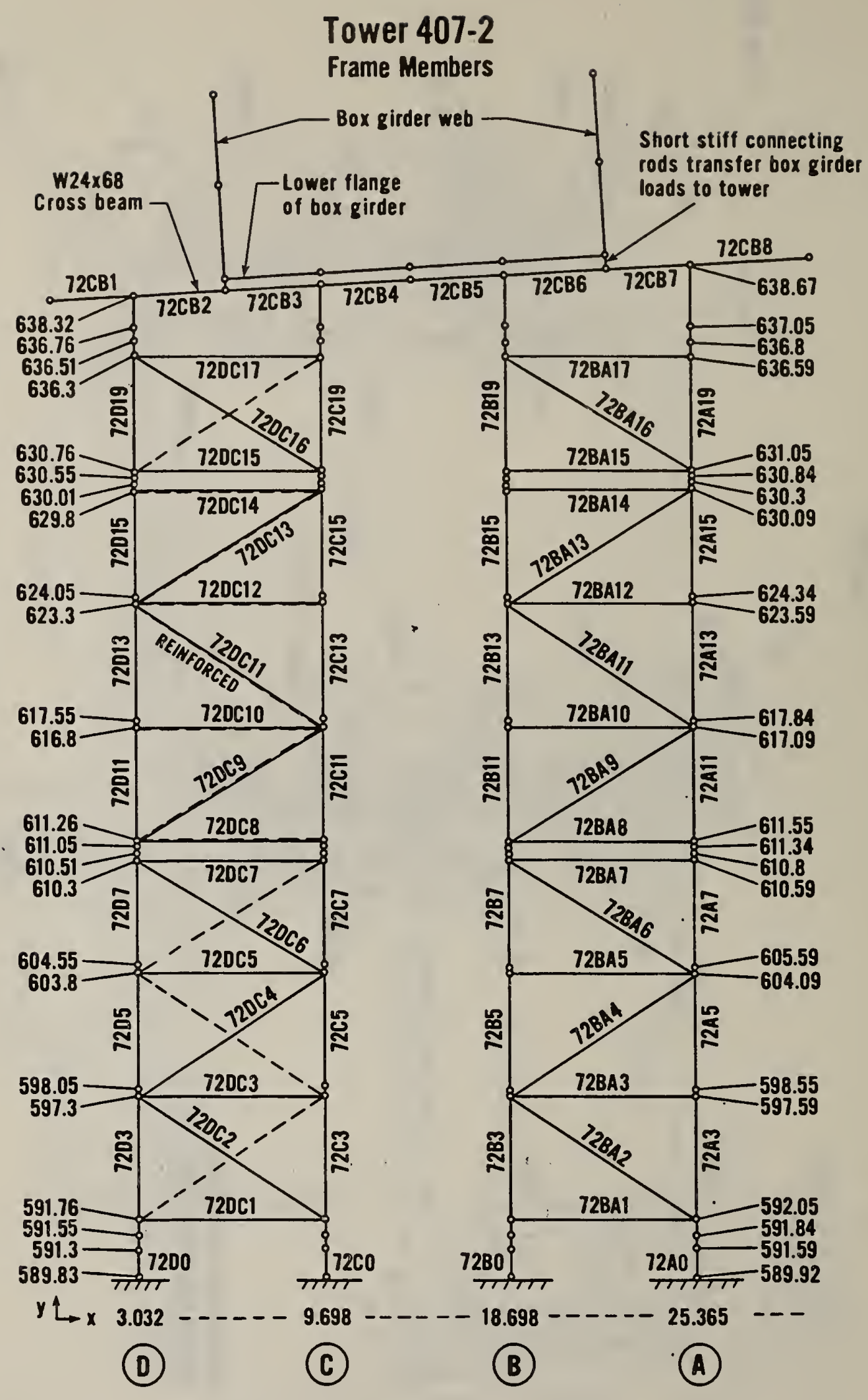

Figure 5.5 Member designations and finite element model of west frames, towers at $\mathbf{4 0 7 . 2}$ 


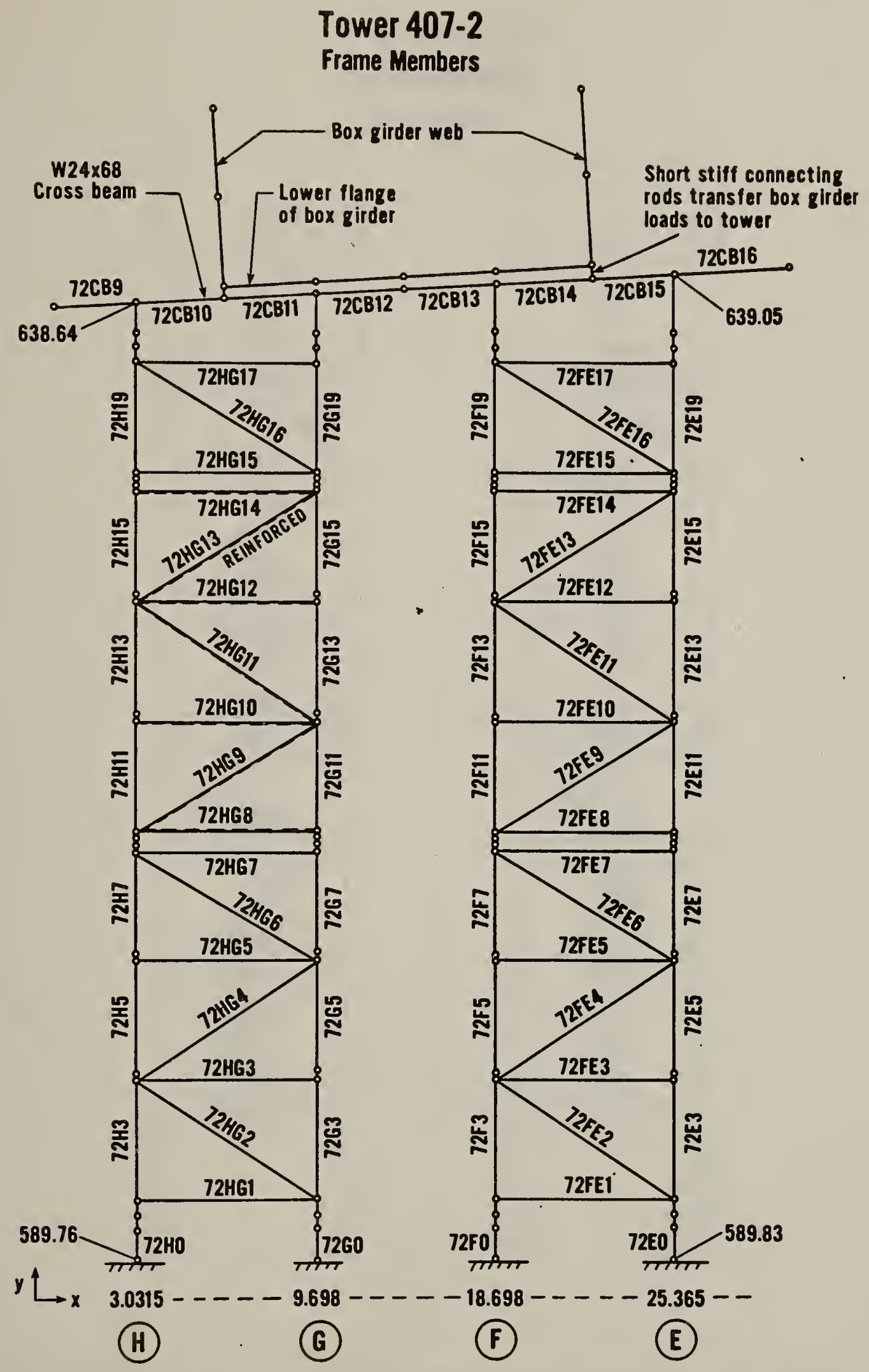
Figure 5.6 Member designations and finite element model of east frames,
towers at 407.2 
Tower 407-2

Truss Members
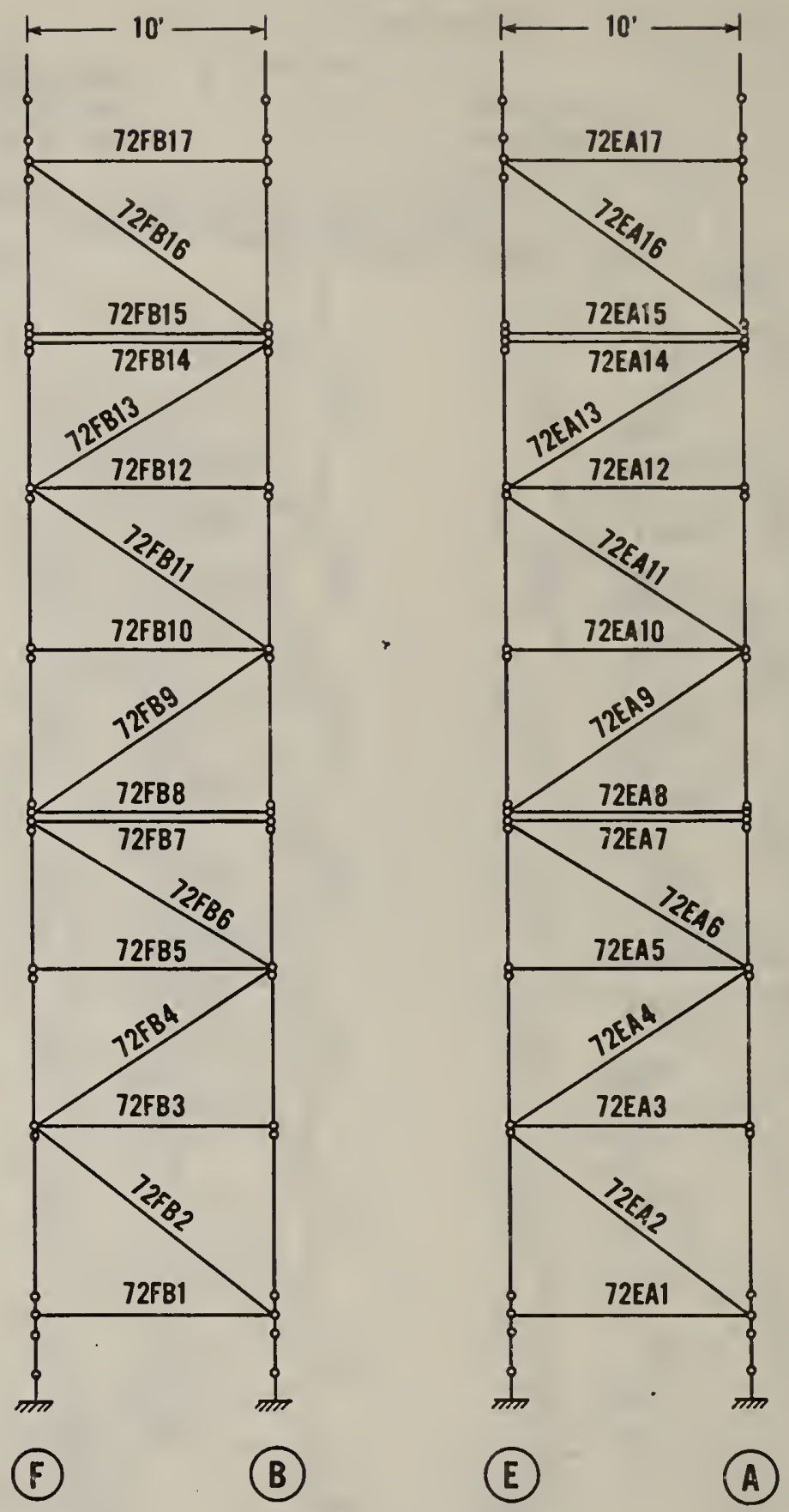

Figure 5.8 Finite element truss brace designations for towers at 407.2 , panels FB and EA 


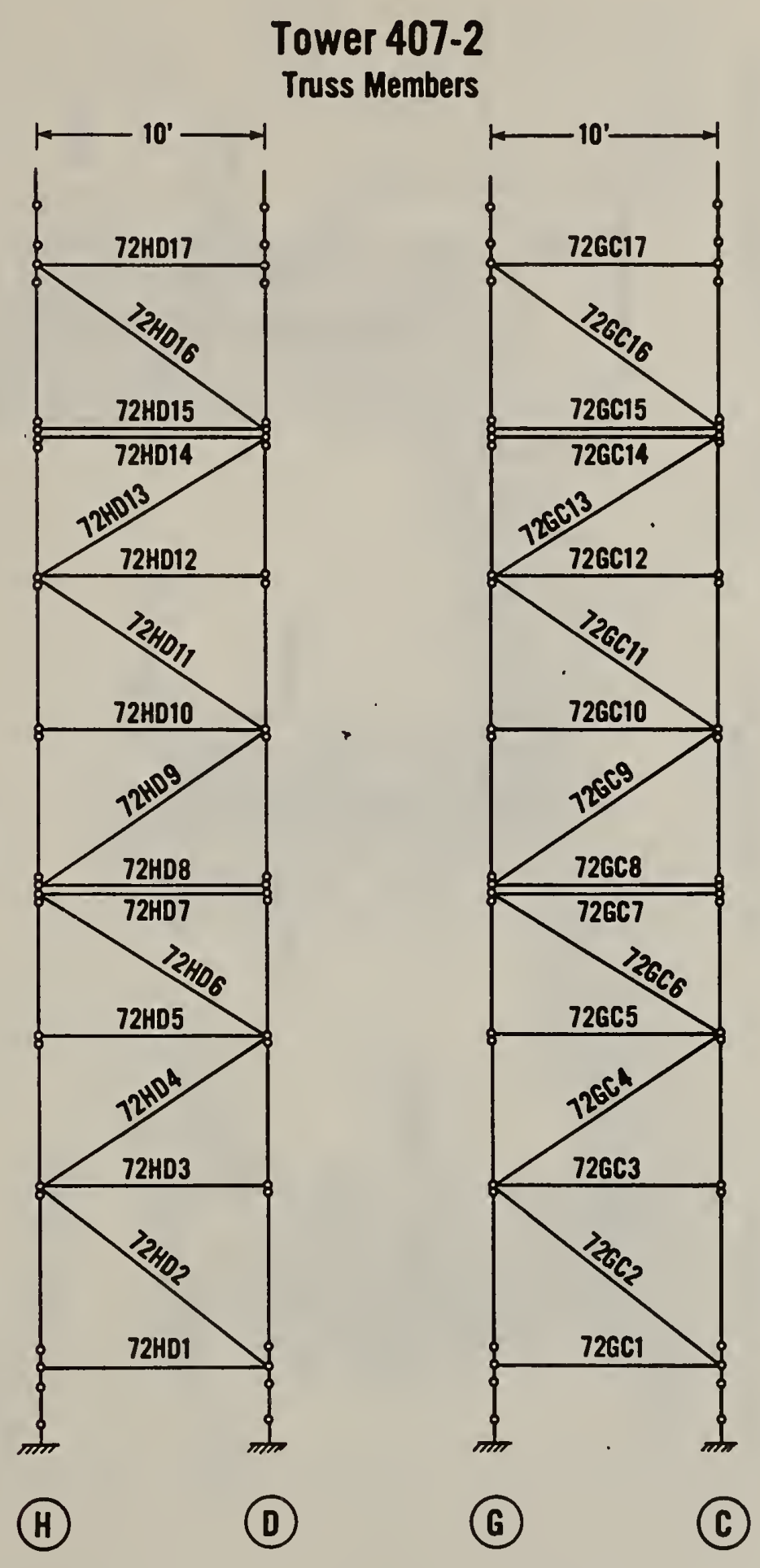

Figure 5.8 Finite element truss brace designations for towers at 407.2 , panels $\mathrm{HD}$ and $G C$ 


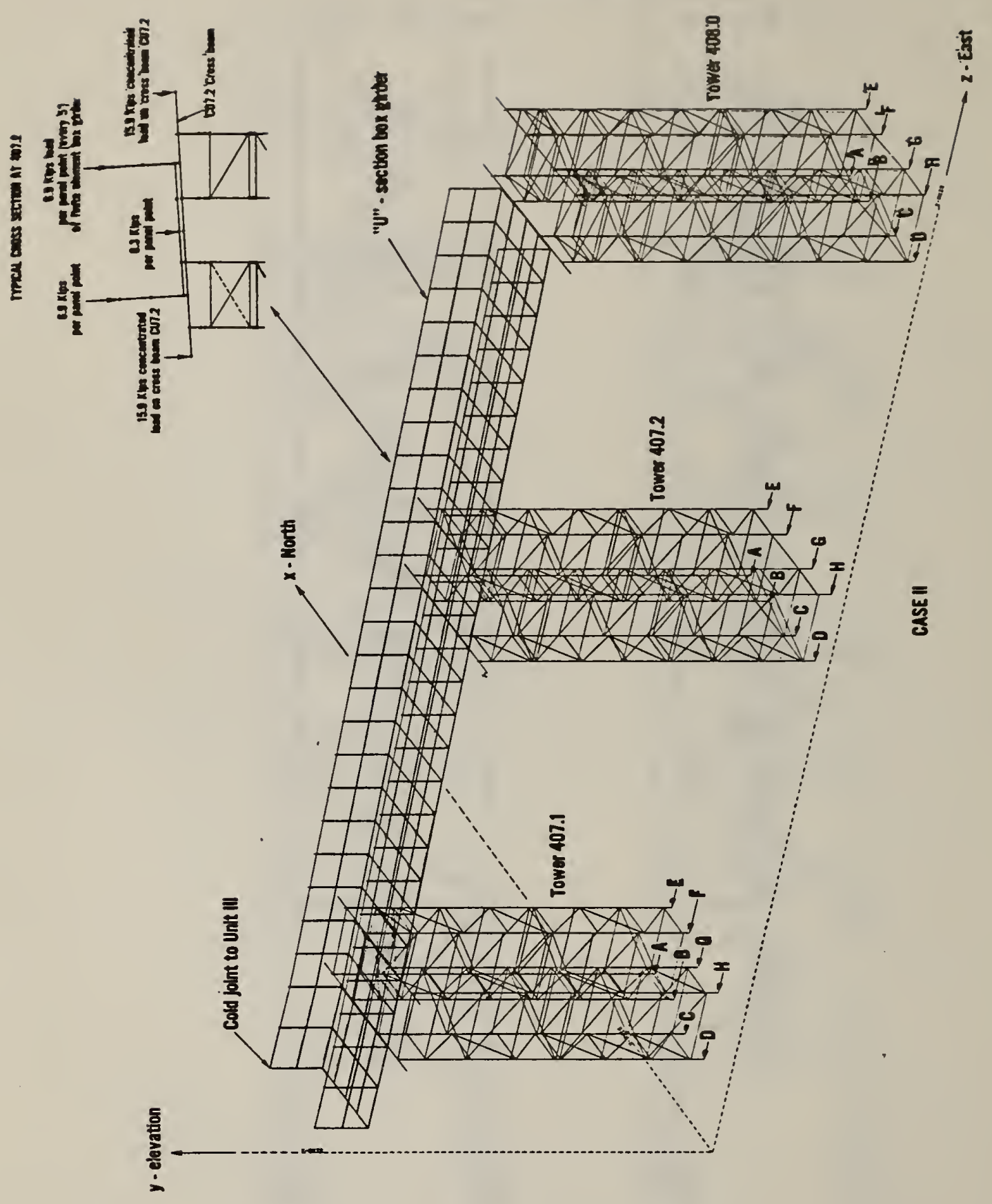

告 


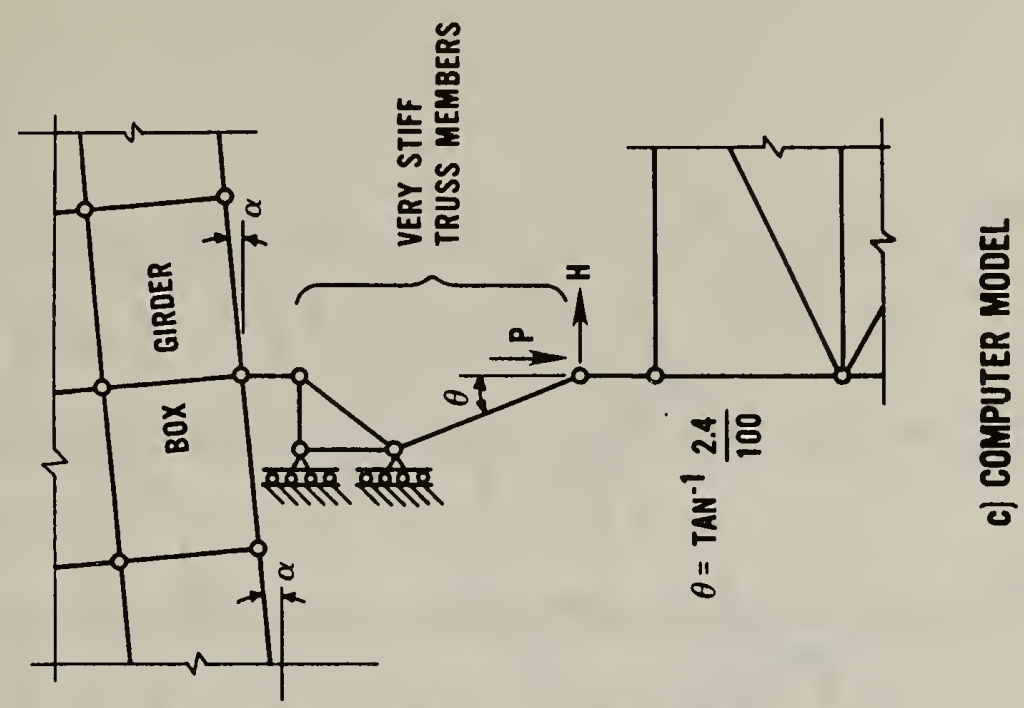

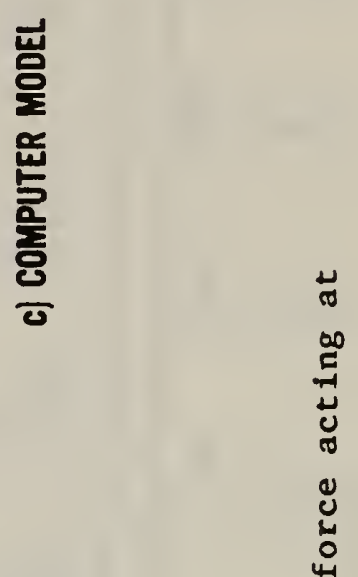
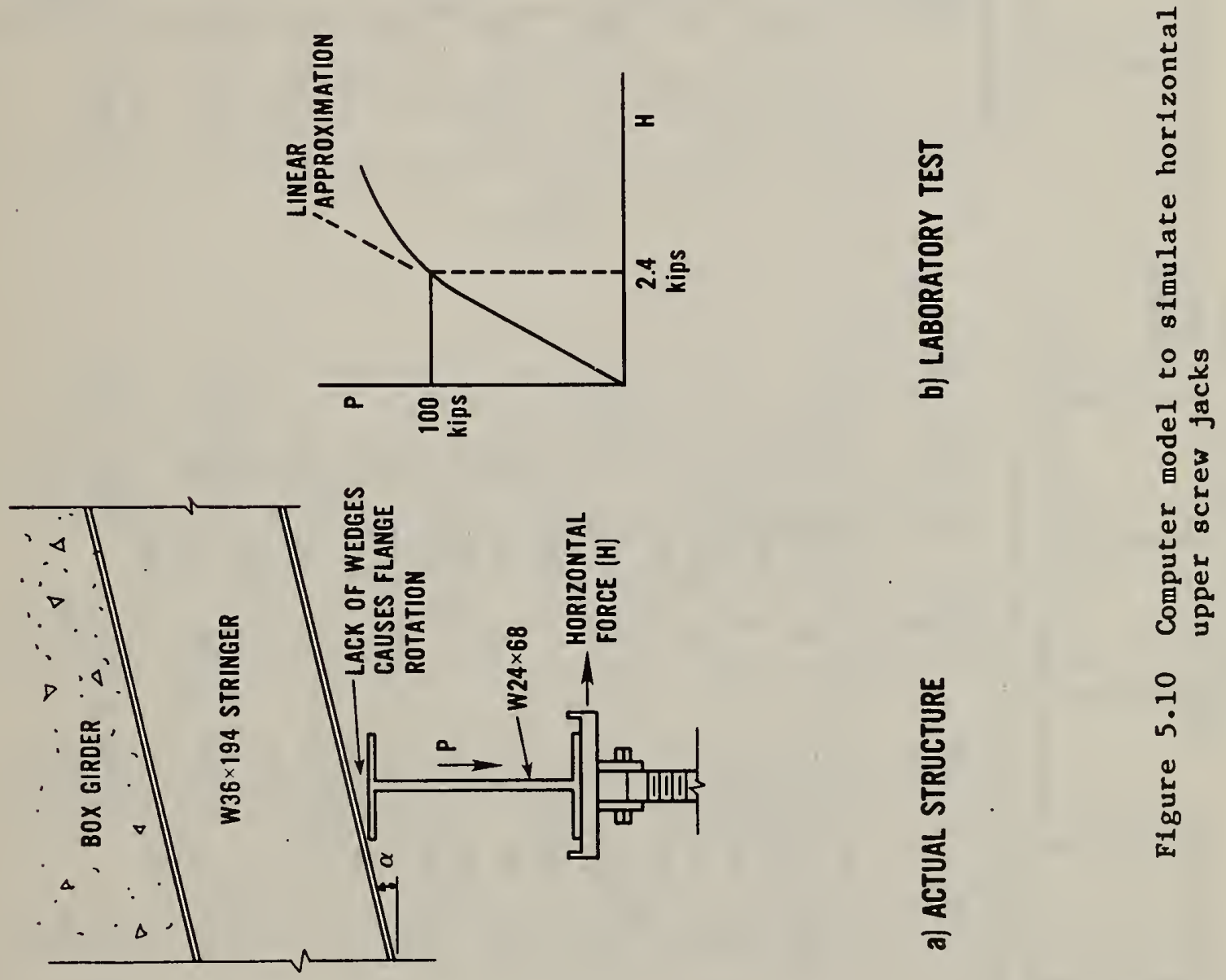

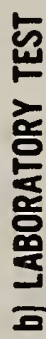

ํㅜㄹ

$\underbrace{0}_{\substack{\infty \\ 0}}$ 


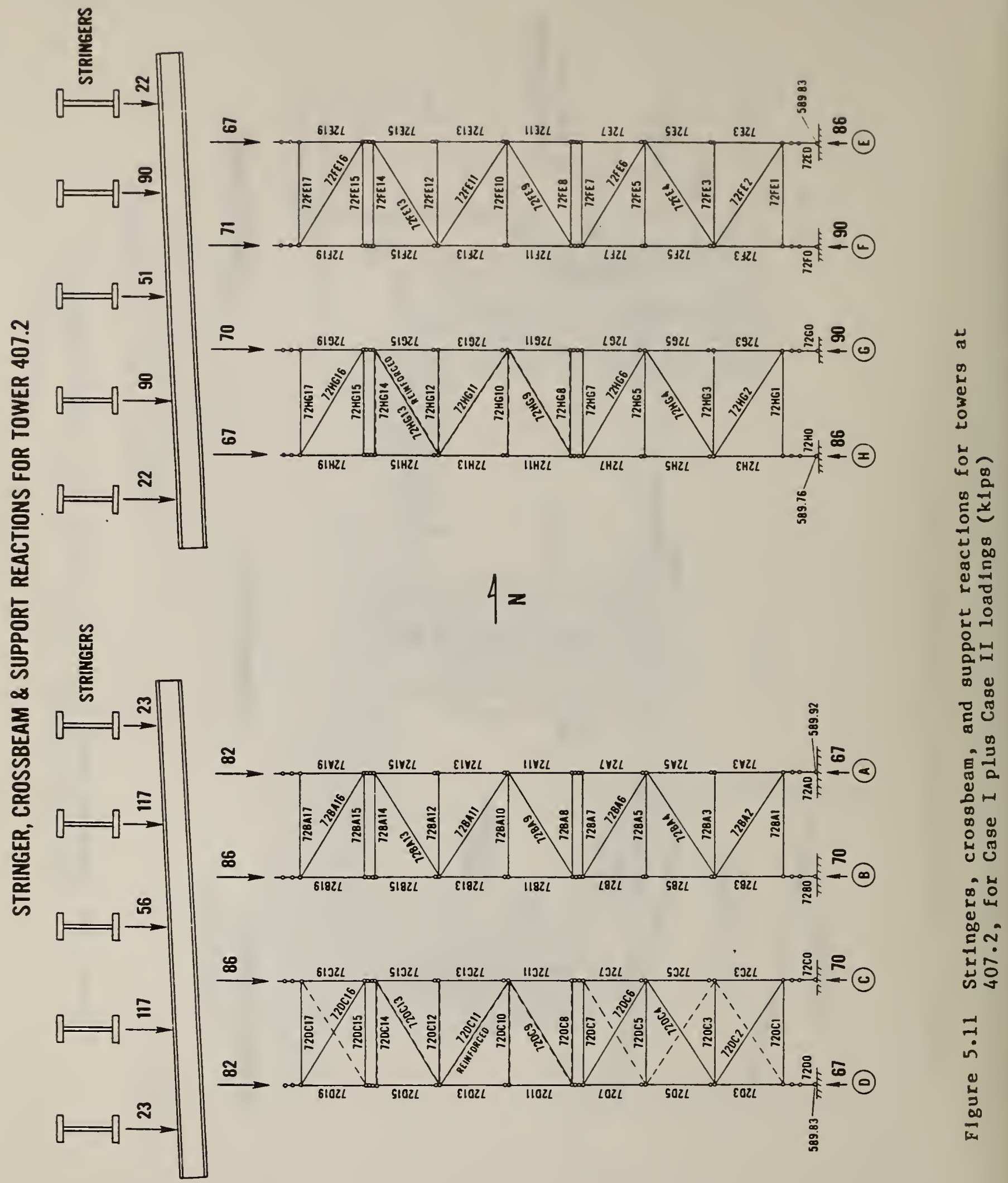



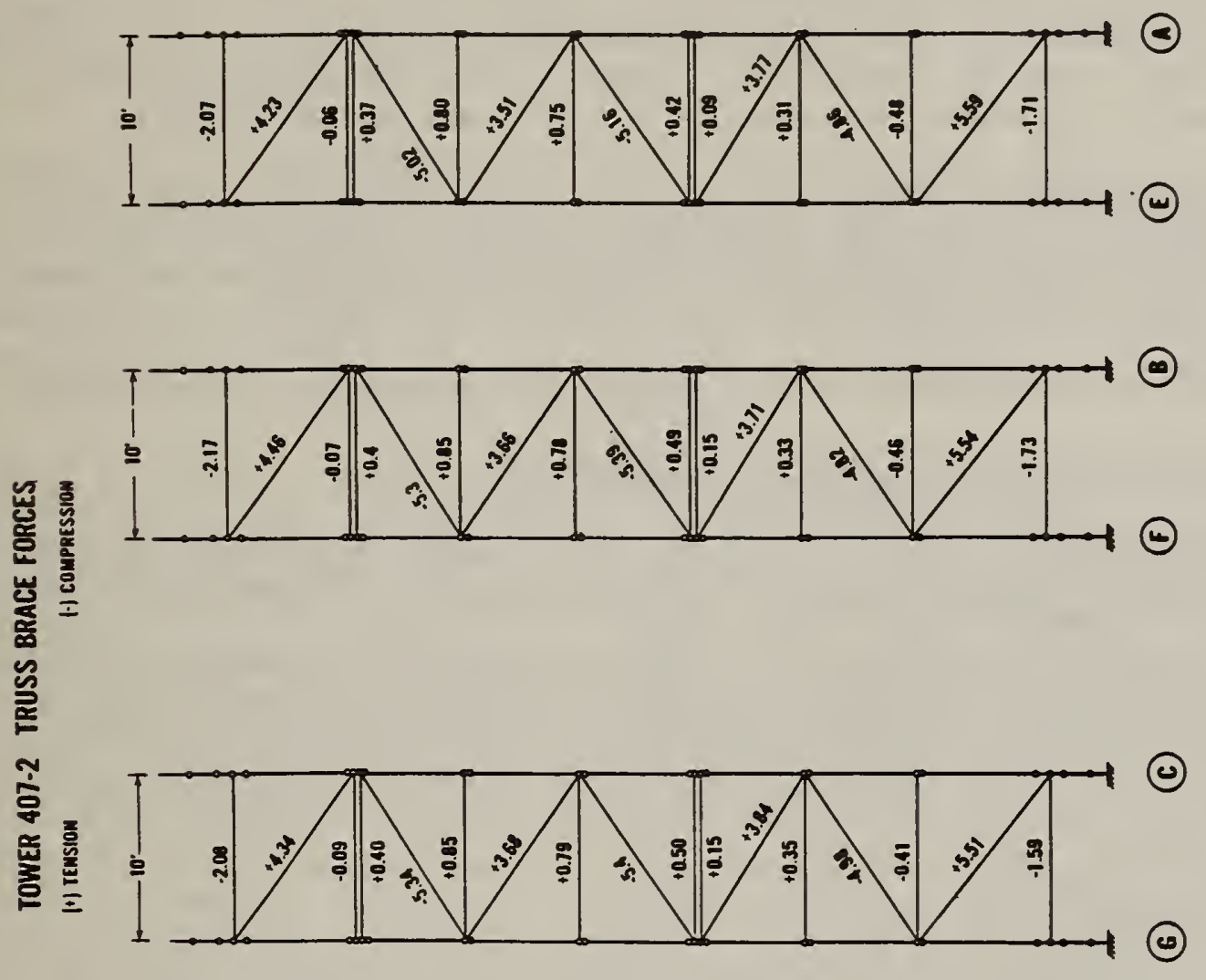

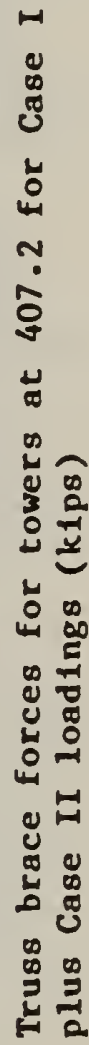
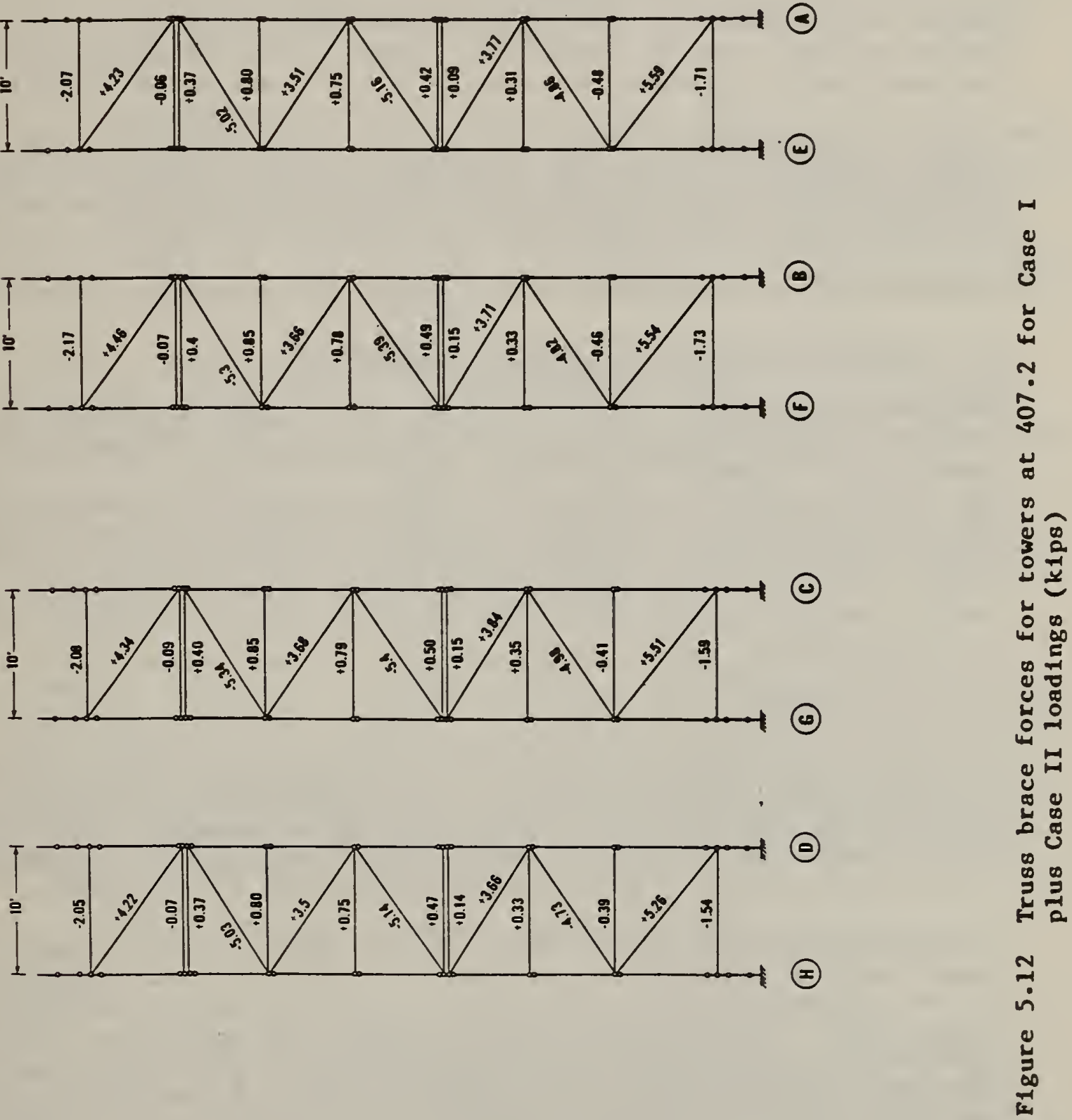


\subsection{INTRODUCTION}

This chapter evaluates the results of tests of the falsework components and assemblies at the NBS laboratories, the results of the load tests at the site, the results of the structural analysis, and observations made during the field and laboratory investigations. In addition, the estimated load capacity for each of the falsework components is presented for the purpose of determining the likely cause of the collapse.

Section 6.2 compares the capacities of individual components of the falsework system with the loads believed to be acting at the time of the collapse. The most 1ikely triggering mechanism of the collapse is identified.

Section 6.3 explains, by means of further structural analyses, how the triggering fallure caused other components to fail, and how this led to a collapse sequence that is consistent with the observations made in chapter 3 . The likely causes of the unit-V collapse are also discussed.

The findings and conclusions of this chapter are summarized in Section 6.4 .

\subsection{CAPACITY EVALUATION OF FALSEWORK COMPONENTS}

This section evaluates the load capacity of individual components of the falsework system between the $4 \times 6$ (3.5 $\times 5.5-1 \mathrm{n}, 90 \times 140-\mathrm{mm})$ joists which supported the plywood formwork (see figure 3.9) and the soil which supported the concrete pads (see figure 3.2). Each load capacity is compared with member forces or stresses produced by the applied loads described in chapter 5 . In the absence of any nationally accepted design standard for falsework in bridge construction, the provisions of the AISC Specification [6.1] are used to compute the capacity of steel members for which experimental results are not available.

\subsubsection{Stringers}

As shown in figure 3.14, there were five 36-in (910-mm) deep stringers in each span between piers 407 and 408. The cross-sectional dimensions of these beams are shown in table 3.2. Based on field measurements, it was concluded that the stringers in spans 7.1 and 8.0 match closely the specified W36 $x 194$ section, while those in span 7.2 were probably W36 $\times 260$ sections.

Based on a nominal yield strength of $36 \mathrm{ksi}$ ( $250 \mathrm{MPa}$ ), the allowable bending moment and the web crippling capacity for a W36 x 194 section are, according to the AISC Specification, $1195 \mathrm{kip}-\mathrm{ft}(1620 \mathrm{kN}-\mathrm{m})$ and $230 \mathrm{kips}$ (1023 kN), respectively. The same quantities for a W36 x 260 section are $2232 \mathrm{kip}-\mathrm{ft}$ $(3027 \mathrm{kN}-\mathrm{m})$ and $279 \mathrm{kips}(1241 \mathrm{kN})$, respectively. The maximum moment at the mid span of the stringers occurred during the Case I loading (section 5.3.1) and had a value of $626 \mathrm{kip}-\mathrm{ft}(849 \mathrm{kN}-\mathrm{m})$ for both wiâe flange sections. The maximum stringer reactions occurred over the towers at 407.2 during loading Case I plus loading Case II and had values of $90 \mathrm{kips}$ ( $400 \mathrm{kN}$ ) for the 
W36 $\times 194$ section and 117 kips ( $521 \mathrm{kN}$ ) for the W36 × 260 section (see $\mathrm{f} 1 \mathrm{~g}$. 5.11). These two different reactions result from the continuity of the concrete box girder over the two supports provided by the shoring towers. When these moment and reaction values due to construction loads are compared with the AISC allowable values of the two stringer cross sections, it is found that the allowable strength values exceed the maximum applied moment and reactions by large margins. The shear capacities of the webs were also computed and they were found to be far in excess of the shear resulting from the applied loads.

Based on the above comparisons, it is concluded that the stringers had adequate capacity to support the applied loads and they did not initiate the collapse.

\section{2 .2 Crossbeams}

Based on fleld measurements of the cross-sectional dimensions of the crossbeams, it was concluded that those used in unit IV were W24 x 68 sections. Because the distances between the stringer loads and the U-head reaction points are relatively small compared to the depth of the beam (see figure 3.9), the bending moments resulting from the applied loads are small and do not control the crossbeam capacity. Thus, the capacities of the crossbeams are checked for shear, web crippling and vertical web buckling.

Using a nominal yield strength of $36 \mathrm{ksi}$ ( $350 \mathrm{MPa}$ ), the AISC allowable shear capacity of a $\mathrm{W} 24 \times 68$ section is $135 \mathrm{kips}(600 \mathrm{kN})$. This value is substantially greater than maximum shear of $59 \mathrm{kips}(260 \mathrm{kN})$ occurring between stringer S2 of span 8.0 and the $U$-head reaction at leg $A$ as shown in figure 5.11 .

In accordance with the AISC Specification, the maximum concentrated load that a W24 x 68 section can support without crippling of the web due to a localized force is $276 \mathrm{kips}(1230 \mathrm{kN})$. This capacity is about 2.34 times the maximum stringer reaction of $117 \mathrm{kips}$ ( $521 \mathrm{kN}$ ) (see figure 5.11 ).

The AISC specification does not cover the elastic buckling of the web due to vertical loading. Thus, the web buckling capacity was computed using the equations given in reference 6.2. Elastic buckling loads based on (1) free rotation of the flange about the longitudinal axis and on (2) restraint of the flange from rotating are $166 \mathrm{kips}(740 \mathrm{kN})$ and $243 \mathrm{kips}(1080 \mathrm{kN})$, respectively. The expected vertical buckling capacity lies in between these two values. With a maximum stringer reaction of $117 \mathrm{kips}$ ( $521 \mathrm{kN}$ ), vertical buckling of the web would not have occurred due to the applied loads.

Thus, it is concluded that the crossbeams did not initiate the collapse.

\section{2 .3 U-Heads}

As described in section 3.3 .2 and illustrated in figure 3.8 , a $U$-head has several components. A $2 \times 3-i n(51 \times 66-\mathrm{mm})$ steel block which supports the pivoting head is welded to a $5 / 8-$ in $(16-\mathrm{mm})$ thick circular plate, which is in turn welded to a $3-i n(76-\mathrm{mm})$ diameter threaded bar. It was noted in the field investigation that at $407.1,407.2$ and 408 the $U$-heads had broken off at the weld connections of the circular plate. Thus, the strength of these welded connections appeared to have controlled the strength of the U-heads. 
Because there were varlations in the sizes and quality of the screw jack welds, it was not possible to predict the expected capacities of the U-heads used in the towers at 407.2. The sizes of the welds measured on the cross-sections used for metallographic analysis showed that in most cases they were either about equal to or somewhat less than $1 / 4$ in $(6.4 \mathrm{~mm})$. The minimum size of fillet welds required by the American Welding Society Specification [6.3] for a 5/8-in $(16-\mathrm{mm})$ thick plate is $1 / 4 \mathrm{in}(6.4 \mathrm{~mm})$.

As explained in section 4.4 (figures 4.27 and 4.30), in the falsework assembly tests the screw jacks experienced tensile strains only at low vertical loads. As the vertical load increased on the crossbeam, the tensile strains disappeared. The cross-section of the threaded bar remained in compression up to the maximum load. Furthermore, at the maximum load the relative displacement between the top and bottom flanges of the crossbeam was sma11, less than $1 / 2$ in $(12 \mathrm{~mm})$. The maximum vertical loads (135 kips $(600 \mathrm{kN})$ in test (534 kN) in test $\equiv 1$ ) coincided with the onset of extensive yielding in the web of the crossbeam. These maximum loads are less than the elastic buckling strength of the crossbeam web noted in section 6.2.2. In the tests, the web was subjected to axial load plus out-of-plane bending moment, and the maximuin load was attained when stresses due to the combined loading reached the yield strength.

The maximum loads in the falsework assembly tests are greater than the maximum computed load of $86 \mathrm{kips}(383 \mathrm{kN}$ ) on the U-heads at legs B and C (see figure 5.11). The fallure of the falsework assembly was govenned by the strength of the crossbeam rather than by the strength of the U-head. This observation suggests that U-heads would not have falled under the applied loads. Thus, it is unlikely that a U-head fallure initiated the collapse of unit IV.

\subsubsection{Shoring Towers}

For a tower with four legs consisting of square tubes of $6 \times 6 \times 1 / 4-1 \mathrm{n}(150 \times$ $150 \times 6.4 \mathrm{~mm}$ ) cross section, the compressive yield load is $1118 \mathrm{kips}$ ( $4975 \mathrm{kN}$ ) or $280 \mathrm{kips}(1240 \mathrm{kN}$ ) per leg based on the specified yieid strength of $50 \mathrm{ksi}$ ( $345 \mathrm{MPa}$ ) which is given in the shore tower manufacturer's data sheet. The AISC allowable load is $150 \mathrm{kips}(667 \mathrm{kN})$ per $1 \mathrm{eg}$. If the whole tower is treated as a pinned column, the critical elastic buckling load is much greater than the yield load. Therefore, the tower would not fall by elastic buckling as a cnlumn. In actual load tests reported by the manufacturer for $13-\mathrm{f}=(4-\mathrm{m})$ shoring tower frames, fallure occurred by local buckling of a tubular leg at stress values above the specified yield strength of $50 \mathrm{ksi}$ ( $345 \mathrm{MPa})$. The maximum test loads were $324 \mathrm{kips}(1440 \mathrm{kN})$ and $295 \mathrm{kips}(1312 \mathrm{kN})$ per leg. These values are higher than the yield load of $280 \mathrm{kips}(1246 \mathrm{kN})$ for a tuhe section having the specified yield strength of $50 \mathrm{ksi}$. The experimental capacities are also comparable to the elastic local buckling solution of $282 \mathrm{kips}(1255 \mathrm{kN}$ ) according to reference 6.3. Therefore, for the maximum tower 1 eg reaction of $90 \mathrm{klps}$ ( $400 \mathrm{kN}$ ) indicated by the structural analysis, it is reasonahle to conclude that the collapse was not inftiated by local buckling of a tower leg or by column buckling of an entire tower. 
Although the tower legs had adequate strength, it is possible that the truss braces could have falled thereby weakening a tower as a whole. To establish the capacity of the braces, six members similar to those used in the towers at 407.2 were tested (see section 4.5$)$. For the three $12 \mathrm{ft}(3.7-\mathrm{m})$ long bracing members that were tested in compression, the maximum load ranged from $5.3 \mathrm{kips}(23.6 \mathrm{kN})$ to $7.1 \mathrm{kips}(31.6 \mathrm{kN})$ depending upon the wall thickness and condition of the tubes. The average maximum load was $6.3 \mathrm{kips}(28 \mathrm{kN})$. For the braces tested in tension, the capacity was governed either by end-bearing failure through the wall of the tubes or by shear fallure of a bolt fastening the braces to the tower legs. The average fallure load for bearing fallure was $12.8 \mathrm{klps}(57 \mathrm{kN})$ and the average fallure load for bolt shearing was $17.5 \mathrm{kips}(78 \mathrm{kN})$.

When the magnitudes of the computed forces in the bracing members are compared with the average strengths, both in tension and compression, it is found that the forces are less than these strengths (see fig. 5.12). However, the computed compressive forces in some of the diagonal members in trusses BF and CG at 407.2 were either equal to or slightly greater than the lowest compressive test value of $5.3 \mathrm{kips}(23.6 \mathrm{kN})$. It should be noted that this low value was attributed to corrosion in a confined area of the tube rather than to an overall small cross-sectional area. In order to examine the consequences of a possible fallure of these highly loaded diagonal members, an analysis was made for the Case II loading with these members removed. The results showed that force redistribution took place and the overall stability of the tower was not affected by the removal of the diagonals. Since in the real structure members would not immediately lose their load carrying capacity upon reaching their buckling loads, the analysis with the diagonal members removed represents a severe condition. Thus, it is unlikely that bracing members failed in tension, and it is unlikely that any diagonal members which might have buckled would have triggered the collapse of the falsework at 407.2 .

\section{2 .5 Sand Boxes}

Load tests were performed on wood sand boxes obtained from the site in order to determine their capacity in transferring load from the lower screw jacks of the towers to the concrete pads. Field observations indicate that slag was used as the filler material for the wood sand boxes at tower locations 407.1, 407.2 and 408. The tests using slag as filler material showed that a load of $160 \mathrm{kips}$ (712 kN) could be maintained without bursting the boxes. Based on this observation, it is concluded that the collapse was not initlated by the failure of a sand box.

\subsubsection{Concrete Pads}

In the field investigation, it was noted that many concrete pads which supported the individual tower legs had cracked. For some of these cracked pads, it was not certain whether the cracks were caused by the impact of falling objects or by excessive loads in the tower legs prior to the collapse.

In order to determine the capacity of the pads, full-scale load tests were carried out at the site, as described in section 4.6 . 
The capacity of a concrete pad in resisting a centrally applied concentrated load depends not only on the strength of the concrete, the size of the pad, and the amount of reinforcement in the pad, but it also depends on the contact pressure distribution between the underside of pad and the soil. Sheet 344 of the structural drawings specifled $10 \times 10-1 n(250 \times 250-\mathrm{mm})$ mesh in the concrete pads, but it did not specify where the mesh should have been placed nor did it specify the required concrete compressive strength. Some of the cores taken from the pads taken at 407.2 contained $0.2-1$ n ( $5-\mathrm{mm}$ ) diameter wire, but the location of the wire in the cores varied randomly as shown in table 4.6. However, this small amount of reinforcement would not affect the bending capacity of the pads and they can be considered as being plain concrete. By treating the pads as plain concrete footings with a unfform soll pressure, the thickness of the pads, according to the ACI-318 Standard [6.6], should have been at least 21 in $(530 \mathrm{~mm})$, for an assumed 4000-psi (28-Mpa) concrete, instead of 12 in $(300 \mathrm{~mm})$ as specifled in the drawings.

At the present time, no guidelines are avallable in the 1iterature to accurately estimate the contact pressure distribution beneath a pad. However, the conservative approach presented in reference 6.4 for the contact pressure distribution and a simple yleld line analysis can be used to estimate the pad capacity. Thus, neglecting the small amount of welded wire-fabric reinforcement in the pad, a simple expression for the pad capacity, $P$, is obtained:

$$
\mathrm{P} \cong 1.25 \mathrm{f}_{\mathrm{r}} \mathrm{h}^{2}
$$

where $f_{r}$ is the modulus of rupture of the concrete and $h$ is the thickness of the pad. Figure 6.1 shows the results of the full-scale load tests. The ordinate $\frac{1}{2} s$ the observed cracking load of the pad (table 4.4) and the abscissa is $f_{r} \cdot h^{2}$. The modulus of rupture was estimated from the average compressive strength, $f_{c}$, of the cores taken from the tested pads (table 4.5) using the accepted expression $f_{r}=7.5 \sqrt{ } f_{c}[6.6]$. The pad thickness, $h, 1$ s based on the average length of the untrimmed cores. Also shown, figure 6.1 is the line representing eq. (6.1), which coincides with the regression line fitted through the origin, excluding the data points $1-2$ and $1-1$. It is seen the theoretical expression (eq. 6.1) represents the experimental values reasonably well, the residual standard deviation of the line is $22 \mathrm{klps}(98 \mathrm{kN})$. The concrete pads used for the full-scale load tests were previously used to support shoring towers in other portions of the ramp and some were impacted by falling debris during the collapse. Thus, some of the pads could have suffered internal damage which was not discernible. It is belleved that the lower than expected strength of pads 1-1 and 1-2 can be attributed to previous damage of the pads.

The values of $f_{r} \times h^{2}$ for pads $A$ through $H$ of the towers at 407.2 are plotted on the abscissa of figure 6.1. These values are computed based on the average strengths and untrimmed lengths of the cores reported in table 4.6. Although the actual strength of the Individual pads could deviate from the straight line $\mathrm{P}=1.25 \mathrm{f}_{\mathrm{r}} \mathrm{h}^{2}$, this line is an avallable means to estimate the expected pad cracking strength. For example, the expected strength for pad $F$ is $94 \mathrm{kips}$ $(418 \mathrm{kN})$ and for pad E it is $109 \mathrm{kips}(485 \mathrm{kN})$. From this figure and the tower leg reactions shown in figure 5.11 , it can be concluded that any of pads $E, F$, $G$, and $H$ could have been a candidate for cracking when the possible scatter of 
actual strength values about the prediction line is taken into consideration. The structural analysis showed that pads $F$ and $G$ at 407.2 were the most heavily loaded pads, each carrying $90 \mathrm{kips}(400 \mathrm{kN})$. As indicated above, the expected capacity of pad $\mathrm{F}$ is $94 \mathrm{kips}(418 \mathrm{kN})$, and figure 6.1 indicates that the expected capacity of pad $G$ is about $100 \mathrm{kips}(445 \mathrm{kN})$. Thus, it is reasonable to conclude that one of the pads $E$ through $H$ cracked, with pad $F$ having the highest likelihood of being the first to crack.

The field investigation revealed that at the time of collapse, no additional concrete was being placed and one would thus conclude that no additional load was being transmitted to the concrete pads. In the full-scale load test, many of the pads cracked during the holding period, when the load level was held constant. This evidence supports the notion that one of the pads could have cracked at a time when no additional load was being placed on the structure.

Cracking of a pad does not, in itself, explain why unit IV collapsed. It only provides a triggering mechanism. The next section investigates the consequences of this initial cracking and explains how it could have led to the collapse.

\subsection{FAILURE MODE ANALYSES}

This section presents the sequential failures of the falsework components which could have occurred subsequent to the likely cracking of pad F at 407.2 and which led to the collapse of unit IV. Probable reasons for the collapse of unit $\mathrm{V}$ are also given.

\subsubsection{Likely Failure Mode of Unit IV}

While pads $E, F, G$, and $H$ are all potential candidates for cracking under the applied loads, the comparison of the analytical results and the computed strength of the pads shows that pad $F$ had the highest probability of being the first to have cracked under the loads present at the time of the collapse. The remainder of this section traces through the sequence of events which would have followed the cracking of pad $F$ and which led to the total collapse of unit IV. Had one of the other pads been the first to crack a similar sequence would likely have developed.

The load-settlement measurements observed during the field tests showed that when the pads failed, the bottom screw jack dropped instantly an average value of about $0.4 \mathrm{in}(10 \mathrm{~mm})$. The actual settlements of eight tests ranged from $0.14 \mathrm{in}(10 \mathrm{~mm})$ to $0.72 \mathrm{in}(18.3 \mathrm{~mm}$ ) (see table 4.4$)$. The structure-falsework system was reanalyzed with $0.4-i n$ settlement applied at leg $F$. The results are shown in figures 6.2 and 6.3 . As a result of the $0.4-i n$ settlement of leg $\mathrm{F}$, the reaction at leg $\mathrm{E}$ increased from $86 \mathrm{kips}$ ( $383 \mathrm{kN}$ ) to $101 \mathrm{kips}$ ( $450 \mathrm{kN}$ ) and the reaction at leg $\mathrm{G}$ increased from $90 \mathrm{kips}(400 \mathrm{kN})$ to $97 \mathrm{kips}(432 \mathrm{kN})$. These increases in reactions placed pads $E$ and $G$ as the next likely candidates for cracking. In addition, the settlement of leg $F$ caused the force in the diagonal 72EA4 to increase from $4.86 \mathrm{kips}(21.6 \mathrm{kN})$ to $9.09(40.5 \mathrm{kN})$ which is greater than the average experimental buckling load of $6.3 \mathrm{kips}(28.0 \mathrm{kN})$. 
The sequence of failure after pad $\mathrm{F}$ cracks is uncertain. Although there is a somewhat higher probability that pad $G$ would crack before pad E, analysis has shown that if pad $G$ cracks additional load is transferred to pad $H$ increasing its total reaction to $101 \mathrm{kips}(450 \mathrm{kN})$. This further increases the likelihood of additional pad cracking along the line of pads $E$ through $H$. Once any two pads along one side of a tower, such as $E$ and $F$ or $H$ and $G$, have cracked the top of the tower translation becomes quite large. The consequences of this translation are discussed later in this section. However, the physical evidence shows that the failure of unit IV initiated on the north side of the ramp. Hence, it is assumed that pad E would crack subsequent to the cracking of pad F, since this is most consistent with the observed data relating to the collapse.

An additional analysis of the structure-falsework system was performed with the following two modifications to the computer model. First, the linearelastic diagonal member 72EA4 was replaced with an elasto-plastic member with its maximum load remaining constant at a value of $6.3 \mathrm{kips}$, the assumed buckling load based on the NBS tests. * Second, a 0.4 in drop of leg $E$ was introduced to represent the settlement of the leg due to the cracking of pad $E$. The results of the analysis are shown in figures 6.4 and 6.5 . It is seen from these figures that only the reaction of pad A changed substantially, from 75 kips $(334 \mathrm{kN})$ to $91 \mathrm{kips}(405 \mathrm{kN})$. Other reactions as well as the forces in the bracing members did not change significantly. The main reason for this is that the total load supported by the towers at 407.2 decreased as a result of the pad fallures, and the load on the towers at 407.1 increased. The load transfer results from the continuity of the U-section over the supports at 407.2 .

Due to the cracking of pads $E$ and $F$ and the buckling of diagonal 72EA4, the analysis indicated that the tops of the towers translated eastward along the longitudinal axis of the ramp. Figure 6.6. shows the estimated positions of the tops of towers at $407.1,407.2$, and 408. The figure shows that the tops of the towers at 407.2 translated longitudinally more than those at 407.1 and at 408. It also shows that at 407.2 the top of the north tower translated longitudinally more than that of the south tower, about 2 in ( $56 \mathrm{~mm}$ ) vs. 1.2 in $(30 \mathrm{~mm})$.

When the tops of the towers translated longitudinally, the bottom flanges of the crossbeams would have translated with the tops of the tower since they were held in the U-heads while the top flanges of the crossbeams would have been held fixed by the friction between the crossbeams and the stringers. As the bottom flange of a crossbeam translates with respect to the top flange, there is a tendency for the deformed shape of the web to change as illustrated in figure 6.7. In this schematic figure, position 1 depicts the initial deformed shape of the web which would have resulted from the absence of the wedges between the top of the crossbeam and the bottom of the stringers which had a

* An additional analysis with the buckled member being removed did not change the forces in the frame or acting on the pads appreciably. 
3.57 percent slope. A similar deformed shape of the web was also observed in the NBS laboratory tests (see figure 4.29). As the top of the tower moved toward the east, the bottom flanges of the crossbeams followed it; and the deformed shapes of the crossbeams would have progressively changed as shown by positions 2, 3, and 4. As illustrated in the figure, while the bottom flange translates, it also rotates and the curvature of the web changes. As a result, the direction of the bending moment on the U-heads also would have changed. The NBS falsework assembly tests did not show this change in curvature of the crossbeam web because the test setup was intended to investigate only the effects on the U-heads when wedges were not used between the stringer and crossbeam. While the bottom of the crossbeam translated in the tests, the rigidity of the test configuration did not allow the web of the crossbeam to change its curvature during the translation.

As has been described in section 4.3, the quality of the welds used to fabricate the U-heads at 407.2 was poor and some of them would not have met the minimum weld size requirement in the AWS specification. Therefore, it is possible that the U-heads could have falled if the applied loads produced tensile stresses on the screw jack. A finite element analysis of the crossbeam was performed in which the translations of the tops of the towers at 407.2 were introduced as relative displacements between the top and bottom flanges. The results showed that bending moments would have developed at the U-heads which produce tensile stresses on the east side of the screw jacks. Appendix $C$ describes the finite element model used for this analysis and presents the resulting deflected shapes of the crossbeam. Figure 4.21 clearly shows that the weld on the east side of the rectangular block fractured. Figures 4.20 and 4.21 reveal compressive yielding on the west side of screw jacks $B$ and $C$, which indicates the direction of fallure of the top of the U-heads. This mode of fallure is consistent with the analytical prediction. Figure 6.8 is presented as further evidence to confirm this behavior. The photograph shows the U-head at leg $D$ of the south tower at pier 406. It is evident that the top of the U-head is bent toward the west. Fallure probably did not occur in this case because the weld quality was sufficient to resist the tensile stresses.

While it is difficult to pinpoint which one of the U-heads at 407.2 failed first, the physical evidence described in chapter 3 points to the U-heads which supported crossbeam CD7.2 (west side). The physical evidence further indicates that the U-heads at tower legs $A$ and $B$ most likely failed first and were followed by fallure of those at legs $C$ and $D$. The observed locations of the failed U-heads and the crossbeams disclose the likely sequence of failure. As described in chapter 3, the U-heads for tower legs A, B, C, and D at 407.2 were found near the base of the towers (see fig. 3.22), whereas the U-heads for legs E, G, and $H$ were found between 407.2 and 408. The U-head for leg $F$ was found in a pile of debris away from the collapse zone. The locations where the U-heads were found suggest that the U-heads at legs $A, B, C$, and D fractured first and fell directly downward, whereas the U-heads at legs $E, F$, $G$, and $\mathrm{H}$ fell with the tops of the towers toward pier 408. The position of crossbeam CD7.2 shown in figure 3.18 suggests that the north end of the crossbeam fell first and stringers $S 1$ and $S 2$ in span 7.2 lost their support. The downward motion of the falling stringers could have pushed the north end of crossbeam CD7.2 toward 407.1. An eyewitness account presented in section 3.3.2 
confirms that the stringers on the north side of the ramp went down first and their collapse propagated to the south.

When crossbeam CD7.2 lost support, all loads at 407.2 were transferred to crossbeam CU7.2. With the east side of the towers being loaded heavily, the towers became unstable and collapsed in a "jackknife" mode as 1llustrated in figure 3.23. As a consequence of this fallure mode for the towers, crossbeam CU7.2 and the U-heads which supported CU7.2 fell towards pier 408. Indeed, they were found near pier 408.

Based on the above discussion, it is concluded that the collapse of unit IV was most 11kely inltiated by the cracking of concrete pads at location 407.2. The analysis of the expected strengths of the pads suggests that pad $F$ would likely have cracked first. As a consequence of pad cracking and because there was no positive support against translation of the tops of the towers, there was an increase in the longltudinal displacement of the tops of the towers toward the east. The only restraint to this displacement was provided by the lateral stiffness of the crossbeam web. With the lateral translation of the bottom of the crossbeams, high bending moments were induced in the U-heads supporting crossbeam CD 7.2. Due to their poor quality, the U-head welds fractured and crossbeam CD 7.2 fell. The loads at 407.2 were then transferred to crossbeam CU7.2, and both towers at 407.2 became unstable and folded, at which time the concrete box girder fractured and the collapse of the entire unit IV ensued.

\subsubsection{Likely Fallure Mode of Unit V}

As noted in section 3.3.2, according to eyewitness accounts, unit $V$ collapsed approximately 5 minutes after unit IV collapsed. Although an exact sequence of events for the collapse of unit $V$ is difficult to reconstruct, its fallure is not difficult to understand when it is realized that the falsework system was not tied together adequately as a unit and no positive stabilizing system was provided.

As a consequence of the fallure of unit IV and the collapse of the shoring towers at 408 , unit $V$ would have become unstable since there were no positive means of providing longitudinal stability to the unit. As discussed in chapter 3 , the external guying system which would have provided stability of the towers in the longitudinal direction was replaced with wire rope X-bracing in the transverse plane of the towers. The $X$-bracing would be effective in the transverse direction but it would not provide stability in the longitudinal direction. Furthermore, the absence of positive connections between the stringers and the crossbeams as well as the lack of a positive connection to pier 409 as called for in the structural drawings made the entire falsework system of unit $V$ vulnerable to longltudinal movements along the axis of the ramp. It is belleved that when unit IV collapsed, the stringers which supported the west end of unit $V$ also fell or were left dangling without support at 408 . This in turn would have damaged the shoring towers at 408.1 and left unit $V$ in a teetering condition. Finally, when this tower became unstable, fallure of unit $V$ propagated in a domino fashion toward the east as the falling stringers struck the remaining towers. 


\subsection{SUMMARY}

The following are the major points resulting from considerations of the laboratory and field tests, of the analyses of the structure-falsework system and of the field observations of the collapse.

1. The loads calculated to have been imposed on the steel stringers were less than the allowable loads of the AISC Specification. It is concluded that the collapse was not initiated by fallure of the stringers.

2. The loads calculated to have been imposed on the crossbeams were less than the allowable loads according to the AISC Specification. It is concluded that the collapse was not initiated by failure of the crossbeams.

3. Metallographic examination of portions of screw jacks from 407.2 showed that the size of the welds varied and that the weld quality was poor. The falsework assembly tests, however, showed that unless a large relative displacement develops between the top and bottom flanges of the crossbeam little or no tension develops in the threaded bar of the screw jack. Because of the lack of tensile stresses under the loading which existed prior to the inftiation of the collapse, it is concluded that the collapse was not triggered by a fallure of the U-heads.

4. The elastic buckling strength of the tower as a whole as well as the local buckling strength of individual tower legs exceed the computed loads. It is concluded that the collapse was not initiated by local buckling of a tower leg nor by the elastic buckling of an entire tower.

5. Load tests on the sand boxes obtained from the field revealed that they had adequate strength to support the tower leg loads. Thus, it is concluded the collapse was not initiated by the failure of a sand box.

6. The concrete pads did not have an adequate margin of safety to support the applied loads. According to the ACI-318 Standard and for a 4000-psi (27.6-MPa) concrete, the thickness of the pads should have been at least 21 in $(530 \mathrm{~mm})$ instead of $12 \mathrm{in}(305 \mathrm{~mm})$ as specifled in the structural drawings.

7. Comparison of the computed loads with the expected strengths of the concrete pads indicated that pads $E$ through $H$ could have been possible candidates for failure. Based on the analysis of the data, it is concluded that pad $F$ most likely failed first and initiated the collapse of unit IV.

8. The following deficiencies contributed directly to the collapse of unit IV: 1 ) the omission of specified wedges between stringers and crossbeams; 2) the concrete pads had an inadequate margin of safety to resist the expected loads; 3 ) the tops of the shoring towers were not adequately stabilized against longitudinal movement; and 4) the weld quality in the U-heads was poor. 
9. The following additional deficiencies contributed to the collapse of unit $V:$ 1) specified one-inch bolts were not provided for connecting crossbeams to stringers and to overlap beams; 2) the special overlap beams at the piers were not constructed as specified; and 3 ) the construction sequence deviated from the specified sequence. 


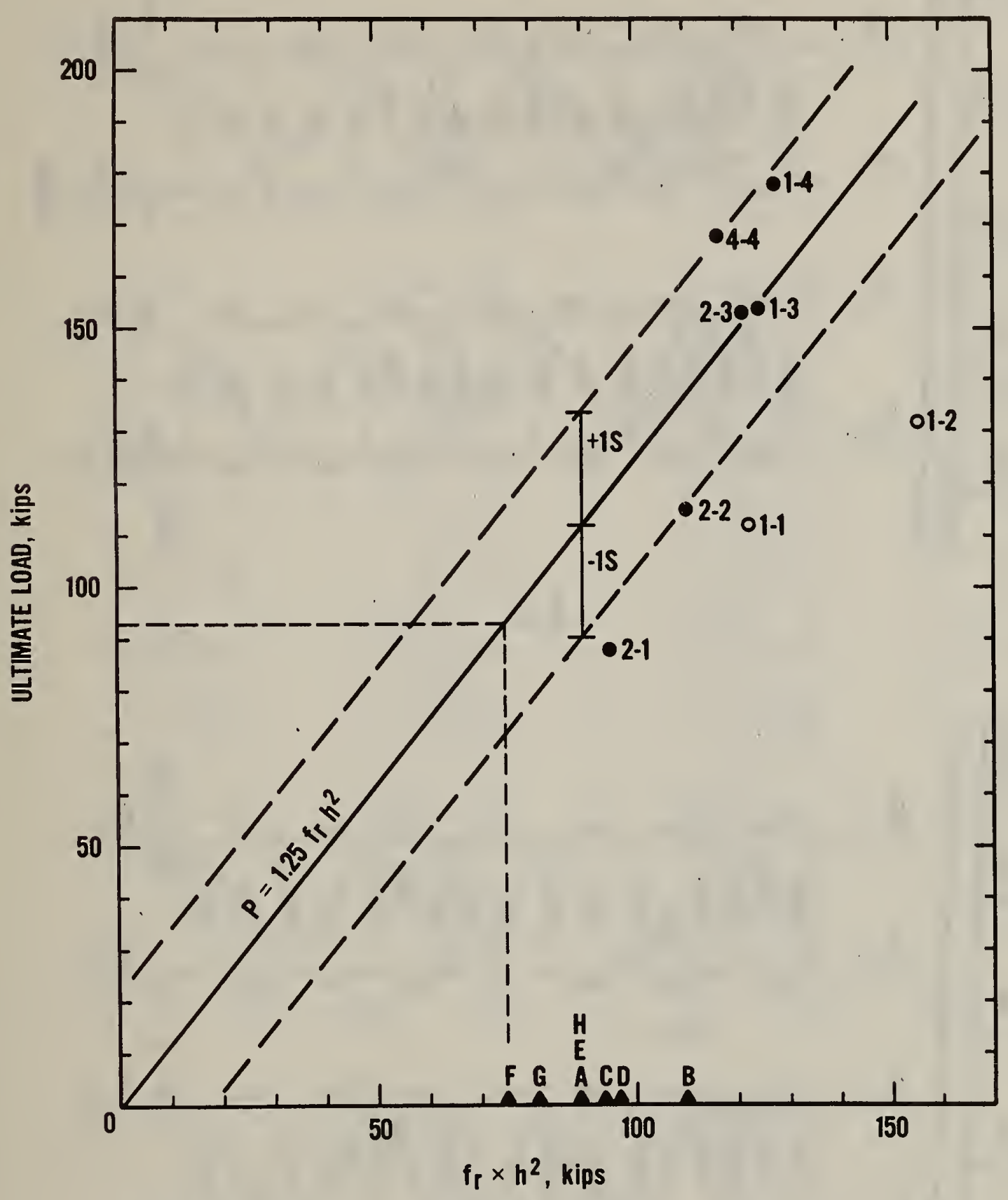

Figure 6.1 Cracking loads of concrete pads in field tests vs. $\left(f_{r} \times h^{2}\right)$ 


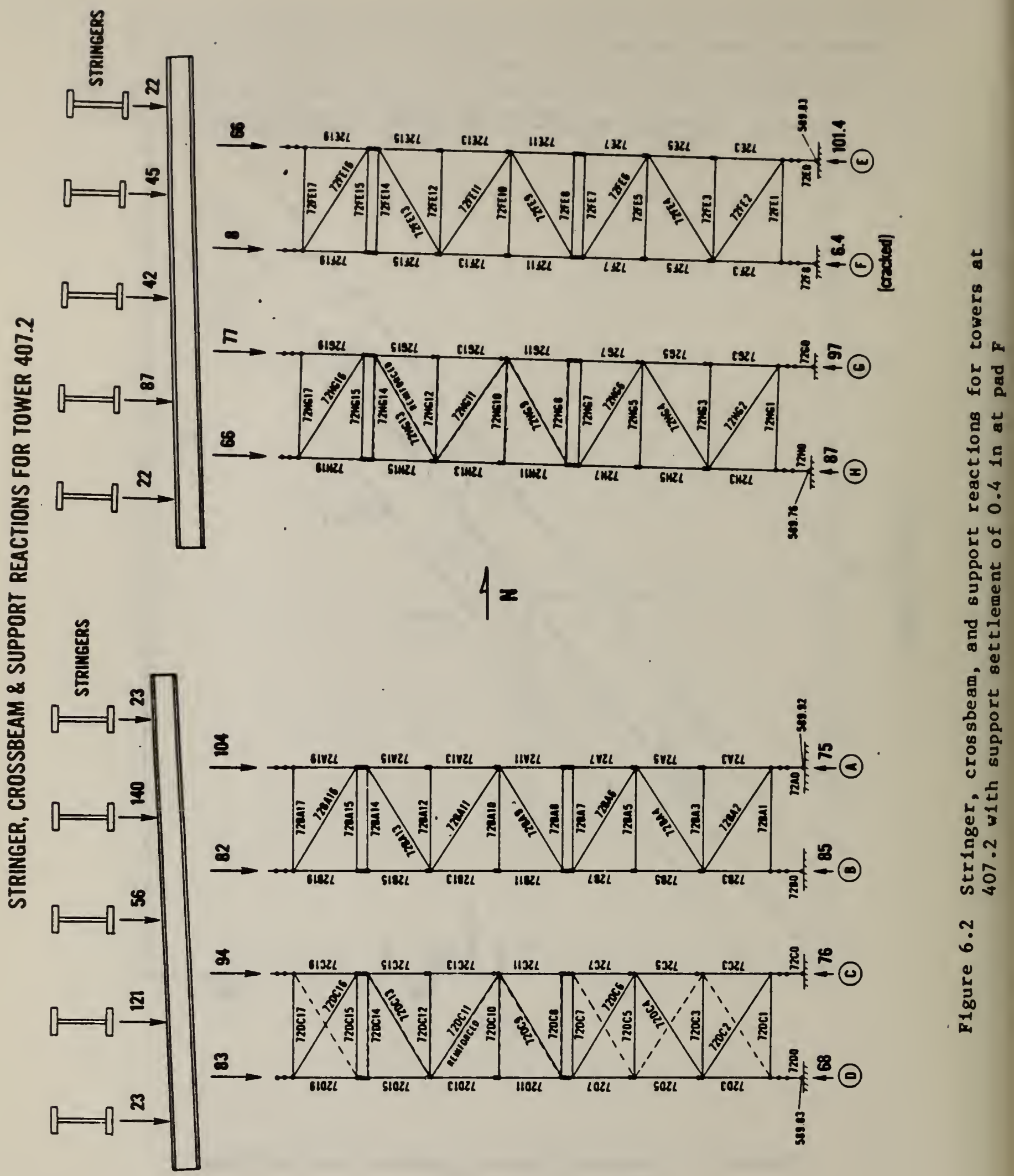


TOWER 407-2 TRUSS BRACE FORCES

(+) TENSION

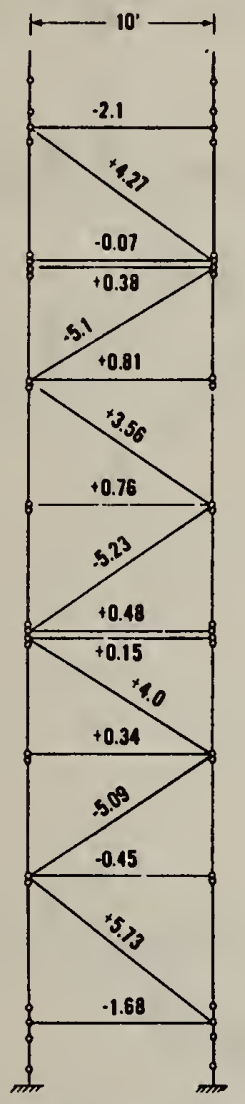

(A)

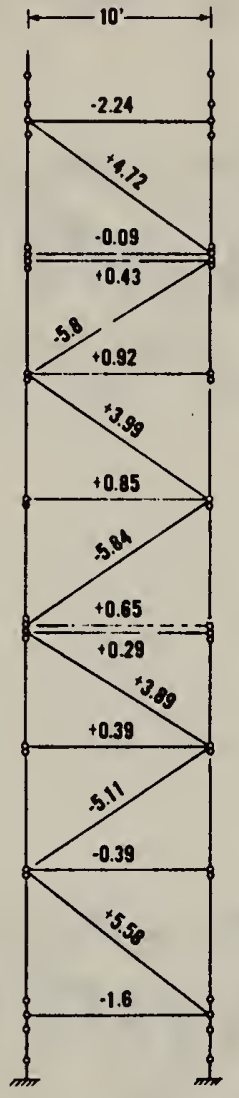

(C)
(C)

(D)

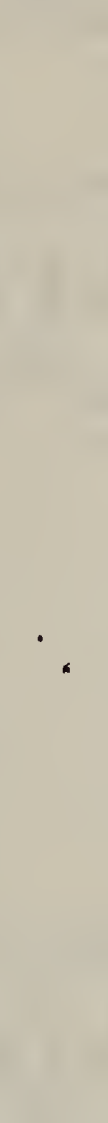

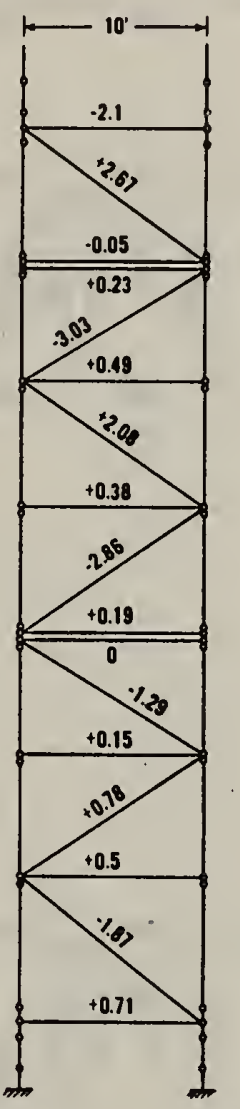

(F)

[cracked]

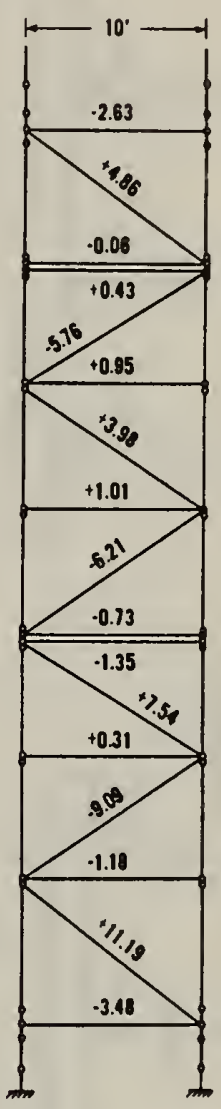

(E)

(a)

Figure 6.3 Truss brace forces for towers at 407.2 with support settlement of 0.4 in at pad F 


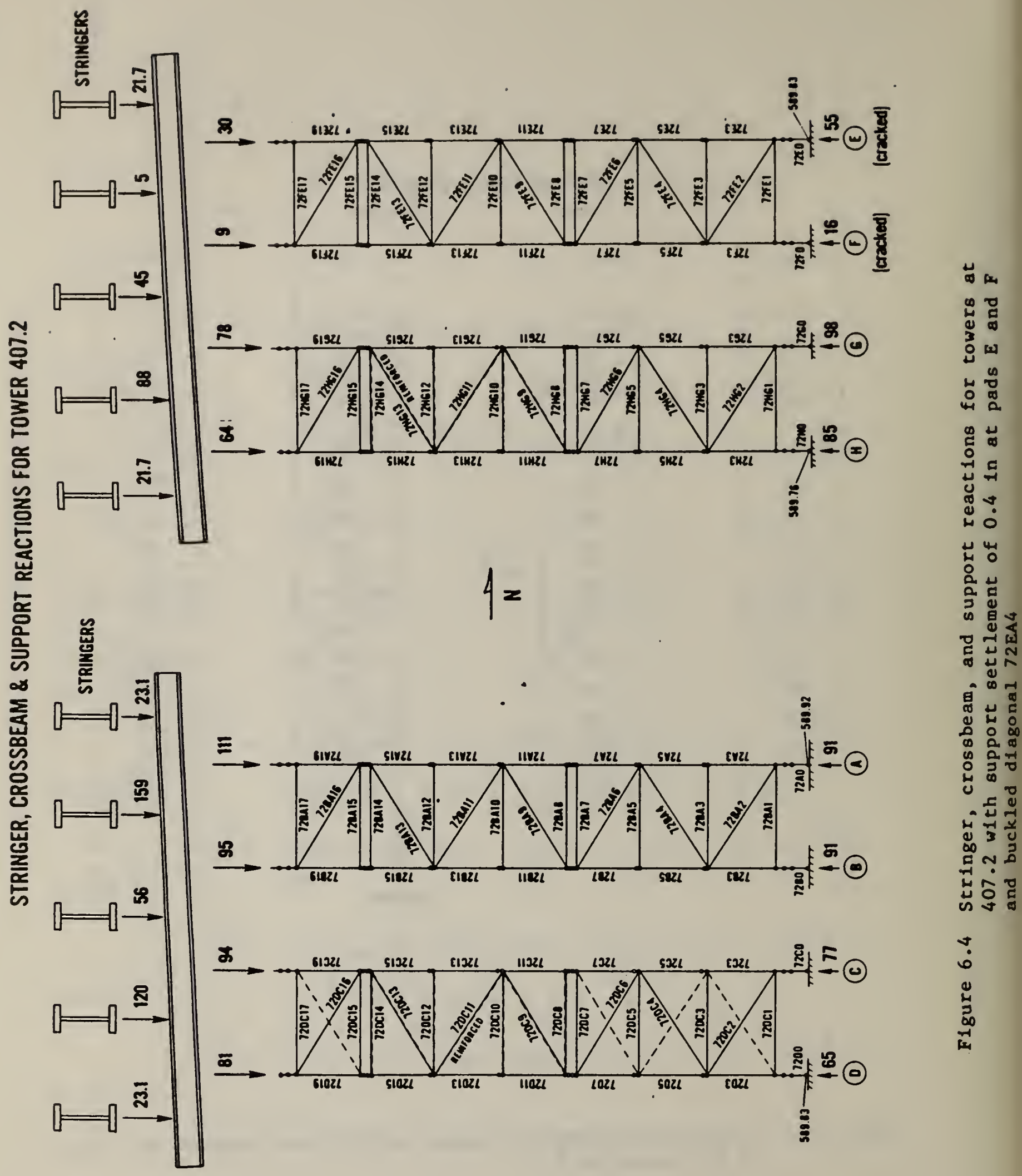


TOWER 407-2 TRUSS BRACE FORCES

(t) TEKSION

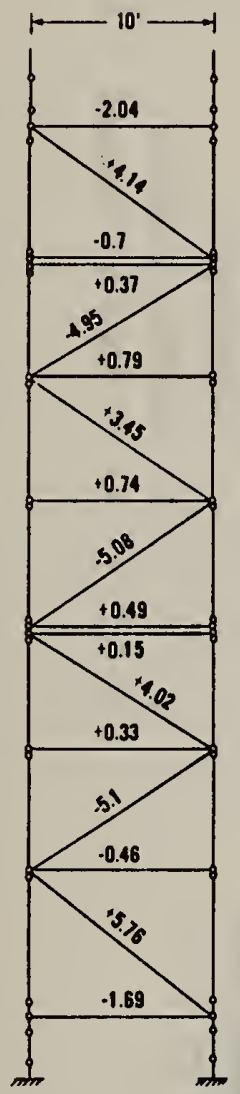

(11)

(1)

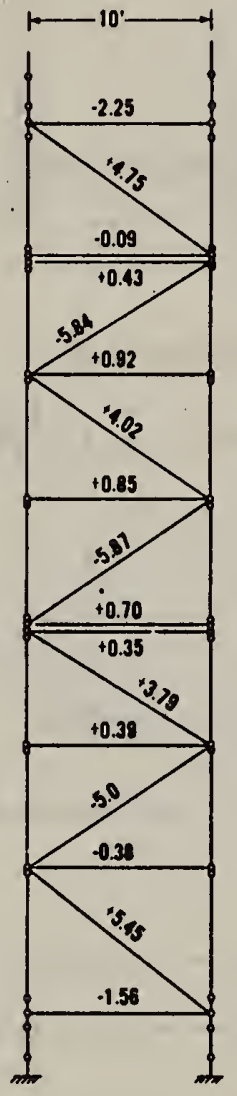

(G)
H Compression

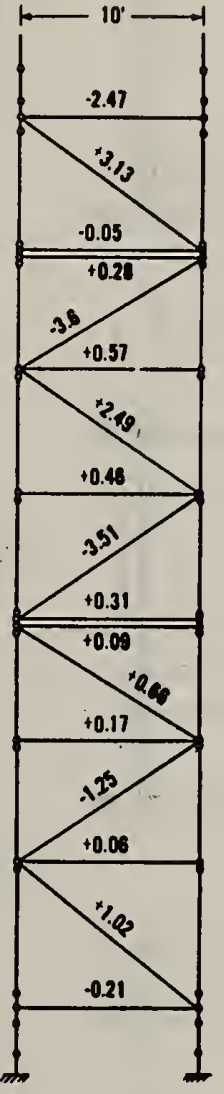

(F)

(B) (cracked)

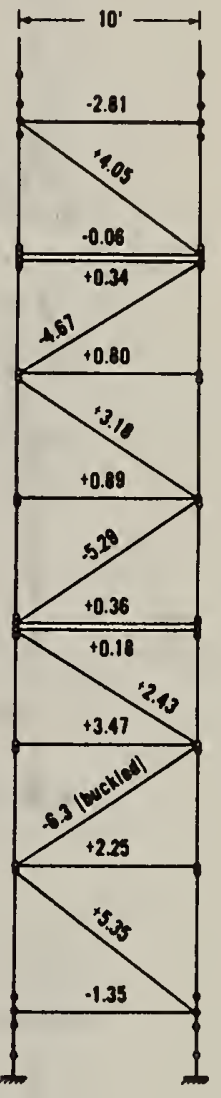

(a) (cracked)

(a)

Figure 6.5 Truss brace forces for tower 407.2 with support settlement of 0.4 in at pads $E$ and $F$ and buckled diagonal 72EA4 

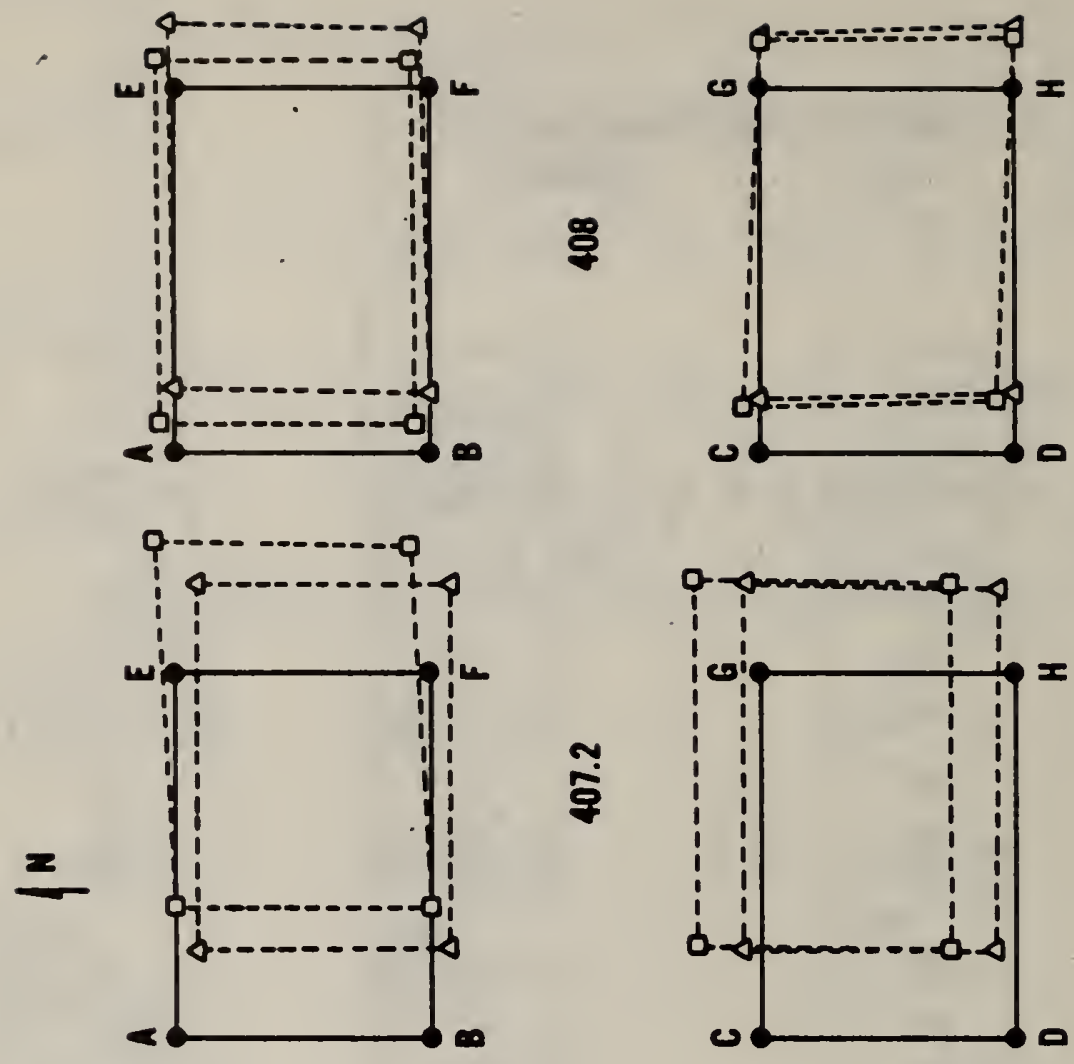

$E$

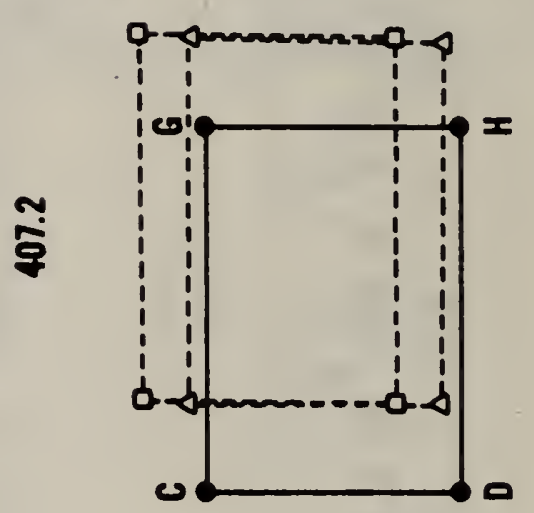

先
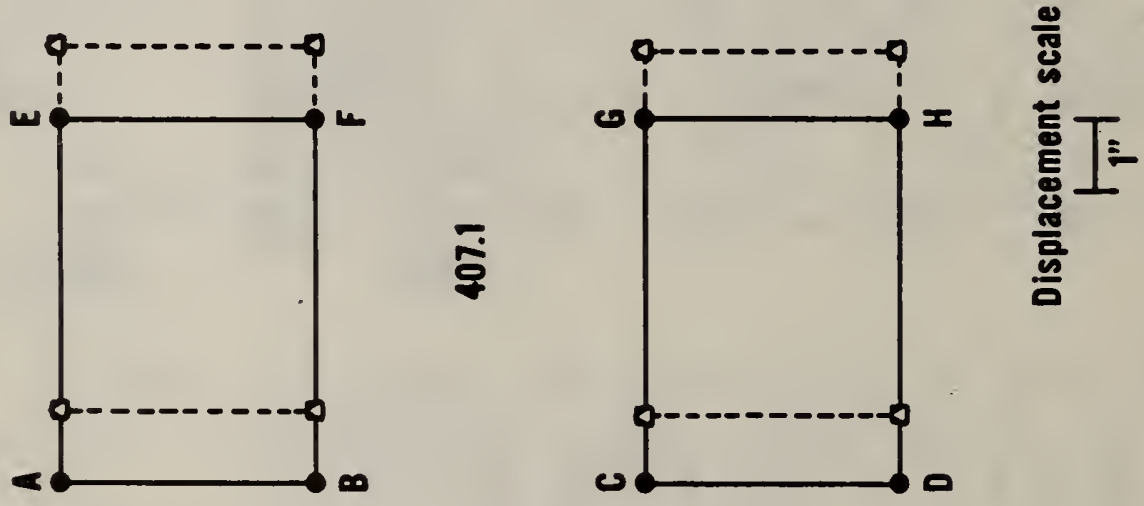

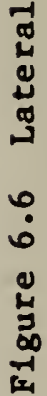




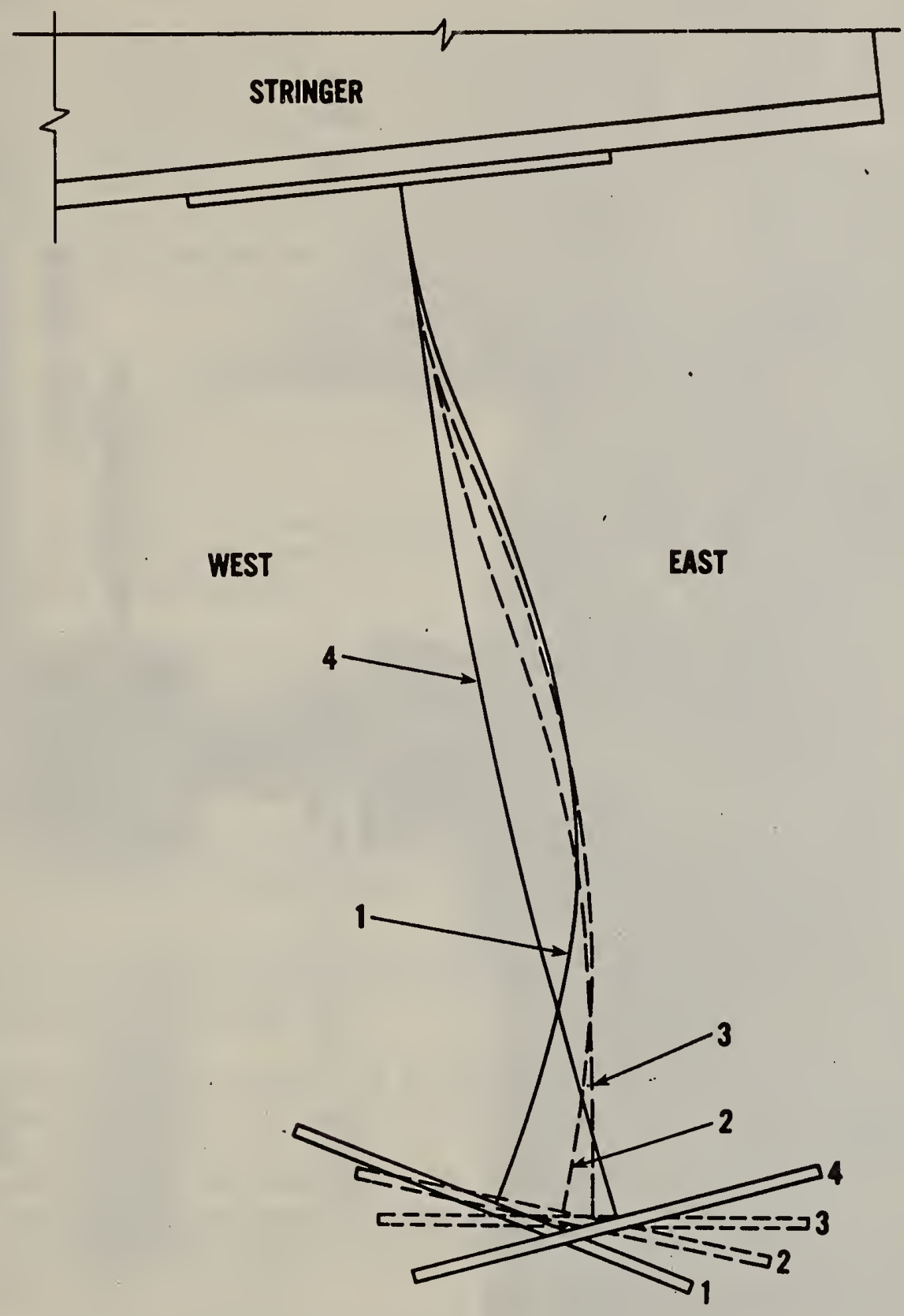

Figure 6.7 Schematic representation of the change in the deformed shape of the crossbeam web as the bottom flange translates eastward 


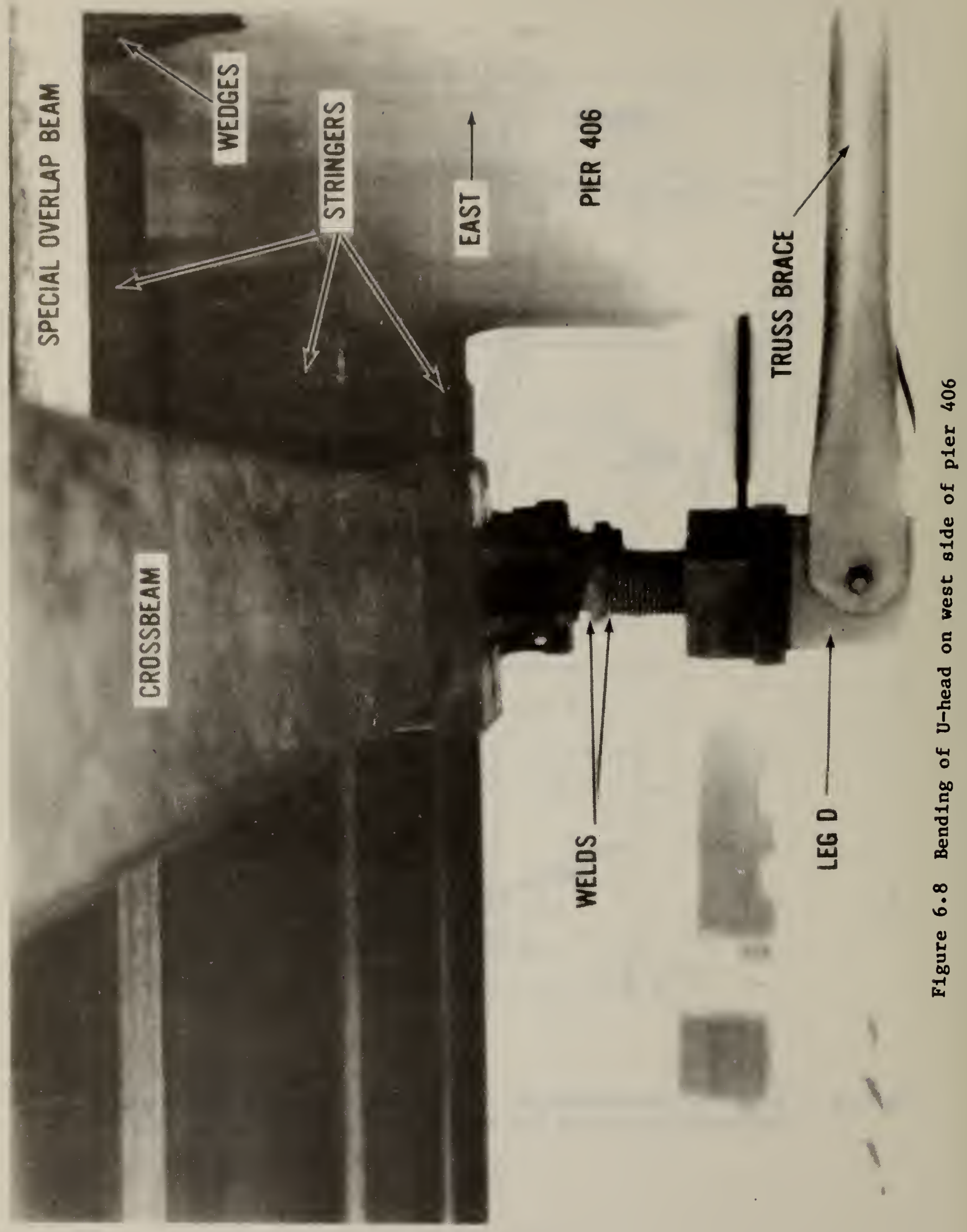




\section{CONCLUSIONS}

Following the collapse of Ramp C of the Riley Road Interchange in East Chicago, Indiana while under construction, the National Bureau of Standards (NBS) was requested by the Occupational Safety and Health Administration to carry out an investigation to determine the most 11kely cause of the collapse. In response to this request, the NBS carried out an extensive field investigation and comprehensive laboratory tests of falsework components and concrete specimens. The investigation was supported by structural analyses of the ramp structurefalsework system under the loading conditions believed to have existed at the time of collapse.

Based on evaluations of fleld observations, of the test results, and of the analytical results, the following specific conclusions are drawn from this investigation:

1. The collapse of unit IV was initiated by a failure in the falsework system at shoring tower location 407.2. This conclusion is supported by the following observations:

a. The collapsed locations of key falsework components indicated that the failure most likely initiated at 407.2 .

b. The accounts of eyewitnesses who were near 407.2 at the time of the failure indicated that the fallure started in this vicinity.

c. The analytical investigation indicated that the falsework at 407.2 was more heavily loaded than that at 407.1 or at 408 .

2. The collapse was most 1ikely initiated by the fallure of a concrete pad supporting a shoring tower leg at 407.2. This conclusion is supported by the following observations:

a. The concrete pads specified in the structural drawings did not have an adequate margin of safety for the expected loads.

b. Any of the pads on the east side at 407.2 could have been 1ikely candidates for failure based on the estimated loads derived from the structural analysis and on their expected strengths derived from tests.

c. Although the U-head welds were variable in size and of poor quality, the loading conditions existing prior to the inftiation of the collapse would not have produced a failure of the U-heads.

d. Al1 falsework components at 407.2 except for the concrete pads had adequate capacity to resist the applied loads.

3. Several deficiencies contributed to the collapse of unit IV. Had any of these deficiencies not existed, it is unlikely that the collapse would have occurred. They were as follows: 
a. Specifled wedges were not used between the stringers and crossbeams to accomodate for the slope of the ramp.

b. The concrete pads did not have an adequate margin of safety for the expected loads.

c. The tops of the shoring towers were not adequately stabilized against translation in the longitudinal direction of the ramp.

d. The welds in the U-heads used at the towers at 407.2 were of poor quality.

4. The collapse of unit $V$ occurred about 5 minutes after the collapse of unit IV. Unit IV collapsed suddenly and without warning, but unit $V$ collapsed in a more gradual "domino-fashion".

a. The collapse of unit IV left unit $V$ without any positive means to provide longltudinal and transverse stablilty to the falsework system.

b. The lack of positive connections between stringers and crossbeams permitted falling stringers to strike shoring towers supporting unit $V$.

5. The following additlonal deficlencles contributed to the subsequent collapse of unit $\mathrm{V}$ :

a. Specifled one-1nch diameter bolts were not provided for connecting crossbeams to stringers and to overlap beams.

b. The special overlap beams at the piers were not fabricated as specified.

c. The construction sequence deviated from the specified sequence. 


\section{REFERENCES}

5.1 Timber Construction Manual, 2nd ed., John Wiley and Sons, Inc., New York, 1974 .

5.2 California Falsework Manual, Division of Structures, State of California Department of Transportation, 162 pp, January 1977.

5.3 ICES STRUDL-II Manual, Department of Civil Engineer1ng, Massachusetts Institute of Technology, R70-77, 341 pp, June 1971.

6.1 "Specification for the Design, Fabrication and Erection of Structural Steel for Buildings," American Institute of Steel Construction, New York, N.Y., November 1980.

6.2 Basler, K., "New Provisions for Plate Girder Design," 1961 Proceedings of National Engineering Conference, American Institute of Steel Construction, New York, N.Y., May 1961.

6.3 "AWS Structural Welding Code," Third Edition, American Welding Soclety, Miami, FL, 1978.

6.4 "Guide to Stability Design Criteria for Metal Structures," Structural Stability Research Council, John Wiley \& Sons, New York.

6.5 Gorbunov-Possadov, M.I. and Serebrjany1, R.V., "Design of Structures on Elastic Foundations," Proceedings of the Fifth International Conference on Soil Mechanics and Foundation Engineering, Vol. I - Divisions I-3A, Dunod, Paris, July 1961.

6.6 Building Code Requirements for Reinforced Concrete, ACI Standard 318-77, American Concrete Institute, Detroit, MI, 1977. 


\section{ACKNOWLEDGEMENTS}

Throughout the course of this investigation, the NBS investigation team recelved full cooperation from the Indiana Occupational Safety and Health Administration (IOSHA) and the Chicago Area Office of the U.S. Occupational Safety and Health Administration (OSHA). The authors of th1s report wish to acknowledge particularly Messrs. James E. White and Ernest H. Vallery of IOSHA and $\mathrm{Mr}$. Robert T. Radcliff of OSHA. Without their assistance, 1t would not have been possible to obtain data needed to carry out this investigation.

The-authors also wish to recognize contributions made by Mr. Charles H. Brady of the Fracture Deformation Division, Center for Materials Science, NBS, for metallographic analyses of welds and Dr. Robert C. Placlous and Mr. Daniel Polanksy of the Radiation Physics Division, Center for Radiation Research, NBS, for radlographing welds.

The authors wish to recognize contributions made by individuals who participated In the 1nvestigation. Dr. Edward 0. Pfrang, Chief, Structures Division, Center for Bullding Technology, Dr. S. George Fattal, Structures Division, CBT, Dr. Felix Yokel, Structures Division, CBT, and Mr. Harold M. Helfer, Visual Arts Group, NBS.

The comments and suggestions made by the reviewers of the report are appreclated.

The fullest cooperation given to the authors by the staffs of the CBT Word Processing Center and of the NEL Graphics Group are gratefully acknowledged. 
APPENDIX A: LOAD-DISPLACEMENT CURVES OF SCREW JACK BASES

IN THE FULL-SCALE LOAD TESTS 


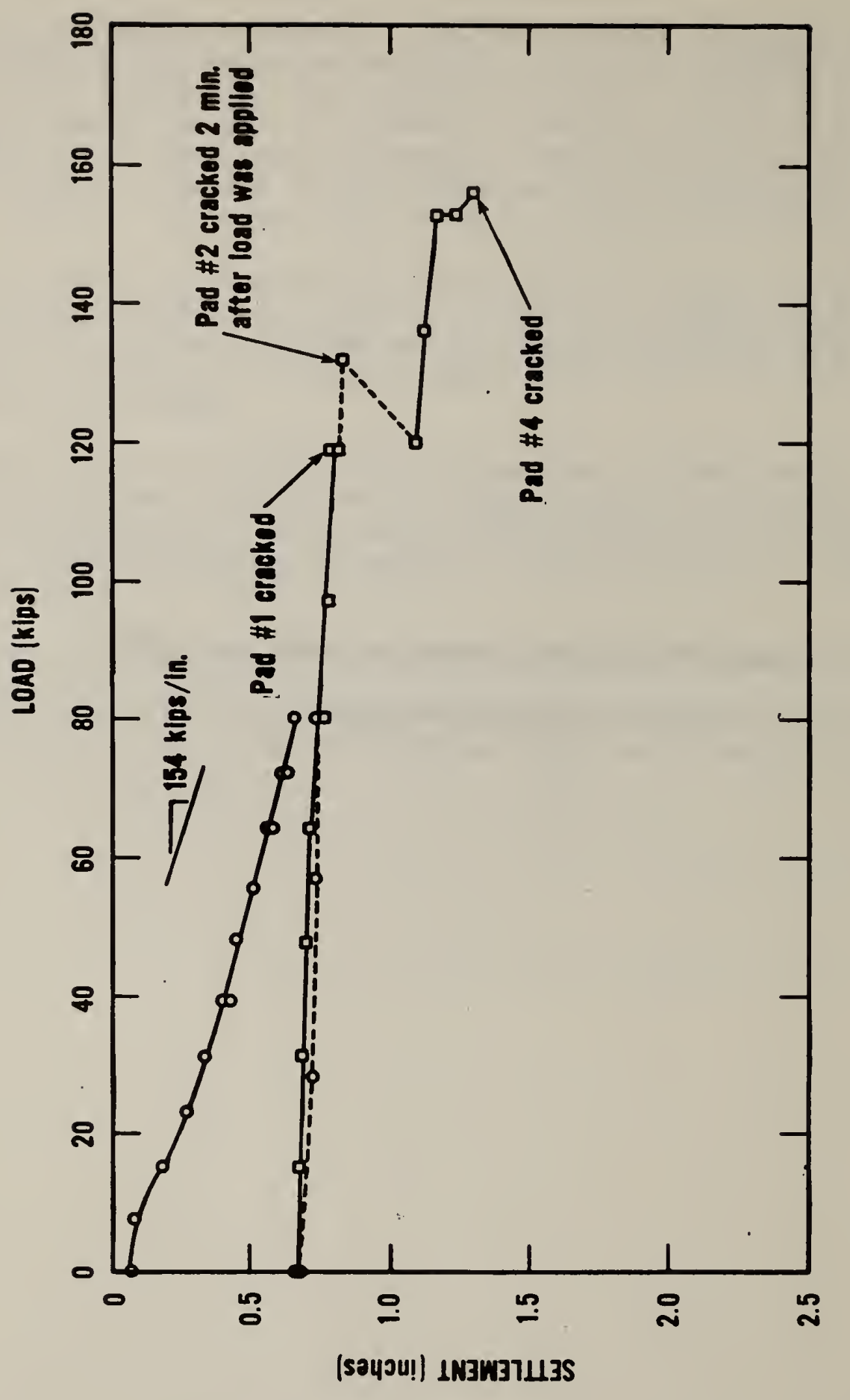

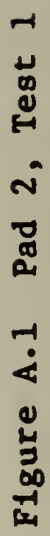




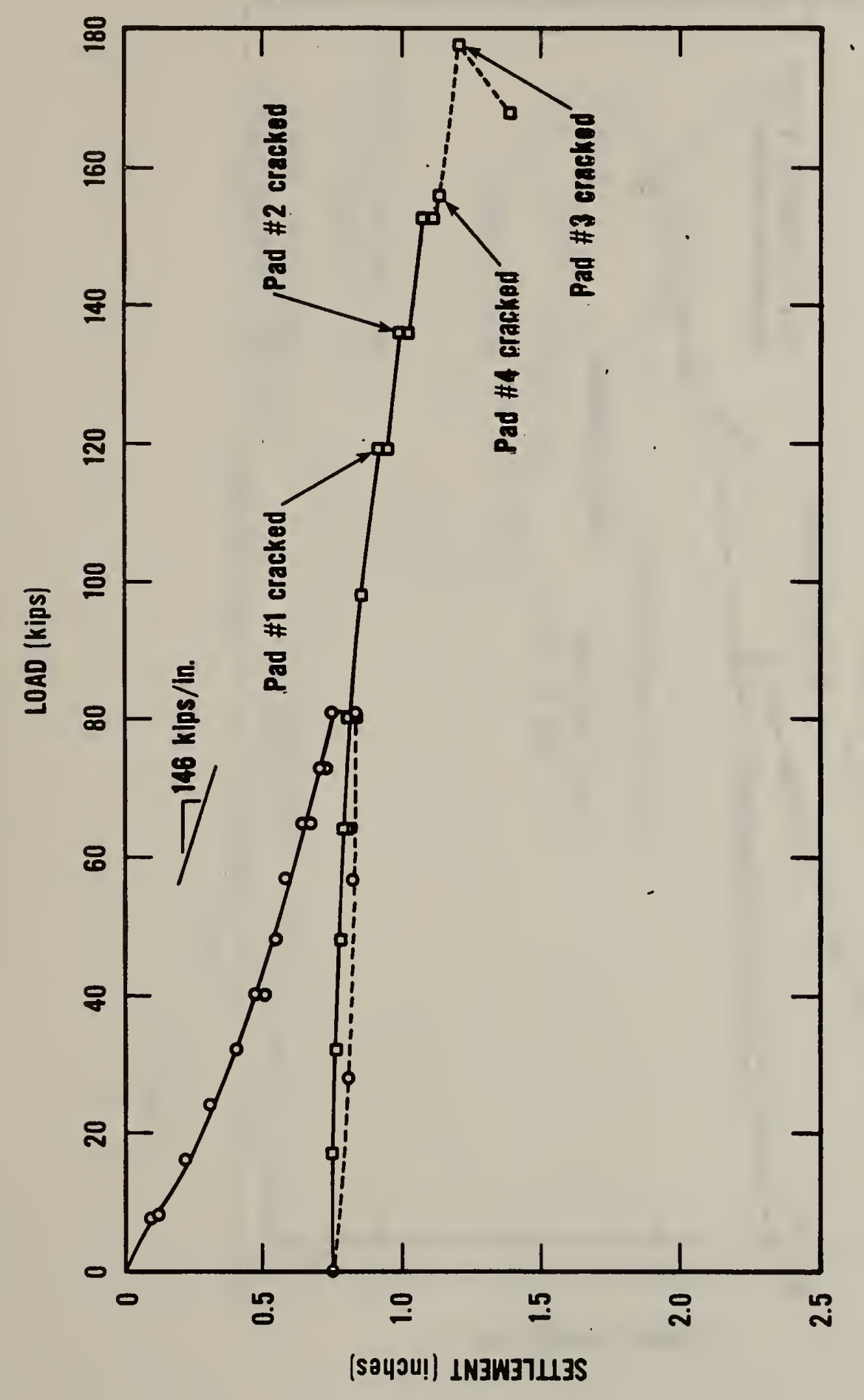

苟 


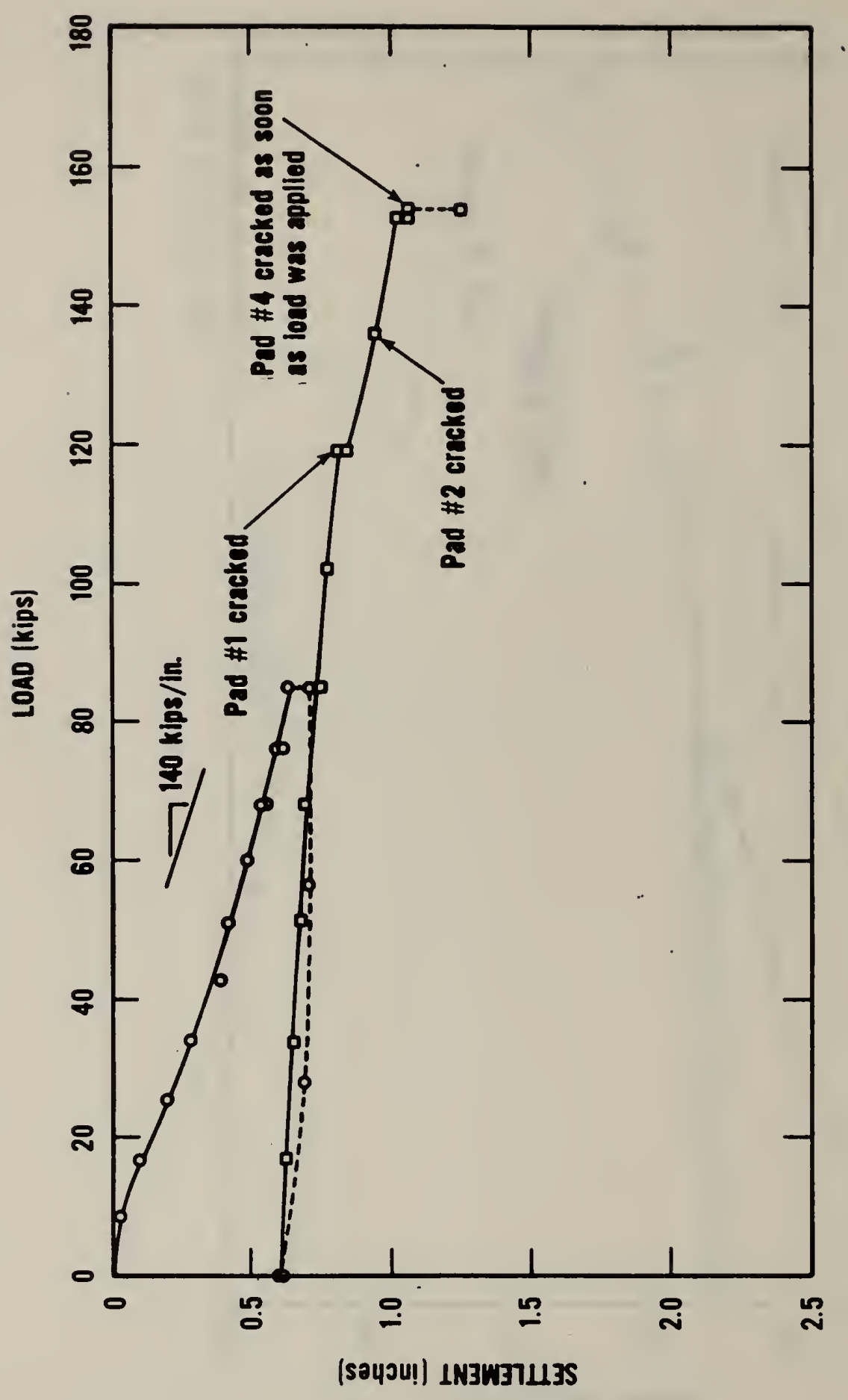

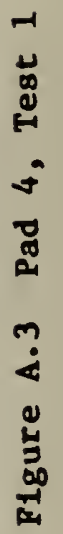




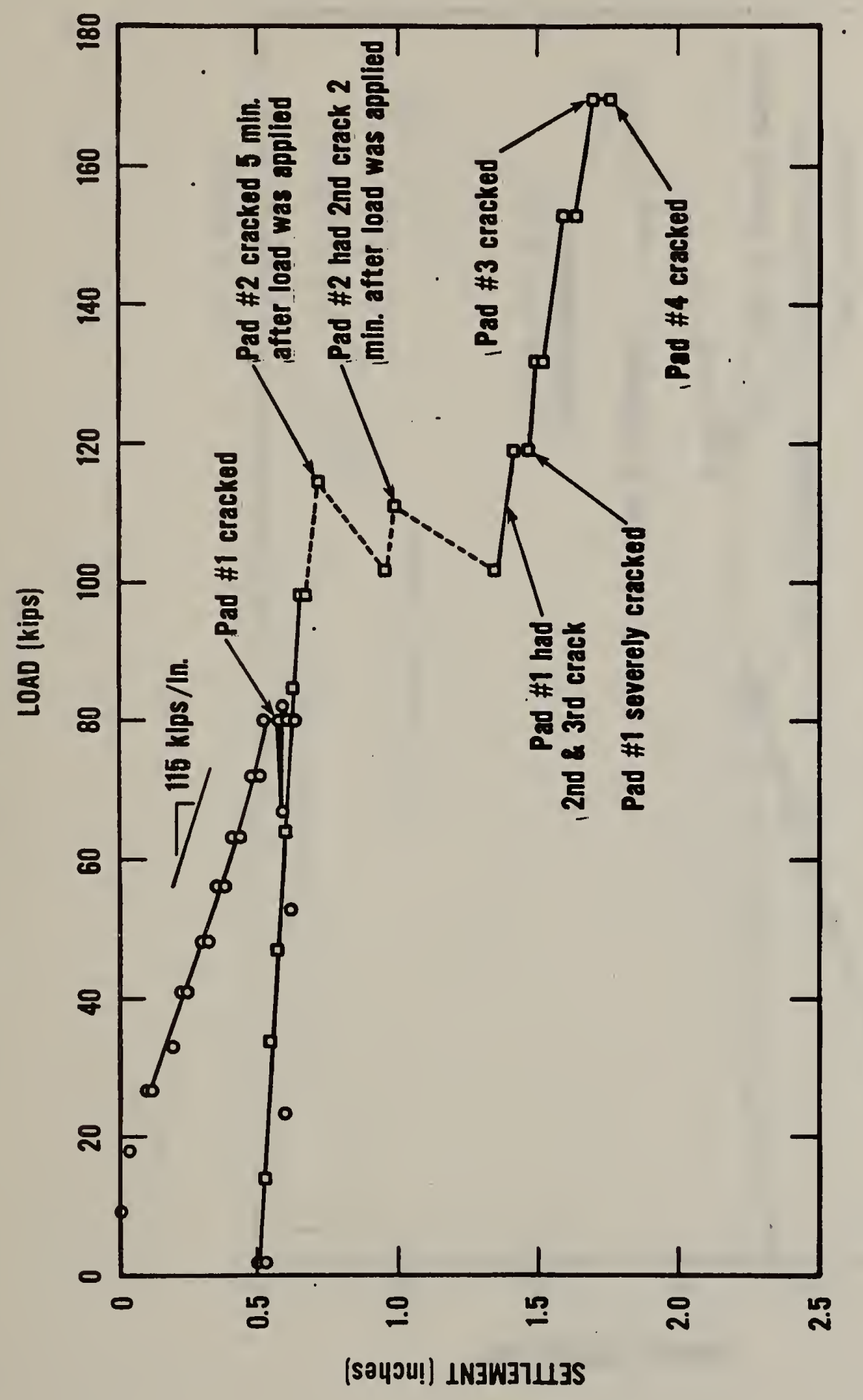

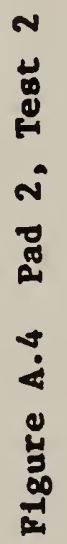




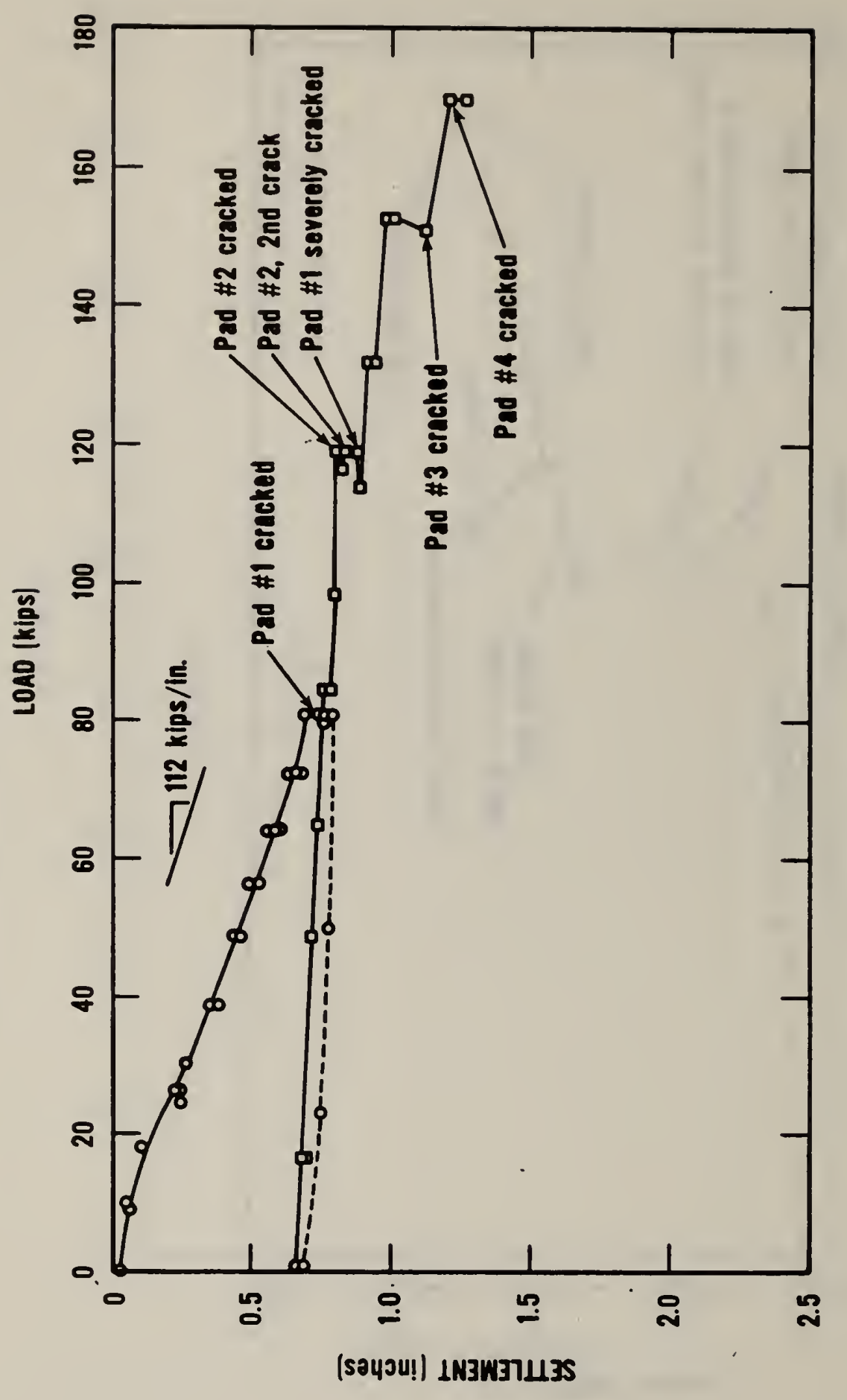

م 


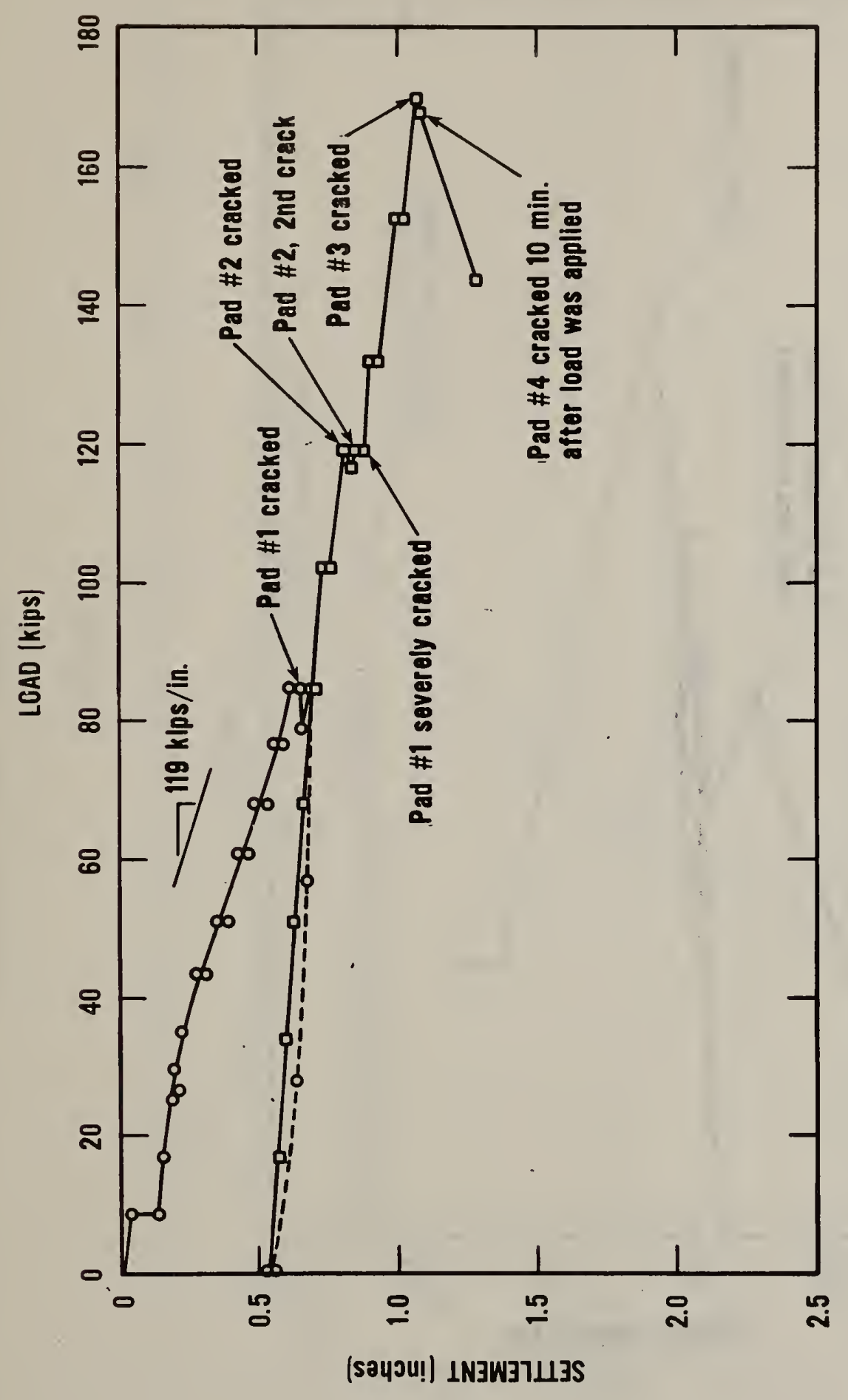

$N$
0
0
0
0
0
0
0
0
0
4
3
0
0
0 


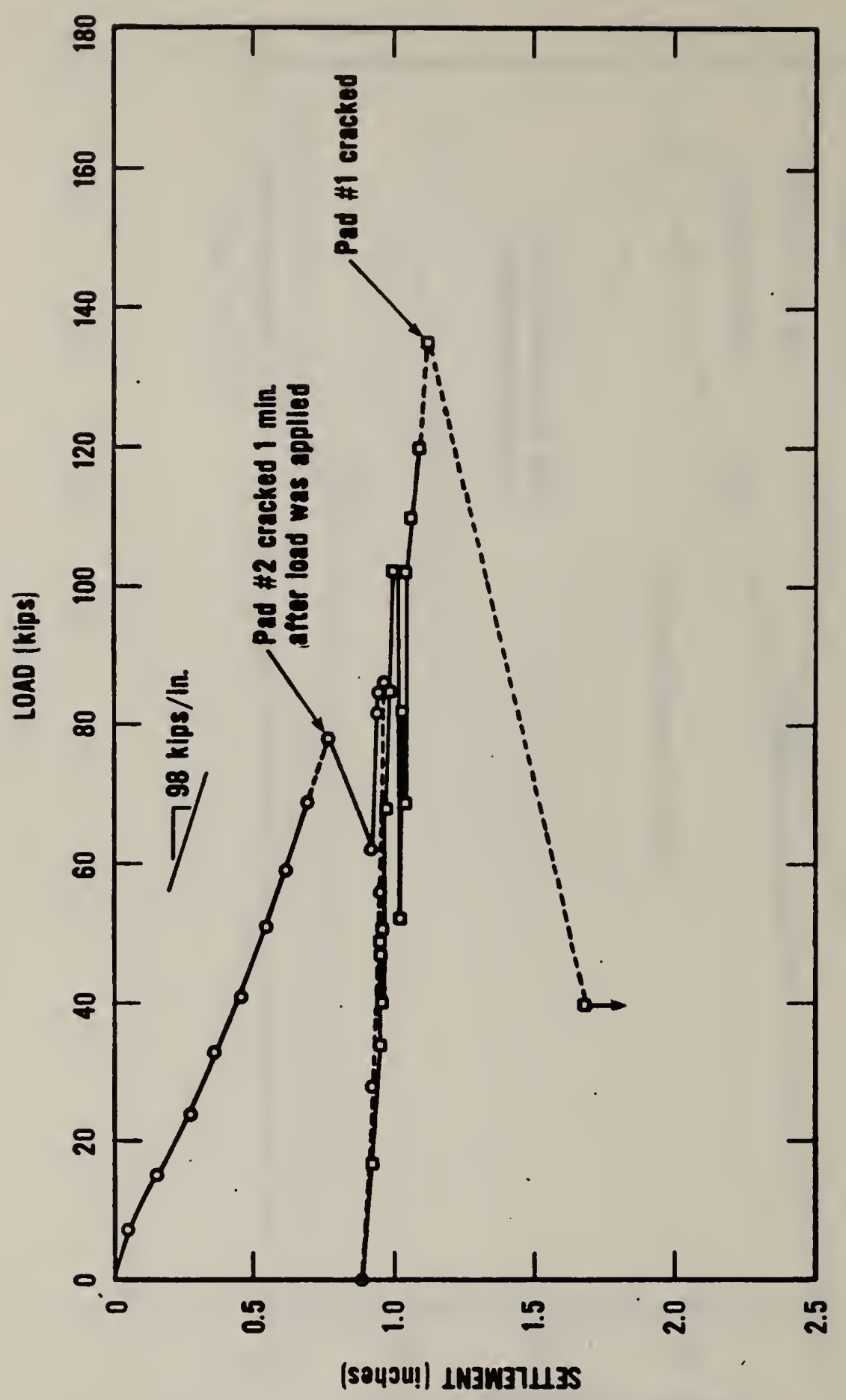

盛 


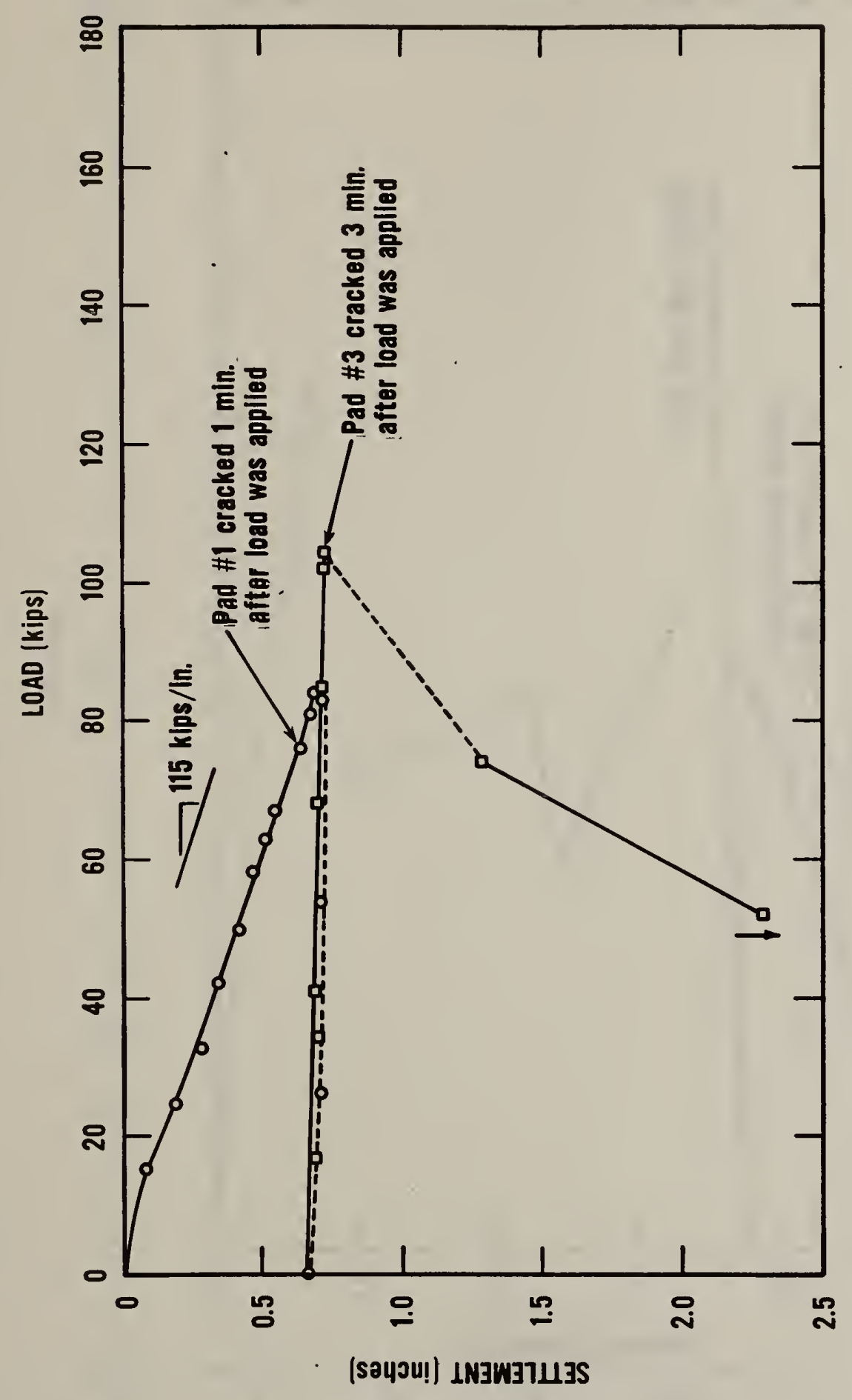

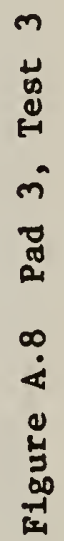




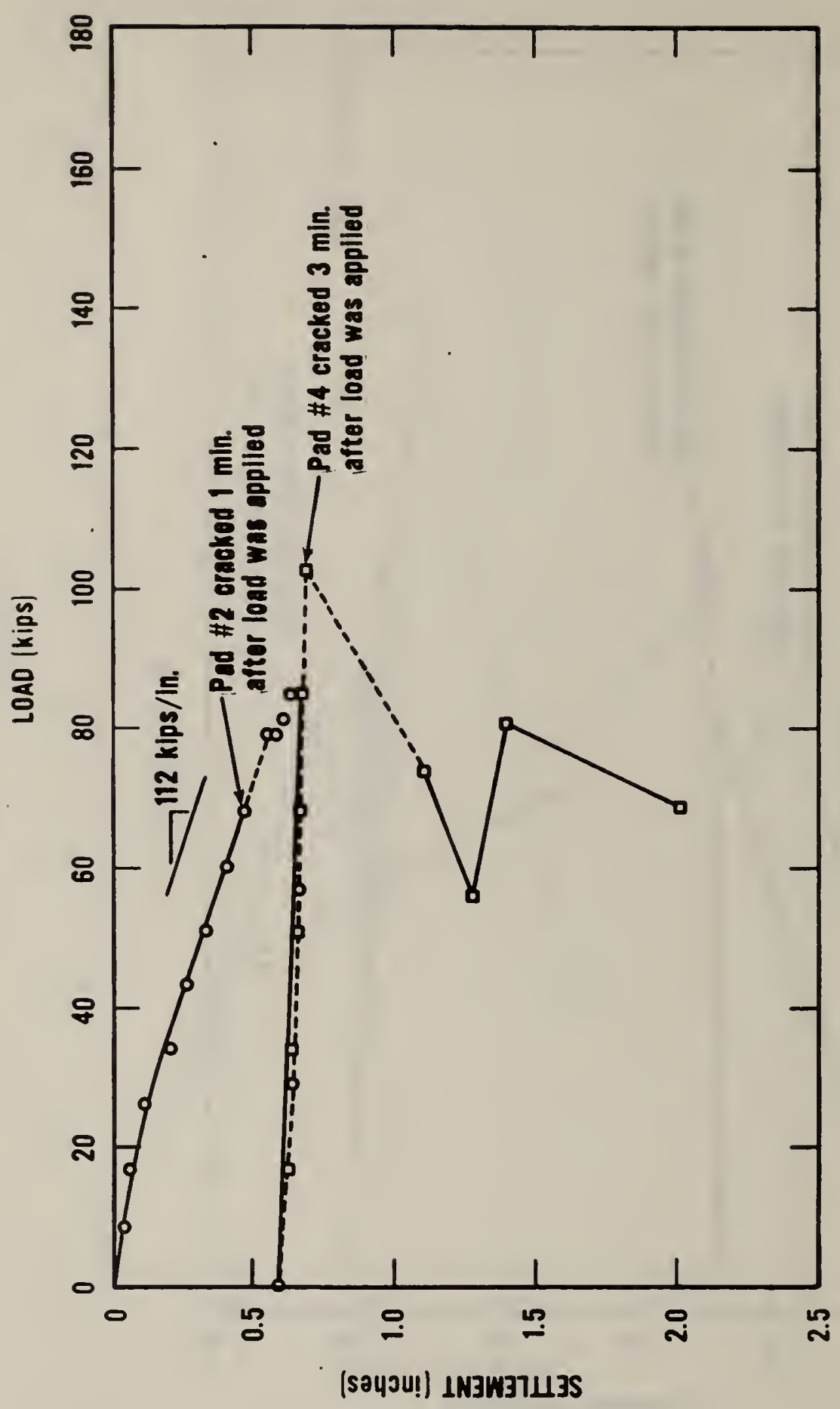

$m$
0
0
0
0
0
0
0
0
0
5
0
0
0
2 


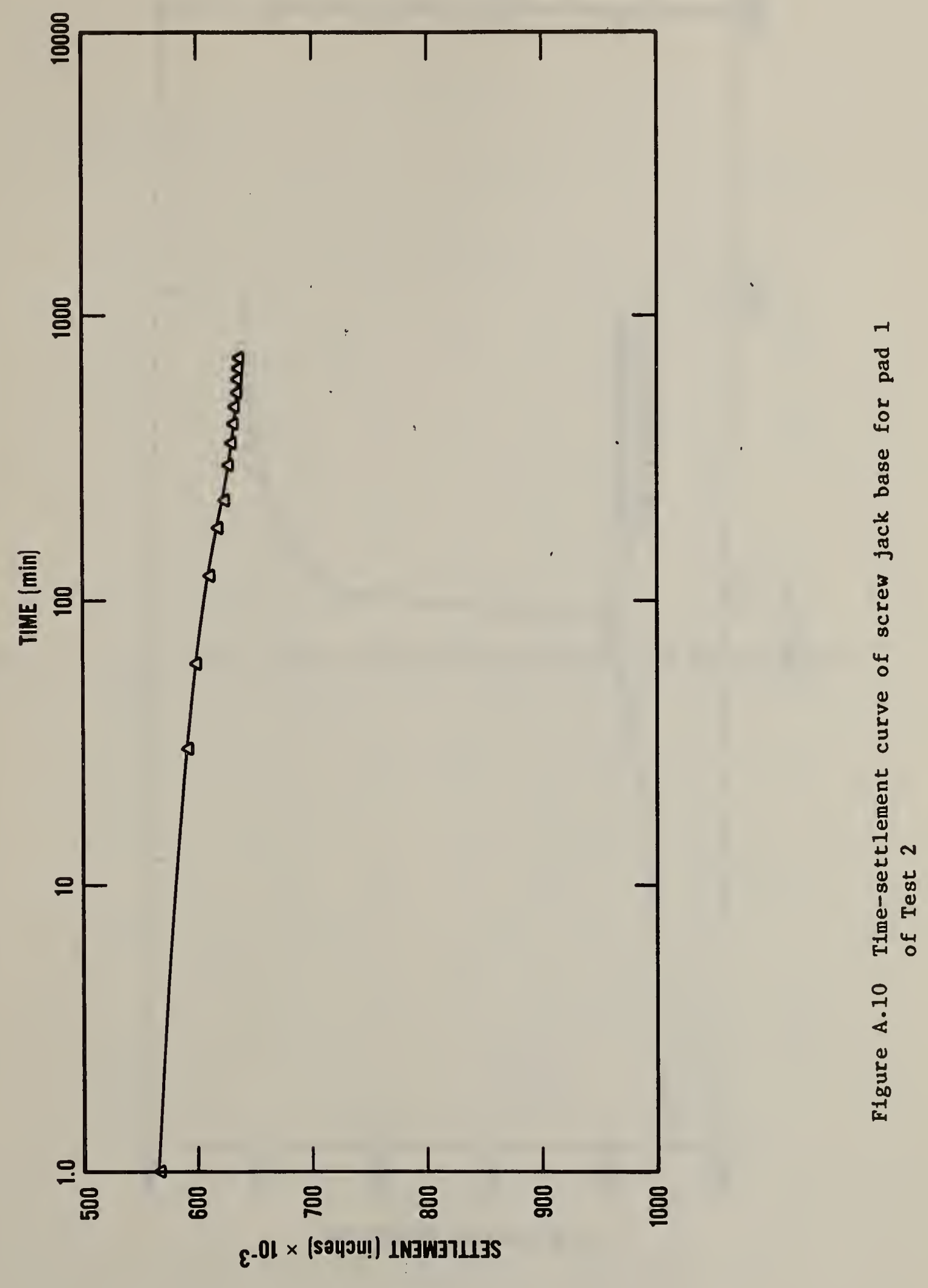




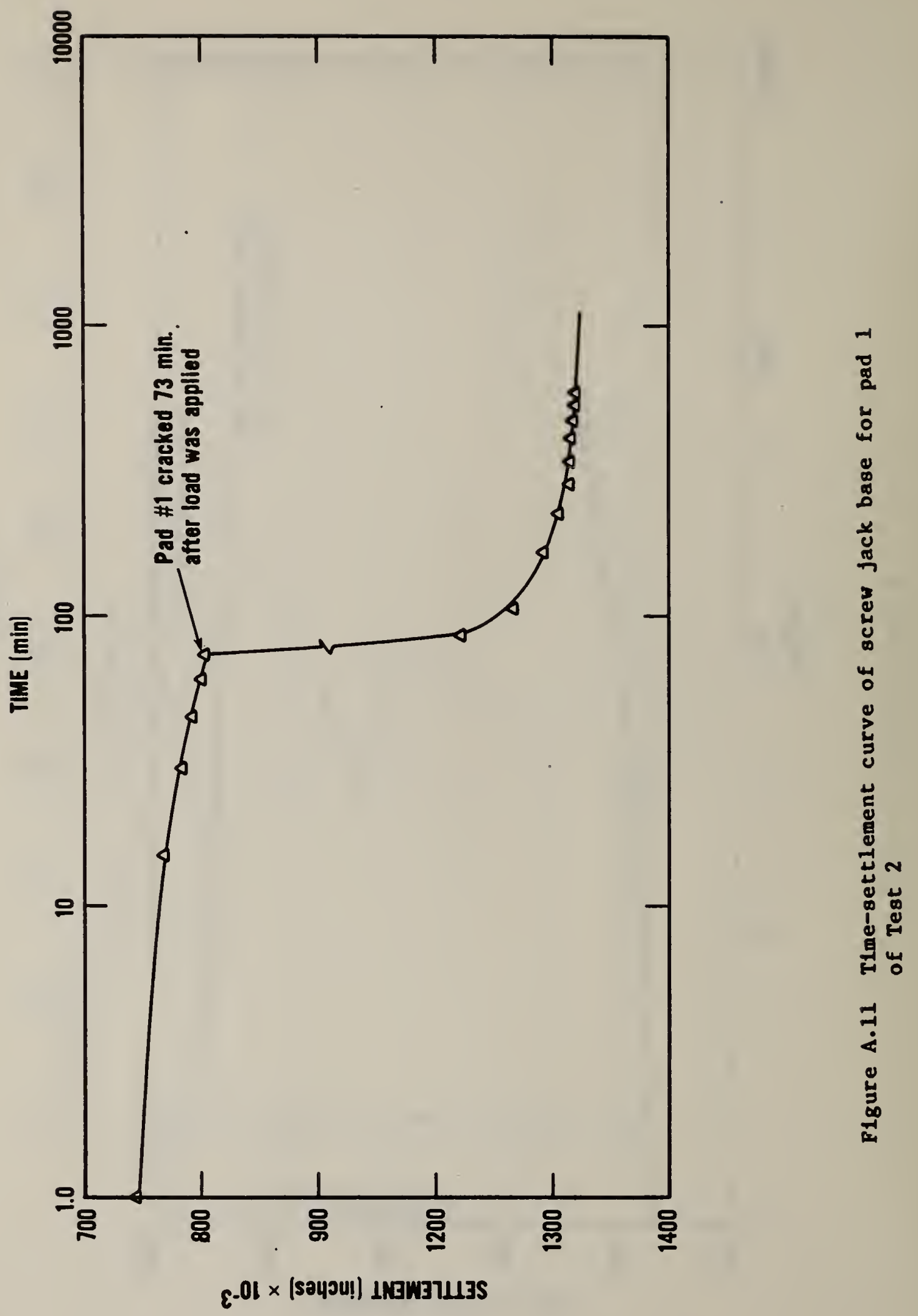


APPENDIX $B$ : SHORING TOWER FINITE ELEMENT MODELS AND MEMBER DESIGNATIONS 


\section{TOWER 407-1}

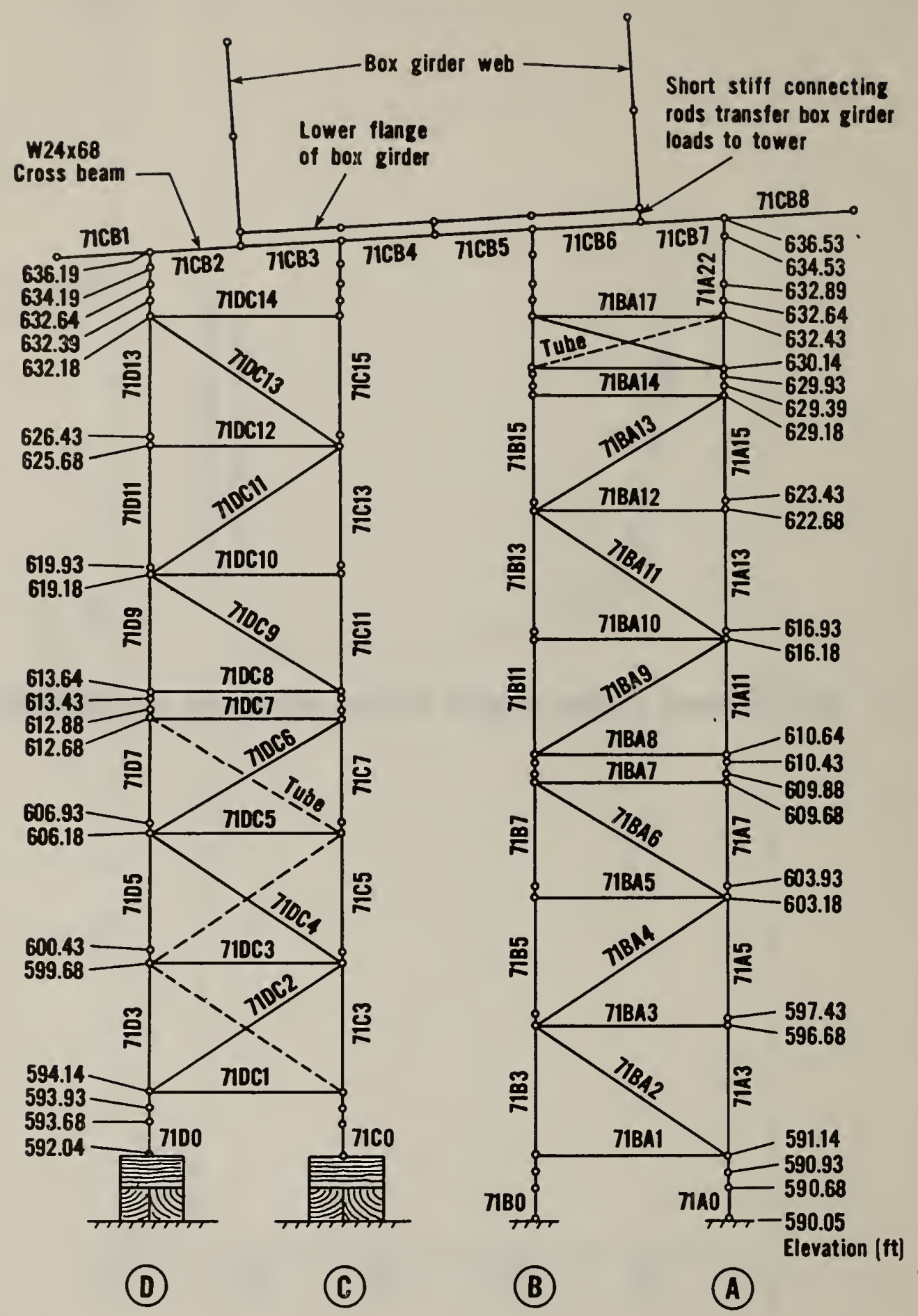

Figure B.1 West frames of towers at 407.1 


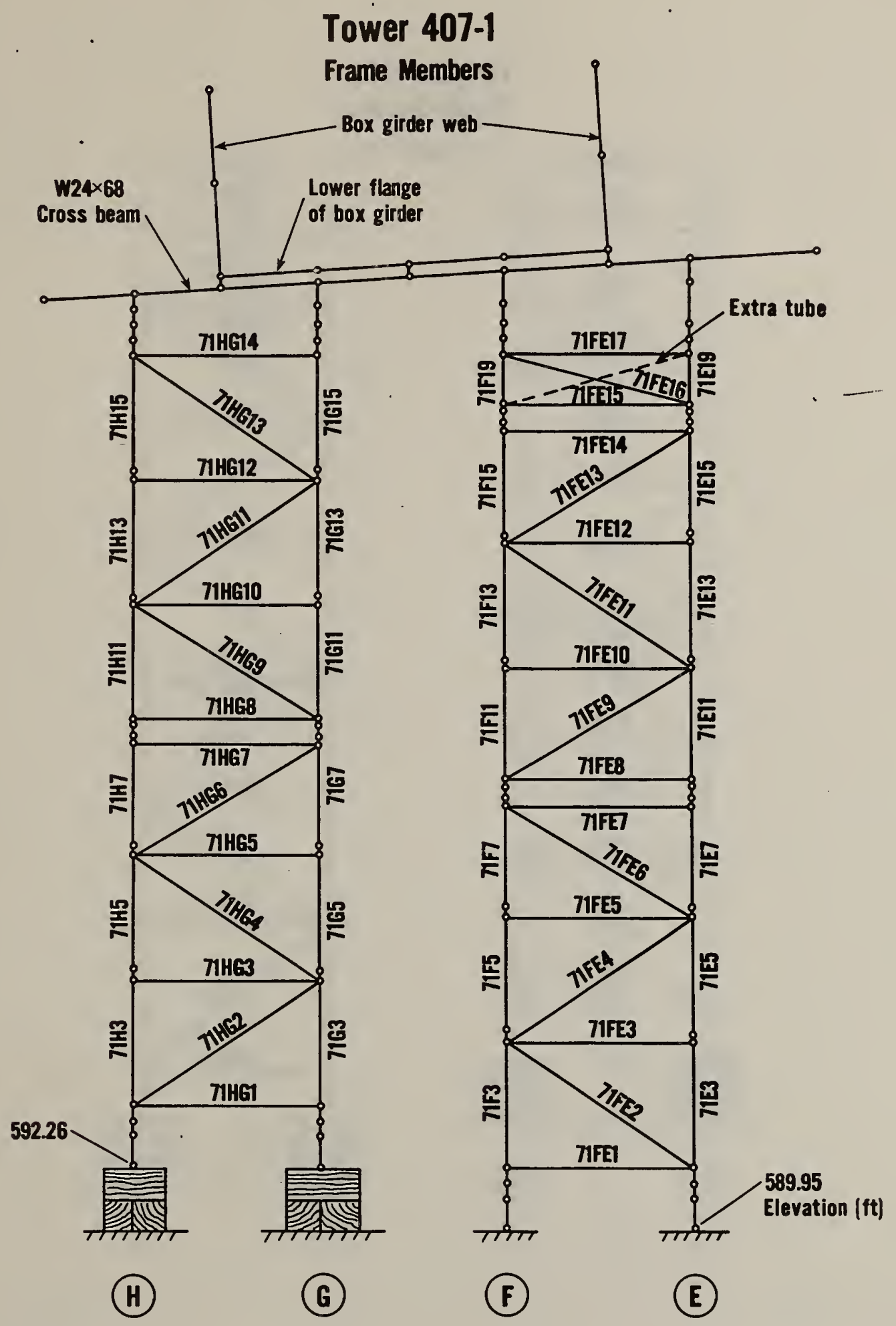

Figure B.2 East frames of towers at 407.1 
Tower 407-1

Truss Members

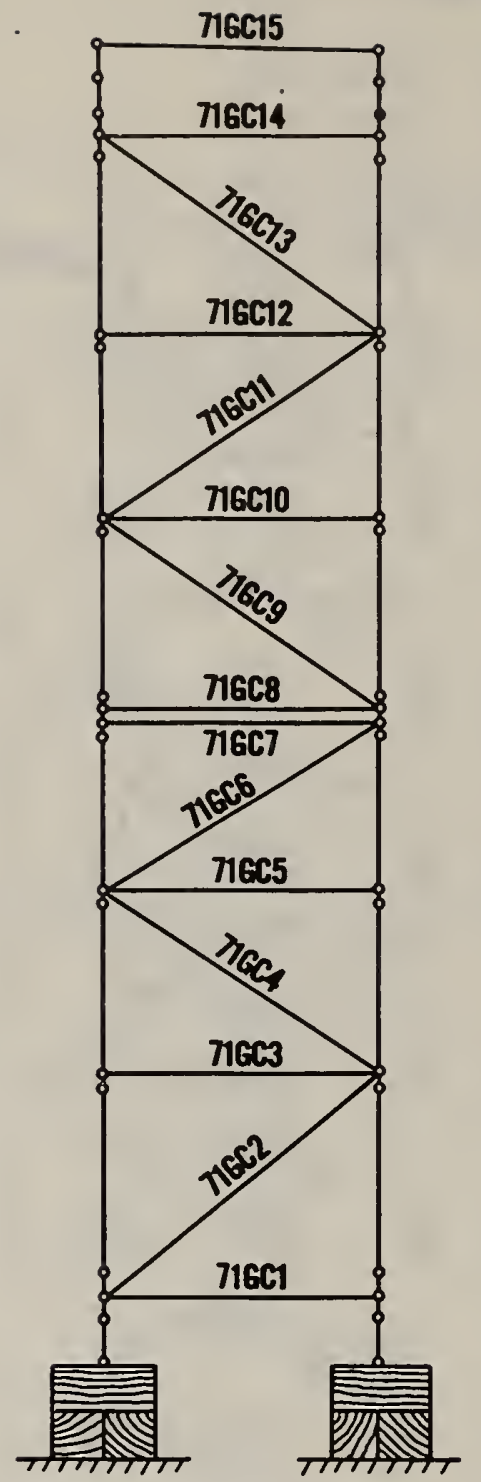

(G)

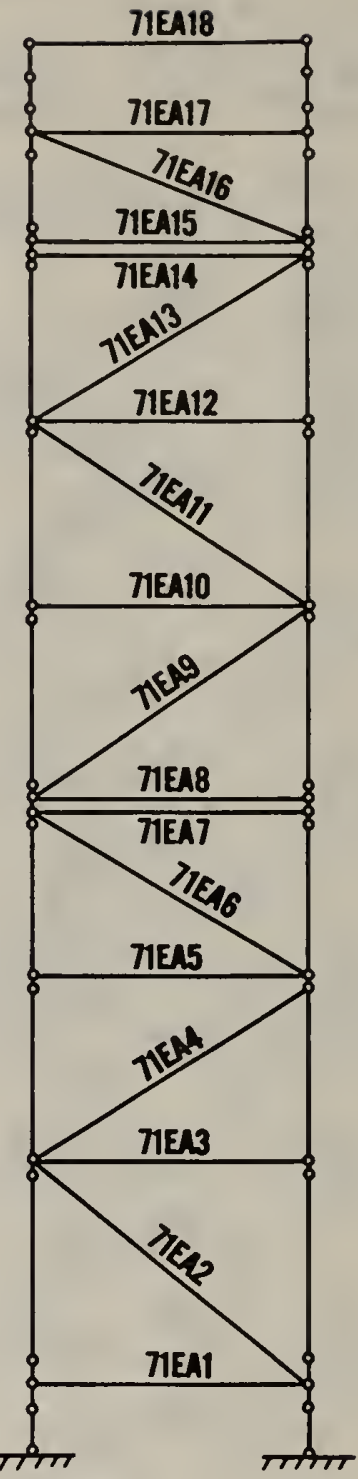

(E)

(A)

Figure B.3 Truss panels AE and CG of the towers at 407.1 


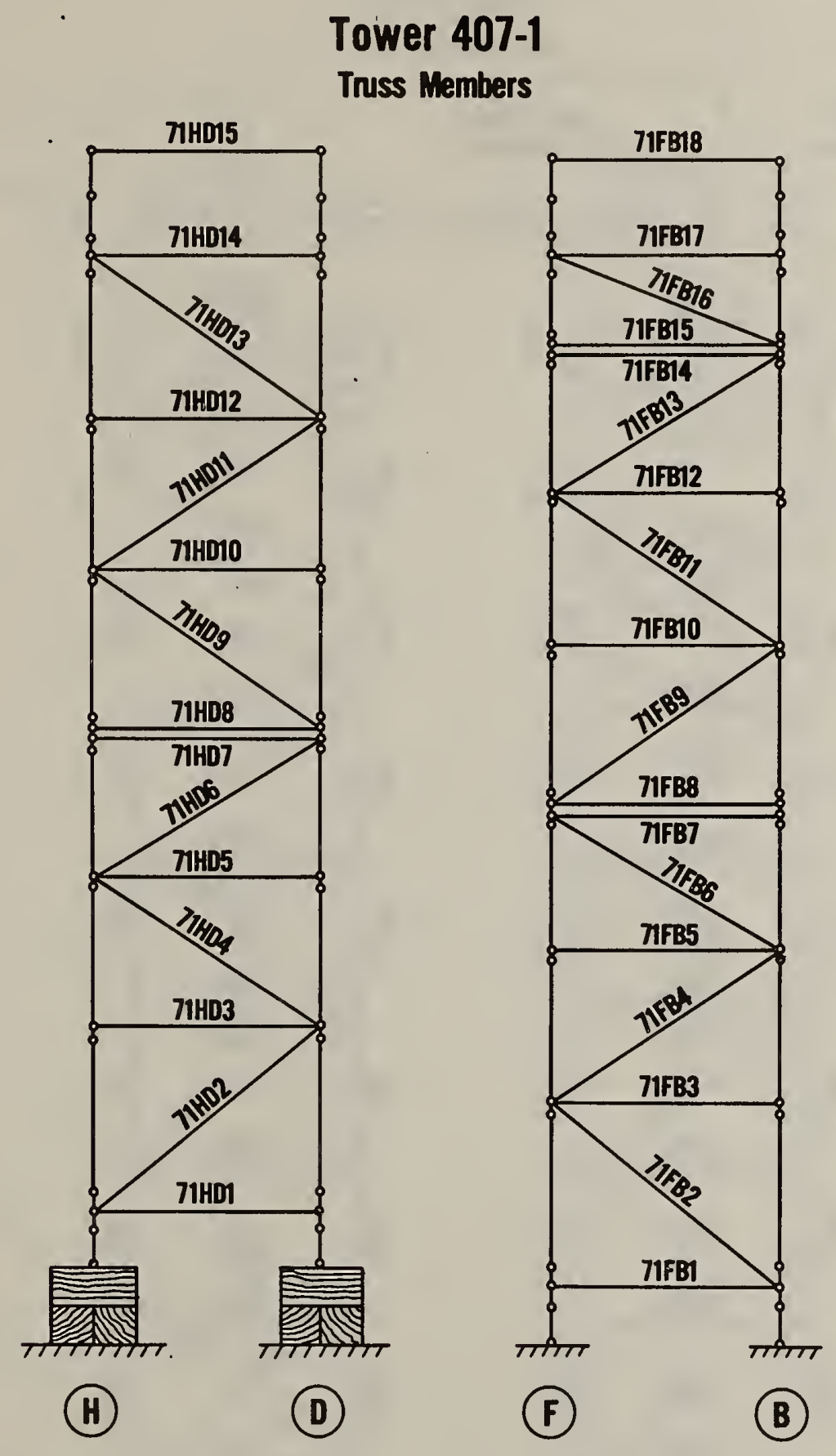

Figure B.4 Truss panels BF and DH of the towers at 407.1 


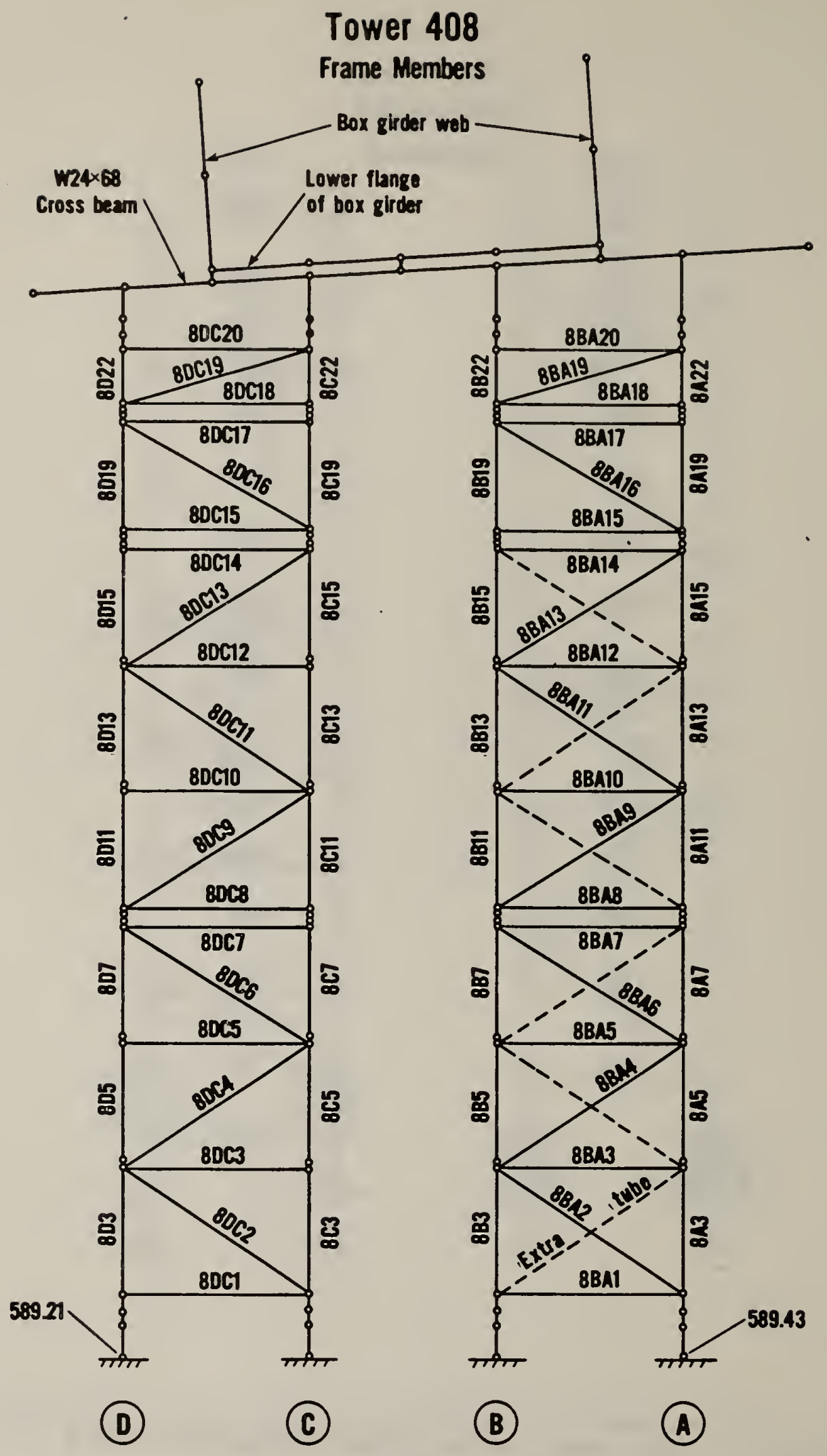

Figure B.5 West frames of towers at 408 


\section{Tower 408}

\section{Frame Members}

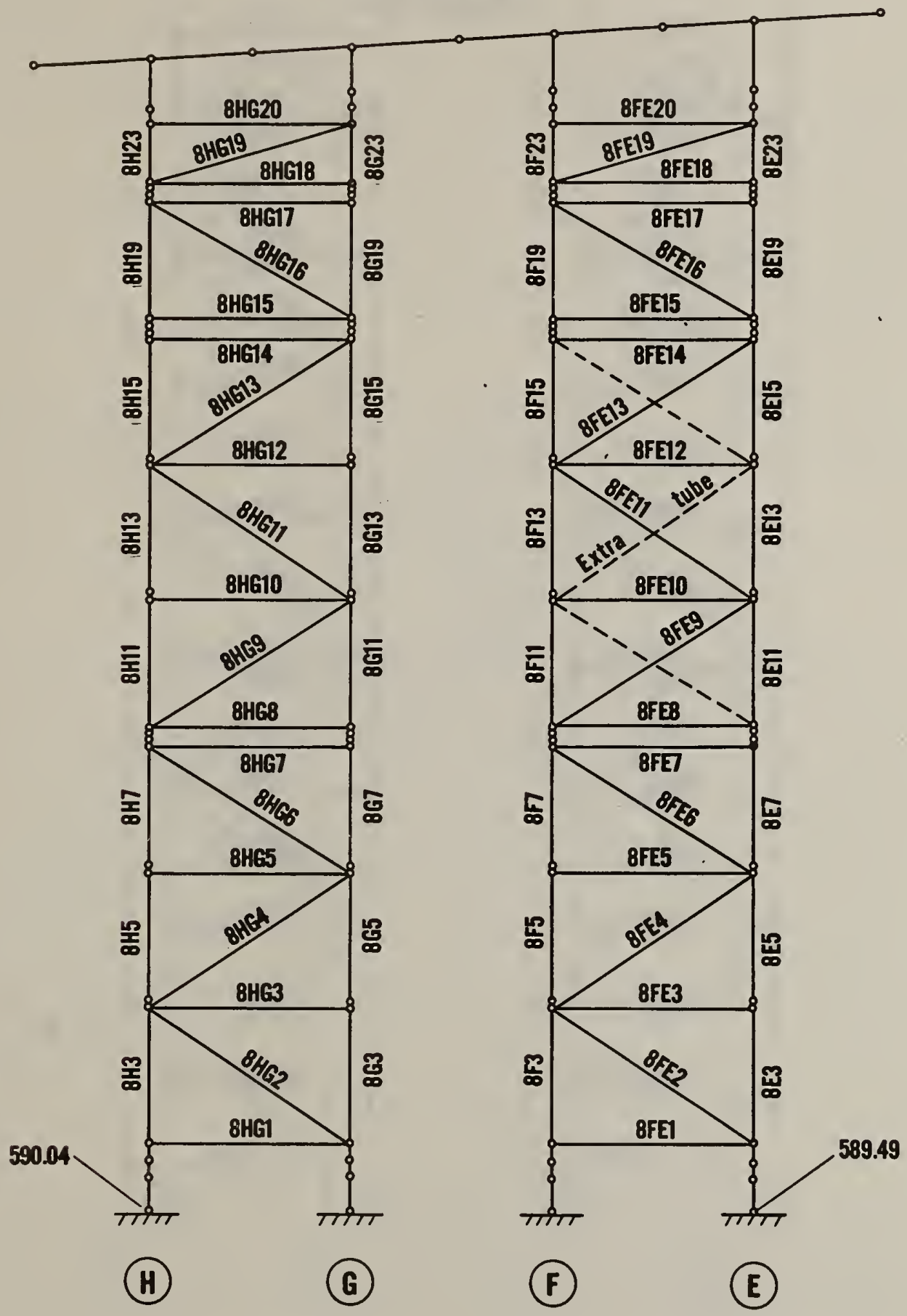

Figure B.6 East frames of towers at 408 
Tower 408

\section{Truss Members}

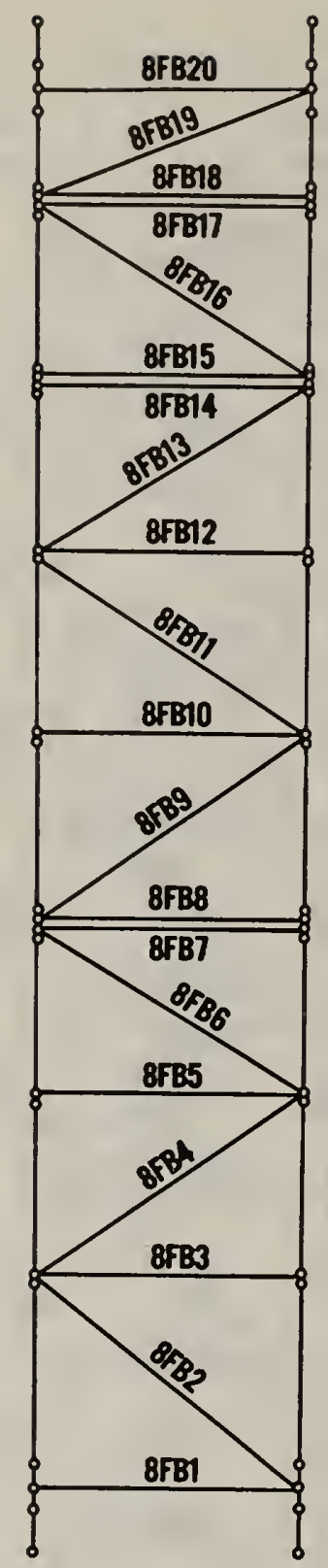

(F) B

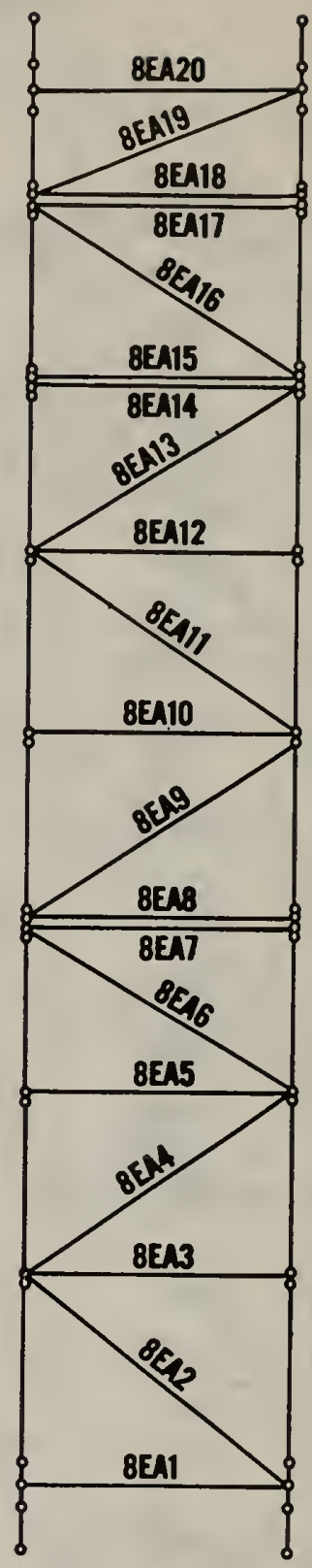

(E) (A)

Figure B.7 Truss panels $\mathrm{AE}$ and $\mathrm{BF}$ of towers at 408 


\section{Tower 408}

\section{Truss Members}

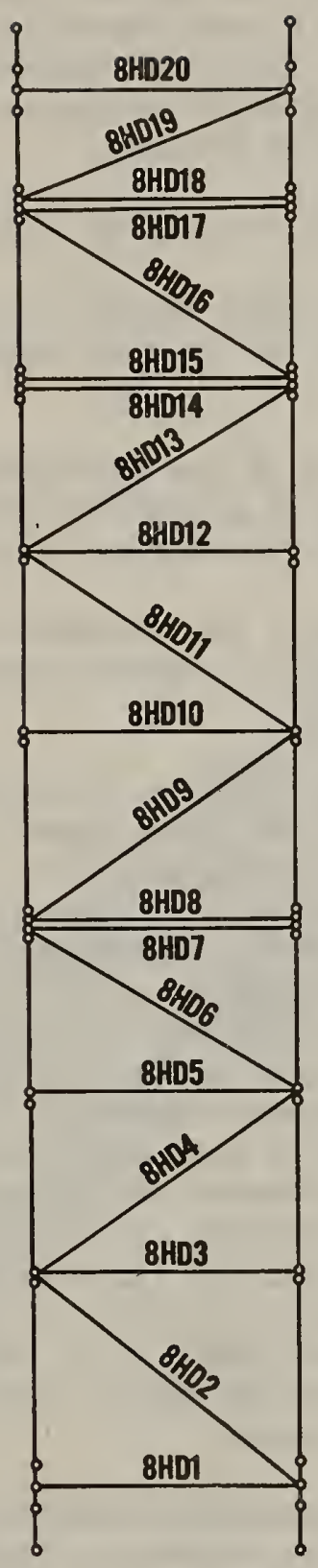

(H)

(D)

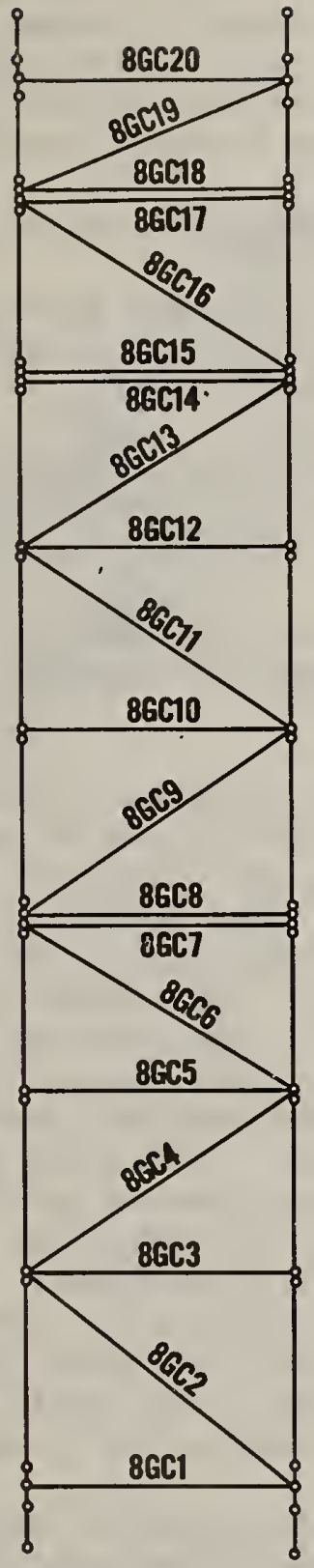

(G)

(c)

Figure B. 8 Truss panels CG and DH of towers at 408 


\section{APPENDIX C: FINITE ELEMENT ANALYSIS OF CROSSBEAM CD7.2}

As part of the structural analysis to examine the behavior of crossbeam CD7.2 subjected to the translation of the tops of the towers at 407.2, a separate analysis was performed. This crossbeam was supported by the four U-heads at legs A, B, C and D. Figure C.l shows the finite element mesh used to model the crossbeam. Overlapping plate bending (type 'BPR') and membrane (type 'PSR') elements were used to account for the three dimensional response of the structure. The applied boundary conditions were as follows:

1. The stringer reaction points were assumed to act as fixed supports.

2. The vertical reactions from'the U-heads were applied as a distributed load to the web of the crossbeamiacross the contact width of the U-head top plate.

3. The calculated longitudinal deformations of the crossbeam along the axis of the ramp (figure 6.6) were applied as lateral displacements of the lower flange of the crossbeam at the supporting $U$-heads.

4. For the initial analysis the top plates of the U-heads were assumed to provide restraint against rotation of the lower flange at the support points.

The resulting analysis produced a deflected shape for the crossbeam as shown in figure C.2. From this figure it can be seen that the largest differential displacements (lateral and torsional) of the lower flange occur at the north end of the crossbeam. This configuration introduces large moments into the upper screw jacks at tower legs $A$ and $B$ which tend to rotate those screw jacks towards the west. The induced moments are sufficient to overcome the axial compression due to the vertical jack reaction and produce significant tensile stresses on the east side of the upper screw jacks. This analysis assumed that the $U$-heads provided complete rotational restraint to the lower flange of the crossbeam. In reality there would be some rotation of the U-head along the transverse axis due to fabrication tolerances and elastic deformations. This would tend to reduce the resulting tensile stresses below the values based on this first analysis. Nevertheless, the induced moments would very likely still be sufficient to result in tensile stresses on the east side of the screw jacks. Given the small size and poor quality of the observed welds in the screw jacks it is likely that the U-heads would have failed and permitted the lower flange of the crossbeam to rotate.

A second analysis was performed in which the U-heads were assumed to provide no rotational restraint to the lower flange of the crossbeam. All other boundary conditions and applied loads were the same as in the first analysis. The resulting deflected shape is shown in figure C.3. This change in curvature of the crossbeam web agrees with the changes described in figure 6.7 . 
Stringer contact area: Fixed support

$1116<164060$
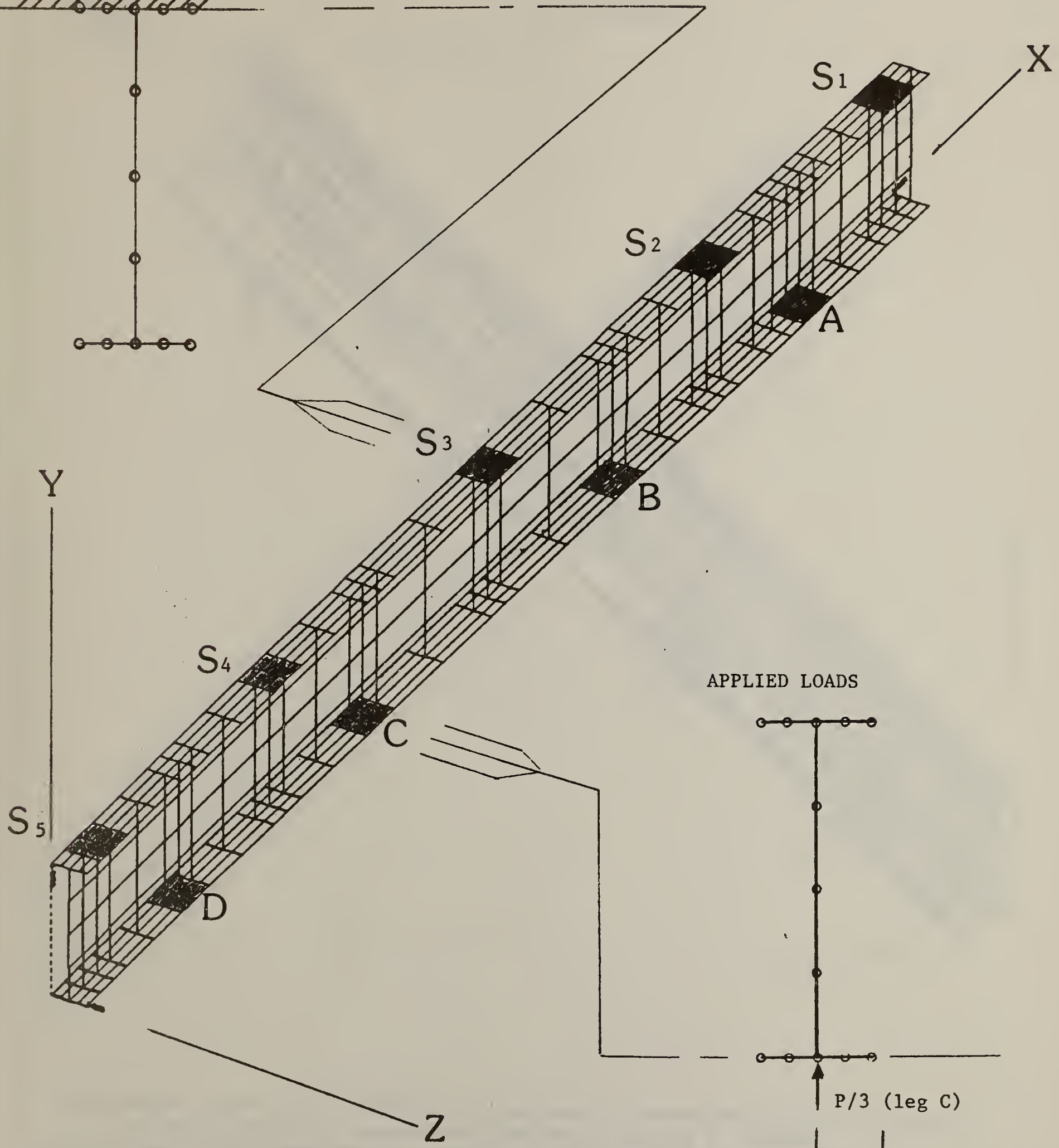

APPLIED LOADS

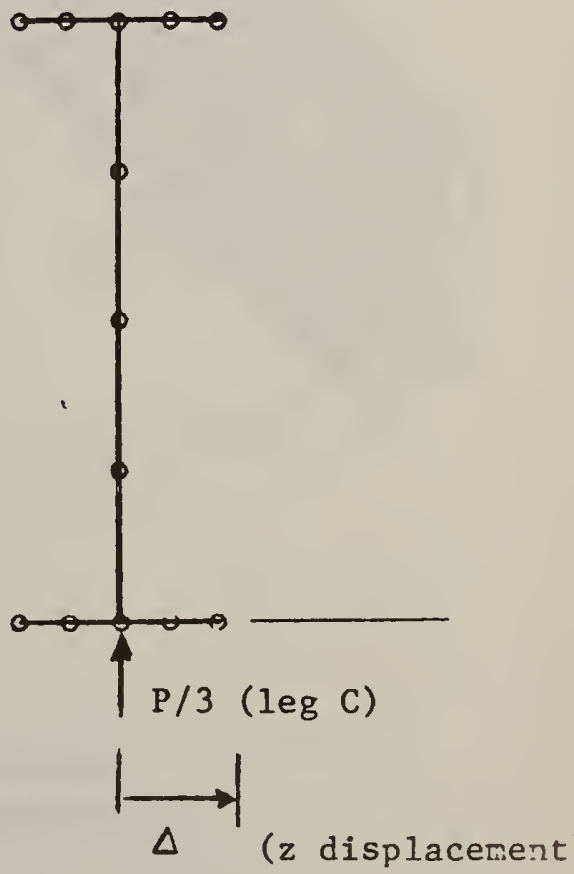

Figure C.1 Finite element mesh used to model crossbeam CD7.2. Shaded areas indicate contact reglons from stringers or U-head supports. 


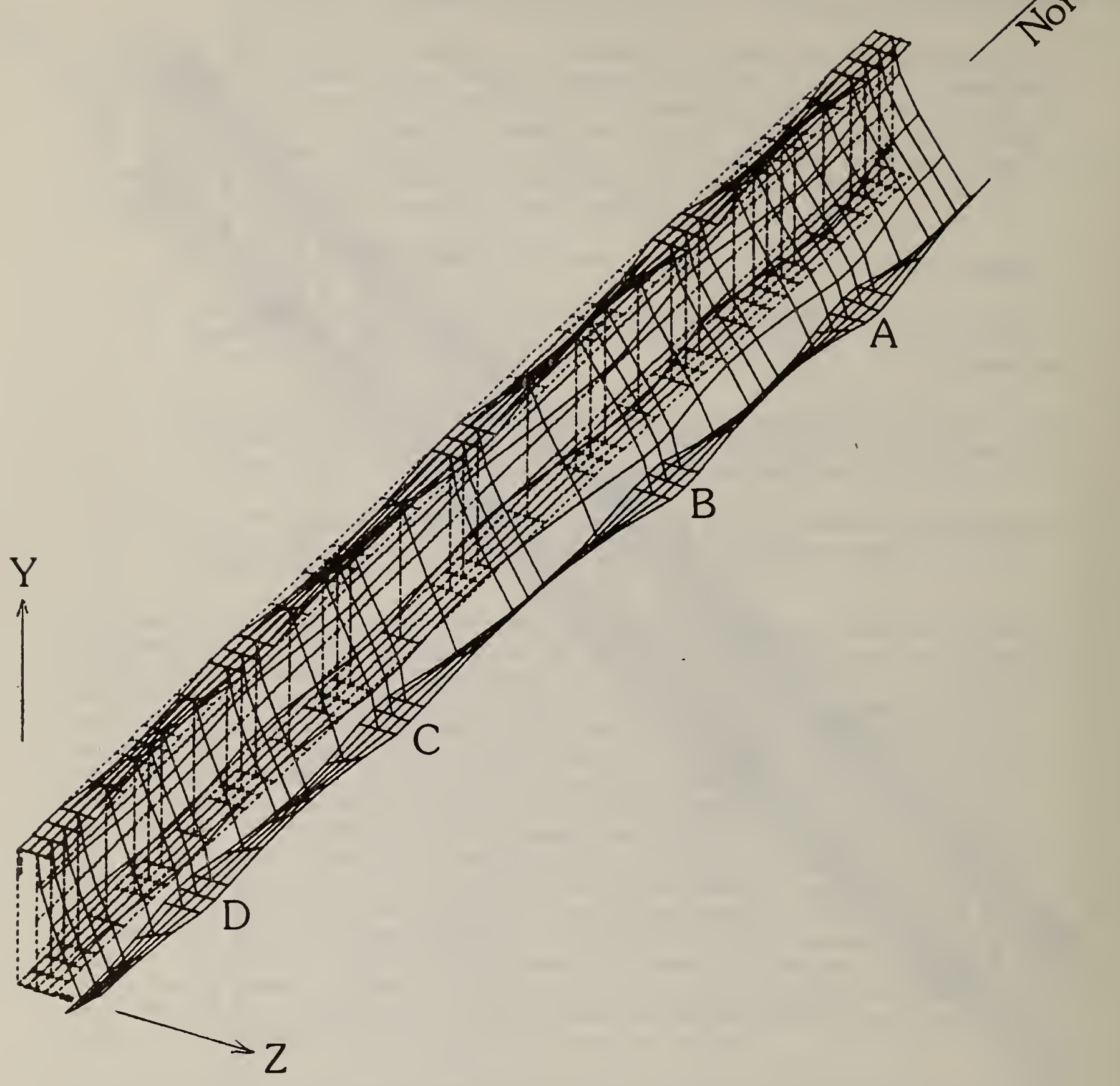

Figure C.2 Deflected shape of crossbeam for analys1s \#1. U-head supports are assumed to provide rotational resistance to bottom flange of crossbeam. Dotted Iines indicate original position of undeformed beam. 
CROSSBEAM $C D 7.2$

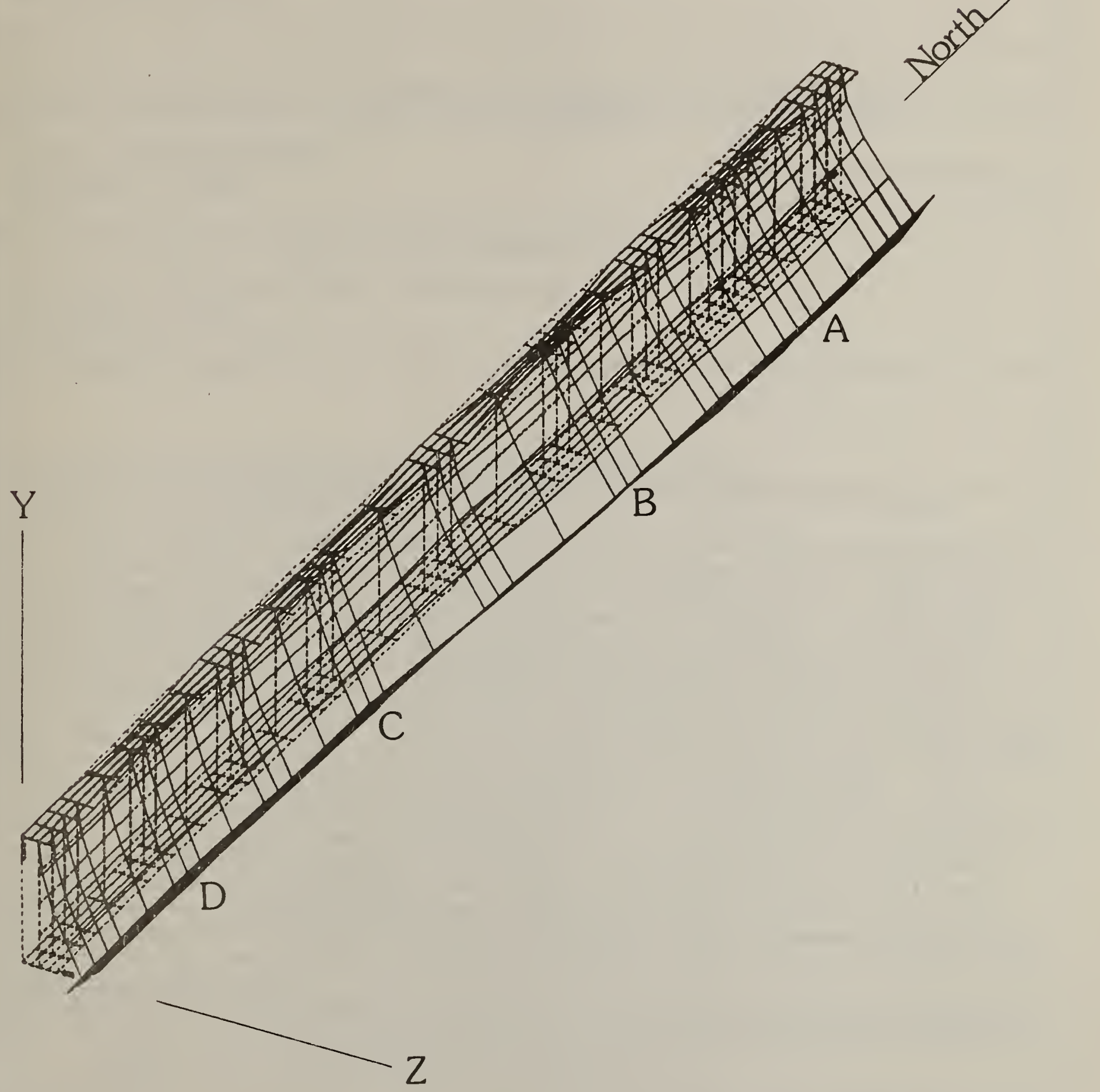

Figure C.3 Deflected shape of crossbeam for analysis $\$ 2$. U-head supports are assumed to provide no rotational resistance to bottom flange of crossbeam. Dotted lines indicate original position of undeformed beam. 

BIBLIOGRAPHIC DATA

SHEET (See instructions)

1. PUBLICATION OR
REPORT NO.
NBSIR 82-2593

3. Publlcation Date

October 1982

4. TITLE AND SUBTITLE

INVESTIGATION OF CONSTRUCTION FAILURE OF THE RILEY ROAD INTERCHANGE RAMP, EAST CHICAGO, INDIANA

5. $\operatorname{AUTHOR}(S)$

N. J. Carino, H. S. Lew, W. C. Stone, R. M. Chung, and J. R. Hoblitzell

\begin{tabular}{l|l} 
6. PERFORMING ORGANIZATION (If joint or other than NBS, see instructions) & 7. Contract Grant No.
\end{tabular}

NATIONAL BUREAU OF STANDARDS

DEPARTMENT OF COMMERCE

8. Type of Report \& Perlod Covered

WASHINGTON, D.C. 20234

9. SPONSORING ORGANIZATION NAME AND COMPLETE ADDRESS (Street, Clty, State, ZIP)

Occupational Safety and Health Administration

Department of Labor

Washington, D.C. 20001

10. SUPPLEMENTARY NOTES

Document describes a computer program; SF-185, FIPS Software Summary, Is attached.

11. ABSTRACT (A 200-word or less factual summary of most significant information. If document includes a signiflcant bibllography or (literature survey, mention it here)

The National Bureau of Standards (NBS), at the request of the Occupational Safety and Health Administration, conducted an investigation to determine the most likely cause of the collapse of a portion of a highway ramp in East Chicago, Indiana. The accident occurred on April 15, 1982, and resulted in the death of 13 workers. A team of engineers from NBS and the Federal Highway Administration carried out an extensive field investigation, in cooperation with personnel from the Indiana Occupational Safety and Health Administration, to ascertain the conditions prior to and after the accident. In addition, the NBS performed physical tests on key components of the temporary support system used to build the ramp. A structural analysis was also performed to compute the magnitude of the forces acting in various components of the support system. The calculated forces were compared with the expected strengths of these components. It is concluded that the most likely triggering mechanism of the collapse was the cracking of a concrete pad supporting a leg of the shoring towers. It is shown that this initial failure caused additional components to fall which ultimately led to the collapse of the support system and major segments of the partially completed ramp. It is further concluded that the following deficiencies contributed directly to the collapse of a unit of the ramp construction: 1) specifled wedges were omltted between stringers and crossbeams; 2) the concrete pads supporting the shoring towers had an inadequate margin (CONTINUED ON NEXT PAGE)

12. KEY WORDS (Six to twelve entries; alphabetical order; capitallze only proper names; and separate key words by semicolons) Bridge; collapse; concrete; construction; fallure investigation; falsework; field load tests; formwork; post-tensioning; structural analysis

13. AVAILABILITY

Unlimited

For Official Distribution. Do Not Release to NTIS

Order From Superintendent of Documents, U.S. Government Printing Office, Washington, D.C. 20402.

[] Order From National Technical Information Service (NTIS), Springfield, VA. 22161

14. NO. OF PRINTED PAGES

213

15. Price 
INVESTIGATION OF CONSTRUCTION FAILURE OF THE RILEY ROAD INTERCHANGE RAMP, EAST CHICAGO, INDIANA

ABSTRACT - (continued)

of safety to resist the expected loads; 3) the tops of the shoring towers were not adequately stabilized against longitudinal movement; and 4). the weld quality in the U-heads supporting the crossbeams was poor. Had any of these deficiencies not existed, it is unlikely that the collapse would have occurred. Additional deficiencies contributed to the subsequent collapse of another ramp unit. They were as follows: 1) specified one-inch bolts were not provided for connecting crossbeams to stringers and overlap beams; 2) special overlap beams at the piers were not constructed as specified; and 3) the construction sequence deviated from the specified sequence. 


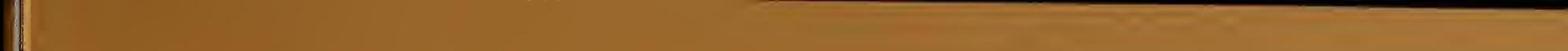


